\section{MICROFILMED BY}

CENTRAL MICROFILM UNIT PUBLIC ARCHIVES OF CANADA OTTAWA, ONTARIO

$24 / 174$ DATE

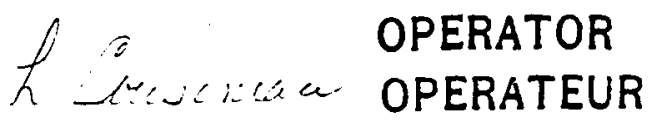

\section{MICROFILME PAR LE} SERVICE CENTRAL DU MICROFILM ARCHIVES PUBLIQUES DU

\author{
CANADA \\ OTTAWA, ONTARIO
}

REDUCTION $15 X$

EXPOSURE

EXPOSITION 3.2 


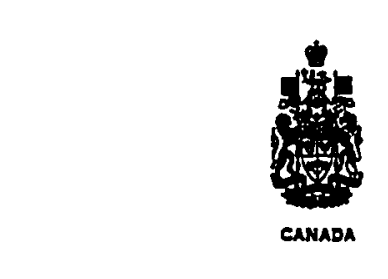

NATIONAL LIBRARY OF CANADA

CANADIAN THESES

ON MICROFILM
BIBLIOTHĖQUE

NATIONALE

DU CANADA

THĖSES CANADIENNES

SUR MICROFILM

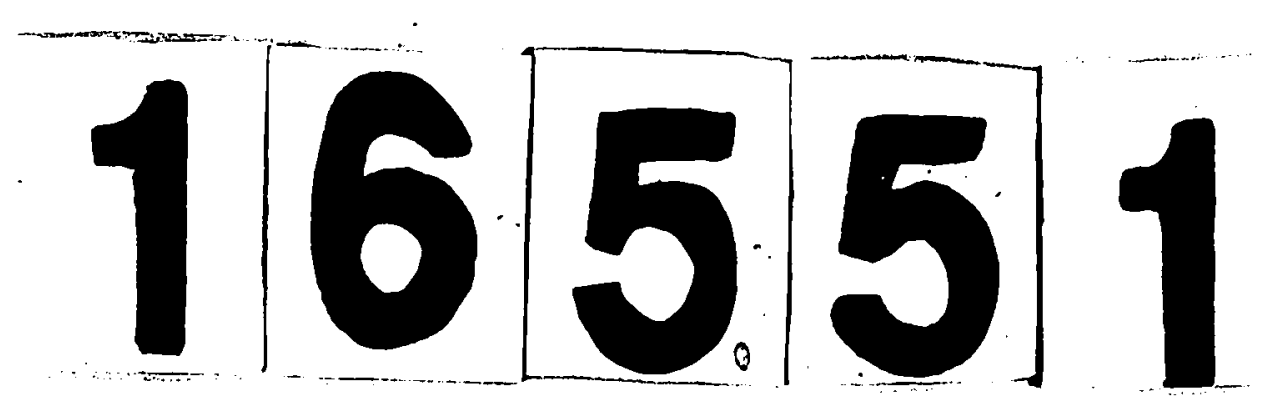




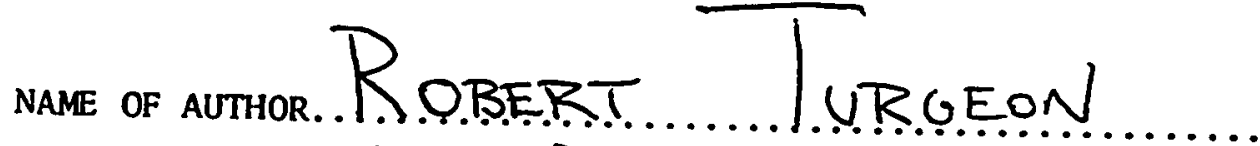
TITLE OF THESIS. L.EAF... DEvELOPMENT AND PHLOEM TRANSPORT. IN I. CUYYURBTA PEPO . STUDIES ON THE PHYSIOLOGY AND STRUCTURE OF THE DËVELOPONं̈̈ LEAF

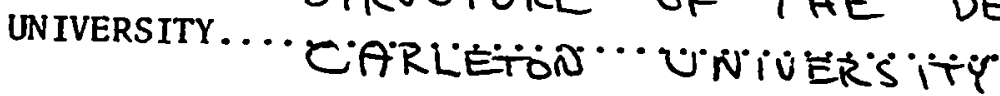
DEGREE FOR WHICH THESIS WAS PRESENTED................. YEAR THIS DEGREE GRANTED.....19.7.3

Permission is hereby granted to THE NATIONAL LIBRARY OF CANADA to microfilm this thesis and to lend or sell copies of the film.

The author reserves other publication rights, and neither the thesis nor extensive extracts from it may be printed or otherwise reproduced without the author's written permission.

(Signed) PERMANENT ADDRESS:

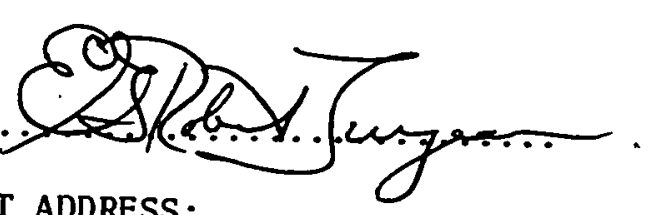

216. SHAGHNESSY BLUD

Dated.............. 1973

WILLOWOALE OANT.

NL-91 (10-68) 
To my Mother and Father 


\title{
LEAF DEVELOPMENT AND PHLOEM TRANSPORT \\ IN Cucurbita pepo. STUDIES ON THE PHYSIOLOGY AND STRUCTURE OF THE EXPANDING LEAF.
}

\author{
by \\ Edmr... Ren Robert Turgeon B.Sc.(Hons.)
}

A thesis submitted to the Faculty of Graduate Studies in partial fulfillment of the requirements for the degree of Doctor of Philosophy.

\author{
Carleton University \\ Ottawa, Ontario \\ August, 1973
}

C) Eđawarà Guy Robert Turgeon 1973 
The undersigned hereby recommend to the Faculty of Graduate Studies acceptance of this thesis, submitted by Robert

Turgeon, B.Sc. (Hons.), in partial fulfillment of the requirements for the degree of Doctor of Philosophy.

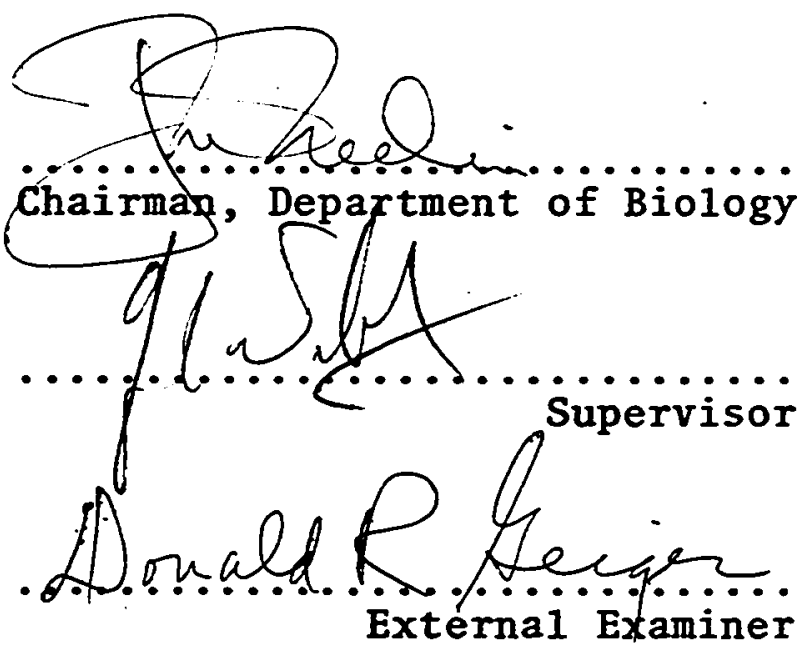

Carleton University August 13, 1973 


\section{ACKNOWLEDGEMENTS}

I would like to thank Dr. John A. Webb for his advice and encouragement throughout the work. Most of the electron microscopy was done while the author was a visitor in the laboratory of Dr. Ray F. Evert, Department of Botany, University of Wisconsin, Madison. I am especially grateful to Dr. Evert for his hospitality, generosity and advice.

I would also like to express my appreciation to Dr. George Setterfield for discussions on all aspects of the work.

I am grateful for the receipt of National Research Council Scholarships and an Ontario Graduate Fellowship.

Special thanks to A.F. 
ABSTRACT

The capacity of a growing leaf blade of Cucurbita pepo to import ${ }^{14} \mathrm{C}$-labelled photoassimilate is lost in a basipetal direction. Import into the lamina tip stops when the blade is $10 \%$ expanded. Development of the leaf progresses linearly with time and the lamina base stops importing when the blade is $45 \%$. expanded. Export capacity also develops basipetally and follows immediately the loss of import capacity, at least in the lamina base. The small amount of material initially exported from the leaf tip is redistributed to the still-importing leaf base, delaying export from the lamina until the blade is 35 expanded.

Loss of import capacity by the petiole is both basipetal and dorsoventral. The proximal, adaxial portion of the petiole is the last region to cease importing ${ }^{14} \mathrm{C}$. Leaves of Beta vulgaris L. and Nicotiana tabacum L. also lose import capacity in a basipetal direction.

The lamina is first capable of net $\mathrm{CO}_{2}$ fixation when approximately $8 \%$ expanded. Photosynthetic capacity develops basipetally and the maximal rate of $\mathrm{CO}_{2}$ fixation for the whole lamina is achieved at 70 expansion. Increased photosynthetic activity is paralleled by the expansion of intercellular spaces and decreased respiration both in the dark during the day and at night. The rate of respiration of 
mature leaves in the dark during the day is three times the value at night.

The relative growth rate of the lamina increases to a maximum before net photosynthesis significantly affects the carbon balance. Initial rapid growth is therefore heavily dependent on imported nutrients. In each area of the lamina import ceases after the growth rate has considerably decreased and photosynthetic capacity has increased enough to provide an excess of carbohydrate. The leaf tip ceases to import when the relative growth rate of the whole lamina peaks, thereby ensuring that maximal export continues into the lamina until the requirements for rapid growth have been satisfied.

The synthesis of the translocation sugars raffinose and stachyose begins after the leaf tip stops importing but before export from the lamina begins. Sucrose is synthesized by much younger leaves. The pattern of ${ }^{14} \mathrm{C}$ incorporation following the application of ${ }^{14} \mathrm{CO}_{2}$ to developing leaves supports the view that myo-inositol is a precursor of galactinol and that galactinol supplies a galactose moiety to raffinose for the synthesis of stachyose.

The minor venation develops basipetally so that the vascular tissue in the distal region of partially grown leaves is more mature than in the physiologically lessadvanced proximal region. In each area of the lamina development of the minor venation proceeds from the largest 
toward the smallest veins. The adaxial (internal) phloem develops before the abaxial (external) phloem. Many sieve elements in the adaxial phloem of the smallest minor veins are mature (the sieve plate pores are open) while import continues. The maturation of abaxial sieve elements of fourth and fifth order veins, which are probably the largest veins capable of loading photoassimilate, coincides with the onset of export. Abaxial sieve elements in the finest ramifications of the minor venation do not mature until after export has begun.

U1trastructural observations suggest that the abaxial phloem is primarily responsible for vein loading. The companion cells are large, contain many parietally located mitochondria and are connected to cells of the bundle sheath by numerous plasmodesmata. The adaxial phloem does not appear to be as highly specialized for vein loading.

Although the proportionate size relationship of sieve elements and companion cells in the adaxial and especially the abaxial phloem is not typical of the phloem in the rest of the plant the ultrastructure of all sieve elements is essentially similar. Sieve elements are joined to each other by well-differentiated sieve plates with pores. Sieve plate pores of the abaxial sieve element are narrow and are usually plugged with P-protein. Those of the adaxial sieve elements are wide and are usually free of obstruction. All sieve elements are enucleate, the tonoplast and ribosomes are absent and the cytoplasm is characteristically degenerate. 
TABLE OF CONTENTS

Page

List of Tables .......................... xi

List of Figures ........................... xi

INTRODUCTION $\ldots \ldots \ldots \ldots \ldots \ldots \ldots \ldots \ldots \ldots \ldots \ldots \ldots \ldots \ldots$

LITERATURE REVIEW ........................ 3

A. Leaf Development .................... 3

I. Structure ...................... 3

II. Carbon Balance .................... 7

B. Phloem Metabolism ...................... 9

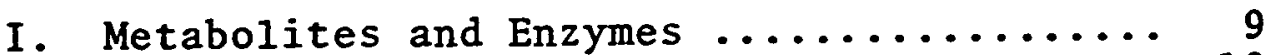

II. Metabolic Inhibitors ................. 12

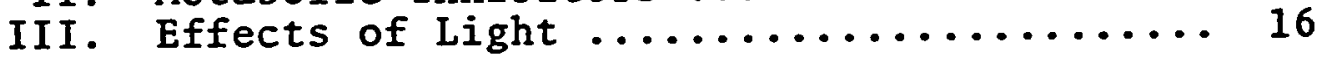

C. Phloem Ultrastructure ................... 17

I. Sieve Element ..................... 18

(1) Sieve Plate .................. 18

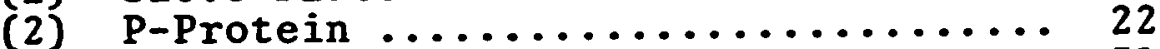

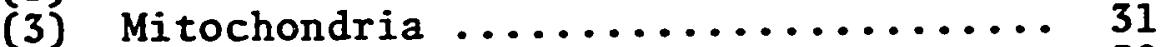

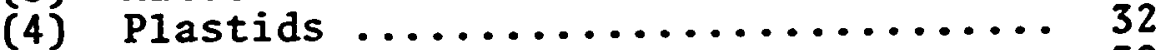

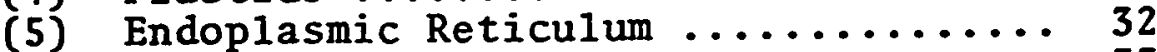

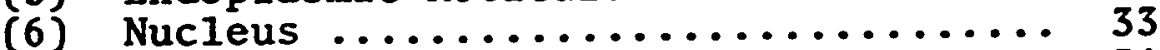

(7) Tonoplast .................... 34

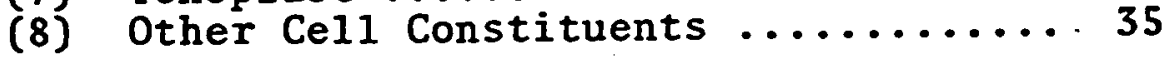

II. Companion Cell .................. 36

D. Translocation Mechanisms ................. 37

I. Independent Transport Mechanisms ....... 39

(1) Cytoplasmic Streaming ........... 39

(2) Activated Diffusion ............. 41

(3) Surface Migration ............... 43

II. Mass Flow Mechanisms ................ 45

(1) Transport of Water ............. 46

(2) Bidirectional Transport .......... 47

(3) Activated Mass Flow .............. 50

(a) Strand Theories ............ 50

(b) Electroosmosis ............ 52 
(4) Simple Mass Flow ............. 53

(a) Pressure Flow ............. 53

(b) Volume flow .............. 56

E. Minor Vein Structure $\ldots \ldots \ldots \ldots \ldots \ldots \ldots \ldots \ldots .58$

I. Vein Pattern ..................... 59

II. Vein Length ..................... 60

III. Vein Histology $\ldots \ldots \ldots \ldots \ldots \ldots \ldots \ldots \ldots 61$

F. Minor Vein Ultrastructure ............... 66

G. Vein Loading ............................ 69

I. Active vs. Passive Uptake ............ 70

II. Path of Sugar Movement $\ldots \ldots \ldots \ldots \ldots \ldots \ldots, 75$

MATERIALS AND METHODS $\ldots \ldots \ldots \ldots \ldots \ldots \ldots \ldots \ldots \ldots \ldots, 81$

A. Growth of Plants ................... 81

B. Plant Age $\ldots \ldots \ldots \ldots \ldots \ldots \ldots \ldots \ldots \ldots \ldots \ldots, 82$

C. Leaf Measurements .................. 84

D. Choice of Leaves $\ldots \ldots \ldots \ldots \ldots \ldots \ldots \ldots \ldots \ldots, 84$

E. ${ }^{14} \mathrm{CO}_{2}$ Labelling $\ldots \ldots \ldots \ldots \ldots \ldots \ldots \ldots \ldots \ldots \ldots \ldots, 84$

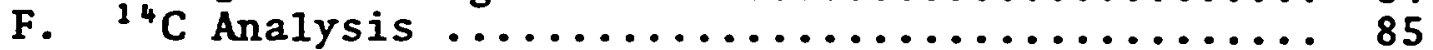

G. Autoradiography of Whole Leaves $\ldots \ldots \ldots \ldots \ldots \ldots .86$

H. Translocation Period ................. 86

I. Labelling, Extraction and Chromatography of

Sugars and Related Compounds ............ 87

$\mathrm{J}$. Infrared Analysis of Photosynthesis and

Respiration ...................... 89

K. Statistical Analysis of Results $\ldots \ldots \ldots \ldots \ldots \ldots, 95$

L. Electron Microscopy ................... 95

M. Light Microscopy $\ldots \ldots \ldots \ldots \ldots \ldots \ldots \ldots \ldots \ldots \ldots 96$

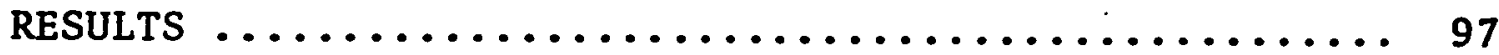

A. Import and Export in a Developing Leaf ....... 97

I. Cessation of ${ }^{14} \mathrm{C}$ Import into the Leaf Blade of C. pepo .................. 97

II. Cessation of ${ }^{14}$ Import into the Petiole of $\mathrm{C}$. pepo f...................... 103

III. Cessation of ${ }^{i 4} \mathrm{C}$ Import into Leaves of

IV. Beta vulgaris and Nicotiana tabacum .... 105

IV. Development of Export Capacity of $\underline{C}$.

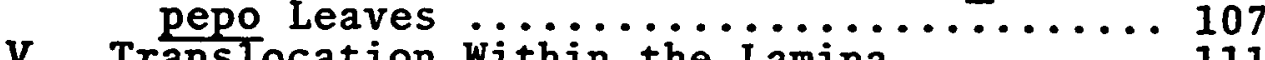

V. Translocation Within the Lamina .........111

B. Carbon Balance of the Developing Leaf ........ 113

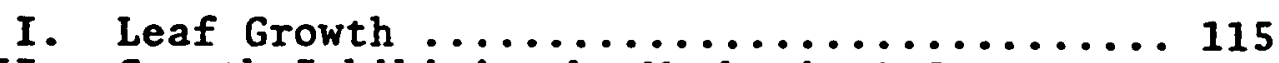

II. Growth Inhibition by Mechanical Stress ... 119

III. Photosynthesis and Respiration ......... 122 
Page

IV. Development of Intercellular Spaces ..... 126

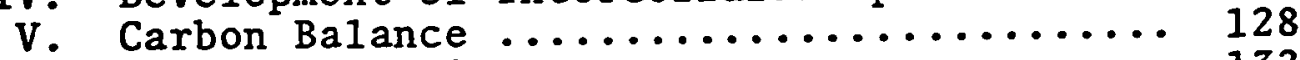

VI. Sugar Synthesis .................... 132

C. Micro-autoradiography of ${ }^{14} \mathrm{C}$ Following ${ }^{14} \mathrm{CO}_{2}$

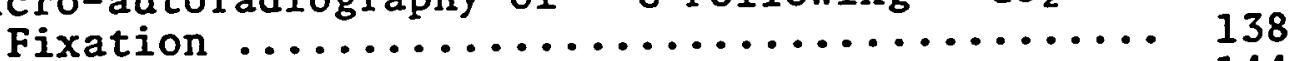

D. Structure of Minor Veins in Mature Leaves ...... 144

E. U1trastructure of Minor Veins in Mature Leaves . 148

I. Abaxial Phloem ..................... 148

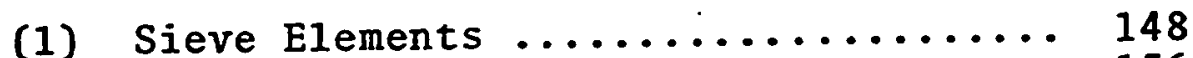

(2) Companion Cel1s ................ 156

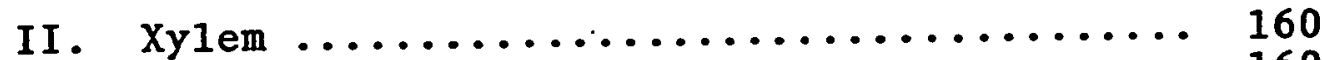

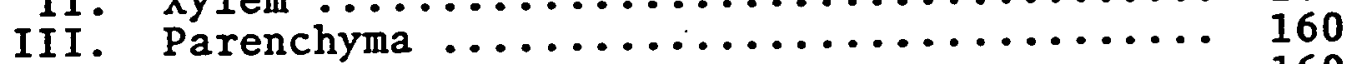

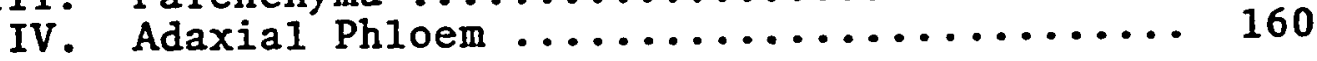

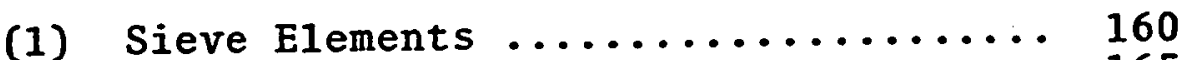

(2) Companion Cells ................ 165

F. Development of the Minor Veins ............. 166

I. Ultrastructure .................. 166

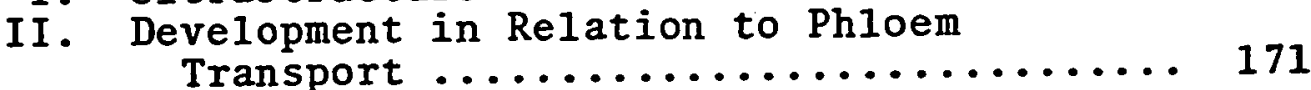

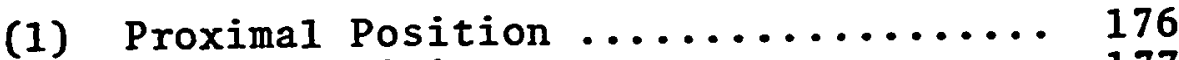

(2) Distal Position ................ 177

DISCUSSION .............................. 180

A. Import and Export in the Development Leaf ..... 180

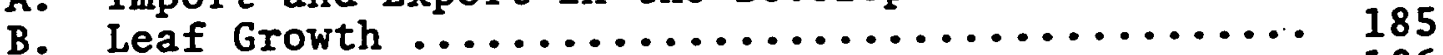

C. Photosynthesis and Respiration .............. 186

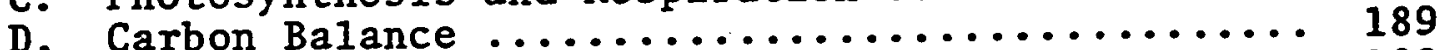

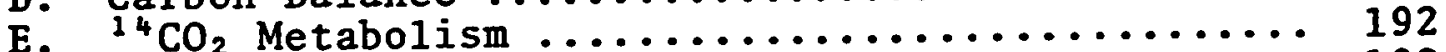

F. Structure of Mature Minor Veins .............. 199

G. U1trastructure of Mature Minor Veins .......... 201

I. Sieve Elements .................... 201

II. Companion Cells ................... 205

H. Minor Vein Development .................. 207

SUMMARY $\ldots \ldots \ldots \ldots \ldots \ldots \ldots \ldots \ldots \ldots \ldots \ldots \ldots \ldots \ldots \ldots \ldots \ldots \ldots \ldots \ldots$

LITERATURE CITED ......................... 214 


\section{LIST OF TABLES}

Table

Page

1.

Size relation between sieve elements and companion cells in abaxial phloem of minor veins in leaves of Cucurbita pepo

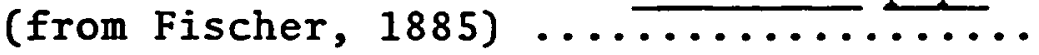

2. The amount of ethanol insoluble ${ }^{14} \mathrm{C}$, expressed as a percentage of the total ${ }^{14} \mathrm{C}$, found in each analyzed plant part, when either lamina 5 or lamina 3 had been supplied ${ }^{14} \mathrm{CO}_{2}$ for $5 \mathrm{~min}$ and translocation was allowed to proceed for 2 hr before analysis .................

3. Growth in length and fresh weight of petioles and shoots of control and handled plants. Data are presented as mean and standard error of mean. Significance of difference was evaluated by two-tailed $t$-test ............... 


\section{LIST OF FIGURES}

Figure

page

1. Procedure for the extraction, purification, and chromatography of the neutral fraction of leaves supplied with ${ }^{14} \mathrm{CO}_{2}$.

2a-b. (a) Schematic diagram of apparatus used to measure $\mathrm{CO}_{2}$ flux in single,

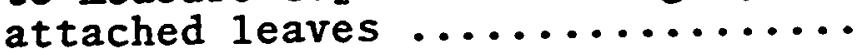

(b) Diagram of Lucite leaf chamber ....

3. Calibration curve for infrared gas analyzer .......................

4a-d. Autoradiographs of lamina 5 of $4 \mathrm{C}$. pepo plants which imported ${ }^{14} \mathrm{C}$ from leaf 3 for 2 hr ......................

5. Pattern of ${ }^{14} \mathrm{C}$ distribution along the length of leaf 5 of $C$. pepo after supplying ${ }^{14} \mathrm{CO}_{2}$ to 1 eaves 3,2 and 4 at $0 \mathrm{hr}, 3 \mathrm{hr}$ and $6 \mathrm{hr}$ respectively ......

6. Development of leaf 5 of $C$. pepo expressed as the percentage of the total lamina length still importing ${ }^{14} \mathrm{C} \ldots \ldots$.

7. $\quad{ }^{14} \mathrm{C}$ activity in the lamina and petiole of leaf 5 of $C$. pepo expressed as a percentage of the total ${ }^{14} \mathrm{C}$ translocated from the lamina of leaf 3 in $2 \mathrm{hr} \ldots .$.

8. Relative ${ }^{14} \mathrm{C}$ activity in the distal and abaxial halves of importing petioles of leaf 5 of $C$. pepo compared to the activity in the proximal and adaxial halves respectively ................

9a-b. Autoradiographs of importing leaves of $\frac{\text { Beta vulgaris (a) and Nicotiana tabacum }}{\text { (b). }}$ from the same plant .............. 
10. Autoradiograph of lamina 5 of $C$. pepo. Although the leaf blade was too young to export (LPI 0.7 ), ${ }^{14} \mathrm{C}$ activity was present in the midrib and lamina outside the fed tip-region $2 \mathrm{hr}$ after ${ }^{14} \mathrm{CO}_{2}$ was

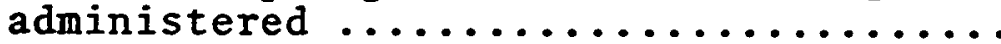

11. The amount of ${ }^{14} \mathrm{C}$ translocated from the lamina of leaf 5 of $\mathrm{C}$. pepo in $2 \mathrm{hr}$ expressed as a percentage of the total ${ }^{14} \mathrm{C}$ fixed. Either the entire lamina or just the extreme base of the lamina was

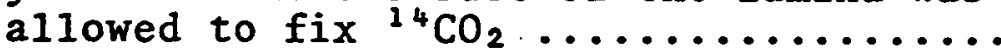

12. The amount of ${ }^{14} \mathrm{C}$ translocated in $2 \mathrm{hr}$ from lamina 5 of $\mathrm{C}$. pepo to: petiole 5, above leaf 5 , between leaf 5 and roots,

13. Growth rate of $2 \mathrm{C}$. pepo plants, one grown in the greenhouse, the other in

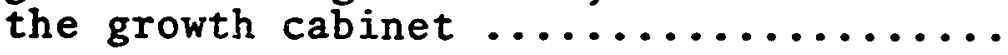

14. Area of lamina 5 of C. pepo, grown either in the greenhouse or growth cabinet, plotted against leaf age ......

15. Dry weight increase of lamina 5 of $C$. pepo plants grown in the growth cabinet

16. Increase in length of petiole 5 of C. pepo plants grown in the growth cabinet

17. Effect of handling on the ratio of length to volume of petioles of $C$. pepo. Data for petioles 1 to 4 have been combined.

18. Exchange of $\mathrm{CO}_{2}$, during a 24-hr period, from lamina 5 of a $\mathrm{C}$. pepo plant grown in the growth cabinet. Values for respiration in the dark during the day period are also included ..............

19. Net photosynthesis, night respiration, and dark day-time respiration of lamina 5 of C. pepo plants plotted against leaf age $\ldots \ldots \ldots \ldots \ldots \ldots \ldots \ldots \ldots \ldots \ldots$ 
20. Development of intercellular spaces in the distal and proximal regions of

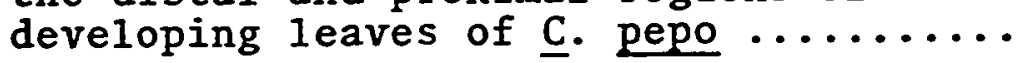

21. Carbon balance over a 24-hr period, of

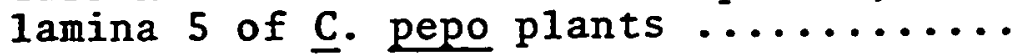

22. Relative carbon balance, over a 24-hr period, of lamina 5 of $\underline{C}$. pepo ........

23. Percentage of total fixed ${ }^{14} \mathrm{C}$ recovered in the ethanol insoluble fraction of lamina 5 of $C$. pepo plants which had been exposed to ${ }^{14} \mathrm{CO}_{2}$ for $5 \mathrm{~min}$ and frozen immediately or 2 hr later .......

24. ${ }^{14} \mathrm{C}$ in the neutral fraction expressed as a percentage of the total ethanol soluble ${ }_{14} \mathrm{C}$. Lamina 5 of $\mathrm{C}$. pepo plants was exposed to ${ }^{14} \mathrm{CO}_{2}$ for $5 \min \ldots \ldots \ldots \ldots \ldots$

25. Amount of ${ }^{14} \mathrm{C}$ in the translocation sugars, sucrose stachyose and raffinose, expressed as a percentage of the total ${ }^{14} \mathrm{C}$ in the neutral fraction. Lamina 5 of $C$. pepo plants was exposed to ${ }^{14} \mathrm{CO}_{2}$ for $5 \mathrm{~min} \ldots \ldots \ldots \ldots \ldots \ldots \ldots \ldots$

26. Amount of ${ }^{14} \mathrm{C}$ in galactinol, myoinositol, glucose, and fructose, expressed as a percentage of the total ${ }^{14} \mathrm{C}$ in the neutral fraction. Lamina 5 of $C$. pepo plants was exposed to ${ }^{14} \mathrm{CO}_{2}$ for 5 min .....................

27. Amount of ${ }^{14} \mathrm{C}$ in stachyose, raffinose, sucrose, galactinol and myo-inositol, expressed as a percentage of the total ${ }^{14} \mathrm{C}$ fixed by the leaf during a 5 -min exposure to ${ }^{14} \mathrm{CO}_{2} \ldots \ldots \ldots \ldots \ldots \ldots \ldots \ldots \ldots$

28. Photograph of two $C$. pepo plants demonstrating growth inhibition by mechanical stress. The plant on the left had been handled daily for 3 weeks as described. The plant on the right, from the control group, was left undisturbed .......... 
29. Transection of mature minor vein. The leaf tissue was prepared for light microscopy by freezing in isopentane cooled with liquid nitrogen, and direct embedment into Spurr resin ..........

30. Faradermal view of cleared leaf stained with safranin. Light micrograph ......

31. Transection of mature minor vein. Light micrograph ....................

32. Paradermal section of minor vein abaxial phloem. Light micrograph ..........

33. Paradermal section of tracheids in a blind ending. Light micrograph .......

34. Paradermal section of mature minor vein adaxial sieve elements. Light micrograph .......................

35. Paradermal section of adaxial companion cell and sieve elements. Light micrograph ........................

36. Transection of young leaf. Light micrograph. Minor vein in centre of picture (between arrows) has apparent1y arisen from divisions in the third layer of cells from the upper leaf surface ......

37. Transection of developing minor vein. Light micrograph ................

38. Paradermal section of mature minor vein abaxial sieve elements and companion cells. Electron micrograph ..........

39. Paradermal section of a sieve plate between two mature, abaxial sieve elements. Electron micrograph ........

40. Paradermal section of a sieve plate between two mature abaxial sieve elements. Electron micrograph ........

41. Paradermal section of two mature abaxial sieve elements and a companion cell. Electron micrograph ............... 
xvi

Figure

page

42. Paradermal section of two mature abaxial sieve elements. Electron micrograph ...

43. Transection of three mature, abaxial sieve elements and surrounding companion cells. Electron micrograph ..........

44. Paradermal section of a mature abaxial sieve element showing a P1-protein body in longitudinal view. Electron micrograph ......................

45. Transection of a mature abaxial sieve element and companion cell. Electron micrograph. Endoplasmic reticulum in the sieve element is arranged in the form of a stack ..................

46. Paradermal section of an abaxial companion cell and bundle sheath cells joined by numerous plasmodesmata which occur in clusters. Electron micrograph

47. Longitudinal section through the common walls of a companion cell and a bundle sheath cell. Electron micrograph. The wall is traversed by numerous plasmo-

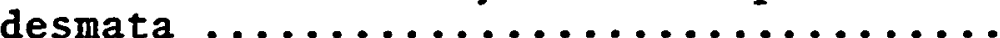

48. Transection of an abaxial companion cell and sieve element. Electron micrograph

49. Transection of the abaxial phloem of a fifth order vein. Electron micrograph

50. Transection of a mature minor vein tracheid filled with amorphous, electrondense material. Electron micrograph ...

51. Paradermal section of mature adaxial sieve elements. Electron micrograph ...

52. Paradermal section of sieve plate between two mature adaxial sieve elements. Electron micrograph. P4protein is associated with the pores...

53. Paradermal section of mature adaxial sieve element showing two P-protein bodies. Electron micrograph ......... 
54. Transection of mature adaxial phloem. Electron micrograph ................

55. Paradermal section of adaxial sieve element showing parietal distribution of p-protein and cell organelles. Electron

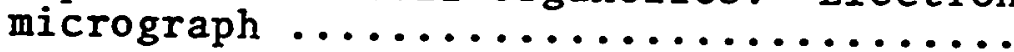

56. Paradermal section of mature adaxial sieve element and companion cell.

Electron micrograph

57. Paradermal section of adaxial companion cell. Electron micrograph. Note the density of cytoplasm compared to other

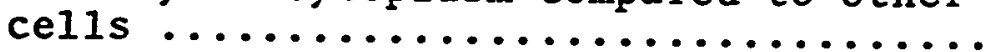

58. Paradermal section of adaxial companion cell showing densely compacted ribosomes. Electron micrograph ...........

59. Transection of immature minor vein. Electron micrograph ...............

60. Transection of minor vein nearing maturity. Electron micrograph ........

61. Paradermal section of an immature, adaxial sieve element and other unidentified cells. Electron micrograph .....

62. Paradermal section of sieve plate between two immature adaxial sieve elements. Electron micrograph ........

63. Paradermal section of adaxial sieve elements. Electron micrograph ........

64. Paradermal section of an immature adaxial sieve element. Electron micrograph. Dense material, presumably composed of P-protein fibrils has accumulated at one end of the cell ...........

65. Schematic outline drawings of developing areoles in paradermal view ...........

66. Paradermal section of developing areole in the plane of the adaxial sieve elements. Light micrograph .......... 
xviii

Figure

page

67. Paradermal section of developing areole partially in the plane of the xylem.

light micrograph..$\ldots \ldots \ldots \ldots \ldots \ldots \ldots$ 


\section{INTRODUCTION}

During growth, from initiation to maturity, the leaf undergoes profound changes in biochemical and physiological activity. The young leaf is dependent on nutrients supplied by other regions of the plant and carried to it by the vascular tissues. At maturity the leaf is capable of producing an excess of food which is exported to regions of the plant that are not self-sufficient. When expansion is approximately half complete there is a transition period during which import of food to the lamina stops and export is initiated. Since the leaf becomes an asset to the carbon economy of the plant only when net export begins, an understanding of the transition of the lamina from an importing to an exporting organ is fundamental to the study of plant nutrition and productivity. Further, the study of changing patterns of food movement may provide an insight into the mechanisms of vein loading and phloem transport.

Although there is a wealth of data on various aspects of leaf development there has been little attempt to integrate the data and determine the relationships between growth, structural development, carbon flux, and the transport of assimilates. The purpose of the present study was to correlate pertinent aspects of the cytology, biochemistry and physiology of a single developing leaf of the squash 
plant (Cucurbita pepo var. melopepo f. torticollis Bailey) during the transition period between phloem import and export.

Work was carried out in four major areas. I. The changing pattern of translocation was monitored by ${ }^{14} \mathrm{C}$ tracer techniques including scintillation counting and the autoradiography of whole leaves. II. $\mathrm{CO}_{2}$ exchange, under controlled environment conditions, was studied by infrared gas analysis and the results were combined with growth data to derive a balance sheet of carbon exchange within the growing lamina. III. The initial synthesis of sugars carried in the translocation stream was detected by supplying leaves with ${ }^{14} \mathrm{CO}_{2}$ and analyzing the subsequent distribution of ${ }^{14} \mathrm{C}$ within leaf metabolites. IV. The structural development of the minor veins in relation to phloem transport was studied at the light microscope level. This study was preceded by an examination of the ultrastructure of the minor veins of mature leaves. 


\section{LITERATURE REVIEW}

\section{A. LEAF DEVELOPMENT}

\section{Structure}

Leaf development, especially initiation and early growth, has been extensively studied and it is beyond the scope of the present work to review the entire field in detail. A brief outline of the development of dicotyledonous leaves is given and special attention is paid to areas of particular interest.

Leaf initiation in dicotyledonous plants begins with the formation of a lateral protrusion, the leaf buttress, on the apical meristem. Participation of the two growth zones of the shoot apex, the tunica and the corpus, in producing the leaf buttress varies with species (Foster, 1936). Continued growth produces an erect peg-like protuberance on the buttress which is often somewhat flattened on the adaxial side. This peg, the leaf axis, first grows in length through apical meristematic activity and later by intercalary growth (Esau, 1965). During growth in length of the leaf axis procambium develops in continuity with the procambium in the buttress and stem.

The lamina is initiated by two bands of cells, the marginal meristems, located along the margins of the axis 
(Foster, 1936). Growth from the marginal meristems may begin before apical growth of the leaf axis is finished. The layers of the lamina are initiated early in development by a regular pattern of divisions in the marginal meristems. The origin of the different layers of the lamina from the marginal meristem varies in different species (Esau, 1965; Foster, 1936). Continued division of cells in the lamina occurs in the anticlinal plane, that is at right angles to the surface of the leaf. In this way the number of cell layers remains constant although the area of the blade increases.

This type of meristem, which is composed of parallel cell layers growing in one plane, is termed a plate meristem (Esau, 1965). In some species periclinal divisions in the "plate" meristem give rise to additional layers of mesophyll (Dunne, 1966; Maksymowych and Wochok, 1969).

Unequal growth of the various layers of the leaf creates characteristic differences in the form of the cell layers. Cell division ceases first in the upper epidermis and continues longest in the palisade layer (Avery, 1933; Heslop-Harrison, 1962). Two periods of growth, cell division and cell expansion, may be recognized although these stages overlap to a certain extent (Sunderland, 1960; Maksymowych and Kettrick, 1970).

Cessation of intercalary growth and the maturation of tissues occurs in a basipetal direction, especially in 
narrow leaves (Esau, 1965). Lateral expansion is combined with basipetal maturation in broad leaves. Basipetal differentiation is manifest by many parameters of growth, both structural and physiological. Avery (1933) found a linear growth gradient along the midrib from the tip to the base of the tobacco leaf. Cell division ceases first in the tip and last in the basal lobes of Xanthium (Maksymowych, 1961) and spinach (Saurer and Possingham, 1970). Differentiation of the epidermis of Aster (Delisle, 1938) and the xylem, cuticle, stomata and intercellular spaces of tobacco (Avery, 1933) also proceeds basipetally. Larson et al. (1972) found that photosynthesis was greatest in the tips of developing Populus leaves and decreased almost linearly toward the base. The development of the leaf vascular system proceeds first acropetally and then basipetally. As the leaf grows the procambium of the midvein differentiates acropetally and the lateral veins of the first order develop from the midrib toward the leaf margins (Pray, 1955a). Protophloem and protoxylem develop acropetaily in continuity with earlier formed vascular elements. Metaphloem and metaxylem differentiate basipetally in the larger strands. Much of the protophloem and protoxylem is obliterated by continued elongation of the tissue (Esau, 1955).

The small veins of the leaf develop basipetally so that the leaf apex is the first to complete the development of the procambial system (Avery, 1933). Throughout the 
lamina successively formed procambial strands arise in continuity with those formed earlier (Pray, 1955a,b) so that differentiation is a continuous process. The small veins develop as a unit between previously formed procambial strands although the vein endings differentiate progressively from strands delimiting the areoles (Pray, 1963). Vein endings of Liriodendron are initiated by the time the leaf is $2.5 \mathrm{~cm}$ long (Pray, 1955a).

The smallest veins may be uniseriate in origin, that is they may arise from a cell series one cell in diameter (Pray, 1955a). Larger veins are, of course, multiseriate in origin. In tobacco (Avery, 1933) small veins commonly arise from division of a single file of cells (one cell in transverse section) in the upper layer of the future spongy mesophyll (third cell layer from the adaxial surface). One of the daughter cells of the initial division undergoes another division and the upper of these three cells becomes a bundle sheath cell as do the cells lateral to the lower two. Divisions of the lower two cells give rise to the remainder of the bundle.

Since the bundle originates from a single file of cells all members of the bundle, including companion cells, sieve elements, parenchyma and tracheids are closely related ontogenetically (Morretes, 1962). When viewed in paradermal section the coincident end walls of the cells of the minor vein, including the bundle sheath, clearly reveal the direct 
ontogenetic relationship. Because of the orderly appearance of cells the minor vein is often referred to as being composed of links.

In larger strands maturation of the phloem precedes that of the xylem. In tobacco, which has bicollateral bundles, the development of the internal phloem of the large bundles of the leaf lags behind that of the external phloem (Avery, 1933). This pattern is to be expected since the internal phloem of dicotyledons is initiated somewhat later than the external (Esau, 1939). Minor veins of tobacco do not contain internal (adaxial) phloem.

\section{Carbon Balance}

The development of the photosynthetic function of leaves has been studied although not as thoroughly as might be expected. Most investigations have been agriculturally oriented and as a result have concentrated on the photosynthetic activity of the whole growing plant rather than a single developing leaf. Very young leaves show a net loss of $\mathrm{CO}_{2}$ but upon expansion photosynthetic capacity rapidly develops. Full photosynthetic capacity is attained when the leaf is three-quarters to fully expanded, and it then slowly declines (Richardson, 1957; Kriedmann, 1968; Larson and Gordon, 1969; Dickmann, 1971; Larson et a1., 1972; Ryle, 1972; Fraser and Bidwe11, 1973). As the leaf ages the light saturation point steadily increases, then drops again 
(Richardson, 1957). The $\mathrm{CO}_{2}$ compensation point steadily decreases during development (Kriedmann, 1968). Dark respiration values are high in young leaves and decrease as the leaf ages (Kriedmann, 1968; Larson and Gordon, 1969; Dickmann, 1971). Salin and Homann (1971) found lower photorespiratory activity in young than in old leaves while Fraser and Bidwell (1973) could find no significant change in photorespiration during leaf ontogeny.

The direction of phloem transport changes in growing leaves. When young and unable to sustain growth and metabolism through photosynthesis the leaf is a physiological sink, importing material in the phloem. When larger and capable of sufficient photosynthetic assimilation of carbon the importing of material stops and assimilates are exported from the leaf (Milthorpe and Moorby, 1969). Numerous studies have shown that in a single leaf these two stages overlap; that is, the leaf imports and exports sinultaneously (Jones et a1., 1959; Thrower, 1962; Webb and Gorham, 1964). Jones and Eagles (1962) suggested that this bidirectional transport is due to export from mature regions of the leaf and import by immature regions. Since the development of the leaf is basipetal in direction, import presumably continues into the basal region of the leaf while export proceeds from the more mature tip (Jones and Eagles, 1962).

A young leaf has two sources of carbonphotoassimilation and translocation. Photoassimilated 
carbon is primarily channeled into protein while translocated sugars contribute more carbon to insoluble carbohydrate (Joy, 1967).

\section{B. PHLOEM METABOLISM}

\section{Metabolites and Enzymes}

Proposed mechanisms of phloem transport may be classified as those which require a continuous input of energy to drive assimilate flow and those which require energy only for the maintenance of the living condition of the conducting cells. In an effort to provide evidence for one or another mechanism the metabolism of phloem has received considerable attention.

Many samples of phloem exudate and aphid stylet exudate have been tested for ATP. Kluge and Ziegler (1964) found ATP in phloem exudate of 17 out of 18 species tested. Activity was present only in the first drop of exudate, indicating that ATP was not being translocated. This result has not been confirmed by recent investigations. ATP levels were not found to change during exudation from cut phloem (Kluge et al., 1970) or from severed aphid stylets (Gardner and Peel, 1969, 1972). Concentrations of ATP are in the order of $600 \mu \mathrm{g} \mathrm{m} 1^{-1}$ exudate (Gardner and Peel, 1969, 1972; Kluge et a1., 1970). By comparison the concentration of ATP 
is $49 \mu \mathrm{g} \mathrm{g}^{-1}$ in maize roots (Bledsoe et al., 1969) and $10 \mathrm{\mu g}$ $\mathrm{g}^{-1}$ in carrot xylem tissue (Atkinson et al., 1966). Gardner and Peel (1972) found that application of fluoride reduced the mobile ATP concentration to an undetectable level and stopped exudation. However, exudation did not stop for an hour after the ATP had been eliminated.

Phosphorus is apparently metabolized in sieve elements. Many studies have shown that phosphorus is phloem mobile (for example, Seth and Wareing, 1967). However, aphid stylet exudate gave no reaction for inorganic or organic phosphorus (Peel and Weatherly, 1959) indicating perhaps that it is rapidly utilized. The incorporation of inorganic ${ }^{32} \mathrm{P}$ into organic phosphate esters was detected within 15 minutes of application to willow bark (Gardner and Peel, 1972). It is difficult to assess these results for most of the transformations of the ${ }^{32} \mathrm{P}$ could have taken place before entry into the sieve tubes. Inorganic ${ }^{32} \mathrm{P}$ was incorporated in vitro into a number of organic phosphates including ATP by phloem exudate (Kluge et al., 1970). Histochemical studies have revealed a considerably higher phosphatase activity in phloem than in surrounding tissues (Swanson, 1959; Lester and Evert, 1965; Zee, 1969a). Lester and Evert (1965) found acid phosphatase activity in sieve elements, companion cells and phloem parenchyma of Tilia americana. In the sieve element phosphatase activity was concentrated in the slime strands. Zee (1969a) found 
the strongest phosphatase activity of the phloem of pisum in the sieve element reticulum and in the region of the sieve plate pores. No activity could be detected in association with mitochondria, plastids or, in contradiction to Lester and Evert (1965), with slime. In young sieve elements phosphatase activity was detected in cisternae of the endoplasmic reticulum and saccules of the dictyosomes.

Peroxidase activity is also strong in the plasmalemma and cell wall of locust and sycamore sieve elements and even stronger in the vacuoles and tonoplast of the companion cells. Little activity is seen in storage parenchyma or in xylem elements (Czaninski and Catesson, 1969). Peroxidase activity is also present in phloem exudate (U1lrich, 1961).

Phloem exudate contains most of the enzymes of the glycolytic sequence (Kennecke et a1., 1971). U1lrich (1961) has suggested that the phloem has a complete respiratory system but under oxygen stress is capable of anaerobic respiration aided by peroxidase. The evidence for these conclusions is continuing respiration under anaerobic conditions and the we11-documented sensitivity of translocation to cyanide (see below). Oxygen stress may be a normal condition for phloem considering the lack of intercellular spaces in the vascular bundle. Duloy and Mercer (1961) decided, on the basis of inhibitor studies, that respiratory pathways in the parenchyma and phloem of a number of species 
are identical.

Studies on the respiration of phloem are not conclusive. There has been no reliable experiment to date which has separated phloem respiration from the respiration of surrounding ground tissue. Values for "phloem" respiration are usually comparable to those for other tissues (Canny, 1960; Canny and Markus, 1960; Duloy and Mercer, 1961). High respiratory values obtained from isolated bundles of Rheum (Kursanov, 1961) may easily have resulted from wounding (Crafts and Crisp, 1971, p. 284).

\section{Metabolic Inhibitors}

Inhibitors have been used in attempts to block translocation. If transport inhibition can be correlated with specific sites of inhibitor action some insight into the translocation mechanism may be gained. Interpretation of these experiments is made difficult by possible transport of the inhibitor to source or sink regions (Kendall, 1955; Duloy and Mercer, 1961) which may be under more direct metabolic control than the path phloem (Geiger, 1966).

Cyanide is perhaps the most potent chemical inhibitor of translocation (Curtis, 1929; Ullrich, 1961; Willenbrink, 1966; Ho and Mortimer, 1971). Ho and Mortimer (1971) applied ${ }^{14} \mathrm{C}$-cyanide to sugar beet petioles. The labelled inhibitor was quickly picked up in the transpiration stream and carried to the leaf. By autoradiography of 
whole leaves following a short pulse of ${ }^{14} \mathrm{CO}_{2}$ it was shown that transport from the mesophyll to the minor veins, i.e. vein loading, was not affected but that transport of ${ }^{14} \mathrm{C}$ along the veins was blocked. It was possible to inhibit translocation by applying the cyanide to the petiole after the veins had been loaded. These experiments clearly indicate that cyanide inhibits long distance phloem transport. U11rich (1961) attributes cyanide sensitivity to inhibition of peroxidase which aids anaerobic phloem respiration.

Ul1rich (1961) did not find anoxia inhibitory to translocation although Curtis did (1929). When Geiger and Christy (1971) removed $\mathrm{O}_{2}$ from a sink leaf of sugar beet, translocation to the leaf was immediately and completely blocked. However, within 2 hours translocation rose to $50 \%$ of the control rate and remained constant for up to 8 hours of continuous anaerobiosis. Similarly Sij and Swanson (1973) found that anoxia inhibited transport through the petiole of Cucurbita pepo for approximately one hour. After this period translocation continued at normal rates, under continued anaerobic conditions, for 24 hours. Further anoxia resulted in irreversible transport inhibition.

Inhibitors of oxidative phosphorylation (oligomycin and dinitrophenol) caused a cessation of aphid stylet exudation after a number of hours of application although ATP concentration was not affected (Gardner and Peel, 1972). 
When Harel and Reinhold (1966) supplied dinitrophenol (DNP) to the translocation system transport was inhibited. However when they first fed the leaf and later excised it, transport of ${ }^{14} \mathrm{C}$-sucrose already in the translocation stream was not affected. They attribute the DNP effect to inhibition of vein loading. Kendall (1955) on the other hand concluded that DNP directly affects long distance transport. Kendall (1955) found that sodium fluoride produced a similar inhibitory effect.

Translocation is inhibited by cold (Whittle, 1964; Webb and Gorham, 1965; Geiger, 1966; Swanson and Geiger, 1967; Bowling, 1968; Geiger and Sovonick, 1970). The effect of cooling to $0^{\circ} \mathrm{C}$ is very rapid (Swanson and Geiger, 1967; Webb, 1971). In fact cooling at one point seems to cause. simultaneous inhibition of transport all along the path from the source to the cold block (Webb, 1971; Walding and Weatherly, 1972). Many plants acclimate to localized cold blocks, that is after a time translocation will begin again and continue through the block (Swanson and Geiger, 1967; Webb, 1971; Walding and Weatherly, 1972). The effect of chilling is reversible (Webb and Gorham, 1965).

The primary effect of cooling on translocation is not yet clear. Although many characteristics of cooling inhibition parallel cold inhibition of cytoplasmic streaming, this is probably not the cause of translocation blockage since cytoplasmic streaming, in the usual sense of cyclosis, 
has not been reported in mature sieve elements. Coulson et al. (1972) could find no stoichiometric relationship between translocation, petiolar respiration, and petiolar ATP turnover rates in chilled phloem. They conclude that cold does not inhibit transport by blocking metabolic reactions. Similarly Coulson and Peel (1971) were able to. detect continuing respiration of translocated sugars in willow stems at $0^{\circ} \mathrm{C}$. They found, in fact, that in mature stems low temperatures lead to an increase in the rate of breakdown of translocated sugars, relative to the breakdown at $25^{\circ} \mathrm{C}$.

Giaquinta and Geiger (1973) constructed Arrhenius plots of translocation velocity and mass transfer rate in a chilling sensitive plant (Phaseolus vulgaris). These plots showed a break in slope at $8^{\circ} \mathrm{C}$. When Arrhenius plots of petiolar respiration and cytoplasmic streaming were made they showed no similar break. At $1^{\circ} \mathrm{C}$ protein crystals in the sieve tubes of this plant showed no significant displacement when the sieve tube was cut although significant displacement did occur at $25^{\circ} \mathrm{C}$. From these data it was concluded that temperature sensitivity is due to physical blockage of the sieve tubes and not to metabolic inhibition of the driving force of translocation.

This conclusion was substantiated by an ultrastructural study of petioles which were flash-frozen and freezesubstituted. Sieve plate pores of petioles cooled to $0^{\circ} \mathrm{C}$ 
before freezing were occluded with cytoplasmic material which lines the walls, but does not occlude the pores, of sieve elements at $25^{\circ} \mathrm{C}$.

\section{Effects of Light}

Translocation, especially of exogenously applied substances, may be inhibited by darkening the fed leaf (Gustafson, 1956; Barrier and Loomis, 1957; Moorby, 1964 ; Hartt, 1965; Husain and Spanner, 1966; Geiger and Batey, 1967; Plaut and Reinhold, 1969). Plaut and Reinhold (1969) removed $\mathrm{CO}_{2}$ from the air following feeding of ${ }^{14} \mathrm{CO}_{2}$ to a single leaf kept in the light and diminished translocation in bean plants. They concluded that the reduction of transport caused by leaf darkening is a result of the elimination of concomitant photosynthesis. An inhibitor of photosynthesis $(3(3,4$-dichloropheny 1$)-1,1$-dimethyl urea) also reduced transport.

The reduction of caesium transport by leaves of pea plants in the dark has been attributed to a dependence on simultaneous transport of sugar or a metabolic requirement for sugar (Moorby, 1964). Support for this conclusion comes from Husain and Spanner (1966) who found that ${ }^{137} \mathrm{Cs}$ moved in darkened leaves of rye only when sucrose was added. The only other feasible explanation is that translocation is light sensitive. This alternative was disregarded by Moorby (1964) and is certainly not consistent with the findings of 
Husain and Spanner (1966). However, the following year Constance Hartt (1965) proposed that translocation in the leaf of sugar cane is under photocontrol. She found that one factor controlled basipetal transport at 100 footcandles. Another factor controlled polarity and was saturated at 50 foot-candles. If the fed and upper parts of the leaf were completely darkened there was a very significant increase in acropetal translocation which is usually minimal. This same phenomenon had been reported earlier by Thaine et al. (1959) in the soybean. Since the compensation point of photosynthesis is 120-125 foot-candles in sugar cane, Hartt concluded (1965) that a loss of concomitant photosynthesis is not the cause of transport inhibition but in fact translocation, at least in the leaf, is under photocontrol.

In summary then, it seems clear that transport in the phloem is affected by a number of treatments which may affect phloem metabolism. The evidence suggests, however, that metabolic energy is required for the maintenance of the phloem and is not used directly to drive assimilate flow.

\section{PHLOE: $:$ ULTRASTRUCTURE}

Early 1ight microscope investigations (see Esau, 1969) correctly interpreted many features of sieve element structure and development such as the disruption of the 
tonoplast and the enucleate state of the mature cell. In recent years the increased resolution of the electron microscope has greatly expanded our knowledge although problems of tissue preservation have not yet been completely overcome.

The mature sieve tube is under 10 to 30 atmospheres of pressure (Weatherly, 1962) and is readily damaged by even the most delicate treatments. It is undoubtedly the most difficult plant tissue to preserve. Early hopes that fine structural analysis of phloem would lead to a better understanding of translocation have not been realized.

This review will cover the more important papers dealing with phloem ultrastructure and will concentrate primarily on the literature of the last five years. For a more complete treatment, especially of the older literature, see Esau's comprehensive work (Esau, 1969).

\section{Sieve Element}

\section{(1) Sieve P1ate}

The sieve tube conduit is interrupted at regular intervals by sieve plates perforated with sieve plate pores. The need for sieve plates in translocation remains obscure. However the phylogenetic trend has, if anything, been toward shorter sieve elements and consequently more sieve plates per unit length of sieve tube (Esau, 1969).

of particular interest to the study of translocation is the content of the sieve plate pores of the functional 
ce11. It is now recognized that massive accumulations of material on the sieve plate (the so-called slime plug) observed by early investigators were only wounding artifacts. However slime, or in modern terminology p-protein, is still frequently observed in sieve pores, a condition which is variously interpreted as a response to pressure release upon wounding (Johnson, 1968; Anderson and Cronshaw, 1969; Cronshaw and Anderson, 1969; Shih and Currier, 1969; Anderson and Cronshaw, 1970; Behnke, 1971a) or as the true nature of the functional pore (Mishra and Spanner, 1970; Siddiqui and Spanner, 1970). There is more general agreement that the plasmalemma lines the pores and is thus continuous from sieve element to sieve element (Engleman, 1963; Evert and Murmanis, 1965; Northcote and Wooding, 1966).

Attempts have been made to kill and fix phloem without causing the usual pressure release and subsequent fixation artifacts. Esau and Cheadle (1965) used the hollow petiole of Cucurbita to advantage by filling the interior with fixing solution (potassium-permanganate). The sieve plates which they observed were not densely plugged but did contain dispersed slime. Engleman (1963) applied formaldehyde laterally to stems of Impatiens and observed plates with open pores. An attempt to decrease pressure in sieve tubes (Anderson and Cronshaw, 1970) by wilting plants resulted in less frequent plugging of sieve pores. However, a similar experiment (Siddiqui and Spanner, 1970) produced 
completely different results. Siddiqui and Spanner (1970) also attempted to kill plants rapidly by immersing them in boiling water. They interpreted the results of all their experiments as indicating a plugged condition of functional pores.

Johnson (1968) rapid-froze intact tissue and freezeetched the phloem. His micrographs do not suggest plugging of the pores. Cronshaw and Anderson (1969) fixed whole Nicotiana plants. They also froze and subsequently fixed intact plants. Their results support the concept of unplugged sieve plate pores. When Esau et al. (1967) examined virus-infected sugar beet they found virus particles plugging the pores much as P-protein does in the usual preparations. They concluded that the pores are normally unplugged.

The modern consensus is, therefore, that sieve pores are not completely plugged as earlier work with the light and electron microscopes indicated. However, even the most recent micrographs show the presence, to some extent, of P-protein in the pores whether these pores are plugged or not. It is quite conceivable that P-protein does occupy a portion of the pores in functioning sieve elements. Perhaps P-protein lines the pores, as in Hill's (1908) interpretation or takes on a more elaborate arrangement. Callose, a B1-3 glucan (Clarke and Stone, 1962), lines the pores of even rapid-frozen sieve elements (Shih 
and Currier, 1969). Since deposition of callose is an enzymatic reaction this result clearly indicates that a small amount of callose exists in functional sieve elements. The function of callose is still basically unresolved. McNairn and Currier (1968) increased callose deposition and retarded translocation by heating the translocation path to $40-45^{\circ} \mathrm{C}$. However Eschrich et al. (1965) did not observe slowing of the translocation of either ${ }^{14} \mathrm{C}$-assimilates or fluorescein in petioles of Cucurbita when strong callose deposition had been induced. Eschrich (1965) has proposed that callose regulates the water balance of the transport system by non-osmotically removing water from the symplast and transferring it to the apoplast.

Callose appears to be involved in the normal development of sieve plate pores. Callose is deposited over a plasmodesma at the site of a future pore. During this period endoplasmic reticulum profiles are closely appressed to the callose platelet. Wall material continues to be deposited between callose platelets while it is eroded from beneath the platelet around the plasmodesma. Perforation of the callose platelet compleies the opening of the pore and signals the maturation of the sieve element (Esau and Gill, 1972).

This sequence of events suggests a possible role for callose in the development of sieve elements. Perhaps callose is substituted for cellulosic wall material so that 
the pores may be opened by a single selective hydrolytic enzyme without causing undue damage to the cell cytoplasm or cell wall. In the case of xylem vessel members this complex series of events is unnecessary since the cytoplasm dies when the end wall perforation is complete and the primary wall is often partially hydrolyzed (Esau, 1965).

\section{(2) P-Protein}

S1ime was first observed in sieve elements of Cucurbita in 1854 by Hartig, the discoverer of the sieve element. Since that time argument over the nature, development, and arrangement of slime in the mature sieve element has continued unabated. Interest has not been deterred by the complete absence of evidence that slime is involved in the translocation process.

Since the word slime (translated from the German word schleim) does not properly describe the proteinaceous nature of the substance, the term P-protein $(p=$ phloem) was proposed by Esau and Cronshaw (1967). The terms slime and P-protein are now used interchangeably. P-protein is first recognized in very young sieve elements where it aggregates in the form of particles of varying shape, the P-protein bodies (Cronshaw and Esau, 1967, 1968a; Northcote and Wooding, 1966; Wergin and Newcomb, 1970). The P-protein bodies enlarge and, as the tonoplast of the cell breaks down, the bodies begin to swell and disaggregate. This process is 
usually described as dispersal of the p-protein. There is little consensus in the literature as to the arrangement of dispersed $\mathrm{P}$-protein in functional sieve elements. P-protein arises in the cytoplasm of immature tobacco sieve cells in the form of tubules $231 \pm 2.5 \AA$ in diameter (Cronshaw and Esau, 1967). This is termed P1-protein. The P1-protein aggregates to form compact masses of tubules, the P1-protein bodies. At about the same time that the tonoplast and nuclear membrane break down the P1-protein bodies disperse and striated fibrils $149 \pm 4.5 \AA$ appear (P2-protein). It is assumed that P2-protein is derived from P1-protein.

The situation is more complex in Cucurbita (Cronshaw and Esau, 1968a). Tubules of P-protein arise in the cytoplasm and aggregate to form bodies. Because of the similar appearance and dimensions of these tubules (diameter $242 \pm$ $3.6 \mathrm{~A})$ they are considered identical to the tubules of Nicotiana and are called P1-protein. P1-protein bodies are approximately $1 \mu$ in diameter. Unlike the situation in Nicotiana the P1-protein bodies normally fail to disperse. A second type of body in Cucurbita sieve elements consists of aggregated fibrils termed P3-protein. These P3-protein bodies are approximately 3 times the diameter of P1-protein bodies. The P3 fibrils usually, but not always, develop into tubules $179 \pm 8.2 \AA$ in diameter (P4-protein) while still aggregated as a body. Just prior to the maturation of 
the sieve element both P1 and P3 (or P4) bodies are evident. The P1 bodies are usually located adjacent to the larger P3 (or P4) bodies. As the tonoplast and nuclear membrane break down the P3 (or P4) protein bodies swell, fuse and disperse. into fine fibrils. In the extrafasicular bundles of Cucurbita the protein bodies do not disperse (Cronshaw and Esau, 1968b). These authors state that "dispersal or nondispersal [of the P3-P4 protein bodies] can be related to the positions of the sieve elements relative to the vascular bundles," since P-protein bodies of sieve elements within the vascular bundles disperse while those of sieve elements not found in the bundle do not.

Northcote and Wooding (1966) describe fibrils of 190-210 $\AA$ diameter aggregated into slime bodies in Acer pseudoplatanus. These bodies later disperse to produce thinner striated 80-100 $\AA$ fibrils with an axial repeat of approximately $80 \AA$ (Wooding, 1967). The wider fibrils are tubular and probably represent the P1-protein of Cronshaw and Esau (1967). In tobacco callus phloem Wooding (1969) recognized $P 1$ and $P 2$ protein but very little dispersal from the P1 to the P2 form took place. This led Wooding to suggest that the change from the tubular to the fibrillar form of P-protein may be induced by or be responsible for the onset of translocation.

Wergin and Newcomb (1970) describe the development of the crystalline P-protein body of soybean sieve elements. 
P-protein is first evident as a finely granular material in the sieve element cytoplasm. Masses of this material accumulate and tubules ( $135 \AA$ diameter) appear. The tubules aggregate (see also Palevitz and Newcomb, 1971) to form a crystalline P-protein body which may reach 15-30 $\mu$ in length. This body eventually disperses into fine striated fibrils which fill the lumen of the sieve element. The most complex arrangement of tubules to form P-protein bodies probably occurs in the Popilionaceous legumes where there are distinct head and tail regions of the crystalline body (Wergin and Newcomb, 1970; Palevitz and Newcomb, 1971).

In tobacco (Parthasarathy and Mühlethalar, 1969; Cronshaw and Anderson, 1971) and Mimosa (Esau, 1971) the $\mathrm{P}$-protein tubules in the $\mathrm{P}$-protein bodies appear to be connected by fine fibrils. Tubules often appear to be arranged hexagonally in transections of tobacco P-protein bodies (Cronshaw and Anderson, 1971). Cucurbita tubules usually have a four- or six-sided packing arrangement with a center-to-center spacing of $295 \AA$ (Cronshaw and Esau, 1968b). Tubules of soybean $P$-protein bodies are spaced equidistantly with a center-to-center spacing of $180 \AA$ (Palevitz and Newcomb, 1971). Mimosa P-protein tubules are in a pentagonal or hexagonal arrangement (Esau, 1971).

P-protein tubules appear to be composed of subunits. Cross sections of tobacco P1-protein tubules were analyzed by image reinforcement (Parthasarathy and Mühlethalar, 
1969). The analysis suggested that the tubules are composed of six sub-units in transverse section with some evidence that each sub-unit is itself a dimer. In longitudinal section tubules have regular striations with a period of 60 to $100 \AA$. The striations are approximately $60 \AA$ wide. Parthasarathy and Mühlethalar (1969) presented a model in which the tubule consists of a double helix of sub-units similar in appearance to a microtubule. It is suggested that unwinding the double helix produces the fibrillar form of P-protein.

Esau (1971) has recently described the formation of tubules in Mimosa. In a parietal position in the immature cell fibrillar material is organized into a threedimensional system of five- and six-sided elongated compartments. The tubules arise in the corners of the compartments. In this way a highly ordered system of tubules develops and forms a P-protein body with tubules usually grouped in a five- or six-sided arrangement and often interconnected with fibrils. The micrographs in this paper are quite convincing.

A number of laboratories have shown recent interest in the isolation and analysis of p-protein. These studies are undoubtedly aimed at elucidating a possible role for $\mathrm{P}$-protein in translocation.

The similarity of $\mathrm{P}$-protein to microtubules led Wooding (1969) to attempt to disrupt P-protein tubules with colchicine or cold. He was not successful. Walker and 
Thaine (1971) collected phloem exudate from Cucurbita into buffer containing thiol-reducing agents. Soluble and insoluble fractions were separated by centrifugation and filtration and analyzed by DEAE chromatography and gel electrophoresis. Eighteen proteins were recognized in the soluble fraction and four in the insoluble fraction. One of the soluble proteins appeared to be responsible for gelling of the exudate when the thiol-reducing agents were removed.

A similar study by Eschrich et al. (1971) identified twelve water soluble proteins in Cucurbita exudate by polyacrylamide gel electrophoresis. There appears to be two or three major protein bands in their preparation. Most of the proteins did not exhibit enzyme activity although some showed peroxidase, acid phosphatase or aldolase activity. No ATPase activity could be found. Electron microscopy was used to ensure that exudate originated in cut sieve tubes. Weber and Kleinig (1971) collected Cucurbita exudate and identified, by Sephadex 6200 purification and gel electrophoresis, five major protein components of molecular weights 15,$000 ; 28,000 ; 59,000 ; 116,000 ; 220,000$. These values are almost exactly double each other indicating perhaps the formation of dimers. Exhaustive dialysis did not dissociate the proteins over 100,000 molecular weight. In further experiments (Kleinig et al., 1971a,b) vinblastine, the periwinkle alkaloid known to precipitate actin-like proteins and microtubular proteins, was used to 
precipitate Cucurbita exudate proteins. All five species of protein behaved identically in their precipitation by vinblastine and the proteins aggregated into filaments, as do actin-like filaments, when dialized against $0.1 \mathrm{M} \mathrm{KCl}$ (K1einig et al., 1971a). Colchicine did not bind sieve element protein although it does bind actin-like protein and microtubular protein. Free nucleotides were present in the exudate but no ATPase activity could be found (Kleinig et al., 1971b).

Kollmann et al. (1970) collected exudate from Cucurbita and Nicotiana which they negatively stained and examined in the electron microscope. They observed two forms of filamentous structure, a $40 \AA$ diameter filament with a beaded appearance and a $90 \AA$ filament which possibly consisted of two helically arranged $40 \AA$ filaments. A chemical analysis revealed mostly protein with trace quantities of nucleic acid. Lipids and polysaccharides were not detected.

There is little agreement on the arrangement of P-protein in functionally mature cells. Certain authors have reported the existence of strands, presumably composed of P-protein, in mature sieve elements. Thaine (1962) proposed a theory of translocation based on a hypothetical structure of tubular strands passing from cell to cell through the sieve plate pores. He identified these strands by 1ight (Thaine, 1962) and phase (Thaine et a1., 1967) 
microscopy. Strands were also identified in quick frozen material cut on a cryostat (Jarvis and Thaine, 1971) although the micrographs were not convincing. Recently Thaine (1969) has proposed, without any supporting evidence, a rather detailed internal structure for these strands, including the presence of contractile protein.

Sieve element strands have also been reported by Evert and his associates (Evert and Derr, 1964; Evert and Murmanis, 1965; Evert and Alfieri, 1965; Evert et al., 1966; Tamulevich and Evert, 1966). These strands were envisaged as extending the length of the cell and from cell to cell through the sieve pores. In later papers Evert and co-workers (Evert and Deshpande, 1969; Evert et a1., 1969) decided that these strands were formed during fixation by aggregation of finer strands of $P$-protein found in a parietal position in the cell and composed of striated fibrils.

Another theory of translocation presented by Fensom (1972) is based on a model of micro-peristaltic movement in strands of contractile lipoprotein. Again supporting structural evidence is scanty.

The strand theories of Thaine and Fensom derive some support from the demonstration of contractile protein isolated from vascular bundles (not sieve elements!) of Nicotiana and Cucurbita (Yen and Shih, 1965). The contractile properties were identified by viscosity drop upon 
addition of ATP and by the presence of ATPase activity. Both these characteristics are common to actinomyosin solutions. Another report of contractile protein, in pea tendrils, is based on the same assays (Jaffe and Galston, 1967).

Although a contractile mechanism of translocation is exciting there is little evidence that P-protein has contractile properties. P-protein is precipitated by vinblastine but this is by no means specific for actin-like proteins. Kuo and Lou (1966) reported the presence of ATPase in slime by histochemical tests but studies from two independent laboratories have failed to find ATPase activity associated with P-protein exudate (Eschrich et al., 1971; Kleinig et al., 1971b).

Williamson (1972) did not find any effect of cytochalasin $B$ on the movement of ${ }^{24} \mathrm{C}$-assimilates or on the ultrastructure of the sieve element of Lepidium sativum (but see Thompson and Fensom (1972)). P-protein filaments from phloem exudate showed no ability to bind heavy meromyosin subfragment 1 as do actin-like proteins.

It now seems that $P$-protein is not universally found in higher plants. It has not been identified in any tissue of corn (Singh and Srivastava, 1972) or the leaves of Hordeum (Evert et a1., 1971) or wheat (Kuo et a1., 1971). In addition the $P$-protein bodies in the extrafasicular bundles of Cucurbita fail to disperse and therefore could not 
form strands. These bundles are capable of translocating ${ }^{14} \mathrm{C}$-assimilates (Webb and Gorham, 1964). Both models (Thaine, 1969; Fensom, 1972) envisaging contractile mechanisms explicitly equate P-protein with contractile protein.

P-protein is not restricted to sieve elements. It is often found in companion cells and in phloem parenchyma cells (Cronshaw and Esau, 1968a). P-protein has been identified in nuclei of immature sieve elements of Tilia (Evert and Deshpande, 1970).

\section{(3) Mitochondria}

Electron microscopy has confirmed the presence of mitochondria in mature sieve elements. Generally the number of mitochondria is not large (Shih and Currier, 1969). They are usually wel1-preserved and appear much like those typically found in nucleate cells (Esau and Cronshaw, 1968a; Shih and Currier, 1969; Zee, 1969b), although they may have fewer internal membranes and the cristae often appear swollen (Esau and Cronshaw, 1968a).

Esau and Cronshaw (1968a) suggested that different reactions of mitochondria in sieve elements and nucleate cells to fixation indicates some inherent difference in the organelles themselves. This is not necessarily true. Severe disruption of the sieve element will undoubtedly cause some artifacts in fixation of the mitochondria beyond those which are experienced by mitochondria in nucleate cells. 


\section{(4) Plastids}

Plastids are present in sieve elements although they lack grana (Esau and Cronshaw, 1968a; Shih and Currier, 1969; Zee, 1969b; Behnke, 1972). Starch is commonly found but is only rarely seen in some species (e.g. Cucurbita). The starch in sieve element plastids stains red with iodine rather than blue-violet (McGivern, 1957). Phytoferritin has been observed in sieve tube plastids of Atriplex (Behnke, 1971b).

Behnke has attempted to relate sieve tube plastid structure, to angiosperm systematics (Behnke, 1972). He distinguishes two types of plastids, an S-type which stores only starch and a P-type which elaborates a protein inclusion. P-type plastids may also store starch. Although Cucurbita has S-type plastids, starch is rarely seen and then usually in young sieve elements (Esau and Cronshaw, 1968a).

\section{(5) Endoplasmic Reticulum}

Endoplasmic reticulum (ER) is well represented in developing sieve elements and is found to a greater or lesser extent in the mature cell. The ER is early associated with developing callose platelets, the sites of future sieve plate pores (Esau and Cronshaw, 1968b; Wooding, 1969). ER may also be found closely appressed to the surface of P-protein bodies (Cronshaw and Esau, 1967). The 
amount of $E R$ in the sieve element appears to be at a maximum just before the loss of many cell components and the perforation of the pores (Esau and Gill, 1972). The ER may be the source of autolytic enzymes responsible for protoplast degradation (Zee, 1969a; Esau and Gil1, 1972). Acid phosphatase is located in the cisternae of the ER (Zee, 1969a).

In the mature cell ER is occasionally seen in the sieve plate pores (Behnke, 1971a; Evert et a1., 1971). Rough ER is no longer found. Smooth ER is found in two forms (Esau and Cronshaw, 1968b). It is either in a parietal position one cisterna in depth against the plasma membrane or in the form of stacks (sieve element reticulum) usually aligned parallel to the cell wall (Esaw and Cronshaw, 1968b; Mishra and Spanner, 1970; Esau and Gill, 1972). Sieve element reticulum is probably composed of a single manyfolded cisterna (Esau and Cronshaw, 1968b).

\section{(6) Nucleus}

The mature sieve element is usually enucleate although nuclei may persist in some species, especially lower plants, conifers (Evert and Alfieri, 1965; Evert et al., 1970), and woody dicots (Evert and Deshpande, 1969; Evert et al., 1970). There are reports that the nucleolus may be extruded and persist in otherwise enucleate sieve elements (Shih and Currier, 1969; Mishra and Spanner, 1970). Deshpande and Evert (1970) could not confirm reports of 
extruded nucleoli in four species.

The nucleus of differentiating sieve elements becomes lobed (Esau and Cronshaw, 1968b) before its disappearance. A detailed description of the degeneration of nuclei of the root protophloem of Nicotiana is given by Esau and Gill (1972). The continued survival of the enucleate sieve element demonstrates that the nucleus is not absolutely required for the function and maintenance of differentiated cells. The sieve elements of woody dicotyledenous species are known to survive and function through two seasons or more and the phloem of palms functions for at least fifty years (Parthasarathy and Tomlinson, 1967).

\section{(7) Tonoplast}

The concept that the tonoplast breaks down in mature sieve elements dates from early light microscope investigations and has been confirmed by electron microscopy.

Membrane fragments that are often seen in mature sieve elements may be remnants of the tonoplast (Esau and Cronshaw, 1968b; Evert et al.; 1968; Kuo et a1., 1971). Evert et al. (1969) and Evert and Deshpande (1969) suggested that the tonoplast may normally be present in mature sieve elements of elm and called for a re-examination of the tonoplast-free state in mature sieve elements in general. 
(8) Other Cell Constituents

Ribosomes are abundant in immature sieve cells but the mature element with open pores has few, if any, ribosomes (Srivastava and O'Brien, 1966; Cronshaw and Esau, 1967; Esau and Cronshaw, 1968b). Similarly, although rough ER is abundant in immature sieve elements only smooth ER is present in the mature state (Esau and Cronshaw, 1968b). The absence of ribosomes is the clearest indication that protein synthesis terminates when sieve elements reach structural and functional maturity.

Although dictyosomes are not found in mature sieve elements they are abundant in young cells, especially in those with growing cell walls (Northcote and Wooding, 1966; Cronshaw and Esau, 1968a). Dictyosomes begin to disappear about the same time that the tonoplast and nucleus disperse (Cronshaw and Esau, 1968a).

Immature phloem cells contain bodies, termed spiny vesicles (Newcomb, 1967; Cronshaw and Esau, 1968a; Evert and Deshpande, 1969; Esau and Gill, 1970a,b), which are possibly derived from dictyosome vesicles. Spiny vesicles are approximately the same size and shape as dictyosome vesicles but appear coated with a large number of projecting spines. The frequent close association between spiny vesicles and developing P-protein bodies (Newcomb, 1967; Esau and Gill, 1970b) has led to the suggestion that these vesicles are concerned, in some manner, with P-protein formation. This 
association could not be confirmed by Esau and Gill (1970b) in sugar beet. Spiny vesicles are not restricted to sieve elements; they are also found in companion cells and parenchyma cells (Cronshaw and Esau, 1968a).

Mature sieve elements retain their plasmalemma and may be plasmolyzed (Currier et al., 1955). The plasmalemma lines the sieve plate pores (Evert and Murmanis, 1965; Engleman, 1963; Northcote and Wooding, 1966). Microtubules line the plasmalemma of a mature sieve element in Figure 13 of a paper by Cronshaw and Esau (1968b).

\section{Companion Cell}

Companion cells are usually cytologically distinct from parenchyma cells although this may be difficult to detect. The most characteristic feature of companion cells is the density of the cytoplasm. Electron micrographs show that this density is due in large part to the abundance of ribosomes and the presence of numerous organelles and membrane systems (Esau, 1969). The ground substance of the cells may also be very dense (Cronshaw and Esau, 1968a).

Mitochondria are numerous and well-developed in companion cells. Plastids usually have few internal membranes although they may be differentiated into chloroplasts (Esau, 1967). P-protein is present in companion cells and phloem parenchyma cells (Cronshaw and Esau, 1968a). Companion cells have characteristic connections with 
sieve elements. On the sieve element side the plasmodesma is relatively large and on the companion cell side it is branched. In one plasmodesma of Cucurbita 27 branches were counted (Evert et al., 1966). Plasmodesmata between companion cell and companion cell (Cronshaw and Esau, 1968a) and between companion cell and parenchyma cell (Evert et al., 1966) may also be branched in Cucurbita. Where the plasmodesmata branch there is a median cavity which may be filled - with convoluted tubular membranes (Esau, 1969).

\section{TRANSLOCATION MECHANISMS}

The elucidation of the phloem transport mechanism is a problem that has engaged investigators for over one hundred years.

The major difficulty with translocation physiology is the lack of adequate technique. Translocation is a whole-plant process and is not easily approached by common biochemical methodology. The conducting cells are extremely labile and are easily damaged by even the most delicate manipulations.

Early hopes that tracers, especially ${ }^{14} \mathrm{CO}_{2}$, would provide unequivocal answers to many important questions have been largely disappointed. Although rates and directions of translocation have been successfully determined with tracers these experiments have, for the most part, only confirmed 
earlier work. The most important questions that must be answered deal with intercellular transport and water balance and these are among the most difficult of all physiological problems.

There are many recent reviews of translocation (Swanson, 1959; Esau, 1961; Richardson, 1968; Wardlaw, 1968; Weatherly and Johnson, 1968; Esau, 1969; Milthorpe and Moorby, 1969; Eschrich, 1970; Canny, 1971; Crafts and Crisp, 1971; MacRobbie, 1971). Perhaps the most comprehensive review is by Crafts and Crisp (1971).

Towards the end of the last century two major theories of phloem transport were advanced: the protoplasmic streaming theory of de Vries in 1885 and the pressure flow hypothesis first evidenced by the phloem exudation experiments of Hartig in 1858 and presented by Munch in 1927 (see Crafts and Crisp, 1971). Since that time other suggestions have been made but speculation has far outstripped the accumulation of solid evidence.

Theories of translocation may be classified as those in which transport of solvent and solute occur together (mass flow) and those wherein solute moves through a relatively immobile solvent (without a common name but here called "independent transport" mechanisms). The independent transport mechanisms are: (1) cytoplasmic streaming, activated diffusion, (3) surface migration. The mass flow mechanisms may be sub-divided into those which require 
constant input of energy along the translocation path (activated mass flow) and those which require no direct energy expenditure aside from that required to load and unload the conducting conduit. The activated mass flow hypotheses are electroosmosis and two strand theories presented by Thaine and Fensom. Simple mass flow theories are the well-known "pressure flow" hypothesis of Munch, and "volume flow," a new proposal by Eschrich et al (1972).

\section{Independent Transport Mechanisms}

\section{(1) Cytoplasmic Streaming}

De Vries first suggested the involvement of cytoplasmic streaming in translocation in 1885 and the idea was revived by Curtis in 1935. By this mechanism solutes are carried in the cytoplasm and passed from cell to cell through the sieve plate by diffusion. There is no need for simultaneous transport of solvent. It was recognized very early that cyclosis observed in parenchyma cells is one or two orders of magnitude too slow to account for observed rates of translocation.

Mason and Phillis (1936) considered that streaming might continue through the sieve pores. In this case half the pores would carry cytoplasm one way and half the other way. The problem here is that sugar will be transported in both directions so that considerable translocation must 
occur to achieve little net transport. Mason and Phillis calculated that a respiratory rate of 2.5 grams of sucrose per cubic centimeter of sieve tube per day would be required to drive this amount of streaming (see Spanner, 1962). This is one or two orders of magnitude above the value calculated from rates of respiration of intact bundles (Weatherly and Johnson, 1968).

A modification of the cytoplasmic streaming theory was presented by Thaine $(1961,1962)$. Thaine claimed to have seen, in light microscope preparations, strands of cytoplasm 1 to $7 \mu$ in diameter passing from sieve element to sieve element through the sieve plate pores. Within these strands particles about $0.5 \mu$ in diameter and in linear order approximately $3 \mu$ apart were seen moving at rates between 3 and $5 \mathrm{~cm} \mathrm{hr}^{-1}$. Thaine proposed that other materials in the sieve tubes may move faster than the particles.

Thaine's observations were severely criticized by Esau et al. (1963). They examined material similar to that used by Thaine and could find no evidence of cytoplasmic streaming or the movement of particles. They suggested that the strands observed by Thaine were merely lines caused by diffraction of light from walls out of focus. Thaine et al. (1967) attempted to prove the existence of strands by colour interference microscopy. Since strands were different in colour to the sieve plate and surrounding walls they were 
judged to differ in density and thickness from these other structures. Although Thaine et al. (1967) may have observed real strands there is little evidence that these strands are present in undamaged tissue. It appears likely that strand formation is an artifact of wounding (Evert and Deshpande, 1969; Evert et a1., 1969).

\section{(2) Activated Diffusion}

The term activated diffusion is difficult to define. It is not a mechanism in the true sense; it is a mathematical description of observed translocation kinetics. The basis of this concept is the similarity of diffusion kinetics to translocation kinetics, derived largely from tracer studies.

Proponents of this concept maintain that trans10cation kinetics can be described by Ficks' Second Law of Diffusion

$$
M=D d S / d x
$$

where $M$ is the amount of material diffused, $D$ is the diffusion coefficient, $S$ is the concentration of the substance and $x$ is the distance. The problem is that the diffusion coefficient is many orders of magnitude larger than that for normal diffusion of sucrose through water. Mason and Maskell (1928) calculated the value of $D$ to be $0.07 \mathrm{~cm}^{2}$ $\mathrm{sec}^{-1}$. The diffusion coefficient for sugar in water is $D=5 \times 10^{-6} \mathrm{~cm}^{2} \mathrm{sec}^{-1}$. 
Transport by a "diffusion analogue" system is envisaged as being a mechanism in which metabolic energy is used in an unknown fashion to increase the diffusion constant. Fisher $(1970 a, c)$ has criticized this idea stressing instead that translocation profiles arise from factors which operate within the leaf, not the path phloem. Fisher suggests, in fact, that critical analysis of tracer profiles rules out the diffusion-analogue system because there is no spreading of the profile with time (1970a).

Mason and Phillis (1936) rejected mass-flow on the basis of the plugged condition of sieve pores and postulated instead that assimilates move by "accelerated diffusion" through stationary cytoplasm. Metabolic energy would be used to maintain "some special organization of the cytoplasm," which would reduce resistance to solute movement so that materials would "diffuse in the sieve tube at rates comparable with those in a gas." As can be readily seen from this early example it is one thing to describe translocation kinetics and quite another to base a mechanism on them.

Canny (1962) and Canny and Phillips (1963) accepted Thaine's concept of transcellular strands (Thaine, 1961) and proposed a mechanism of activated diffusion in which materials move through the strands in opposite directions within one sieve tube. The amount of transport would be proportional to the difference in sucrose concentration between the up and down streams (Canny and Phillips, 1963). 
Reasonable rates of movement could be maintained by such a system if lateral leakage is low. This probably is not the case (Peel and Weatherly, 1962; Spanner, 1962).

Evidence for a diffusion analogue system was presented by Canny and Askham (1967). They placed aphids on mature leaves of Vicia faba and labelled another leaf with ${ }^{14} \mathrm{CO}_{2}$. Radioactivity was detected in the aphids in a 6-hour experiment. This apparent movement against the flow of translocation could only be explained, according to Canny and Askham, by activated diffusion in which tracer diffuses in a pattern of its own and not according to the established gradient of sugar concentration. In these experiments more than enough time was available for label to be transferred to the xylem and carried to mature leaves in the transpiration stream.

It appears from the above considerations that activated diffusion is not an adequate explanation of translocation in a mechanistic sense. As Canny points out (1971) proposed theories of translocation must be able to explain observed translocation kinetics; however, there does not appear to be much hope that descriptions of kinetics in themselves will lead us closer to an acceptable explanation of phloem transport.

\section{(3) Surface Migration}

This theory has not received much popular support 
although it has been advanced often, most recently by Fensom (1972), as a component of a multiphase transport system observed in Heracleum bundles.

A demonstration of surface migration is easily made following the example of Honert (Crafts and Crisp, 1971). Water containing the indicator chlorphenol red is overlayed with a layer of ethyl ether saturated with water. When potassium oleate containing potassium hydroxide is applied to the interface between these liquids it rapidly spreads along the interface and may be followed by the change in colour of the indicator solution. Velocity in such a system may be very high $\left(2.5 \mathrm{~cm} \mathrm{sec}{ }^{-1}\right)$. Surface migration has been offered as an explanation for extremely high translocation velocities (> $1000 \mathrm{~cm} \mathrm{hr}^{-1}$ ) occasionally observed (Nelson, 1962; Fensom, 1972) in tracer studies.

There are a number of objections to this theory. First, as with other proposals, theory is not backed by sound evidence. An interface must be present upon which the migration may proceed. Transcellular strands may provide the necessary structure (Thaine, 1965; Fensom, 1972) but the existence of these strands is not certain. It is doubtful as well whether there is enough volume available on the surface of sieve tube cytoplasm to carry the quantities of sugar known to flow through the sieve tube (Crafts and Crisp, 1971, p. 279).

There is another difficulty with this physical 
concept. Different solutes carried in the phloem would be expected to have very different properties at the flow interface and hence be carried at varying rates and possibly in different directions. Neglecting occasional reports to the contrary the great weight of evidence favours a collective movement of compounds, both endogenous and externally applied, through the sieve tubes. This seems incompatibie with surface migration.

\section{Mass Flow Mechanisms}

The concept of a mass flow of solution through the phloem logically followed from the observations and experiments of Hartig and 1858 on phloem exudation. Indeed, many plant physiologists thought of translocation in terms of a mass flow (Crafts and Crisp, 1971) until the discovery of protoplasmic plugs on sieve plates. Mass flow fell out of favour until it was revived by the pressure flow hypothesis of Münch published in 1927.

Mass flow will account for the commonly observed relationship between assimilate sources and sinks; the flow is maintained along natural pathways of utilization. The phenomenon of exudation through cuts in phloem or through severed aphid stylets is explained. The coordinated movement of solutes including exogenously applied tracers is a simple consequence of the theory. 


\section{(1) Transport of Water}

An absolute requirement of any mass flow mechanism is that water be transported. It would seem that this is a simple way of distinguishing between mechanisms of mass flow and those in which solute moves without simultaneous transport of solvent. Experimental demonstration of water movement in sieve tubes has, however, not been a simple task. Exudation from cut phloem is an obvious example of water movement but because of the damage inflicted this flow may be artifactual. Continued exudation from cut aphid stylets is more compelling evidence.

Attempts have been made to demonstrate simultaneous movement of ${ }^{14} \mathrm{C}$-tracers and ${ }^{3} \mathrm{H}$-water (HTO). In reality these are not good experiments. Water is moving in the xylem in the direction opposite to assimilate flow and if HTO leaks into the transpiration stream the results will be greatly complicated (Trip and Gorham, 1968b). Secondly, it is known that the hydrogens of water rapidly exchange with each other. It is impossible to distinguish between exchange and true water flow.

A very convincing experiment demonstrating water flow was performed in 1961 by Ziegler and Vieweg. They placed two thermocouples $5 \mathrm{~mm}$ apart in contact with the phloem of an intact bundle of Heracleum. At a position midway between the thermocouples the phloem was warmed with a $0.5 \mathrm{~mm}^{2}$ beam of light. The downstream thermocouple registered a higher 
temperature than the upstream one. It was possible to calculate a flow velocity of between 35 and $70 \mathrm{~cm}$ per hour, in good agreement with other data.

\section{(2) Bidirectional Transport}

The pressure flow hypothesis will not account for bidirectional transport of solution in the same sieve tube. Bidirectional transport in the plant is easily demonstrated with tracers. Since individual leaves often export assimilates both acropetally and basipetally there is little doubt that streams of assimilate from different leaves must commonly pass one another flowing in opposite directions. The question that must be answered is whether bidirectional flow occurs in the same or separate sieve tubes.

Biddulph and Cory $(1960,1965)$ studied simultaneous movement of ${ }^{14} \mathrm{C}$ and ${ }^{32} \mathrm{P}$ and found no evidence that bidirectional movement occurred within a single phloem bundle. Peterson and Currier (1969) supplied internodes of different plants with fluorescein and observed patterns of flow in free-hand sections. They never observed movement in two directions within the same bundle. When fluorescein was applied to the petiole of Ecballium (Cucurbitaceae) leaves, which were simultaneously importing and exporting, the dye often travelled toward the stem in the external phloem and toward the blade in the internal phloem. It should be noted that these leaves were only $5 q$ expanded. Leaves usually 
import and export simultaneously only for a brief period when they are approximately $50 \%$ expanded. No experimental evidence was provided to support the contention that bidirectional transport was in fact occurring.

Trip and Gorham (1968a) followed the movement of ${ }^{3} \mathrm{H}$-sugars and ${ }^{14} \mathrm{C}$-assimilates into and out of a half-grown leaf of Cucurbita. Autoradiographs showed both tracers to be in the external phloem. The internal phloem contained no obvious tracer, perhaps because internal phloem develops later than external phloem (Avery, 1933). In mature squash leaves export of ${ }^{14} \mathrm{C}$-assimilates takes place in both internal and external phloem (Webb and Gorham, 1964). The possibility that plants possessing bicollateral bundles use the internal and external phloem for transport in opposite directions deserves further study. The papers of Peterson and Currier (1969) and Bonnemain (1965) suggest that this may often be the case.

Eschrich (1967) made a detailed study of simultaneous transport of ${ }^{14} \mathrm{C}$ and fluorescein by analyzing the honeydew of aphids placed midway between the two sources. He found that $42 \%$ of the aphids collected both tracers. Although these experiments may have demonstrated bidirectional transport in the same sieve tube, Eschrich argues that anastomoses between sieve tubes could account for the same result. It should also be pointed out that an aphid may constitute an exceptionally large sink and thereby attract assimilates 
from a number of sources.

Ho and Peel (1969) conducted similar experiments with aphids placed on willow shoots. Almost all the aphids collected both tracers. Again these authors argue that bidirectional movement of tracers may be occurring in one sieve tube but the possibility of lateral movement toward the aphid stylet is not discounted.

Trip and Gorham (1968a) designed an experiment to test whether bidirectional transport occurs in single sieve tubes. Tritiated sugar was applied to one leaf and ${ }^{14} \mathrm{CO}_{2}$ to another. When the two fronts met the tissue was frozen and prepared for autoradiography. Tritium was screened out of some of the autoradiographs with a layer of gelatin. In this way it was possible to detect ${ }^{14} \mathrm{C}$ and ${ }^{3} \mathrm{H}$ in serial sections presumably with a single sieve tube. They argue that their results can not be explained by a mass flow mechanism.

This experiment is worthy of repetition in other 1aboratories. Crafts and Crisp (1971) have criticized the experiment on the grounds that in a three-hour period sieve tubes in the half-expanded leaf could reverse their direction of transport. This is hardly a valid criticism since the experiment was repeated four times with similar results and it is difficult to believe that such a reversal could have occurred at just the right moment four times in succession. The comments of Crafts and Crisp demonstrate 
the unwillingness of investigators to accept the concept of bidirectional flow in one sieve tube, although the weight of evidence appears to favour it. This reluctance is apparently based on considerations of mechanism. It is difficult to envisage bidirectional flow in any system save those based on cytoplasmic streaming or transcellular strands, both rather unpopular concepts.

\section{(3) Activated Mass Flow}

\section{(a) Strand Theories}

Strand theories are usually considered to be modifications of the cytoplasmic streaming concept. However, the strands are immobile and a solution is supposed to flow through or around them. For this reason they are best considered to be types of mass flow.

In a recent article, Thaine (1969) has elaborated his earlier proposed theory of translocation (Thaine, 1961, 1962). According to this new concept tubules within tubes carry the assimilate while the outer tubes, composed of contractile filaments, drive the flow.

Recently, Fensom (1972) proposed a theory similar to Thaine's, again an "activated mass flow" hypothesis. In this proposal, strands, composed of contractile protein (microfibrillar material or P-protein) carry a stream of assimilates internally. This flow is driven by a microperistaltic movement of the contractile protein. A mass 
flow of solution in the sieve tube lumen is also driven by this microperistalsis. A third component of translocation, surface migration, is also envisaged. This theory is based on experiments involving injection of tracers into single sieve elements. Label is quickly detected both upstream and downstream. Different tracers may apparently move independently. Label is often detected in discrete pulses. These results are not, in Fensom's opinion, compatible with a single driving mechanism. Fensom also produced calculations to prove that both mass flow components of his system are capable of carrying the required amounts of sugar and that energy requirements are not excessive.

The problem with both Thaine's and Fensom's proposals is that they are heavy on speculation and light on substantiating evidence. The biggest drawback is the reliance on contractile protein. As discussed above there is little evidence for or against the presence of contractile protein in sieve elements and the little evidence that does exist is mostly negative.

In addition it is now clear that the occurrence of P-protein in the sieve elements of higher plants is not universal (see section on P-protein). Although Fensom's hypothesis is a three-component system the two major components are driven by $\mathrm{P}$-protein structures and the third is a surface migration component which also requires strands.

Calculations supporting given theories of 
translocation are a useful supplement to hard evidence. It has been shown all too often in the past, however, that manipulation of figures can provide supporting evidence for almost any theory. Until proper physiological, biochemical and ultrastructural data are produced to support these strand hypotheses they must be viewed with scepticism.

\section{(b) Electroosmosis}

Electroosmosis is another activated mass flow theory. Spanner (1958) and Fensom (1957) originally proposed this mechanism independently. Tyree and Fensom (1970) now think it inadequate. This theory has the advantage that sieve plates act as pumps and their presence is easily rationalized. Spanner (1958) suggested that potassium ions move out of the companion cells on the upstream side of the sieve plates and are reabsorbed on the downstream side. The resultant electric potential across the sieve plate maintains a flow of solution through the pores. The problem with this proposal is the difficulty of measuring electroosmotic potential in intact systems. Attempts to measure potential differences have been made, however. Tyree and Fensom (1970) measured a slight potential which they considered inadequate to account for observed rates of flow. Bowling (1968) measured a potential distribution along sieve tubes and found all the plates to be polarized in the same direction. Bowling's results are difficult to interpret 
because the sieve tubes had been severed at both ends and translocation had undoubtedly ceased.

Although the calculations of Tyree and Fensom (1970) suggest that an electroosmotic driving force would be too modest to account for observed flow rates, they considered the sieve plates to be open. If, on the other hand, pores are plugged with cytoplasm the electroosmotic force would be enhanced, which might more than compensate for the increased hydraulic resistance (Spanner, 1970). In view of this fact, Spanner has repeatedly published electron micrographs of plugged sieve plate pores (e.g. Siddiqui and Spanner, 1970). This topic is discussed in the section dealing with phloem ultrastructure.

MacRobbie (1971) has ruled out electroosmosis on theoretical grounds, the most serious of which is the inability of this mechanism to account for the transport of both anions and cations which the phloem is capable of doing.

(4) Simple Mass F1ow

(a) Pressure F1ow

The concept of pressure flow is simple. Solutes enter the translocation stream at its head, thereby increasing the osmotic and turgor pressure, and are removed downstream. This creates a turgor pressure gradient. Water follows the gradient being pulled in at the head, or source, and pushed out at the sink. By continually adding solute at 
the source and removing it at the sink a steady flow is maintained.

There are a number of objections to the pressure flow hypothesis. Many investigators still consider sieve plate pores to be normally blocked. It is not possible to conceive of pressure flow through plugged pores; the pressure drop required is out of the question (Weatherly and Johnson, 1968). In fact it is difficult to rationalize the presence of sieve plates at all, plugged or unplugged.

Others object to the concept of pressure flow on the grounds that translocation is inhibited or completely blocked by metabolic inhibitors indicating the necessity of energy expenditure to maintain flow. A third objection is the necessity of a large gradient of turgor pressure to maintain flow, especially over the long distances imposed by tall trees.

The first of these objections to pressure flow is still under consideration in the literature but many investigators now think the sieve pores are open (see section on phloem ultrastructure). The second objection has not been resolved either, although evidence that metabolic energy is needed to maintain flow remains equivocal (see section on phloem metabolism).

The third objection to pressure flow is perhaps more serious. Flow is driven by a gradient of turgor pressure. The magnitude of the required gradient is usually calculated 
using the Poiseville equation. Values of approximately one atmosphere per meter are often calculated for the gradient required to drive flow at the higher velocities recorded (Weatherly and Johnson, 1968). Crafts and Crisp (1971) who, it must be recalled, favour the pressure flow theory, obtain a significantly lower value of 0.3 to 0.5 atmospheres per meter. Turgor pressures obtained from measurements of the osmolarity of sieve tube exudate are usually in the order of 10 atmospheres (Weatherly and Johnson, 1968) to 30 atmospheres (Crafts and Crisp, 1971). These pressures are capable then of driving flow over a distance of 10 to 100 meters. These calculations may, at best, just account for pressure flow.

It should be pointed out that flow is a response to a turgor gradient, not turgor. A flow over 100 meters with a resistance to flow of 0.3 atmospheres per meter will be supported by a turgor of 30 atmospheres only if the turgor is reduced to zero in the sink. In actual fact the gradient is probably much less than 30 atmospheres.

The only reliable way to estimate turgor gradients is to measure them. Hammel (1968) attempted to measure turgor pressure in the trunk of oak trees. Although the results suggested a small turgor pressure gradient Hammel stressed the difficulties inherent in measuring gradients in an elastic low-resistance system such as sieve tubes. Zimmerman (1957) measured a gradient of approximately 0.3 
atmospheres per meter in stems of Fraxinus. Pressure flow is not ruled out by these figures but it is on the very borderline of acceptability.

It should also be appreciated that although gradients of turgor have been demonstrated they may not be the driving force behind translocation. A gradient could be created by removal of solute from the translocation stream or by frictional resistance to viscous flow. Demonstration of a gradient does not prove the existence of pressure flow.

\section{(b) Volume Flow}

In a recent paper Eschrich et al. (1972) proposed another mechanism of mass flow which they termed "volune flow." This mechanism does not depend on a gradient of hydrostatic (turgor) pressure. In fact, they provided calculations based on non-equilibrium thermodynamics which show that in a closed system surrounded by a semi-permeable membrane an unequal distribution of solute will not create a gradient of hydrostatic pressure. The osmotic pressure will not be constant throughout the system but the turgor pressure it creates will. This constitutes the driving force. In a semi-permeable tube a gradient of solute creates an equa11y distributed hydrostatic pressure which tends to force water out of the tube. In the region of the tube where the osmotic concentration is high, water will be pulled in against the hydrostatic pressure and in the more dilute region 
hydrostatic pressure will force water out. In this way a flow of water is produced which carries solute with it. By introducing solute at the head of the stream and removing it at the other end the flow is maintained.

The volume flow mechanism requires a relatively open channel as does pressure flow. Metabolic energy is not required along the path except to maintain the living state of the conducting cells. This mechanism also has the advantage that the high gradients of hydrostatic pressure required by pressure flow are not needed. It is claimed that this mechanism will alow bidirectional translocation in the same sieve tube although this author fails to understand how this is possible.

Although much work remains to be done to validate the volume flow hypothesis, it should be noted that Eschrich et al. (1972) dismiss pressure flow on purely theoretical grounds. This conclusion could only have been reached with the use of non-equilibrium thermodynamics which were not available to Münch.

There is a decided advantage to the pressure or volume flow hypotheses that should not be overlooked. From the early days of translocation study it has been recognized that phloem transport follows a source to sink pattern. Flow is from regions of synthesis to those of utilization. Only the pressure and volume flow hypotheses have the inherent ability to explain this phenomenon. No mechanism 
can better explain transport regulation than one which is driven by production and consumption.

\section{E. MINOR VEIN STRUCTURE}

The venation of the dicotyledon leaf may conveniently be divided into major and minor veins. The distinction between these two classes is somewhat arbitrary but not altogether artificial. The vascular elements of the major veins which includes the midrib, main laterals of the midrib and the larger branches of these laterals are, in appearance, similar to the conducting elements of the petiole and stem. The vascular bundles of the major veins are spacially separated from the mesophyll of the leaf by the "rib parenchyma" consisting of large, highly vacuolate parenchyma cells with few chloroplasts. This surrounding tissue is so massive in the larger veins that it produces a large prominent bulge on the abaxial side of the leaf.

Minor veins, on the other hand, are embedded in the mesophyll and usually occupy a median position in the lamina below the palisade layer on a level with the upper spongy mesophy11.

The position of the minor veins undoubtedly facilitates the lateral transfer of material to and from the leaf mesophy11. The major venation appears to function primarily in long-distance conduction. Fisher (1967) has described a 
specialized layer of mesophyll cells in soybean leaves which extends horizontally, between the veins, in the plane of the phloem. These cells evidently serve to conduct photosynthate to the vein.

\section{Vein Pattern}

Typically, the minor venation of dicotyledon leaves is reticulate. The vein terminates blindly within the smallest areas delimited by the veins, the areoles, and is often branched. Occasionally, areoles are without blind endings.

Early discussions of leaf venation were concerned largely with the pattern of major veins and their relation to the growth and development of the leaf as a vole (Foster, 1952). Minor venation was given much less consideration. However, two theories arose to explain the characteristic reticulate pattern (see Foster, 1952). Schuster argued that minor veins develop so that "with the smallest possible length of veins the leaf surface is traversed as. uniformly as possible and thus with a given vein length conduction occurs by the shortest path." This is known as the theory of "areas of minimal perimeter." Goebel (Foster, 1952) postulated that minor veins arise late in ontogeny and tend to orient themselves at right angles to veins of the previous order. He considered vein endings to be incomplete veins. 


\section{Vein Length}

The relative importance of major and minor venation in the functioning of the leaf is indicated by their proportionate lengths. In mesomorphic leaves (Cucurbita not studied) over $90 \%$ of the venation is minor (P1ymale and Wylie, 1944). Liriodendron is typical. The lengths of veins in a $130 \mathrm{~cm}^{2}$ blade are: first order (midrib), $10.2 \mathrm{~cm}$; second order, $96.5 \mathrm{~cm}$; third order, $302.6 \mathrm{~cm}$; total major venation, $409.3 \mathrm{~cm}$; total minor venation, $9,313.0 \mathrm{~cm}$. Essentially similar results have been obtained for sugar beet (Geiger and Cataldo, 1969) in which minor veins occupy $70 \pm 10 \mathrm{~cm} \mathrm{~cm}^{-2}$ and major veins $5.5 \mathrm{~cm} \mathrm{~cm}^{-2}$.

Due to this thorough permeation of the lamina, no mesophyll cell is more than $65 \mu$, on the average, from a minor vein (Wylie, 1939). Among the 66 species of dicotyledons studied Wylie found a good correlation between decreased interveinal distance and increasing proportion of palisade tissue in the leaf. Wylie reasoned that those cells with the greatest lateral contact (spongy mesophy11) facilitate transport between mesophyll and veins and a greater proportion of these cells in the leaf allows veins to be more widely separated.

Geiger and Cataldo (1969) found the average minimum distance from a mesophyll cell to a vein to be $73 \mu$ in sugar beet. Each length of minor venation equal to the diameter of an average mesophyll cell (33 $\mu)$ services 29 mesophyll 
cells. The same length of major venation services 370 mesophyll cells.

\section{Vein Histology}

The histology of the minor veins is radically

different from that of the major veins although the changes involved do not occur abruptly and there are veins of intermediate character. In general, the vascular bundles of the major veins closely resemble those of the petiole and stem. Phloem and xylem are usually separated spacially by parenchyma tissue which in larger veins may even have cambial activity. If the plant has bicollateral bundles, the bicollateral condition is usually evident in the large veins enclosed in rib parenchyma (Fischer, 1885).

Tracheary elements are vessels in major veins and the secondary thickening of the walls may resemble those in the xylem of the stem. The phloem contains the usual complement of cell types: sieve elements, companion cells, and phloem parenchyma. The appearance of the sieve elementcompanion cell complex resembles closely the phloem of the stem.

In the minor veins the $x y l e m$ and phloem are in close continuity. In the finest veins the separating parenchyma may be absent and it is not uncommon for all cell types in the smallest bundles to be in contact with each other (Esau, 1969). This feature is common to monocots as well (Pray, 
1955b).

Bicollateral veins have been identified only in the family Cucurbitaceae (Esau, 1969). In all other families the minor veins are devoid of adaxial phloem. Generally the adaxial phloem does not continue into veins which are embedded in the mesophyll (Fischer, 1885).

The xylem of the bundle ends is composed of one to three files of tracheary elements. The secondary walls are usually annular or helical (Esau, 1969). The tracheary elements are usually interpreted as being tracheids but the extreme difficulty of recognizing wall perforations in these sma11 cells makes accurate identification very difficult. In some species, for example Liriodendron (Pray, 1954) and Beta (Esau, 1967) a cluster of short, nearly isodiametric, tracheary elements terminate the blind ending. The relative amount of xylem in minor veins is smaller than in major veins. In the minor venation of the cotton plant $20 \%$ of the cross-sectional area of the vascular bundle is phloem, whereas in the primary veins only $4 \%$ is phloem (Phillis and Mason, 1933).

The phloem of minor veins is characterized by a change in relative size of the sieve element and companion cell. The sieve elements become very narrow while the companion cells remain the same size or increase in width. This feature is especially striking in the Cucurbitaceae. Fischer (1885) measured the cross-sectional area of cells of 
the abaxial phloem of Cucurbita pepo. The transectional area of sieve elements steadily decreased while the transectional area of the companion cells at first decreased, then increased considerably (Table 1 ).

Fischer (1885) distinguished two types of vein endings, the main endings (Hauptenden) which arise from veins enclosing the aereoles, and lateral endings (Nebenden) which are very short branches, usually one cell in length, arising from bundles of different orders. The main endings usually have phloem that ends blindly. Xylem may extend beyond the ultimate tip of the phloem as in Liriodendron (Pray, 1954) or more commonly end with the phloem as in Beta (Esau, 1967) and Hosta (Pray, 1955b). The lateral vein endings do not contain sieve tubes although in the Cucurbitaceae elongated nucleate cells occur on the adaxial side of the xylem while dense companion cells occur on the abaxial side. Tracheids occur either alone or with dense companion cells in the lateral endings of all other dicotyledons. In a few plants the main endings do not contain sieve tubes (Aristolochia, Fagus, Juglans, Quercus) and in one plant (Buxus) of the 62 studied by Fischer there were no main endings at all.

Where sieve elements are absent Fischer (see Esau, 1969) termed the large nucleate phloem cell(s) Üebergangszellen (intermediary cell). Fischer thought that these cells received photosynthate from the mesophyll, synthesized 


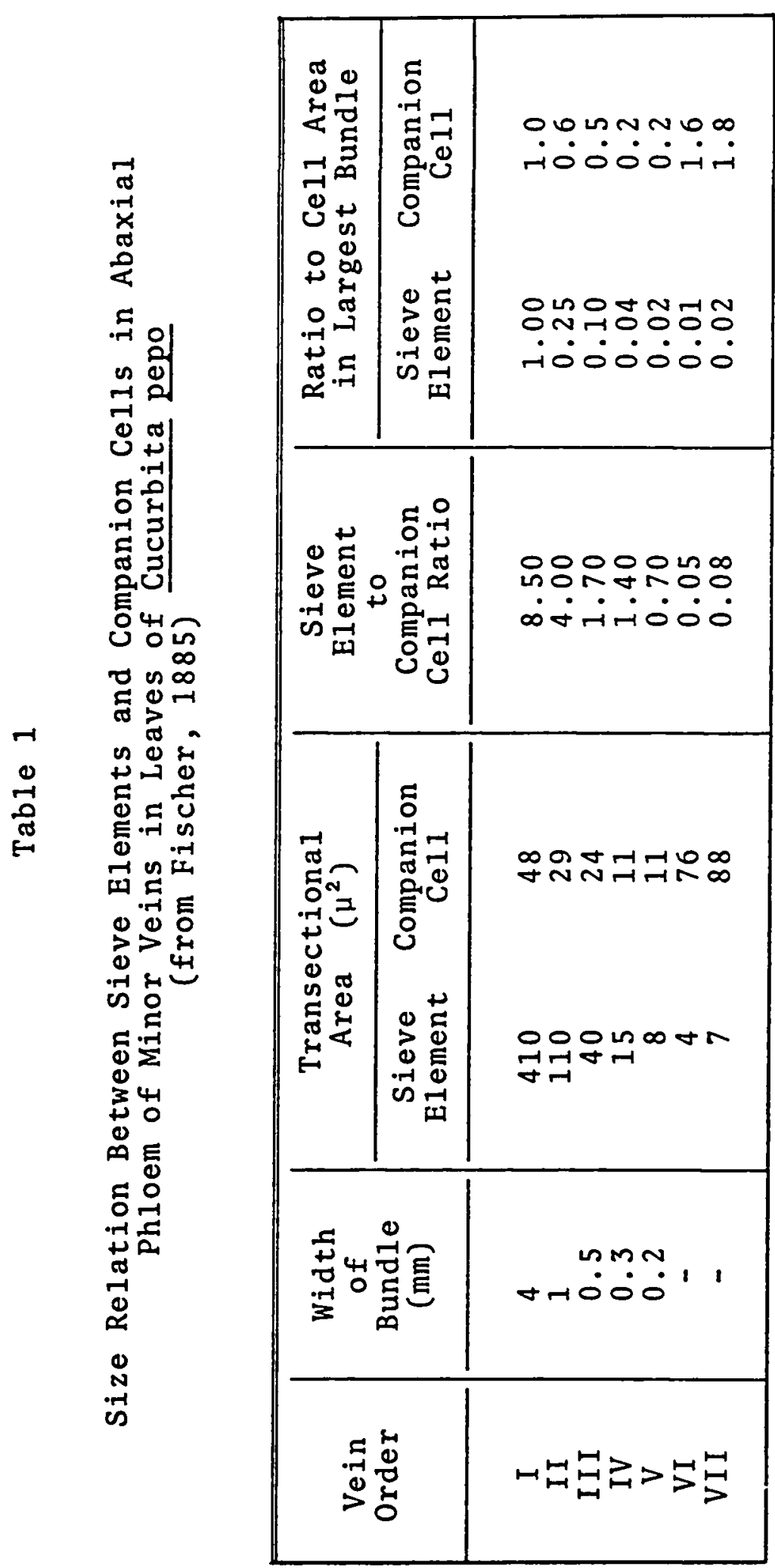


protein, and introduced the proteins into the sieve element for transport. Fischer interpreted the intermediary cells as companion cells when sieve elements were present. He recognized therefore that intermediary cells are analagous to companion cells. In mature minor veins it is difficult to correctly identify companion cells in the ontogenetic sense. Parenchyma cells in the phloem may also be large and contain dense cytoplasm. Developmental studies are required to identify true companion cells.

Although the vascular cells of the minor veins are not enclosed in rib-parenchyma they are not in intimate contact with the mesophyll. A layer of cells, the bundle sheath, encloses the vein. The vein itself is devoid of intercellular spaces. Bundle sheath cells are highly vacuolate and have relatively few chloroplasts. Toward the end of the vein the bundle sheath cells become more mesophyll-like in size, shape, and chlorophyll content (Morretes, 1962).

Chloroplasts of the bundle sheath commonly occupy a parietal position against the wall closest to the mesophyll. In a similar situation where palisade cells directly abut the upper epidermis, chloroplasts are not generally found along the common wall. Haberlandt (1914) attributes this phenomenon to decreased availability of $\mathrm{CO}_{2}$ along walls not directly in contact with intercellular spaces.

The bundle sheath of large minor veins often extends 
vertically to the upper and lower epidermis. This "bundlesheath extension" is made up of parenchymatous cells with few chloroplasts. Of 348 species of mesomorphic dicotyledons examined by Wylie (1952) 210 had bundle sheath extensions. Bundle sheath extensions probably function in supporting the lamina and in restricting the lateral movement of gases and infectious organisms (Wylie, 1952). Wylie (1943) introduced dilute potassium ferrocyanide solution to the transpiration stream of numerous leaves and found that the preferred route of water transport was from the minor vein vascular system to the bundle sheath and bundle sheath extensions and from there to the epidermal layers where it was distributed laterally.

\section{F. MINOR VEIN ULTRASTRUCTURE}

The structure of minor veins, especially the phloem of these veins, has not received a great deal of attention. Part of the reason for this neglect is the small size of minor vein elements, especially the sieve tube members, which has made interpretation at the light microscope level difficult. Only recently have investigators used the increased resolution of the electron microscope to study minor vein structure.

Early work with the light microscope (see Esau, 1969) and a later study with the EM (Trip and Colvin, 1970) 
created an erroneous picture of minor vein phloem structure. The diminutive size of the sieve elements and their sieve plate pores led to the interpretation that minor vein sieve elements are not equivalent to sieve tuber members in the path phloem.

Critical studies with the EM (Esau, 1967; Esau, 1972; Esau and Hoefert, 1971; Gunning et a1., 1968; Geiger et a1., 1971) have reversed this opinion.

Sieve elements of the minor veins of Beta (Esau, 1967; Geiger et al., 1971) and Tetragonia (Esau and Hoefert, 1971) are structurally similar to sieve elements in the stem except for their greatly reduced width. In mature leaves of these species sieve elements are enucleate. They lack dictyosomes, ribosomes and a tonoplast. P-protein and welldifferentiated mitochondria are found. There are no chloroplasts but typical sieve element plastids are present. Endoplasmic reticulum is often arranged in the form of stacks of membranes. Although the presence of typical perforated end walls, or sieve plates, has been overlooked in the past (Trip and Colvin, 1970) these structures are clearly seen in longitudinally sectioned material when viewed with the EM.

Companion cells in minor veins are nucleate, contain a number of small vacuoles, and are richly endowed with ribosomes and a cytoplasmic matrix that gives the cell a dense appearance in either light or electron microscope 
views. Plasmodesmata connect sieve elements and companion cells and these plasmodesmata are branched on the companion cell side. Mitochondria of all phloem parenchyma cells are well developed and are particularly numerous in the dense cells. Endoplasmic reticulum is scarce and is usually rough. Osmiophilic bodies, probably lipid droplets, are found in the parenchyma cells of Tetragonia (Esau and Hoefert, 1971).

The primary walls of mature tracheids in the minor vein of Beta (Esau, 1967) and Tetragonia (Esau and Hoefert, 1971) are partially hydrolyzed. Esau (1967) emphasized that where sieve elements come directly in contact with tracheids the hydrolyzed wall may provide an easy passage for water from tracheid to sieve element as part of a mass flow mechanism of translocation. Hydrolysis of the primary wall of xylem elements is not limited to the minor vein, however (O'Brien, 1970). If the disintegration of the primary wall of primary xylem is a common occurrence, water may pass through almost as easily as through vessel perforations, hence diminishing the functional distinction between tracheids and vessel members (Esau, 1967).

There has been considerable interest in recent years in the specialized parenchyma cells with labyrinth wall ingrowths termed transfer cells. Some confusion exists over the definition of "transfer ce11." Gunning et al. (1968) originally used the term as a literal translation of Üebergangszellen of Fischer (1885). Gunning et al. 
termed those cells with wall ingrowths in minor veins "specialized transfer cells." Although Esau and Hoefert (1971) used the term transfer cell in the original context of Gunning et al (1968) subsequent usage (Gunning and Pate, 1969; Pate and Gunning, 1969) equated the term "transfer cell" with cells displaying wall ingrowths, the original "specialized transfer cells" of Gunning et al. (1968). Since an acceptable translation of Üebergangszellen already exists (intermediary cell) further reference in this work to transfer cells will follow common usage and apply only to those cells with specialized wall ingrowths.

Transfer cells are found in a wide variety of locations in the plant body (Gunning and Pate, 1969). By exposing a large surface area of plasmalemma to the extracytoplasmic environment, transfer cells undoubtedly facilitate absorptive or secretive functions. In leaf minor veins no plasmodesmata were seen to connect transfer cells and bundle sheath cells (Gunning et a1., 1968), although a few were noted later (Gunning, personal communication). Positive identification of transfer cells was made in 22 of 200 families of dicotyledons and one of 42 families of monocotyledons examined (Pate and Gunning, 1969).

G. VEIN LOADING

The capture of light energy and the synthesis of 
carbohydrate takes place primarily in the leaf mesophyll of higher plants. To be translocated, food must be moved from its site of synthesis to the conducting sieve elements.

This process will be termed vein loading.

Many questions about the mechanics of vein loading are unanswered. Is vein loading an active process? Are sugars loaded against a gradient? In what form are sugars loaded? Along what route does the sugar trave1?

\section{Active vs. Passive Uptake}

The term vein loading, although popular, is not a particularly good one for it implies the use of energy in a distinct "loading" step. Although this may be the case, there has as yet been no unequivocal demonstration of such a step. The concept of active loading has arisen from the notion that there is an uphill gradient of sugar concentration from the mesophyll to the phloem. The high concentration of sugar in the fine ramifications of the minor venation is thought by many to constitute the real source for long distance transport driven by a downhill concentration gradient from source to sink. Although this is a useful hypothesis and fits well with much experimental data, it is still tentative.

To date we have had to rely on mass analysis of phloem tissue for estimates of sugar concentration. The best-known analysis of this type is that of Mason and 
Maskell (1928) in which they found the concentration of sucrose in the midrib and petiole to be higher than in the parenchyma (leaf lamina). Similarly, Kursanov and Brovchenko (1970). found the concentration of sugar in the conducting bundles of sugar beet to be $13.8 \mathrm{mg} \mathrm{g}^{-1}$ fresh weight while the concentration in the mesophyll was only $1.0 \mathrm{mg} \mathrm{g}^{-1}$ fresh weight.

The problem with these figures is: (a) sucrose may be stored in parenchyma cells of the conducting bundle, and (b) a large percentage of water in the mesophyl1, perhaps in the vacuole or apoplast, may have a very low concentration of sugar. If this is true the concentration gradient could be much shallower than it seems or could even be reversed. The latter suggestion seems unlikely, however. The concentration of sugar in the sieve tubes is approximately $10 \%$. If the concentration of sugar in the mesophyll is only $1 \mathrm{mg} \mathrm{g}^{-1}$ fresh weight or approximately $0.1 \%$ the sugar would necessarily have to be dissolved in only $1 \%$ of the available water to be at the same concentration found in the sieve tubes. This seems rather unlikely.

The above arguments presuppose that carbohydrate is transported to the sieve tubes as sucrose. Other possibilities exist. Hexose sugars could diffuse toward the major vein and be converted to transport sugar before entry into the sieve tubes. By synthesizing sucrose from hexose the concentration of hexose in the vein would be reduced and a 
downhill concentration gradient established from the mesophyll to the vein. This model would also explain the lack of hexose sugars in the assimilate stream.

Kursanov (1963) suggested the involvement of phosphorylated sugars in vein loading on the grounds that application of ATP increases translocation. Shiroya et al. (1961) also suggested that phosphorylated intermediates are involved in translocation. Their evidence is even more indirect than Kursanov's. They analyzed radioactive substances in fed leaves of tobacco 5.5 hours after ${ }^{14} \mathrm{CO}_{2}$ presentation and found higher levels of sugar phosphates in those leaves most efficient at translocation. Considering the length of the experiment it is doubtful that these results have anything to do with vein 1oading. Speculation about the involvement of sugar phosphates in vein loading is strengthened somewhat by the demonstration of acid phosphatase activity in phloem (Lester and Evert, 1965; Zee, 1969a) and in the walls of transfer cells (Gunning et al., 1968).

If it is assumed that sugar, in one form or another, is concentrated against a gradient it is then necessary to search for a mechanism of accumulation. The most straightforward explanation to date was offered by Phillis and Mason in 1933. They suggested that sugar moves from the mesophyl1 to the border parenchyma of the minor veins down a concentration gradient. The large densely staining cells of the minor 
vein phloem (Üebergangszellen) collect this sugar actively and transfer it to the sieve elements. This hypothesis led naturally to the speculation that companion cells in general function in removing sugar from surrounding tissue and contributing it to the assimilate stream. In the minor veins the companion cells would be large and active for they would collect a great deal of photoassimilate. Along the phloem path their function would be reduced to one of regulation, collecting sugar from surrounding cells in times of assimilate stress. To date, no better suggestion for the function of companion cells has been made.

It is often assumed in the literature that vein loading is an energy requiring process. However, few attempts have been made to prove this directly. Ho and Mortimer (1971) were able to inhibit long distance transport with cyanide but vein loading was not blocked. There is a possibility that the cyanide, applied to the petiole, was greatly diluted in the leaf blade but increasing the concentration four times did not alter the results. Webb (1970) studied translocation of photoassimilated ${ }^{14} \mathrm{C}$ over a wide range of leaf blade temperatures. ${ }^{14} \mathrm{CO}_{2}$ was supplied to the leaf for 15 seconds when the blade had reached the experimental temperature and translocation was monitored by analyzing the petiole for ${ }^{14} \mathrm{C}$. At $0^{\circ} \mathrm{C}$ photosynthetic fixation of ${ }^{14} \mathrm{CO}_{2}$ was severely restricted but 45 minutes later translocation of ${ }^{14} \mathrm{C}$ could be detected. Although there was 
a 40-minute delay vein loading and translocation did take place at $0^{\circ} \mathrm{C}$.

Some published reports on this subject are misleading. For example, Leonard and Glenn (1968) reported that oxygen deficiency inhibited vein loading. However, their whole leaf autoradiographs resolved only the largest veins. It is impossible to detect the effect, if any, on movement from the mesophyll to the minor veins. Even in this study slight ${ }^{14} \mathrm{C}$ activity could be detected in the larger veins, suggesting that some loading and transport occurred.

Wardlaw (1972) found that "vein loading" in Lolium was inhibited at $0^{\circ} \mathrm{C}$ but his experiments dealt only with lateral movement artificially induced by steam killing the path phloem. This lateral transfer and re-uptake may be analogous to natural vein loading as Wardlaw suggests, but there is no assurance that this is the case. Other experiments in this paper which demonstrate slight temperature sensitivity of normal vein loading are even more difficult to interpret for the temperature was lowered downstream and not at the loading area!

Care must be taken in the design of experiments of this type that vein loading in the strict sense is being studied. Many useful experiments could be patterned after the study by Ho and Mortimer (1971) in which loading was demonstrated by autoradiography of the minor veins following ${ }^{14} \mathrm{CO}_{2}$ application. 


\section{Path of Sugar Movement}

Both the symplast (cytoplasmic continuum) and the apoplast (extracytoplasmic space) are available to material moving from the mesophyll to the sieve tubes. Cell to cell contacts exist along the entire path from palisade cells to sieve elements and plasmodesmata connect all cell types with one notable exception. Between bundle sheath cells and companion cells where the companion cells have wall ingrowths (transfer cells) plasmodesmata are uncommon (see section on minor vein ultrastructure).

There is some evidence to support the view that solutes travel toward the minor veins in the apoplast. Brovchenko (1965) and Kursanov and Brovchenko (1970) placed cut disks of sugar beet leaf on water. They were able to wash out 20 to $30 \%$ of the sugar in the disk within 30 minutes, presumably from the free space (apoplast). Within 60 minutes of washing, the free space is again filled with sugar and repeated leachings may remove up to half the sugar in the disk. Conducting bundles, on the other hand, may be leached once but the washed-out sugar is not replaced. Labelled sugar appears in the free space of the leaf disks ten minutes after assimilation of ${ }^{14} \mathrm{CO}_{2}$.

These papers have one serious shortcoming. Leaf disks contain a great deal of vascular tissue. It is not certain that sugars which are detected in washing come from the free space or are exuded by cut vascular strands. 
Humphreys and Garrard (1971) studied sucrose leakage from excised maize scutella and are of the opinion that leakage occurs from severed phloem strands.

Hawker (1965) measured the sucrose content of the extra-vacuolar spaces of sugar cane stem and found that the concentration in the cell walls and intercellular spaces approaches that of the vacuole. He considered the sucrose in this space to function in sugar storage and intercellular transport. An apoplastic pathway is also proposed for translocate which has left the vascular bundles in the root tip (Cormack and Lemay, 1963).

Apoplastic transport presents a rather difficult problem when one considers water transport within the leaf. Water travels from the xylem toward the stomata through the lamina. If sugar is being transported to the vein in the apoplast it would be confronted with water moving in the opposite direction. It should be recalled at this point that water, at least in leaves with bundle sheath extensions, flows vertically toward the epidermis (Wylie, 1943). Perhaps there is a circulation of water in the lamina from the xylem to the epidermis, laterally along the epidermis, and back to the vein through the mesophy11. On the return journey the water would carry dissolved assimilate with it.

Apoplastic transport could provide a means for selective introduction of sugars to the sieve tubes if membrane associated "permease" enzymes are located within 
the phloem. According to this model materials destined for phloem transport would enter the apoplast at some point and be retrieved by specific carriers located perhaps in the plasmalemma of the large companion cells of the minor vein. It is interesting to speculate that such a carrier, specific for sucrose, would recognize the sucrose moiety of higher members of the raffinose family of sugars and transport all members of this family toward the sieve tubes.

Sugar specific permease enzymes are found in bacteria (Cohen and Monod, 1957) and the green alga Chara has a carrier-mediated transport system located in the plasmalemma which is stereospecific for hexose sugars (Surikow, 1971). Fisher (1970b) has recently provided evidence for membrane interaction with mobile sugars in the leaf. He analyzed tracer kinetic data for a number of substances in the source leaf. The ${ }^{14} \mathrm{C}$ kinetics of sterol glucoside and probably esterified sterol glycoside were similar to those for ${ }^{14} \mathrm{C}$-sucrose export. ${ }^{14} \mathrm{C}$ was only found in the glucose moiety. These sterol derivatives may act as carriers of sucrose between the translocation stream and surrounding cells.

Further evidence for apoplastic sugar transport comes from the demonstration that vascular tissue is capable of accumulating exogenously supplied sugar against a concentration gradient (Phillis and Mason, 1933; Turkina, 1961; Bieleski, 1966a,b). However, phloem will also accumulate 
material from the transpiration stream (Gunning et al., 1968). It is not safe to conclude that sugars are normally removed from the apoplast during vein loading simply because the phloem is capable of doing so under artificial conditions. This mistake was made by Trip (1969) when he fed ${ }^{3} \mathrm{H}$-sugar to leaf vein flaps of sugar beet in an attempt to locate the site of active sugar loading. The label was located by autoradiography in the densely staining companion cells of the minor veins (Üebergangzellen) but this may not have anything to do with normal vein loading. This experiment must be done using natural feeding techniques, i.e. supplying the leaf with ${ }^{14} \mathrm{CO}_{2}$.

Gunning and Pate (1969) have provided indirect evidence for the apoplastic route. They have shown that a strong correlation exists between the development and occurrence of transfer cells and the transport of assimilate in the phloem. Phloem transfer cells are more abundant in minor veins than in any other region of the plant. In variegated leaves of Impatiens, Sedum, and Ligularia transfer cells are few and poorly developed in non-chlorophyllous regions compared with nearby green regions. The development of transfer cells in young leaves of Pisum coincides with the beginning of assimilate export as determined by ${ }^{14} \mathrm{C}-$ labelling studies.

While these observations certainly support the idea that transfer cells accumulate photosynthate from the apoplast, 
the possibility also exists that they simply accumulate substances transported in the xylem and load them into the phloem for transport out of the leaf. Accumulation by transfer cells of xylem-transported material has often been reported (Wooding and Northcote, 1965; Gunning et al., 1968; Pate and O'Brien, 1968; Pate et al., 1970).

Transport by a symplastic pathway is even more difficult to demonstrate than apoplastic transport. Tyree (1970) has shown that on thermodynamic grounds the symplast should be the preferred route of solute transport. Kursanov and Brovchenko (1970) point out, however, that the symplast would be a very aggressive medium for sugars. Unless sugar metabolism is closely regulated or the transported sugar travels through a metabolically inactive compartment this is certainly a valid criticism of the symplast proposal.

Geiger et al. (1971) proposed a model in which sugars move by a symplastic route to the specialized parenchyma cells of the minor vein. The sugars enter the apoplast and are actively accumulated into the symplast of the parenchyma cells and transferred to the sieve element via the branched plasmodesmata which connect these two cells types. Structural evidence from sugar beet leaves was provided but no mention was made of connections between cells of the bundle sheath and minor vein parenchyma. Few, if any, plasmodesmata are present if the parenchyma cell is a transfer cell (see Minor Vein Ultrastructure) but sugar beet parenchyma 
cells are without wall ingrowths (Geiger et al., 1971). Unless plasmodesmata are absent between these cells in sugar beet there is no assurance that apoplastic transport is necessary in this species.

Autoradiography is a possible approach to the study of vein loading, although there are some difficult technical problems. Geiger and Cataldo (1969) quick-froze and autoradiographed leaves of sugar beet which had been fed ${ }^{14} \mathrm{CO}_{2}$ to isotopic saturation. They embedded the leaves in paraffin. Although the label was apparently concentrated in densely staining companion cells of the minor veins the resolution of the autoradiographs was not very high. To overcome problems of "spreading" of high-energy beta particles emitted by ${ }^{14} \mathrm{C}$ it is necessary to use very thin layers of emulsion and thin sections, probably embedded in plastic. It should also be recognized that in studies of this kind there may be difficulties in the interpretation of autoradiographs. First, it must be shown that the label is in transit and not in storage. Second, it should be appreciated that although a cell may be involved in active accumulation, it may not have a large pool of mobile sugar and as a result it will contain little activity. 
MATERIALS AND METHODS

\section{A. GROWTH OF PLANTS}

Seeds of the Early Prolific Straight-neck squash, Cucurbita pepo L. var. melopepo f. torticollis Bailey (1929) were germinated in Perlite in a Sherer Controlled Environment Chamber (model CEL 512-37) under fluorescent and incandescent illumination $\left(400 \mathrm{microeinsteins} \mathrm{m}^{-2} \mathrm{sec}^{-1}\right.$ between 400 and $700 \mathrm{~nm}$ as measured by a L1-190S quantum sensor--Lambda Instruments, Lincoln, Nebraska) with a daylength of 18 hours at $23-26^{\circ} \mathrm{C}$. Seven days after sowing the plants were potted in Perlite and placed in a controlled temperature greenhouse $\left(\mathrm{ca} .23^{\circ} \mathrm{C}\right)$ in which the daylength was extended to 18 hours with supplementary incandescent lamps (80 microeinsteins $\mathrm{m}^{-2} \mathrm{sec}^{-1}$ at the level of leaf 5).

Plants were fed a modified Hoagland's solution prepared as follows: $0.005 \mathrm{MNO}_{3}, 0.002 \mathrm{M} \mathrm{Ca}\left(\mathrm{NO}_{3}\right)_{2} \cdot 4 \mathrm{H}_{2} \mathrm{O}$, $0.005 \mathrm{MgSO}_{4} \cdot 7 \mathrm{H}_{2} \mathrm{O}, 0.001 \mathrm{M} \mathrm{KH}_{2} \mathrm{PO}_{4}, 7.2 \mathrm{ml}$ iron-Versenol solution $1^{-1}, 1.0 \mathrm{ml}$ minor elements $1^{-1}$, titrated to a final $\mathrm{pH} 3.8$ with $9 \mathrm{~N}_{2} \mathrm{SO}_{4}$. The iron-Versenol solution consisted of $1 \mathrm{~g} \mathrm{I}^{-1} \mathrm{Fe}\left(\mathrm{NH}_{4}\right)_{2}\left(\mathrm{SO}_{4}\right)_{2} \cdot 6 \mathrm{H}_{2} \mathrm{O}$ plus $2.1 \mathrm{ml} 1^{-1}$ Versenol. The minor elements were made up as follows: $2.86 \mathrm{~g} \mathrm{H}_{3} \mathrm{BO}_{3}$,

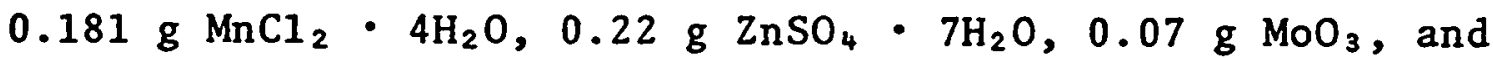
$0.08 \mathrm{~g} \mathrm{CuSO}_{4} \cdot 5 \mathrm{H}_{2} \mathrm{O}^{-1}$. 
Nicotiana tabacum $L$. and Beta vulgaris L. plants were grown in soil in the greenhouse under the same conditions of daylength and temperature.

For studies of growth and carbon balance $\underline{C}$. pepo plants were germinated and potted as described and placed in a controlled environment chamber at a temperature of $26^{\circ} \mathrm{C}$ and illuminated with incandescent lights $(110$ microeinsteins $\mathrm{m}^{-2} \mathrm{sec}^{-1}$ at the level of leaf 5) for 18 hours each day. Plants were fed modified Hoagland's solution as above.

\section{B. PLANT AGE}

The age of $\underline{C}$. pepo plants was determined by the Plastochron Index (PI) (Erickson and Michelini, 1957). The PI establishes the age of a plant on a morphological rather than a temporal basis. In this way plants of the same species with different rates of growth may be closely compared (Michelini, 1958; Maksymowych and Erickson, 1960; Dickmann, 1971; Larson and Isebrands, 1971).

The length of emergent leaves at the shoot apex is used as the morphological scale of development, the plant being $n$ plastochrons in age when the length of a serial leaf $\mathbf{n}$ is equal to a standard value. Between integral plastochron units the age of the plant is determined by the following formula (Erickson and Michelini, 1957) 


$$
P I=n+\frac{\log _{e} L_{n}-\log _{e} x}{\log _{e} L_{n}-\log _{e} L_{n+1}}
$$

where $n$ and $n+1$ are, respectively, the serial number of the leaves just longer and shorter than a standard length $x$, and $L$ is the leaf length. In the present study a petiole length of $30 \mathrm{~mm}$ was chosen as the standard after consideration of the rates of initiation and growth of emergent leaves.

The following example will illustrate the calculation of plant age by the PI. A plant in which the petioles of leaf 5 and leaf 6 are $61 \mathrm{~mm}$ and $18 \mathrm{~mm}$ long respectively is, by the above formula,

$$
5+\frac{4.11-3.40}{4.11-2.89}=5.58 \text { plastochrons in age. }
$$

The PI may be used to establish the age of a whole plant or a single leaf. In the latter case the leaf age is best expressed by the Leaf Plastochron Index (LPI) which is obtained simply by subtracting the serial number of the leaf under study from the PI. For example, when the age of the plant is PI 5.58 the LPI of leaf 5 is 0.58 . This study is concerned with the development of leaf 5 of $\underline{\mathrm{C}}$. pepo and further reference to LPI refers to the LPI of leaf 5 of this plant. The relationship between LPI and time is described in Results. 


\section{LEAF MEASUREMENTS}

The length of leaves was measured with a millimeter ruler to the nearest millimeter. Leaf area was determined by planimetric analysis of leaf tracings (Optical Planimeter, mode1 236, Filotecnica Salmoiraghi, Milan). The dry weight of plant parts was determined after drying to a constant weight in an oven at $90^{\circ} \mathrm{C}$.

\section{CHOICE OF LEAVES}

Leaves were numbered consecutively beginning with the primary leaf. Leaf 5 of $\underline{C}$. pepo was chosen for specific study. In experiments where transport of ${ }^{14} \mathrm{C}$ to 1 eaf 5 was studied, leaf 3 was used as the source leaf, i.e. it was supplied ${ }^{14} \mathrm{CO}_{2}$.

\section{E. ${ }^{14} \mathrm{CO}_{2}$ LABELLING}

Plants selected for experimentation were brought to a laboratory fume hood illumined with water filtered incandescent lights (100 microeinsteins $\mathrm{m}^{-2} \mathrm{sec}^{-1}$ at the level of leaf 5). Following a $30 \mathrm{~min}$ equilibration period the leaf blade to be labelled, which was left intact and attached to the plant, was enclosed in a polyethylene bag sealed around the top of the petiole with a wire tag. ${ }^{34} \mathrm{CO}_{2}$ was generated 
on the piston of a $50 \mathrm{cc}$ syringe by the addition of an excess of $5 \mathrm{~N} \mathrm{H}_{2} \mathrm{SO}_{4}$ to $0.1 \mathrm{ml} \mathrm{Na}{ }^{14} \mathrm{CO}_{3}\left(1.0 \mathrm{~m} \mathrm{Ci} \mathrm{ml}-1,95{ }^{1{ }^{4}} \mathrm{C}\right)$ and introduced to the leaf by inserting the needle of the syringe into the bag and pumping the piston for $15 \mathrm{sec}$. Photosynthesis in the presence of ${ }^{14} \mathrm{C}$ was allowed to continue for 5 min and the polyethylene bag was removed. During the labelling period the petiole of the fed leaf was wrapped in aluminum foil and the rest of the plant was covered with a polyethylene bag to prevent photosynthetic incorporation of ${ }^{14} \mathrm{CO}_{2}$ which may have escaped during the fixation period.

\section{F. ${ }^{14} \mathrm{C}$ ANALYSIS}

At the end of the experimental period plant parts were rapidly excised and immediately frozen in liquid nitrogen, ground with a pestle and mortar, and the fine powder extracted with $80 \%$ ethanol at $70^{\circ} \mathrm{C}$ for $2 \mathrm{hr}$. The insoluble residue was removed by filtration, washed with $80 \%$ ethanol and air dried at room temperature. Triplicate $50 \mu 1$ aliquots of the ethanol extract were counted with a Packard Tri-Carb scintillation counter in $15 \mathrm{~m} 1$ of a cocktail containing 5 grams $1^{-1}$ of 2,5-Diphenyloxazole (PPO) in toluene containing $15 \%$ methanol. The ${ }^{14} \mathrm{C}$ content of the dried alcohol insoluble residues was determined by combusting weighed aliquots of the powder and collecting and counting the evolved ${ }^{14} \mathrm{CO}_{2}$ by the technique of Watson and Williams 
(1970). The apparatus described by Watson and Williams was constructed and used without modification except that the $\mathrm{NaOH}$ washing tower was discarded as unnecessary. Circulation of air was maintained by a peristaltic pump delivering $750 \mathrm{ml}$ air $\min ^{-1}$. Glass and Tygon tubing were used throughout. All scintillation samples were corrected for quenching with an external $\gamma$ source. Results for all plant parts are expressed as the combined values of soluble and insoluble ${ }^{14} \mathrm{C}$.

\section{G. AUTORADIOGRAPHY OF WHOLE LEAVES}

Leaves were cut from the plant and frozen between pre-cooled glass plates at $-38^{\circ} \mathrm{C}$. Freezing of leaves appeared to take place within seconds. The frozen leaves were transferred to pre-cooled Kodak No-Screen $X$-ray films and exposed for 2 or 3 days at $-38^{\circ} \mathrm{C}$ before developing. Unlabelled leaves did not produce any noticeable darkening of X-ray film. In a few experiments leaves were frozen quickly between 2 sheets of dry ice while still attached to the plant. No difference could be detected in results achieved by the two freezing methods.

\section{H. TRANSLOCATION PERIOD}

Preliminary experiments with $\underline{\mathrm{C}}$. pepo indicated that 
within $2 \mathrm{hr}$ of supplying a 5 -min ${ }^{14} \mathrm{CO}_{2}$ pulse to leaf 3 the ${ }^{14} \mathrm{C}$ in leaf 5 reached $90 \%$ of its maximum level. Therefore,

$2 \mathrm{hr}$ was chosen as a suitable translocation period. Following previous work, translocation periods of $2 \mathrm{hr}$ for Beta vulgaris (Geiger and Swanson, 1965), and $6 \mathrm{hr}$ for Nicotiana tabacum (Jones et al., 1959) were used.

\section{LABELLING, EXTRACTION AND CHROMATOGRAPHY OF SUGARS \\ AND RELATED COMPOUNDS}

Following 30 min of equilibration in the laboratory fume hood under the light conditions described above the lamina of leaf 5 of individual plants was excised and quickly inserted into a 2-1iter Erlenmeyer flask in which $0.1 \mathrm{ml}$ of $1 \mathrm{~m} \mathrm{Ci} \mathrm{ml-1} \mathrm{Na}_{2}{ }^{34} \mathrm{CO}_{3}\left(95 \%{ }^{14} \mathrm{C}\right)$ had previously been mixed with excess $5 \mathrm{~N}_{2} \mathrm{SO}_{4}$. The flask was sealed with a rubber stopper. A piece of filter paper placed in the flask was used to absorb the acid after the ${ }^{14} \mathrm{CO}_{2}$ had been 1 iberated and before the leaf was introduced.

The leaf blade was allowed to $\mathrm{fix}{ }^{14} \mathrm{CO}_{2}$ for $5 \mathrm{~min}$ and was then immediately removed and divided into distal and proximal halves. Each half was frozen in liquid nitrogen, ground to a fine powder and twice extracted for a total of 2 hr with $80 \%$ ethanol at $70^{\circ} \mathrm{C}$. The alcohol insoluble residue was collected by filtration, washed with $80 \%$ ethanol, air dried at room temperature and assayed for ${ }^{14} \mathrm{C}$ activity by 
combustion (using the Watson and Williams technique) as described above.

The filtrate was reduced by flash evaporation at $70^{\circ} \mathrm{C}$ to a volume of $4 \mathrm{ml}$. Three of the $4 \mathrm{ml}$ were subjected to ionexchange chromatography. Ion-exchange columns were prepared using $10 \mathrm{~m} 1$ of weak anion (Rexyn $203(\mathrm{OH})$-Fisher research grade 16-50 mesh-regenerated with $2 \mathrm{~N}^{-} \mathrm{NH}_{4} \mathrm{OH}$ ) and $10 \mathrm{ml}$ strong cation (Rexyn $101(\mathrm{H})$ Fisher research grade 40-100 mesh-regenerated with $2 \underline{\mathrm{N}} \mathrm{HC1}$ ) resin in $1 \mathrm{~cm}$ diameter glass tubes.

The columns were fitted together in series so that the leaf extract ran first through the cation resin and then directly through the anion resin. The extracts were passed through the columns followed by $100 \mathrm{ml}$ of water. Preliminary experiments showed that most of the radioactive neutral fraction of plant extracts or radioactive sugar solutions came through the columns with the first 10 to $15 \mathrm{ml}$ of water eluant and no appreciable radioactivity was detected after $50 \mathrm{~m} 1$.

The neutral fraction, emerging from the columns, was flash evaporated at $70^{\circ} \mathrm{C}$ to a volume of $4 \mathrm{ml}$ and reduced to dryness at room temperature with a stream of air. The dried sample was taken up in sufficient water to give a final isotope concentration of approximately $100,000 \mathrm{dpm} \mathrm{m}^{-1}$. Fifty $\mu 1$ samples were spotted on Whatman 3MM chromatography paper alternately with $50 \mu 1$ samples of a solution containing authentic sugars. Chromatograms were run for $44 \mathrm{hr}$ with N-propanol:ethyl acetate: water $(7: 1: 2)$, dried, cut into 
strips, and counted with a Packard radiochromatogram strip scanner equipped with a DISC integrator. The alternate chromatogram strips were sprayed with ammoniacal silver nitrate reagent (Partridge, 1948) to determine the position of the authentic sugars.

The above procedures are outlined in Figure 1.

\section{J. INFRARED ANALYSIS OF PHOTO-} SYNTHESIS AND RESPIRATION

Experiments on leaf carbon balance were performed in

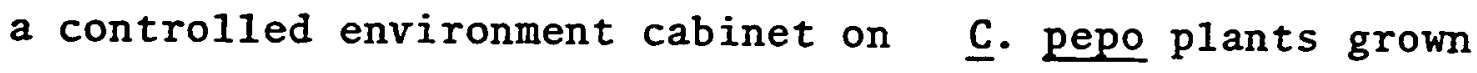
in the same cabinet. The analyses were conducted on single attached leaves in an open gas circuit as shown in Figure 2a.

A peristaltic pump pulled air from the growth chamber through the system. The air passed through a Gilmont No. F1200 flowmeter (Gilmont Inst., Great Neck, N.Y., 11021), a Lucite leaf chamber with a plate glass lid (Fig. 2b), a Drierite tower, a second flowmeter, the sample cell of a Beckman Infrared Analyzer (model 215A) and finally the pump itself.

The infrared analyzer was connected to a Perkin Elmer-Coleman 165 recorder. The first flowmeter and the leaf chamber were situated inside the growth cabinet and were connected to the rest of the apparatus outside the cabinet with Tygon tubing. By using 2 flowmeters, leaks in 


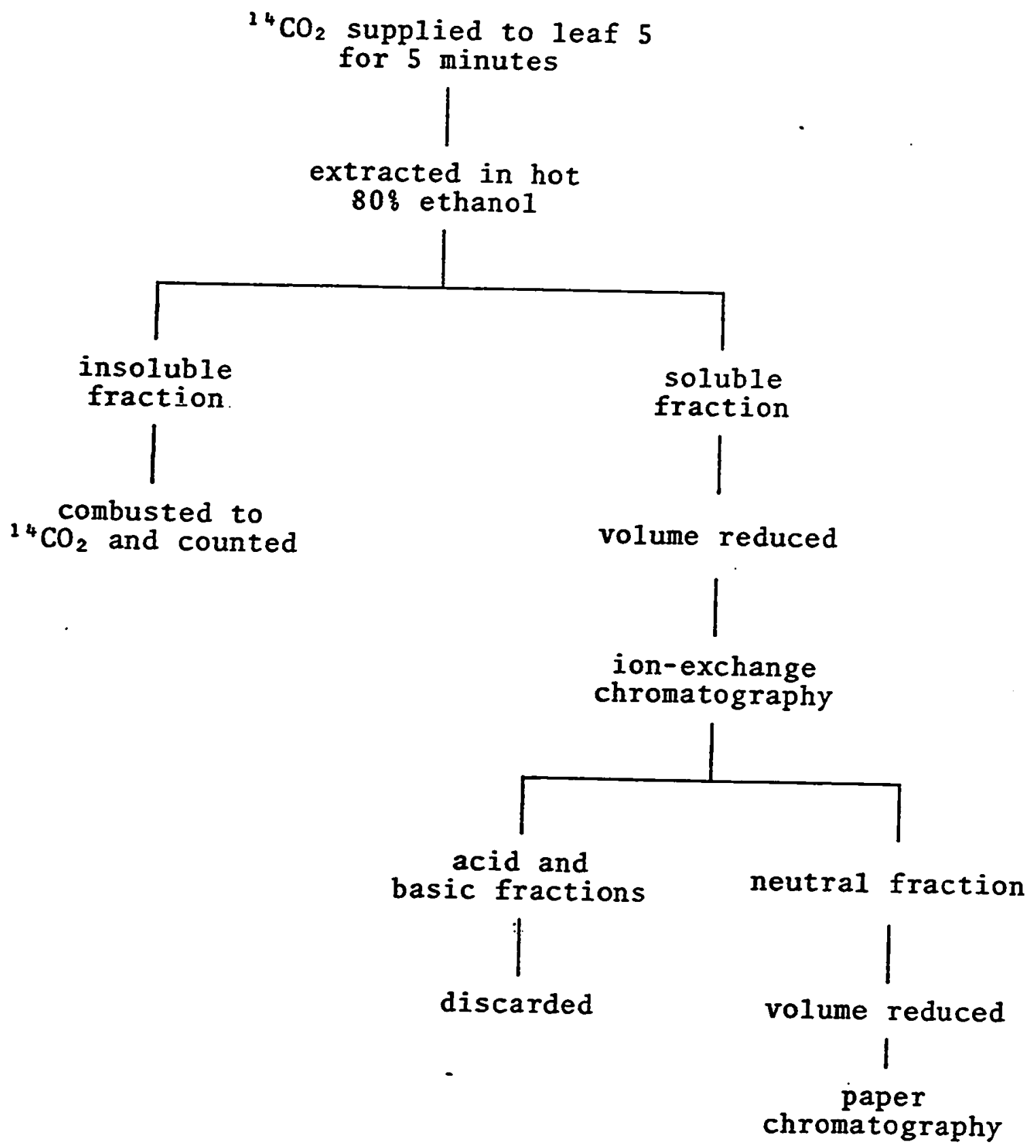

FIG. 1

Procedure for the extraction, purification, and chromatography of the neutral fraction of leaves supplied with ${ }^{1}{ }^{4} \mathrm{CO}_{2}$. 
FIG. $2 a-b$

(a) Schematic diagram of apparatus used to measure $\mathrm{CO}_{2}$ flux in single attached leaves.

(b) Diagram of Lucite leaf chamber. 


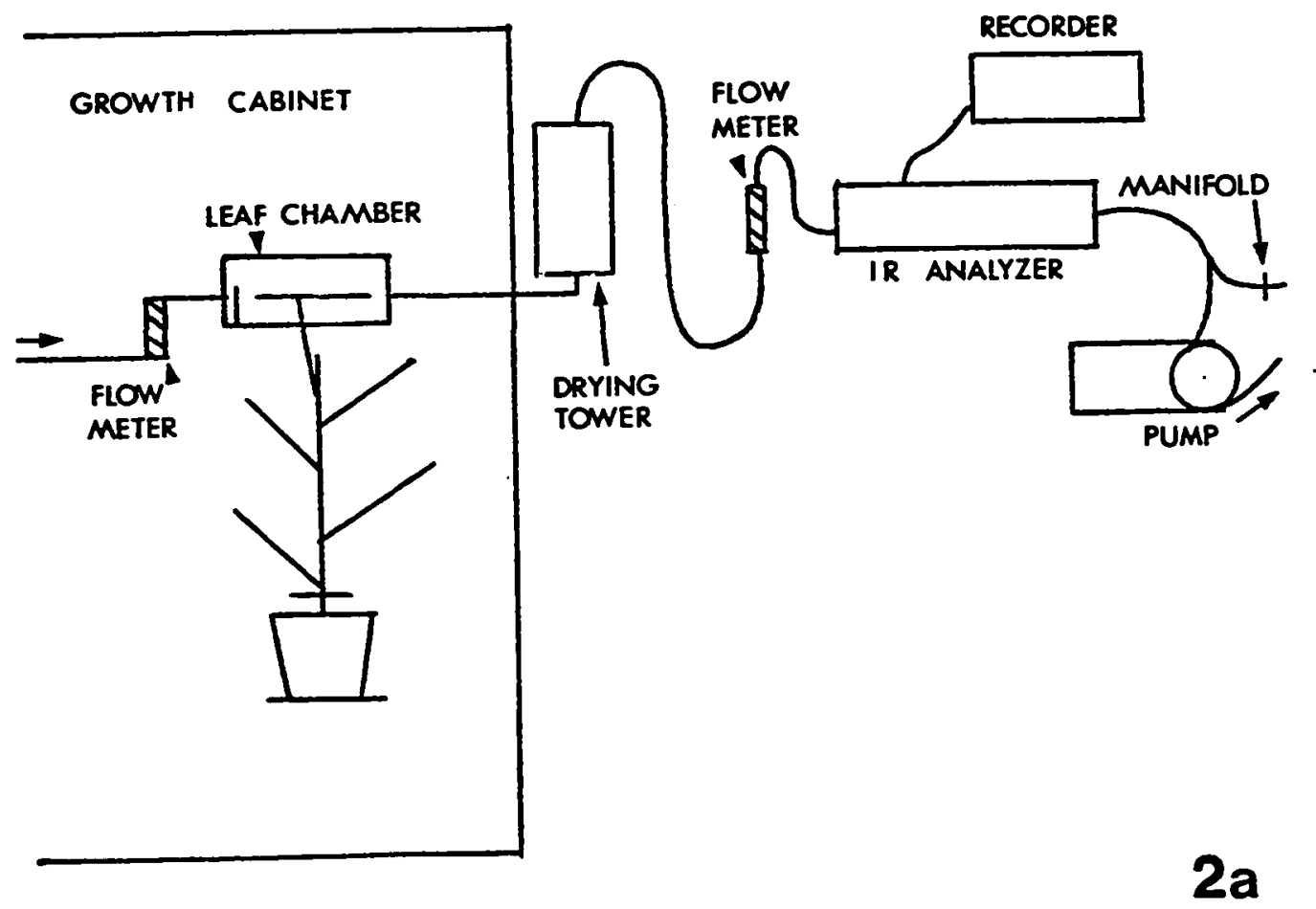

LEAF CHAMBER
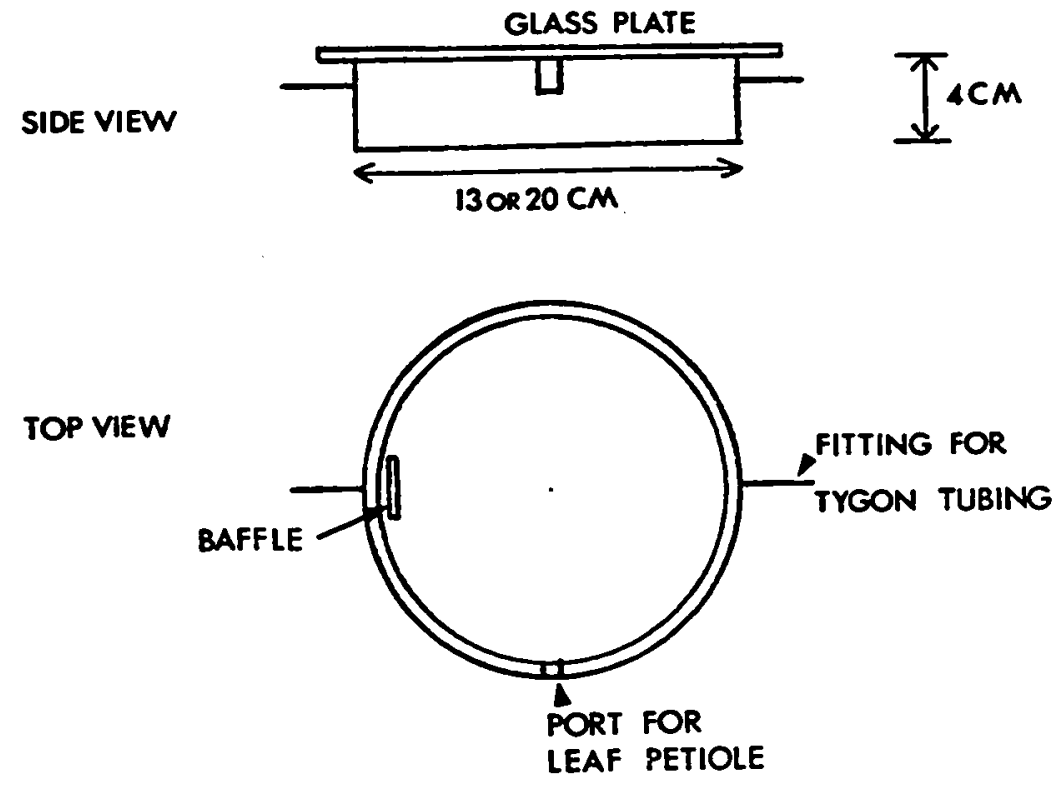
the system could be detected. Two sizes of leaf chamber were used (Fig. 2b)--a chamber of $1225 \mathrm{cc}$ volume for mature leaves and another of $475 \mathrm{cc}$ volume for smaller leaves.

The petiole of the leaf to be analyzed was sealed into the chamber with plasticine softened slightly with petroleum jelly. Silicone stopcock grease was used to obtain a tight seal with the glass lid. A manifold between the second flowmeter and the pump regulated the flow rate. The flow rates used were $750 \mathrm{cc} \mathrm{min}{ }^{-1}$ for large leaves and $160 \mathrm{cc} \min ^{-1}$ for small leaves.

The following procedure was used during an analysis. The petiole of the experimental leaf (leaf 5 in all cases) was sealed into the chamber $30 \mathrm{~min}$ before the analysis to allow the plant to recover from any shock that might have been incurred during handling. The leaf chamber lid was left off during the equilibration period. At the end of the equilibration period a sample of air in the growth cabinet was analyzed. The lid was then placed on the leaf chamber and the chamber connected to the circuit. When a constant reading was obtained (usually within $10 \mathrm{~min}$ ) for air passing through the leaf chamber the lid was removed, the chamber was disconnected from the circuit, and another sample of air in the growth cabinet was analyzed. This procedure was repeated 2 or 3 times. The rate of photosynthesis was calculated from the difference in $\mathrm{CO}_{2}$ level between ambient air and air emerging from the chamber. 
No corrections were made for dark respiration or photorespiration. Therefore, photosynthesis by these measurements is more correctly termed net photosynthesis. Measurements of dark respiration during the day were obtained by the same procedure immediately after the growth cabinet lights were turned off. In dark experiments equilibration was usually attained within 5 min.

During operation the reference cell of the infrared analyzer was filled with $\mathrm{CO}_{2}$ free $\mathrm{N}_{2}$ at atmospheric pressure. To calibrate the instrument compressed air containing 495 ppm $\mathrm{CO}_{2}$ (analyzed--Union Carbide Co., Toronto) and compressed $\mathrm{CO}_{2}$ free $\mathrm{N}_{2}$ were combined in a mixing vessel and passed through the gas analyzer. Flow meters between each cylinder and the mixing chamber allowed the percentage of $\mathrm{CO}_{2}$ to be varied while the combined flow rate was held constant at $750 \mathrm{cc} \min ^{-1}$. The calibration curve is reproduced in Figure 3. The analyzer was zeroed with $\mathrm{CO}_{2}$ free $\mathrm{N}_{2}$ and air containing $495 \mathrm{ppm} \mathrm{CO}_{2}$ was used as the up-scale standard. Calibration curves were obtained 4 times with identical results.

The components of the system were connected with Tygon tubing. The porosity of the tubing to $\mathrm{CO}_{2}$ was checked

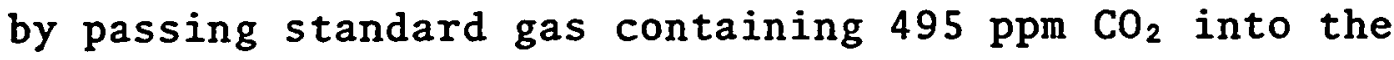
analyzer either directly or through 5 feet of Tygon tubing. No difference could be detected.

Leaf temperature was measured with a chromel-constantan 
FIG. 3

Calibration curve for infrared gas analyzer. 


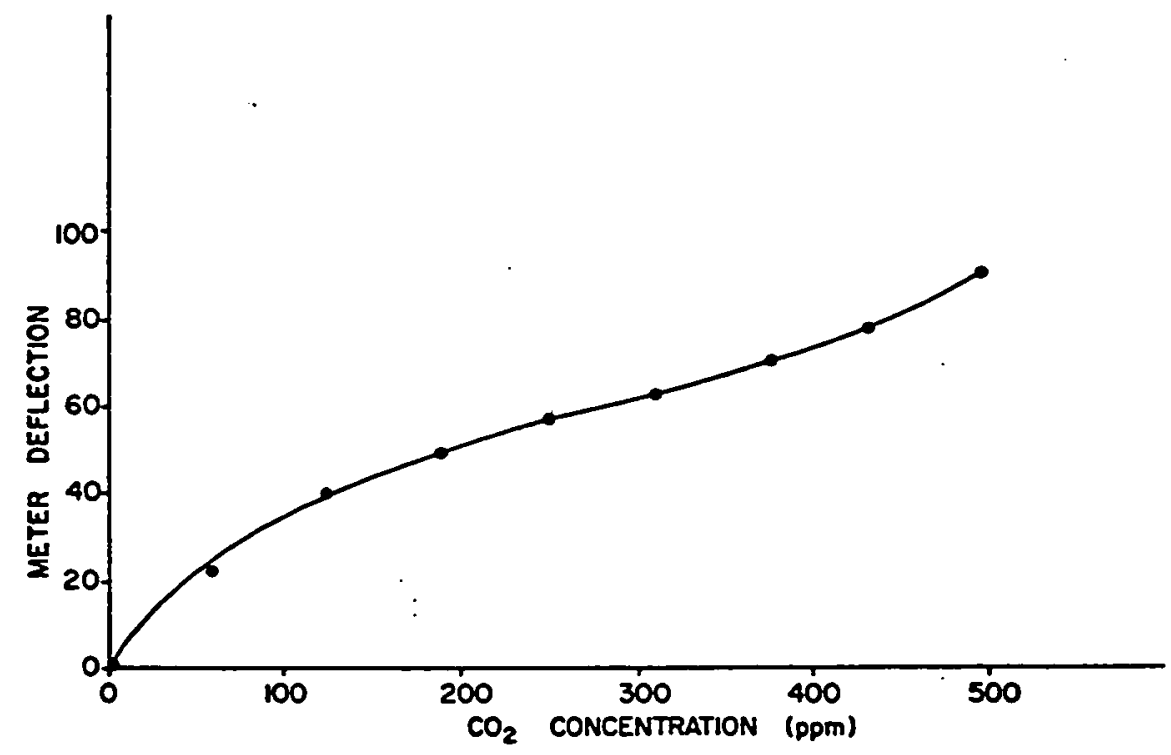


thermocouple inserted into a large leaf vein. Leaf temperatures in both chambers averaged about $1^{\circ} \mathrm{C}$ below the ambient temperature when the lid was off the leaf chamber and from $2^{\circ} \mathrm{C}$ to $4^{\circ} \mathrm{C}$ above the ambient temperature when the chamber was closed during an analysis.

\section{K. STATISTICAL ANALYSIS OF RESULTS}

In experiments where leaf age was the independent variable plants were grouped, at the completion of the experiment, into convenient age classes. Values for dependent variables within each age class were expressed as an arithmetic mean. The mean dependent variable so obtained for each age class was plotted against the arithmetic mean of the ages of plants (leaves) within the age class. Vertical bars on the figures represent twice the standard error of the mean of the dependent variable.

\section{ELECTRON MICROSCOPY}

Pieces of freshly excised leaves were carefully cut into pieces about $1.5 \mathrm{~mm}^{2}$ on a glass slide wetted with 0.05 M sodium cacodylate buffer $\mathrm{pH} 6.8$. The pieces were immediately transferred with a camel hair brush to vials containing 6: glutaraldehyde in the same buffer. The samples were fixed, with gentle aspiration, for $12 \mathrm{hr}$ at room 
temperature, washed in buffer 5 times with a 30-min interval between each washing and post-fixed in $2 \%$ osmic acid in the same buffer overnight in the refrigerator. After fixation in osmic acid the vials were warmed slowly to room temperature, washed in buffer for $10 \mathrm{~min}$, dehydrated in a graded ethanol series over a period of $2 \mathrm{hr}$ and embedded either in Epon-Araldite (Mollenhauer, 1964) or Spurr (1969) resin.

Sections were cut with a diamond knife either on a Reichert $\mathrm{OmU}_{2}$ or Sorvall MT-2 ultramicrotome, mounted on uncoated grids and doubly stained with uranyl acetate and lead citrate for $20 \mathrm{~min}$ each. Specimens were viewed and photographed either with a Siemens Elmiskop 101 microscope at $80 \mathrm{KV}$ or a Hitachi HU-11C microscope at $75 \mathrm{KV}$.

\section{LIGHT MICROSCOPY}

Material embedded for electron microscopy in epoxy resin was cut with glass knives $1 \mu$ thick, stained with methylene blue in sodium borate ( $\mathrm{pH}$ approximately 10$)$, and examined and photographed with a Zeiss Photo-microscope.

For viewing unsectioned material pieces of leaf were cleared in $2.5 \% \mathrm{NaOH}$ at room temperature and stained with safranin in equal parts absolute ethanol and xylene (Pray, 1955a). 
RESULTS

\section{A. IMPORT AND EXPORT IN}

A DEVELOPING LEAF

The maturation of dicotyledonous leaves proceeds in a basipetal fashion (see Literature Review). If the transport functions develop basipetally, that is if the leaf tip loses the ability to import and develops the capacity to export before the leaf base, this would provide an explanation for the ability of partially developed leaves to simultaneously import and export photoassimilate for a short period (Jones and Eagles, 1962).

The following experiments were designed to test this hypothesis. Loss of import capacity was followed by allowing developing leaves to import ${ }^{14} \mathrm{C}$-photoassimilate and then preparing autoradiographs of the whole leaves. Export capacity was determined by measuring the ${ }^{14} \mathrm{C}$ translocated from the leaf after exposure to ${ }^{14} \mathrm{CO}_{2}$. All experiments were performed on greenhouse-grown plants.

I. Cessation of ${ }^{14} \mathrm{C}$ Import into the Leaf Blade of $\underline{C}$. pepo

Thirty-six plants were selected in which the lamina of leaf 5 was between 5 and $60 \%$ expanded. Leaf 3 was offered ${ }^{14} \mathrm{CO}_{2}$ and following $2 \mathrm{hr}$ of translocation the lamina of leaf 
5 was frozen and autoradiographed. Photographs of representative autoradiographs are shown in Figure 4.

When very young the entire leaf imports ${ }^{14} \mathrm{C}$ (Fig. $4 \mathrm{a}$ ).

As the leaf grows the capacity to import is lost progressively, beginning with the leaf tip (Fig. 4b), and continuing basipetally along the leaf length (Fig. 4c,d). Autoradiographs of leaves undergoing this development show a sharp line of demarcation, at right angles to the midrib, between importing (blackened) and non-importing (non-blackened) regions. Basipetal loss of import capacity also begins at the tips of the leaf lobes (Fig. 4c).

These autoradiographs suggest that the ability of the leaf blade to import ${ }^{14} \mathrm{C}$ labelled assimilates is lost in a basipetal direction as predicted by the hypothesis of Jones and Eagles (1962). However, it is possible that the observed labelling pattern in importing leaves is not attribuisble to the developmental stage of the importing leaf itself but to the length of the translocation period or the relative positions of the source and sink leaves. These possibilities were tested by supplying, at intervals, 3 mature leaves of a single plant with ${ }^{14} \mathrm{CO}_{2}$ and periodically monitoring the ${ }^{14} \mathrm{C}$ activity of an importing leaf over a 9-hr period.

A plant was chosen in which leaf 5 was judged to be importing in the basal half only. Leaf 5 was held immobile between glass plates, one below the leaf and two above. A 

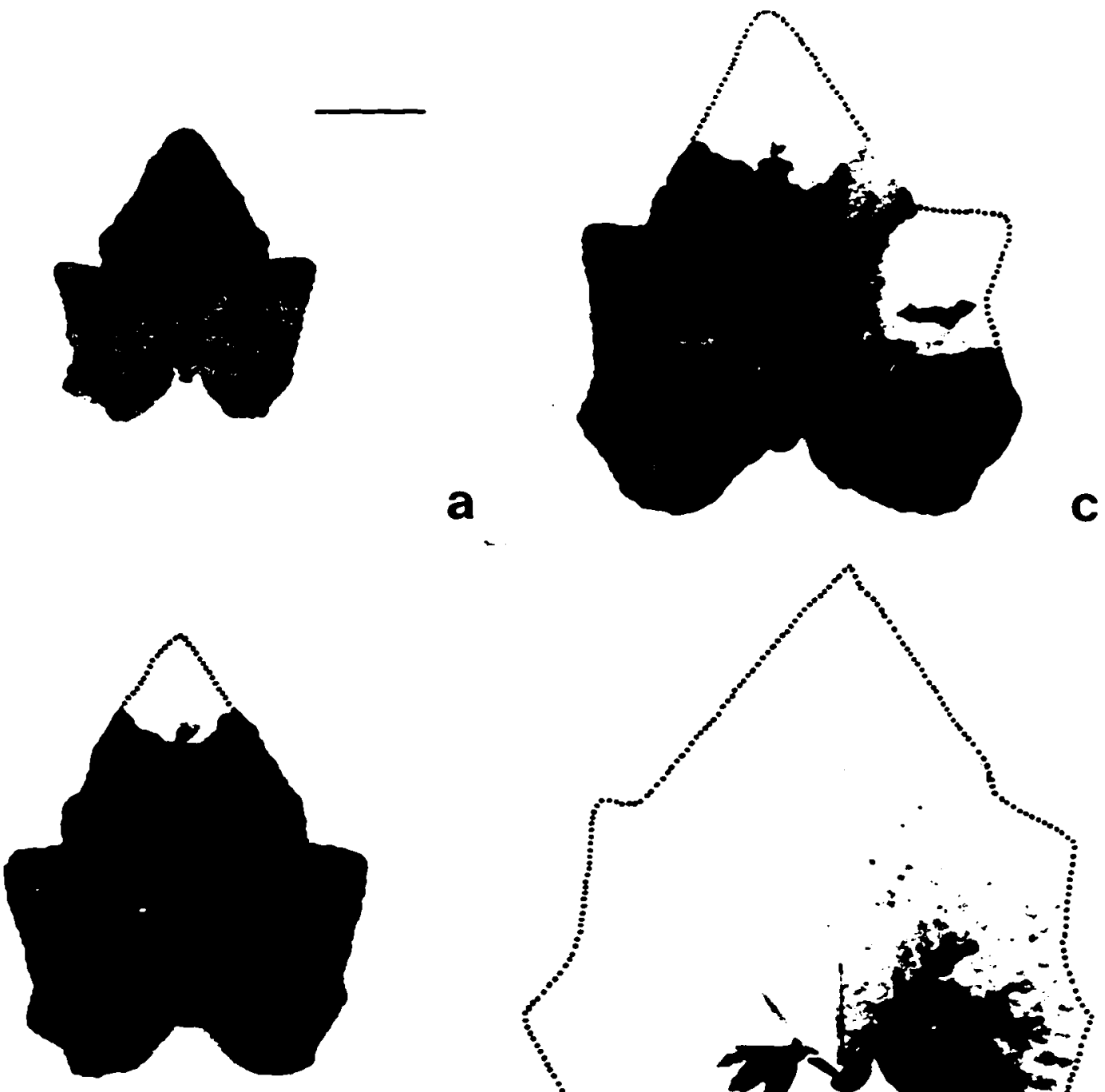

a

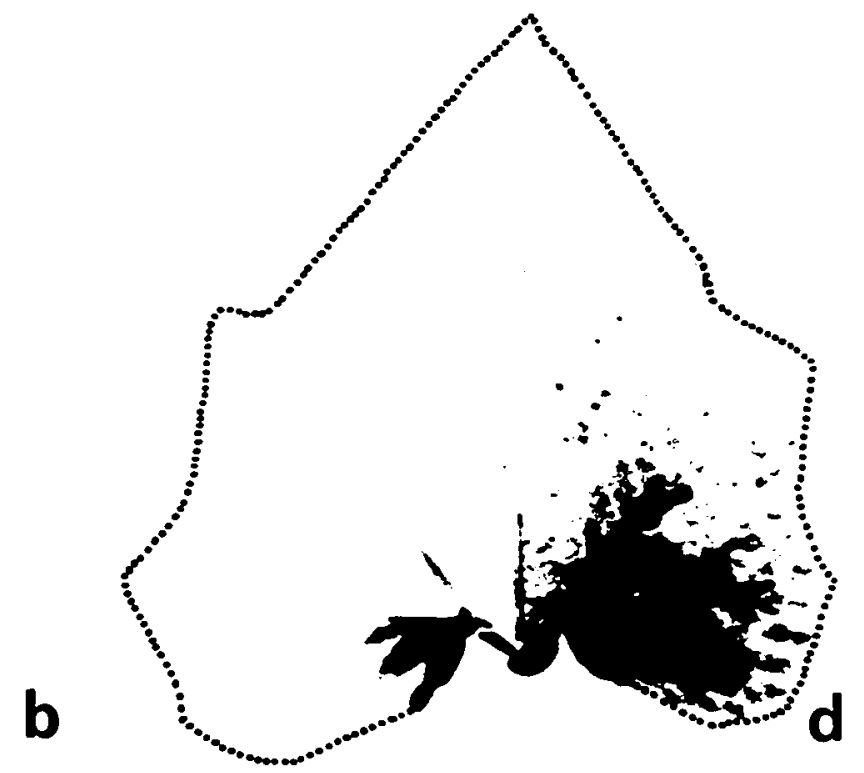



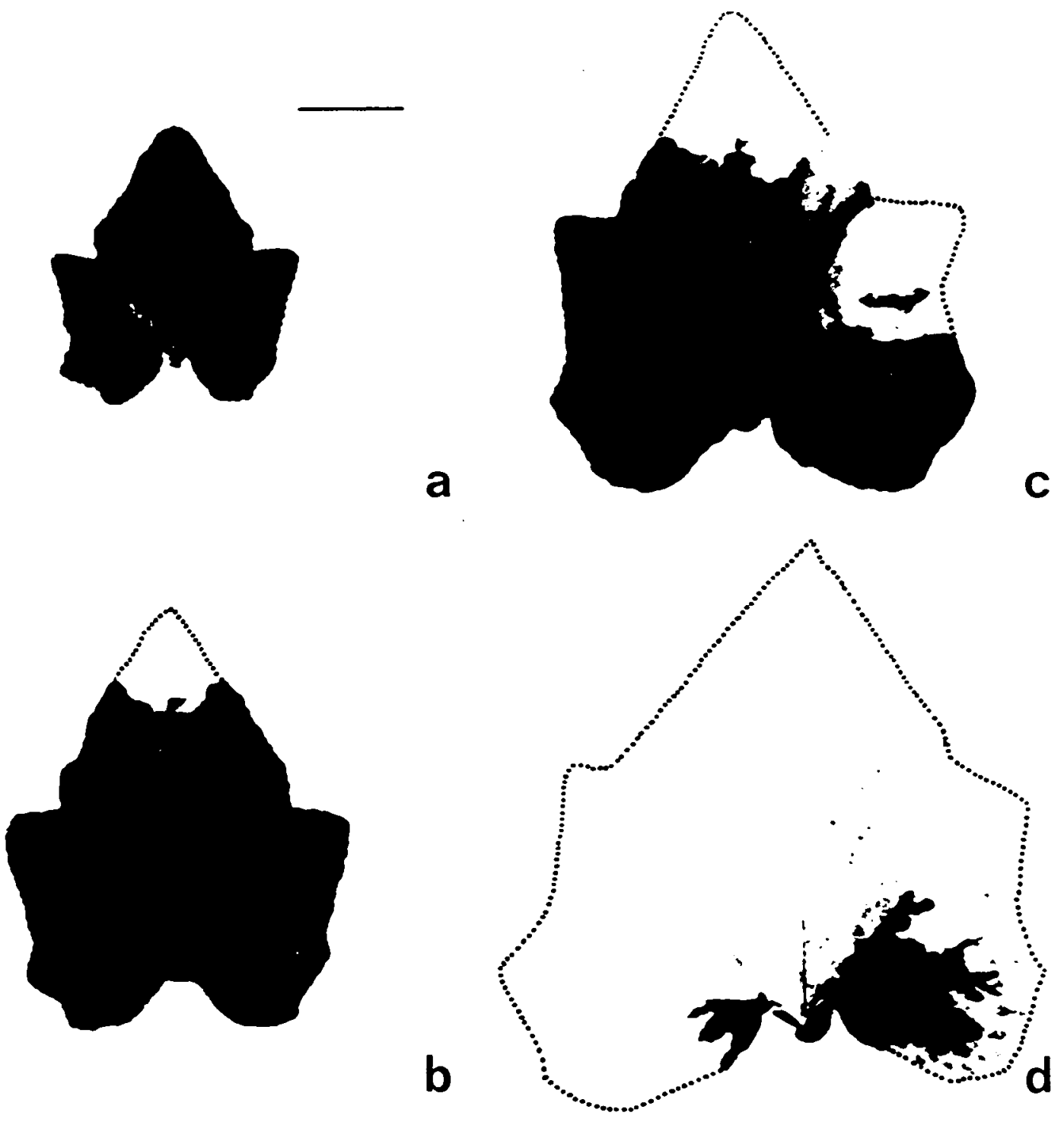
FIG. $4 a-d$

Autoradiographs of lamina 5 of 4 C. pepo plants which imported ${ }^{14} \mathrm{C}$ from leaf 3

for $2 \mathrm{hr}$. Leaf ages were: (a) LPI 0.2;

(b) LPI 0.4 ; (c) LPI 0.8 ; (d) LPI 1.1 .

Scale $=2 \mathrm{~cm}$; all photographs are the same magnification. 
gap, $5 \mathrm{~mm}$ wide, between the two upper glass plates was oriented parallel to and $1 \mathrm{~cm}$ from the midrib of the leaf. An aluminum disk with a slit $5 \mathrm{~mm}$ wide was fitted over the window of a Geiger-Muller (G.M.) counter and by placing the G.M. counter over the glass plate and orienting the slits at right angles to each other an area of the leaf surface, $5 \mathrm{~mm}$ on a side, could be monitored.

${ }^{34} \mathrm{CO}_{2}$ was supplied first to 1 eaf 3 at 0 time as described above and then to leaves 2 and 4 at 3 and $6 \mathrm{hr}$. The level of ${ }^{14} \mathrm{C}$ activity in leaf 5 was monitored every $30 \mathrm{~min}$, beginning at 0 time, for $9 \mathrm{hr}$ at $5 \mathrm{~mm}$ intervals along the length of the leaf. The results, plotted in Figure 5, show that the pattern of ${ }^{14} \mathrm{C}$ transported to the basal half of the lamina of leaf 5 originating in 3 different mature leaves over a 9-hr period remained constant. The pattern of ${ }^{14} \mathrm{C}$ labelling observed in Figure 4 must therefore be due to the degree of development of the importing leaf.

The degree of development of individual leaves was estimated by measuring the distance on the autoradiograph from the junction of the lamina and petiole to the line which demarcates the importing from the non-importing regions of the blade and expressing this distance as a percentage of the total lamina length. This function is termed the percentage of leaf blade importing and is plotted against the Leaf Plastochron Index (LPI) in Figure 6. The progressive basipetal loss of import capacity is 


\title{
FIG. 5
}

\begin{abstract}
Pattern of ${ }^{14} \mathrm{C}$ distribution along the length of leaf 5 of $\underline{\mathrm{C}}$. pepo after supplying ${ }^{14} \mathrm{CO}_{2}$ to leaves 3,2 and 4 at $0 \mathrm{hr}, 3 \mathrm{hr}$ and $6 \mathrm{hr}$ respectively. Leaf age was LPI 0.9. Curves 1-10 represent levels of ${ }^{14} \mathrm{C}$ monitored at the following times: 1, $30 \mathrm{~min}$; 2, $60 \mathrm{~min}$; 3, $90 \mathrm{~min}$; $4,120 \mathrm{~min} ; 5,150 \mathrm{~min}, 190 \mathrm{~min}$ and 210 $\min ; 6,240 \mathrm{~min} ; 7,270 \mathrm{~min} ; 8,300 \mathrm{~min}$; 9,330 and $360 \mathrm{~min} ; 10,540 \mathrm{~min}$.
\end{abstract}

FIG. 6

Development of leaf 5 of $\underline{C}$. pepo

expressed as the percentage of the total lamina length still importing ${ }^{14} \mathrm{C}$. 

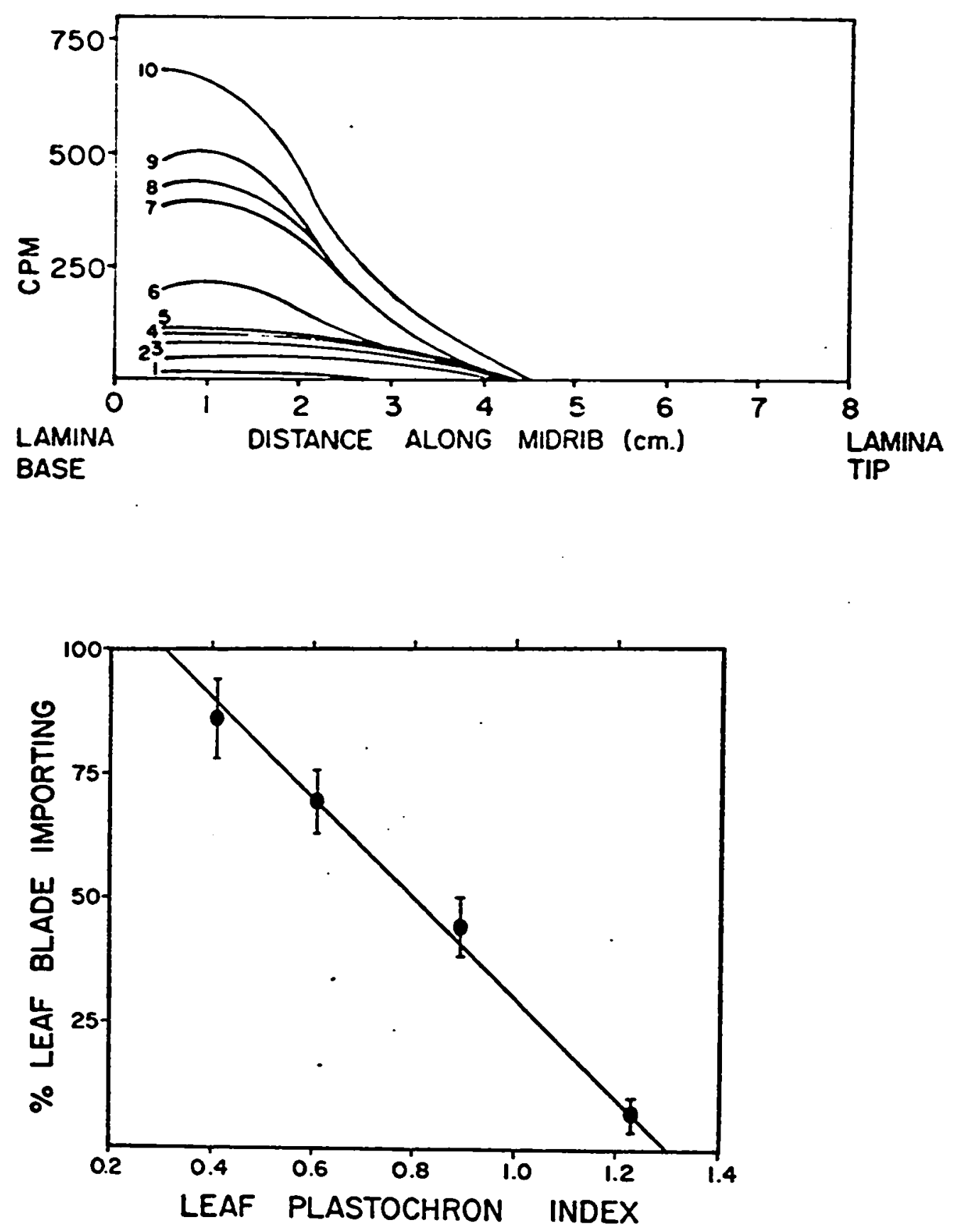
linearly related to LPI (Fig. 6) and therefore to time since LPI is linearly related to time (see Leaf Growth). Loss of import capacity at the tip begins at LPI 0.3 or $10 \%$ leaf expansion (Fig. 14), and by LPI 1.3 (45\% leaf expansion) the lamina no longer imports ${ }^{14} \mathrm{C}$. The time required to complete this phase of development is 1.0 plastochrons or approximately 2 days ( 1 LPI of greenhouse-grown plants equals 2.12 days-see Leaf Growth).

Under these growth conditions one leaf blade of $\underline{c}$. pepo undergoes basipetal loss of import capacity at a time. In experiments where leaves 4,5 and 6 were autoradiographed and leaf 5 was undergoing basipetal loss of import capacity, the whole of the blade of leaf 6 was importing while import to the lamina of leaf 4 had completely stopped.

In a few experiments the petiole of an importing leaf was steam-girdled or a cold block at $0^{\circ} \mathrm{C}$ was applied (Webb, 1967). These treatments, which inhibit phloem transport, stopped the flow of ${ }^{14} \mathrm{C}$ into the importing leaf except for a trace quantity of label which became evenly distributed throughout the lamina. This trace quantity of ${ }^{14} \mathrm{C}$ is also seen in the distal non-importing region of partially importing leaves (Fig. 4d).

A quantitative estimate of the ability of leaf 5 to import photoassimilate from leaf 3 was made from labelling experiments in which the total ${ }^{14} \mathrm{C}$ content of the lamina and petiole of leaf 5 and the rest of the plant was measured 
following $2 \mathrm{hr}$ of translocation of ${ }^{14} \mathrm{C}$ from leaf 3 . The results are shown in Figure 7 where the amount of ${ }^{14} \mathrm{C}$ in leaf 5 is expressed as a percentage of the total ${ }^{14} \mathrm{C}$ translocated from the lamina of leaf 3 in $2 \mathrm{hr}$.

The maximal rate of import into the lamina of leaf 5 occurred at approximately LPI 0.6 , well after the leaf tip had lost the capacity to import. Import to the lamina ceased at LPI 1.3, corroborating the results obtained from whole leaf autoradiography.

In these, and all other translocation experiments described, the amount of ${ }^{14} \mathrm{C}$ found in the ethanol insoluble fraction has been included in the calculation of results. The amount of ethanol insoluble ${ }^{14} \mathrm{C}$, expressed as a percentage of the total ${ }^{14} \mathrm{C}$ found in each of the analyzed plant parts, is presented in Table 2.

II. Cessation of ${ }^{14} \mathrm{C}$ Import into the Petiole of $\mathrm{C}$. pepo

Import of ${ }^{14} \mathrm{C}$ into the petiole of leaf 5 , expressed as a percentage of the ${ }^{14} \mathrm{C}$ translocated from leaf 3 , increases to a maximum at approximately the same time as import to the blade ceases (LPI 1.3) and drops rapidly to zero at LPI 2.0 (Fig. 7).

Autoradiographs of whole leaves between the ages of LPI 1.3 and 2.0 suggest that the loss of import capacity of the petiole is also progressive and basipetal 
Table 2

The amount of ethanol insoluble ${ }^{14} \mathrm{C}$, expressed as a percentage of the total ${ }^{14} \mathrm{C}$, found in each analyzed plant part, when either lamina 5 or lamina 3 had been supplied ${ }^{14} \mathrm{CO}_{2}$ for $5 \mathrm{~min}$ and translocation was allowed to proceed for $2 \mathrm{hr}$ before analysis

\begin{tabular}{|c|c|c|}
\hline Plant Part & $\begin{array}{c}{ }^{14} \mathrm{CO}_{2} \text { supplied } \\
\text { to lamina } 5\end{array}$ & $\begin{array}{l}{ }^{14} \mathrm{CO}_{2} \text { supplied } \\
\text { to lamina } 3\end{array}$ \\
\hline lamina 5 & see Fig. 22 & $\begin{array}{c}\text { 36 } \\
\left(\begin{array}{cll}\text { from } & \text { LPI } & 1 \\
\text { to } & \text { LPI } & 5\end{array}\right)\end{array}$ \\
\hline petiole 5 & 17 & 31 \\
\hline - & 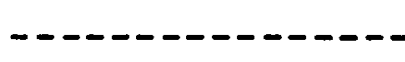 & - - - \\
\hline $\begin{array}{l}\text { all plant parts } \\
\text { above leaf } 5\end{array}$ & 29 & $\begin{array}{c}30 \\
\text { (a11 plant parts } \\
\text { except leaf } 5 \\
\text { combined) }\end{array}$ \\
\hline - - - - - & $\ldots$ & - n \\
\hline $\begin{array}{l}\text { all plant parts } \\
\text { between leaf } 5 \\
\text { and roots }\end{array}$ & 21 & \\
\hline - - - - - - - - - - - - - & ---- & --- \\
\hline roots & 24 & \\
\hline
\end{tabular}


(autoradiographs not presented). In addition, loss of import capacity appears to begin at the abaxial side of the hollow petiole before the adaxial side.

In a quantitative experiment with 30 plants leaf 3 was fed ${ }^{14} \mathrm{CO}_{2}$ and after $2 \mathrm{hr}$ the petiole of leaf 5 was excised. The petiole was divided in half transversely and again longitudinally into adaxial and abaxial halves. Each of the quadrants was weighed and the ${ }^{14} \mathrm{C}$ content analyzed. The results were pooled in such a way that the amount of ${ }^{14} \mathrm{C}$ per unit fresh weight in the distal half of the petiole could be calculated relative to the ${ }^{14} \mathrm{C}$ in the proximal half. Similarly the amount of ${ }^{14} \mathrm{C}$ in the abaxial half was calculated relative to that in the adaxial half.

The results, plotted against leaf age in Figure 8 indicate that at approximately LPI 1.2 the amount of ${ }^{14} \mathrm{C}$ per unit fresh weight imported to the distal half of the petiole relative to the proximal half begins to decrease, i.e. the capacity to import ${ }^{14} \mathrm{C}$ is 10 st in a basipetal direction. At the same time there is a similar though less pronounced dorsoventral loss of import capacity beginning at the abaxial side of the petiole.

III. Cessation of ${ }^{14} \mathrm{C}$ Import into Leaves of Beta vulgaris and Nicotiana tabacum

Autoradiographic experiments similar to those described for $\underline{\mathrm{C}}$. pepo were conducted with Beta vulgaris and 


\section{FIG. 7}

${ }^{34} \mathrm{C}$ activity in the lamina $(\bullet)$ and petiole (o) of leaf 5 of $\underline{C}$. pepo expressed as a percentage of the total ${ }^{14} \mathrm{C}$ translocated from the lamina of leaf 3 in $2 \mathrm{hr}$.

FIG. 8

Relative ${ }^{14} \mathrm{C}$ activity in the distal (•) and abaxial (0) halves of importing petioles of leaf 5 of $\underline{C}$. pepo compared to the activity in the proximal and adaxial halves respectively. 

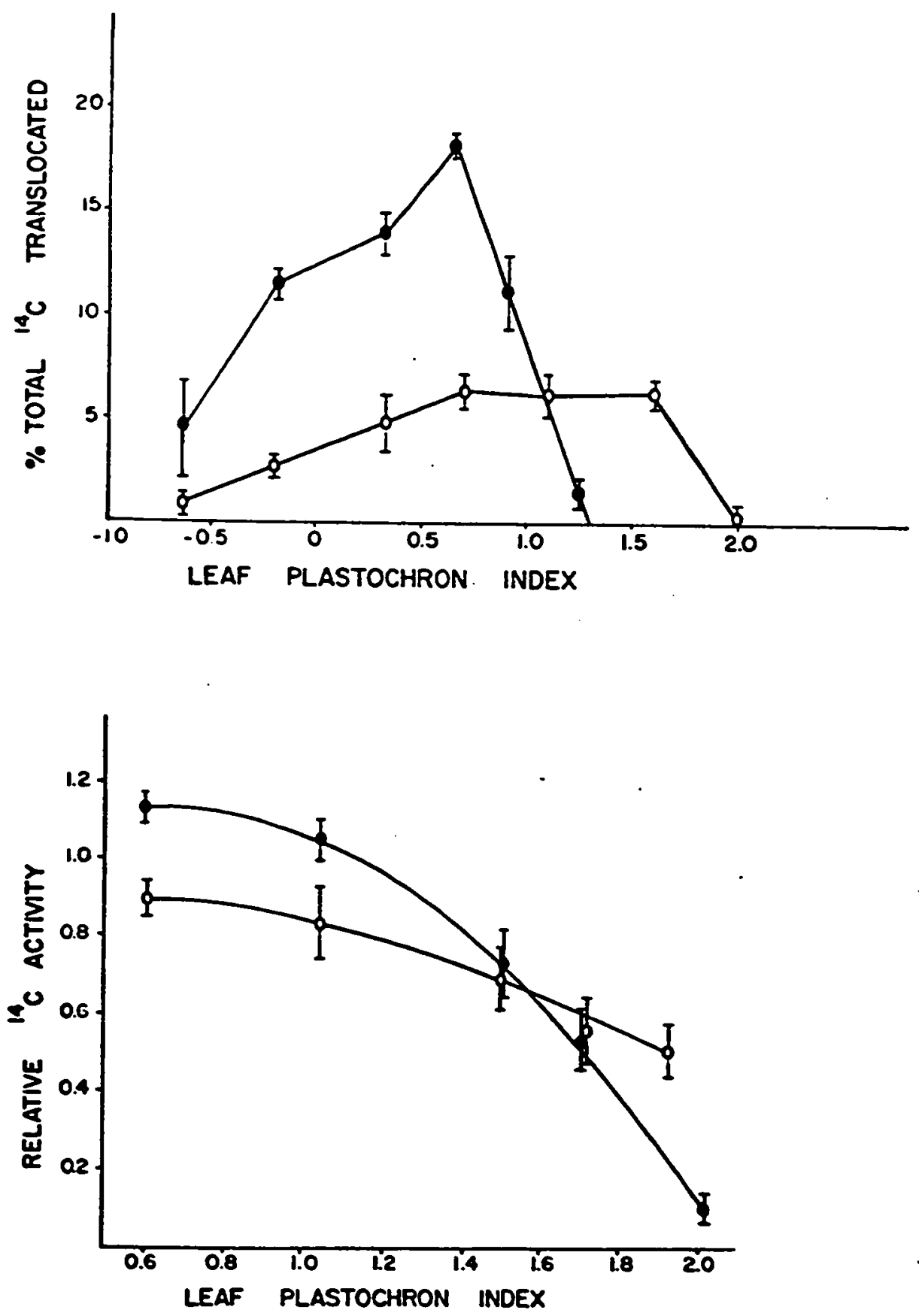
Nicotiana tabacum to establish the pattern of development in these species. Mature leaves of sugar beet (Joy, 1964), and tobacco (Jones et al., 1959), unlike squash (Webb and Gorham, 1964) translocate primarily along the same orthostichy. Therefore three successive mature leaves of these species were offered ${ }^{14} \mathrm{CO}_{2}$. Leaves 8,9 and 10 of a 10-week-old sugar beet plant were labelled and leaves 11 to 15 were frozen and autoradiographed following $2 \mathrm{hr}$ of translocation (Fig. 9a). In the tobacco, leaves 9,10 and 11 of an 8-weekold plant were labelled and following $6 \mathrm{hr}$ of translocation leaves 13 to 18 were frozen and autoradiographed (Fig. 9b). Basipetal loss of import capacity in sugar beet and tobacco leaves is demonstrated by these autoradiographs. The pattern of development in sugar beet and tobacco leaves differs from that of squash, at least under our experimental conditions, in that many leaves on the same plant, rather than one, are undergoing basipetal loss of import capacity simultaneously.

IV. Development of Export
Capacity of $\underline{C}$. pepo
Leaves

The development of export capacity of maturing cucurbit leaves was determined by exposing the lamina of leaf 5 to ${ }^{14} \mathrm{CO}_{2}$ and analyzing the ${ }^{14} \mathrm{C}$ content of the fed leaf blade and the rest of the plant after a further $2 \mathrm{hr}$. Before analysis the plant was dissected into the following 
FIG. 9a-b

Autoradiographs of importing leaves of Beta vulgaris (a), and Nicotiana tabacum (b). In both (a) and (b) all leaves are from the same plant. Scale $=3 \mathrm{~cm}$.

FIG. 10

Autoradiograph of lamina 5 of $\underline{C}$. pepo.

Although the leaf blade was too young to export (LPI 0.7), ${ }^{14} \mathrm{C}$ activity was present in the midrib and lamina outside the fed tip-region $2 \mathrm{hr}$ after ${ }^{14} \mathrm{CO}_{2}$ was administered. Petroleum jelly, used to secure the aluminum foil to the leaf, has prevented exposure of the X-ray film to the strip of lamina adjacent to the heavily labelled tip. Scale $=1.5 \mathrm{~cm}$. 

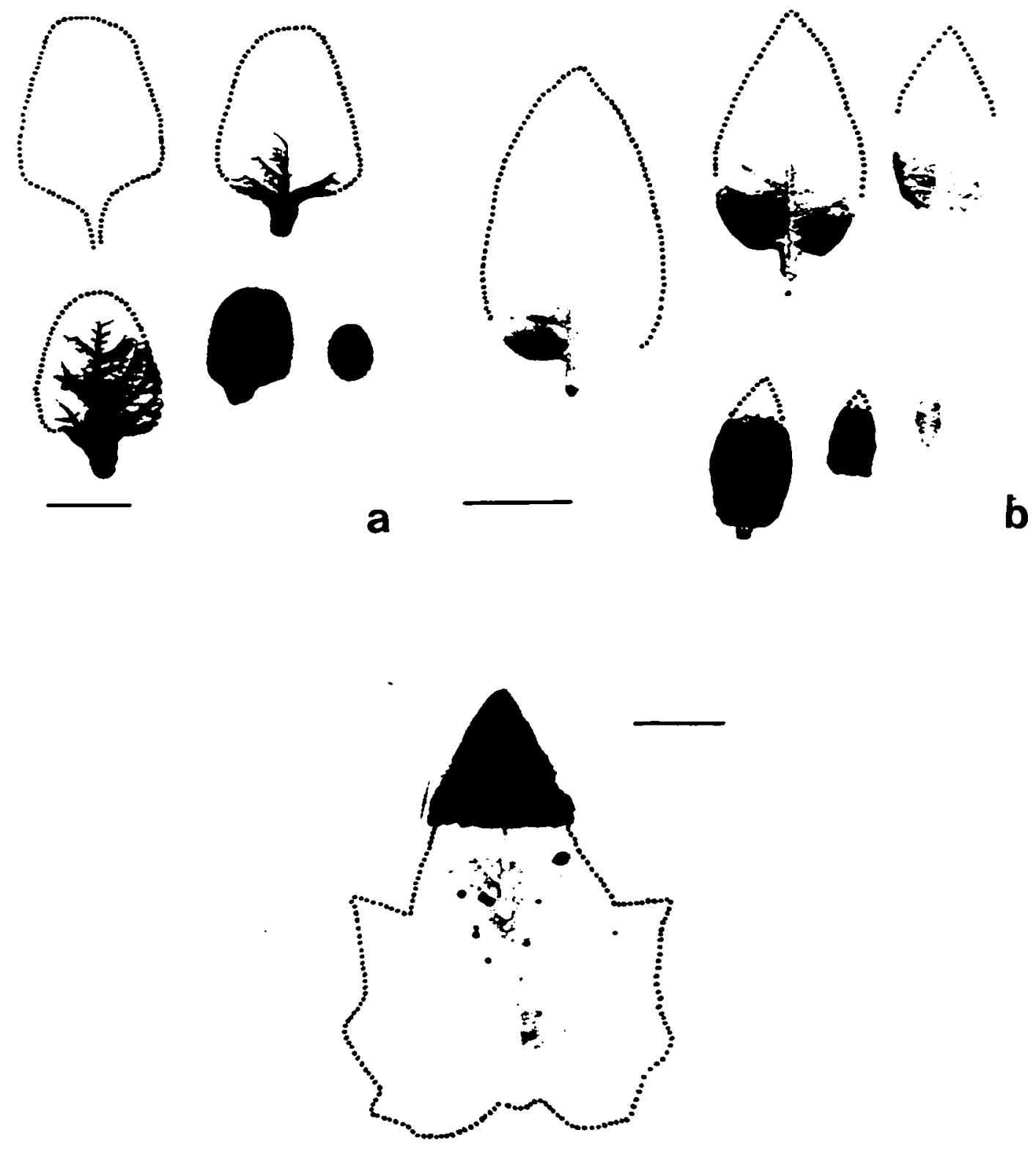

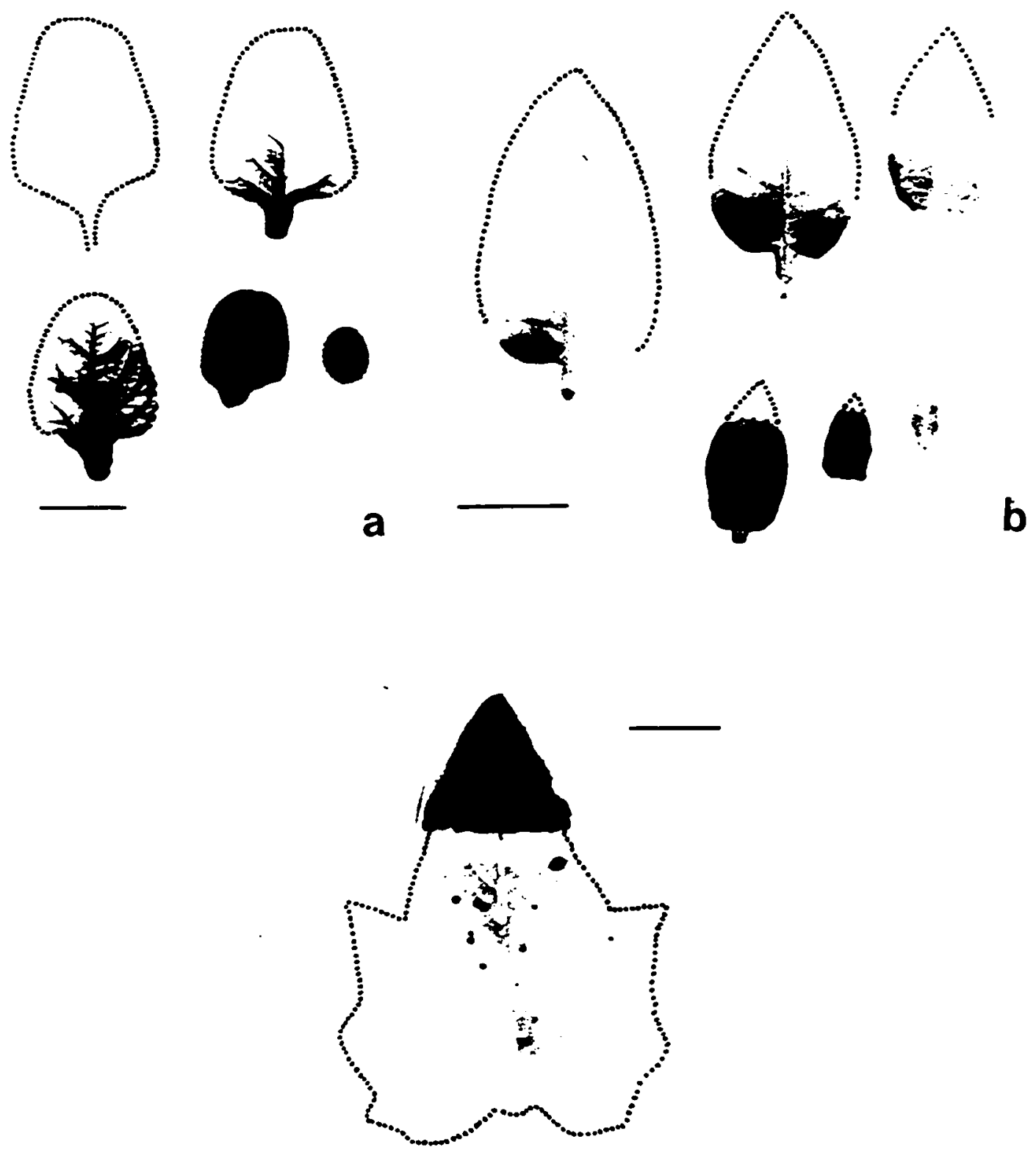
parts: lamina of leaf 5 (fed leaf blade), petiole of leaf 5 all plant parts above leaf 5, roots, and all plant parts between leaf 5 and the roots. In Figure 11 the results, from a total of 40 plants, are expressed as the percentage of total fixed ${ }^{14} \mathrm{C}$ found outside the fed leaf blade with increasing leaf age.

Transport from the leaf blade begins at LPI 1.1 (35\% leaf expansion) and the amount translocated rises sharply before levelling off and again rising at approximately LPI 3.5 (90\% leaf expansion) to a maximum of $50 \%$ of the total ${ }^{14} \mathrm{C}$ fixed.

To determine the amount of material transported to different parts of the plant the amount of ${ }^{14} \mathrm{C}$ in each of the analyzed regions was expressed as a percentage of the total ${ }^{14} \mathrm{C}$ translocated from the fed leaf blade (Fig. 12). When the lamina first begins to export almost all the ${ }^{14} \mathrm{C}$ is recovered from the petiole. The rest of the label is distributed evenly among the other plant parts. By LPI 2.0, when the petiole stops importing from other regions of the plant, the amount of ${ }^{14} \mathrm{C}$ translocated from the leaf blade to the petiole has markedly decreased. From this point on the petiole receives approximately $35 \%$ of the translocated label. There is a gradual trend toward increasing transport upward from leaf 5 while less label is distributed downward. Howthese trends are not statistically significant.

Does the capacity to export develop basipetally in a 
FIG. 11

The amount of ${ }^{14} \mathrm{C}$ translocated from the lamina of leaf 5 of $\mathrm{C}$. pepo in $2 \mathrm{hr}$ expressed as a percentage of the total ${ }^{14} \mathrm{C}$ fixed. Either the entire lamina (•) or just the extreme base of the lamina (o) was allowed to fix ${ }^{14} \mathrm{CO}_{2}$.

FIG. 12

The amount of ${ }^{14} \mathrm{C}$ translocated in $2 \mathrm{hr}$ from lamina 5 of $\underline{C}$. pepo to: petiole 5 $(\bullet)$, above leaf $5(\Lambda)$, between leaf 5 and roots $(a)$, and roots $(0)$. 

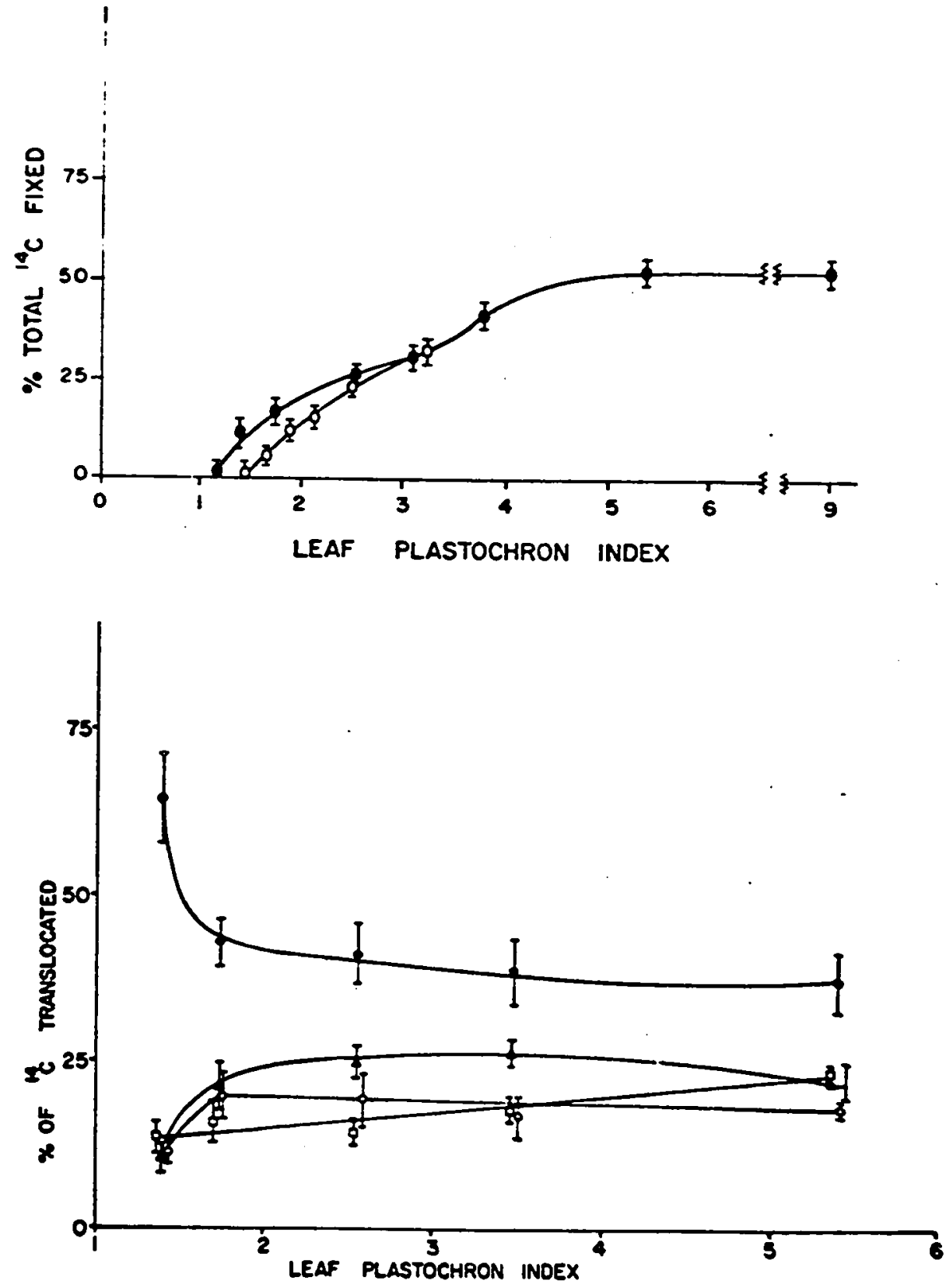
pattern similar to the loss of import ability? If export capacity develops basipetally, covering all but the extreme proximal portion of the lamina, to prevent photosynthetic assimilation of ${ }^{14} \mathrm{CO}_{2}$, should retard the export of ${ }^{14} \mathrm{C}$ until the "front" of development reaches the base of the leaf blade.

To investigate this possibility lamina 5 of 20 plants was covered, except for the extreme base, with aluminum foil secured to the leaf surface with petroleum jelly. In Figure 11 it can be seen that export of ${ }^{14} \mathrm{C}$ from these partially covered leaf blades does not begin until LPI 1.3. This lag strongly suggests that export ability must develop basipetally following closely in pattern the loss of import capacity.

\section{Translocation Within}

the Lamina

Examination of Figure 6 and Figure 11 indicates that export from the leaf blade begins at LPI 1.1 although import by the leaf tip ceases much earlier at LPI 0.3. This suggests a lag period of approximately 0.8 plastochrons (2 days) between the end of the import period and the beginning of export at the leaf tip. At the leaf base, on the other. hand, export immediately follows loss of import capacity (LPI 1.3).

However, during the period between the cessation of 
import at the leaf tip and the beginning of export from the lamina, the base of the lamina is still importing. During this period material may be exported from the leaf tip only to be assimilated by the importing lamina base, thereby delaying export from the leaf blade.

Two experiments were designed to reveal possible transport from the distal to the proximal region of nonexporting leaf blades. In the first experiment ${ }^{14} \mathrm{CO}_{2}$ was applied locally to the leaf tip by covering the base of the leaf with aluminum foil held securely to the leaf surface with petroleum jelly and leaving only the tip of the leaf exposed. ${ }^{14} \mathrm{CO}_{2}$ was presented to the leaf for 1 min and 2 min later the aluminum foil was removed. Two hr later the leaf blade was excised, frozen and autoradiographed for 11 days.

Autoradiographs of leaves as young as LPI 0.7 showed significant ${ }^{34} \mathrm{C}$ label in the midrib and lamina of the basal region indicating export from the leaf tip (Fig. 10). In control experiments the portion of the lamina which had not been fed ${ }^{14} \mathrm{CO}_{2}$ was covered with crushed ice during the $2 \mathrm{hr}$ translocation period. In these experiments no transport of ${ }^{14} \mathrm{C}$ could be detected indicating that the movement of ${ }^{14} \mathrm{C}$ occurs in the phloem (Webb, 1970).

In a second experiment it was reasoned that removal of basal, importing mesophyll tissue might induce precocious transport out of otherwise non-exporting leaves. Ten plants 
were chosen in which the age of leaf 5 was between LPI 0.2 and 1.0. All the basal mesophyll tissue and major lateral veins were removed from leaf 5 with a razor blade leaving only the tip of the leaf distal to the upper leaf lobes intact and attached to the petiole by the undisturbed midrib. These leaves were offered ${ }^{14} \mathrm{CO}_{2}$ for $5 \mathrm{~min}$ and after $2 \mathrm{hr}$ the amount of ${ }^{14} \mathrm{C}$ exported from the leaf blades was measured.

Leaves as young as LPI 0.8 exported significant though small amounts of ${ }^{14} \mathrm{C}$. Six leaves between the ages of LPI 0.8 and 1.0 exported $9.3 \pm 3.4 \%$ of the total ${ }^{14} \mathrm{C}$ fixed. Unaltered leaves of identical age did not export more than $0.7 \%$ of the total ${ }^{14} \mathrm{C}$ fixed. These experiments clearly indicate that transport from the tip to the base of the lamina occurs prior to export from the leaf blade.

\section{B. CARBON BALANCE OF THE DEVELOPING LEAF}

Carbon moves into and out of a leaf in a limited number of ways. A young importing leaf receives carbon from mature parts of the plant. As photosynthetic capacity develops and growth diminishes less carbon is imported. Carbon is lost by respiration and, in older leaves, exported from the leaf.

The carbon balance of a developing or mature leaf over a $24-\mathrm{hr}$ period is described by the following equation 
Photosynthesis = Respiration + Growth \pm Translocation

where photosynthesis is net carbon assimilated during the light period, respiration is total carbon respired during the night period, growth is the increase in weight of carbon over a $24-\mathrm{hr}$ period and translocation is the weight of carbon either imported $(-)$ or exported $(+)$. Note that growth is defined here in a general way as an increase in the weight of carbon without regard for its distribution into various compounds within the leaf. Further, it should be noted that night respiration is defined as the $\mathrm{CO}_{2}$ released during the 6-hr night period. Night respiration is not to be confused with dark respiration during the day which is measured by turning the lights off during the light period.

In the following experiments net photosynthesis and night respiration of plants grown in a controlled environment cabinet were measured with an infra-red gas analyzer, growth was measured by increase in dry weight and the amount of carbon translocated was calculated from the above equation. An independent check was placed on the accuracy of the work by comparing the point of transition from import to export as determined by considerations of carbon balance and ${ }^{24} \mathrm{C}$ displacement studies.

As an excess of carbon becomes available, due to increasing photosynthesis and declining growth and respiration, export from the leaf begins. Excess carbon is removed from the leaf, mostly in the form of selected sugars. An 
experiment was conducted to determine, as closely as possible, when these translocation sugars are first synthesized.

A preliminary series of experiments, similar to those described in the previous section on greenhouse grown plants, were performed on plants grown in the growth cabinet. In some experiments leaf 3 received ${ }^{14} \mathrm{CO}_{2}$ and after $2 \mathrm{hr}$ of translocation leaf 5 was frozen and autoradiographed. In other experiments leaf 5 was supplied ${ }^{14} \mathrm{CO}_{2}$ and ${ }^{14} \mathrm{C}$ displacement was measured. These experiments confirmed the earlier work conducted with the greenhouse grown plants. In addition, there was no significant difference in the relationships between LPI and leaf development between the two growth conditions. Import ceased at the lamina tip at LPI 0.3 and at the lamina base at LPI 1.3. Export from the lamina began at LPI 1.1 .

\section{Leaf Growth}

Since the carbon balance was calculated over a $24-\mathrm{hr}$ period it was necessary to know the relationship between LPI and time. This relationship was determined by daily measurements of petiole length of selected plants grown either in the greenhouse or the growth cabinet. The length of petioles just longer and shorter than $30 \mathrm{~mm}$ were measured with a millimeter ruler with minimal disturbance to the plants. Al1 measurements were made at noon. 
The growth patterns of 2 typical plants are plotted in Figure 13. From PI 4-10, PI is linearly related to time. Plants raised in the growth cabinet grow faster than those raised in the greenhouse. In March the mean growth rate of 5 greenhouse grown plants was 2.12 days per plastochron between PI 4 and 7 . Twelve plants raised in the growth cabinet in April grew at a mean rate of 1.62 days per plastochron between PI 4 and 7 .

The growth of leaf 5 of plants raised in the growth cabinet was studied more closely. Measurements were made of lamina area, fresh weight and dry weight. Petiole length was also measured. The area of lamina 5 increases in a sigmoid fashion to a maximum of $130 \mathrm{~cm}^{2}$ at approximately LPI 4 (Fig. 14). A curve obtained for plants grown in the greenhouse is similar (Fig. 14) although leaf 5 reaches a maximum area of $200 \mathrm{~cm}^{2}$.

The increase in dry weight of lamina 5 closely para11 els increase in area. Slow growth up to LPI 0.0 is followed by a rapid increase in dry weight and a slow levelling off beginning at approximately LPI 1.0 (Fig. i5). The dry weight / fresh weight ratio of lamina 5 remained constant at $13.3 \%$ from LPI 0.0 to 4.0 .

Petiole length increases in a complex fashion (Fig. 16). Initial increase in length parallels closely the pattern of lamina growth. As the lamina reaches full expansion (approximately LPI 4) growth in petiole length at first 
FIG. 13

Growth rate of 2 C. pepo plants, one grown in the greenhouse (•), the other in the growth cabinet (o).

FIG. 14

Area of lamina 5 of $\underline{\text { C. pepo, }}$

grown either in the greenhouse $(\bullet)$ or growth cabinet (o), plotted against leaf age. 

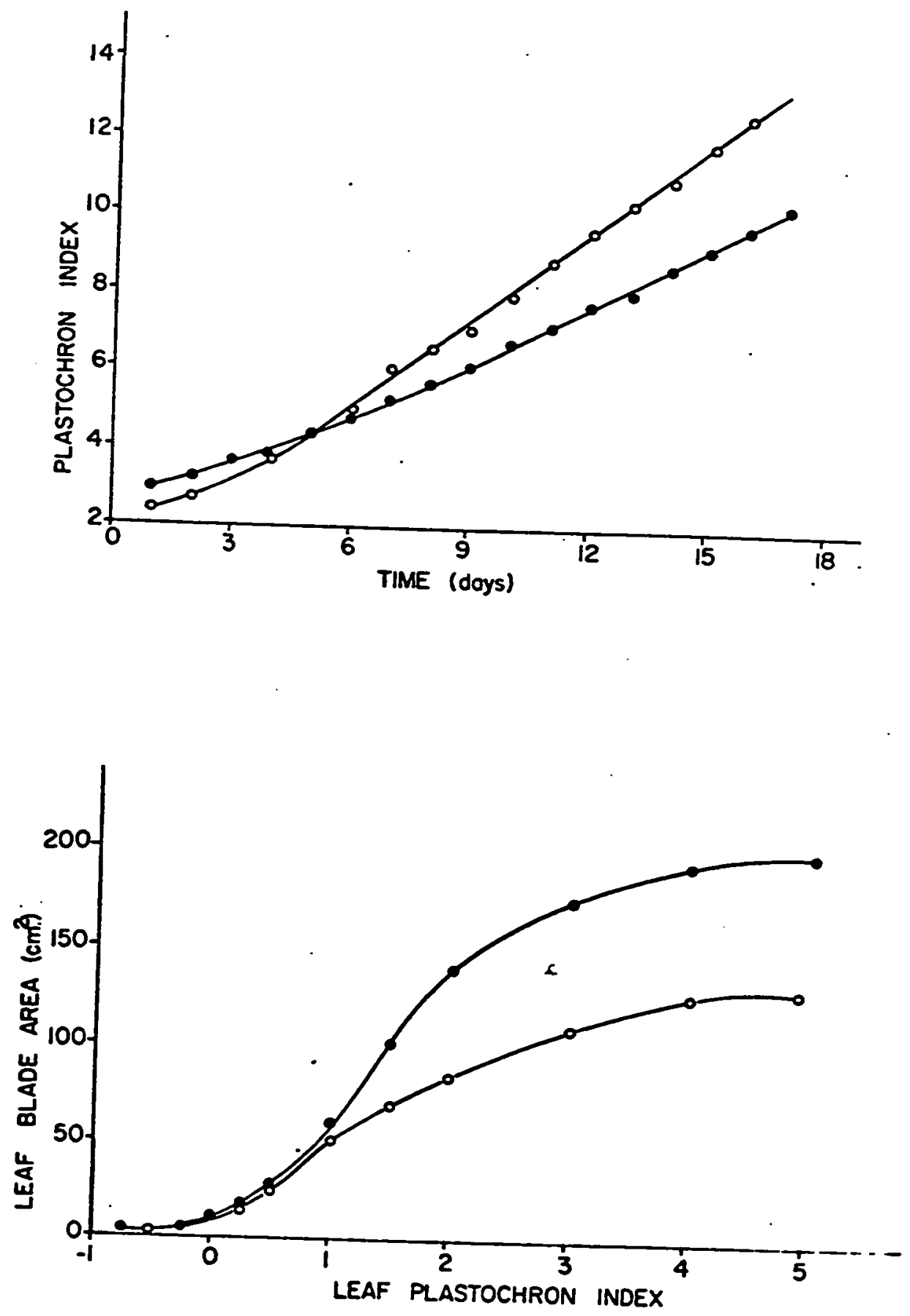
FIG. 15

Dry weight increase of lamina 5 of . pepo plants grown in the growth cabinet.

FIG. 16

Increase in length of petiole 5 of . . pepo plants grown in the growth cabinet. Note change of scale on abscissa. 

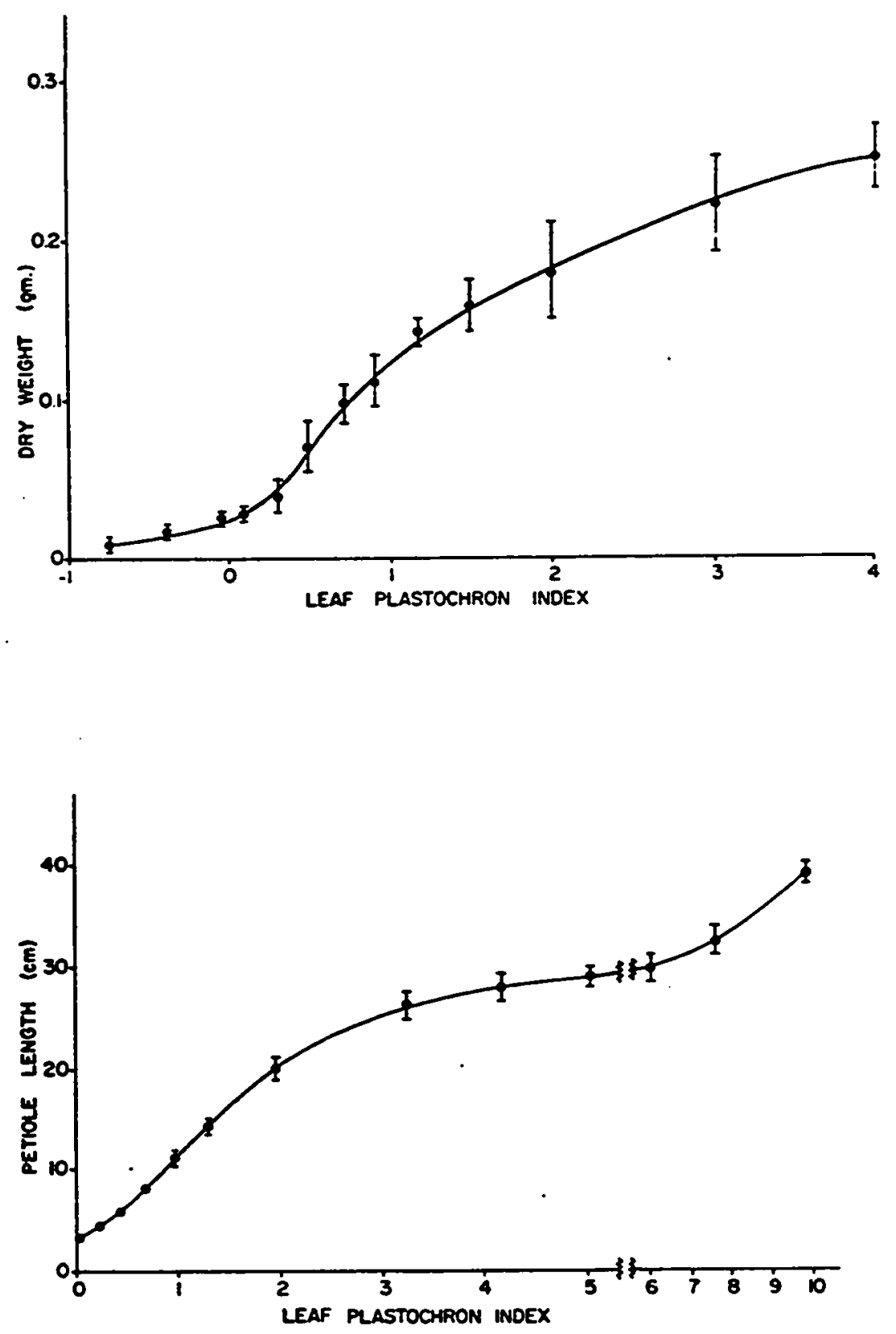
decreases, then begins again and continues slowly until at least LPI 10.

II. Growth Inhibition by Mechanical Stress

The first observations on the growth of squash plants were made by measuring certain parameters of growth of individual selected greenhouse grown plants at daily intervals. Measurements of petiole length were taken with a millimeter ruler and the areas of leaf blades were obtained by planimetric analysis of leaf tracings taken from intact plants. It was soon apparent that plants subjected to these daily measurements were shorter than comparable plants of the same age which had not been measured. Apparently growth was inhibited by the physical stress imposed by taking routine measurements.

These observations were confirmed in a study involving 18 plants. On August 19, 1971, 18 seeds were germinated as previously described, planted in individual pots on August 26 and placed in the greenhouse. Plants were spaced evenly in the greenhouse and numbered consecutively. Evennumbered plants were subjected to gentle physical manipulation at noon each day while the alternate plants were left undisturbed. Manipulation consisted of gently shaking each petiole, individually, for $30 \mathrm{sec}$ and lightly stroking the leaf blade with the fingers once across the upper surface. 
New leaves were similarly treated as they unfolded.

Petioles were numbered 1 to 5 consecutively from the primary petiole. Handing of leaves 1 to 5 was begun on August 28, September 4, September 7, September 10 and September 13 respectively. Once begun the treatment of leaves continued until the plants were harvested on September 17. Each plant was cut into the following parts: petioles, leaf blades, shoot, hypocotyl and roots. Measurements were made of length, fresh weight and area. In addition, the volume of petioles was measured by water displacement. At the time of harvest only leaves 1 to 4 were mature. Analyses were restricted to these 4 leaves so that effects on rate of growth and initiation of new leaves would not influence the results.

The lengths and fresh weights of the stems and petioles of the handled plants were significantly less than in controls (Table 3 ) but the handled petioles showed a significant increase in volume per unit length as measured by water displacement (Fig. 17) which indicates an increase in radial growth. The fresh weights of the leaf blades, roots and hypocotyls were unchanged by treatment as were the leaf blade areas and hypocotyl lengths. A photograph of representative plants from the control and handled groups of plants is shown in Figure 28.

The greatest inhibition of petiole growth occurred among those leaves last to unfold and which were therefore 


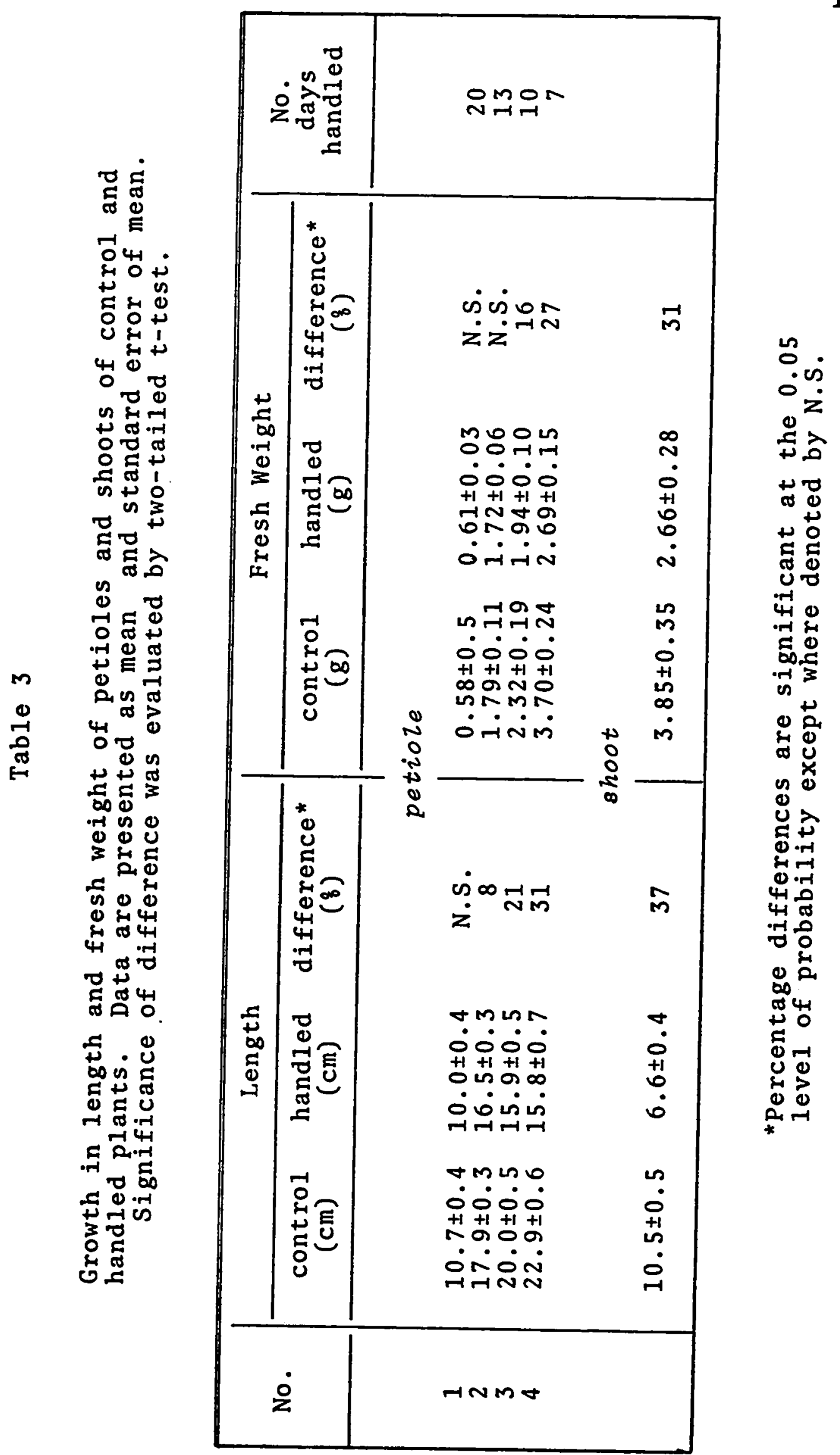


handled least. This suggests that the leaves were at their most sensitive stage before unfolding and that the effect of physical contact was felt by all sensitive regions of the plant, not only by those handled directly.

III. Photosynthesis and Respiration

Al1 plants used for this study were grown in a controlled environment cabinet as described. In a preliminary experiment net photosynthesis, dark respiration (during the day period) and night respiration of a single leaf were measured periodically over a $24-\mathrm{hr}$ period. Plants were chosen in which leaf 5 was fully mature (LPI 4-7). The leaf blade was sealed into the chamber and was not removed until the termination of the experiment. At 3-hr intervals a reading was taken by placing the glass lid on the chamber and recording $\mathrm{CO}_{2}$ flux until equilibrium was attained.

When the level of net photosynthesis had been determined the lights were turned off to obtain a measure of daytime dark respiration. During the night period the lights remained off at all times. When readings were complete the chamber lid was removed.

The results of a representative experiment are plotted in Figure 18. The level of photosynthesis remained constant throughout the day. The level of respiration during the night period remained constant except at the beginning when the leaves respired slightly more. 
FIG. 17

\begin{abstract}
Effect of handing on the ratio of length to volume of petioles of . pepo. Data for petioles 1 to 4 have been combined.
\end{abstract}

FIG. 18

Exchange of $\mathrm{CO}_{2}$, during a 24-hr period, from lamina 5 of a $\underline{C}$. pepo plant grown in the growth cabinet. $(\bullet)$. Values for respiration in the dark during the day period are also included (0). 

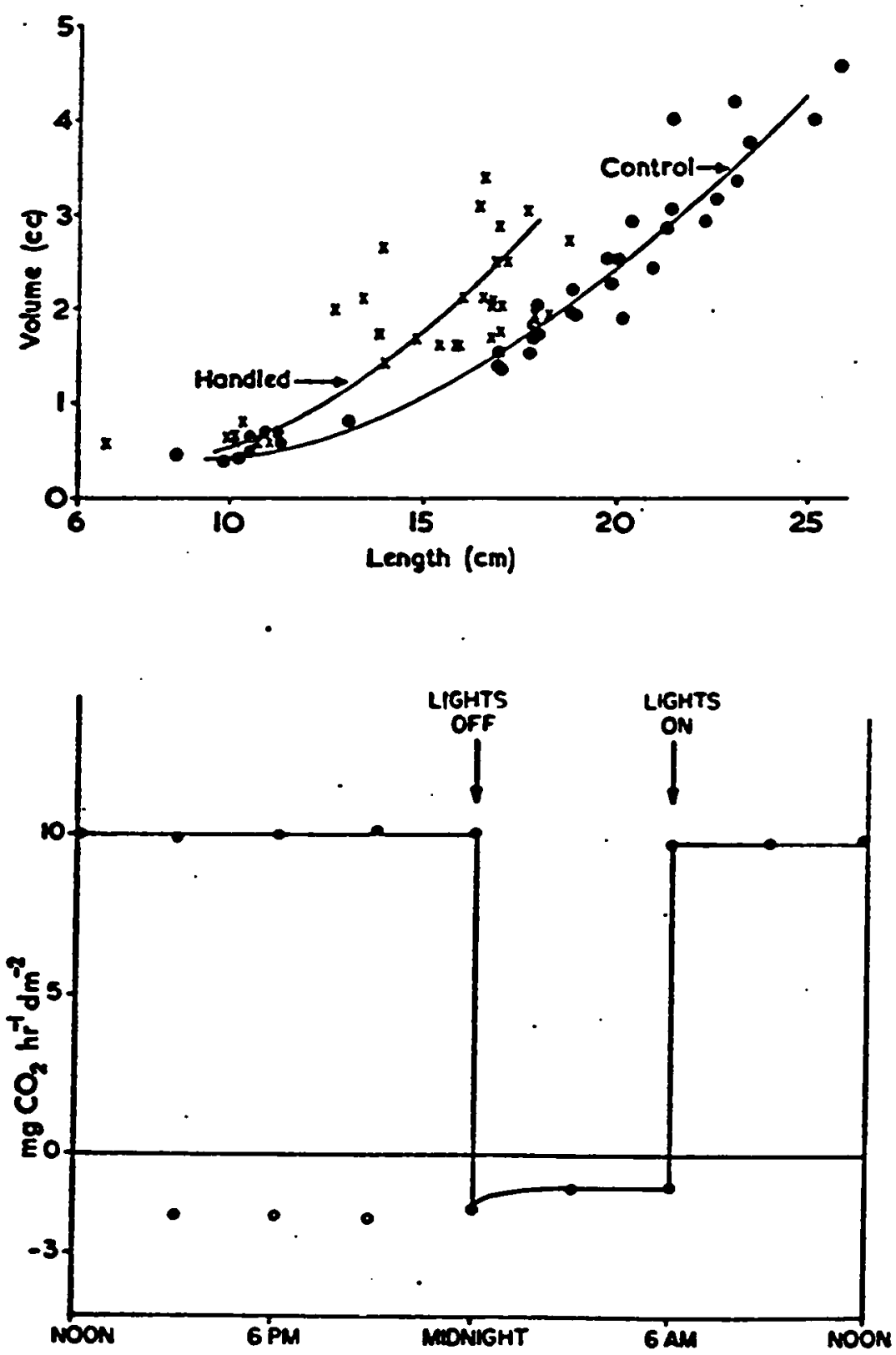
Measurements of dark respiration during the day were consistently greater than night respiration values.

From these experiments it was concluded that reliable measurements of photosynthesis could be taken at any period of the day and that night respiration was best measured after 2:00 a.m.

A large number of measurements of photosynthesis and respiration were made in the controlled environment cabinet with leaves of different ages. In each daytime experiment net photosynthesis and dark respiration values for lamina 5 were obtained. In night experiments respiration alone was measured. Most readings of photosynthesis were taken between 10:00 a.m. and 4:00 p.m. Readings of night respiration were taken between 3:00 a.m. and 5:30 a.m. Upon completion of the experiment the plant was removed from the growth cabinet and values were obtained for LPI, lamina area, lamina fresh and dry weight, and petiole length.

Net photosynthesis is plotted against leaf age in Figure 19. A total of 50 experiments, each on a single plant, are represented. At LPI 0.0 leaf 5 is incapable of net photosynthesis. Approximately $1 \mathrm{mg} \mathrm{CO} \mathrm{hr}^{-1} \mathrm{dm}^{-2}$ of leaf area is lost from these leaves. As the leaf grows photosynthetic capacity increases rapidly. Net photosynthesis begins at approximately LPI 0.1 and reaches a maximum under these conditions of approximately $11 \mathrm{mg} \mathrm{CO}_{2}$ $\mathrm{hr}^{-1} \mathrm{dm}^{-2}$ at LPI 2.0 (70\% leaf expansion). With increasing 
age photosynthetic capacity slowly declines to approximately $8.5 \mathrm{mg} \mathrm{CO} \mathrm{hr}^{-1} \mathrm{dm}^{-2}$ at LPI 7.

Day and night respiration values are also plotted in Figure 19. A total of 20 plants were used in night experiments. Young leaves (IPI 0.0 ) respire approximately $5.5 \mathrm{mg}$ $\mathrm{CO}_{2} \mathrm{hr}^{-1} \mathrm{dm}^{-2}$ in the dark during the day and slightly less at night. As the leaves grow respiration declines and levels off between LPI 1.0 and 2.0. Mature leaves respire $0.75 \mathrm{mg} \mathrm{CO} \mathrm{hr}^{-1} \mathrm{dm}^{-2}$ at night and approximately 3 times this value in the dark during the day.

A short series of experiments were conducted to determine if the distal half of the lamina develops photosynthetic ability prior to the proximal half. Eight leaves between LPI 0.0 and 1.0 were used. Photosynthesis was measured in the usual fashion before and 30 min after the upper half of the lamina had been removed with a razor blade. $\mathrm{CO}_{2}$ fixation by the distal half of the leaf was calculated by subtracting readings obtained for the proximal half from those obtained for the whole leaf. The proximal halves fixed only $62 \pm 16 \%$ of the $\mathrm{CO}_{2}$ per unit area that the distal halves fixed. As a control the leaf was severed in the same way without cutting the midrib and removing the distal half of the lamina. This treatment did not significantly affect readings of net photosynthesis. 
IV. Development of Intercellular Spaces

Since intercellular spaces are necessary for the distribution of $\mathrm{CO}_{2}$ to the mesophyll cells, an experiment was conducted to correlate the development of photosynthetic capacity with the appearance of air spaces in the leaf. Sixteen plants were chosen in which the age of leaf 5 was between LPI 0-4. Samples were removed from the distal and proximal regions of lamina 5 (as described below in the experiment on leaf minor vein development), fixed and embedded in Epon-Araldite as for electron microscopy. Transections of leaf blades were cut $1 \mu$ thick on glass knives, placed on slides and stained with methylene blue. Photographs were taken of regions of mesophyll free from all vascular tissue including minor veins. Photographic negatives were enlarged to approximately $20 \mathrm{~cm} \times 15 \mathrm{~cm}$ and printed. Intercellular spaces and cells, including the epidermis, were carefully cut from the photographs with a razor blade and weighed. Dividing the weight of paper representing intercellular spaces by that representing both intercellular spaces and cells gave the percentage volume of leaf tissue occupied by air spaces. This value is plotted against leaf age in Figure 20.

Air spaces develop at the same time that photosynthetic capacity rapidly increases (compare Figs 19 and 20). In a mature leaf approximately $22 \%$ of the volume of 
FIG. 19

\begin{abstract}
Net photosynthesis (•), night respiration ( $\mathbf{A}$ ), and dark daytime respiration (o) of lamina 5 of C. pepo plants plotted against leaf age.
\end{abstract}

FIG. 20

Development of intercellular spaces in the distal (•) and proximal (o) regions of developing leaves of $\underline{C}$. pepo. Air spaces were calculated as a percentage of the volume of leaf tissue (excluding vascular tissue). 

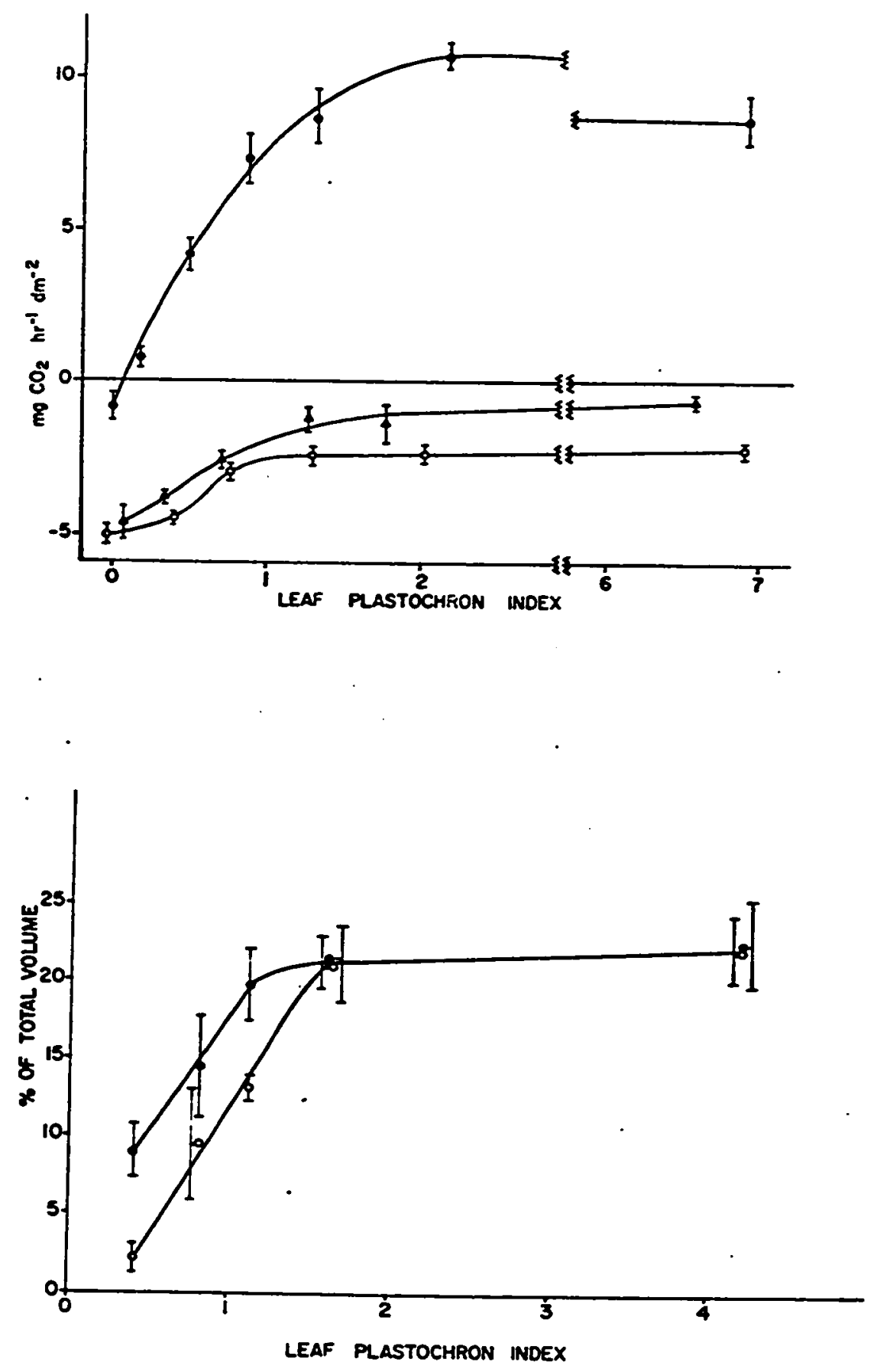
the leaf (excluding vascular tissue) is comprised of intercellular spaces.

\section{Carbon Balance}

Values obtained for net photosynthesis by infra-red gas analysis (Fig. 19) were converted to give a measure of the weight of carbon fixed by the whole lamina over an $18-\mathrm{hr}$ period ( $1 \mathrm{mg} \mathrm{CO} 2$ contains $0.273 \mathrm{mg} \mathrm{C}$ ). Similarly the weight of carbon lost during the 6-hr night period was calculated.

Values for the increase in weight of carbon in 0.1 plastochron intervals were obtained from Figure 15, assuming the dry weight to be $45 \%$ carbon (Stout, 1961). Each 0.1 plastochron increment in growth was multiplied by 6.17 to give values of growth per day since plants grow 0.617 plastochrons in 1 day in the growth cabinet.

Values so obtained are first differentials since they measure the rate of carbon flux over a $24-\mathrm{hr}$ period as time $\rightarrow 0$. The value obtained for net photosynthesis for an 18-hr period is the same as that for a $24-\mathrm{hr}$ period since there is no photosynthesis during the 6-hr night. The same argument applies for night respiration; the amount of carbon respired during the $6-\mathrm{hr}$ night equals the total amount released by night respiration during a $24-\mathrm{hr}$ period.

The balance sheet obtained by the above calculations is presented graphically in Figure 21. At LPI 0.0 all carbon is brought into the leaf by translocation. As growth 
continues, photosynthetic capacity increases. The quantity of carbon translocated into the leaf increases until the growth rate peaks, when it falls sharply. At approximately LPI 0.8 the contributions of photosynthesis and translocation to the influx of carbon into the leaf are equal. Translocation into the leaf (import) stops at LPI 1.1 and translocation out of the leaf (export) begins. This is in close agreement with the beginning of export of ${ }^{14} \mathrm{C}$ photoassimilates (Fig. 11).

As growth declines the amount of carbon exported from the leaf blade approaches that fixed by net photosynthesis. When growth ceases the amount of carbon translocated is equal to that fixed minus the almost negligible carbon respired during the night.

If the values plotted in Figure 21 are divided by the weight of the leaf, equation (1) becomes

$\frac{\text { Photosynthesis }}{\text { Weight }}=\frac{\text { Respiration }}{\text { Weight }}+\frac{\text { Growth }}{\text { Weight }} \pm \frac{\text { Translocation }}{\text { Weight }}$

If the weight of the leaf is expressed in $\mathrm{mg}$ of carbon the weight units cancel and an expression of relative or percentage carbon flux is obtained. For example, if the instantaneous rate of carbon fixation of a leaf containing $0.5 \mathrm{mg}$ carbon is $0.25 \mathrm{mg}$ carbon per 18 (or 24) $\mathrm{hr}$ the relative amount of carbon fixed is $50 \%$ in an 18-( or 24-) $\mathrm{hr}$ period. Relative values so obtained are a measure of the "intensity" of carbon flux, i.e. the ability of a unit 
weight of leaf material to add or remove carbon. It should be noted that the growth factor in equation (2) may also be written $\frac{d W}{d t} \frac{1}{W}$ which is Blackman's Efficiency Index (Blackman, 1919), a well-known index of relative growth intensity.

In Figure 22 each factor in equation (2) is plotted. Growth intensity reaches a peak of 1.55 (155\% increase in carbon over a 24-hr period) at LPI 0.3. Relative translocation closely parallels relative growth between LPI 0.0 and LPI 0.5 , reflecting the intimate relationship between these two functions. As relative photosynthesis increases the close relationship between growth and translocation becomes less apparent. When relative photosynthesis equals relative growth plus relative night respiration, import into the leaf ceases and export begins. As relative growth decreases to zero relative translocation approaches relative photosynthesis (55\% of leaf carbon in $24 \mathrm{hr}$ ) minus the negligible value of relative night respiration.

of particular interest is the fact that relative growth is closely correlated with loss of import capacity. Relative growth peaks at LPI 0.3 and declines rapidly until approximately LPI 1.3 when the decline tapers off and becomes more gradual. It is during this period between LPI 0.3 and 1.3 that import capacity is lost (Fig. 6). The correlation between loss of import capacity and absolute rate of growth as measured by dry weight increase is not as clear (Fig. 21). 
FIG. 21

Carbon balance, over a 24-hr period, of lamina 5 of $\mathrm{C}$. pepo plants. Values for photosynthesis and night respiration were calculated for $18-\mathrm{hr}$ and $6-$ hr periods respectively.

FIG. 22

Relative carbon balance, over a $24-\mathrm{hr}$ period, of lamina 5 of $\underline{c}$. pepo. Values for carbon flux have been divided by the weight of carbon in the lamina. 

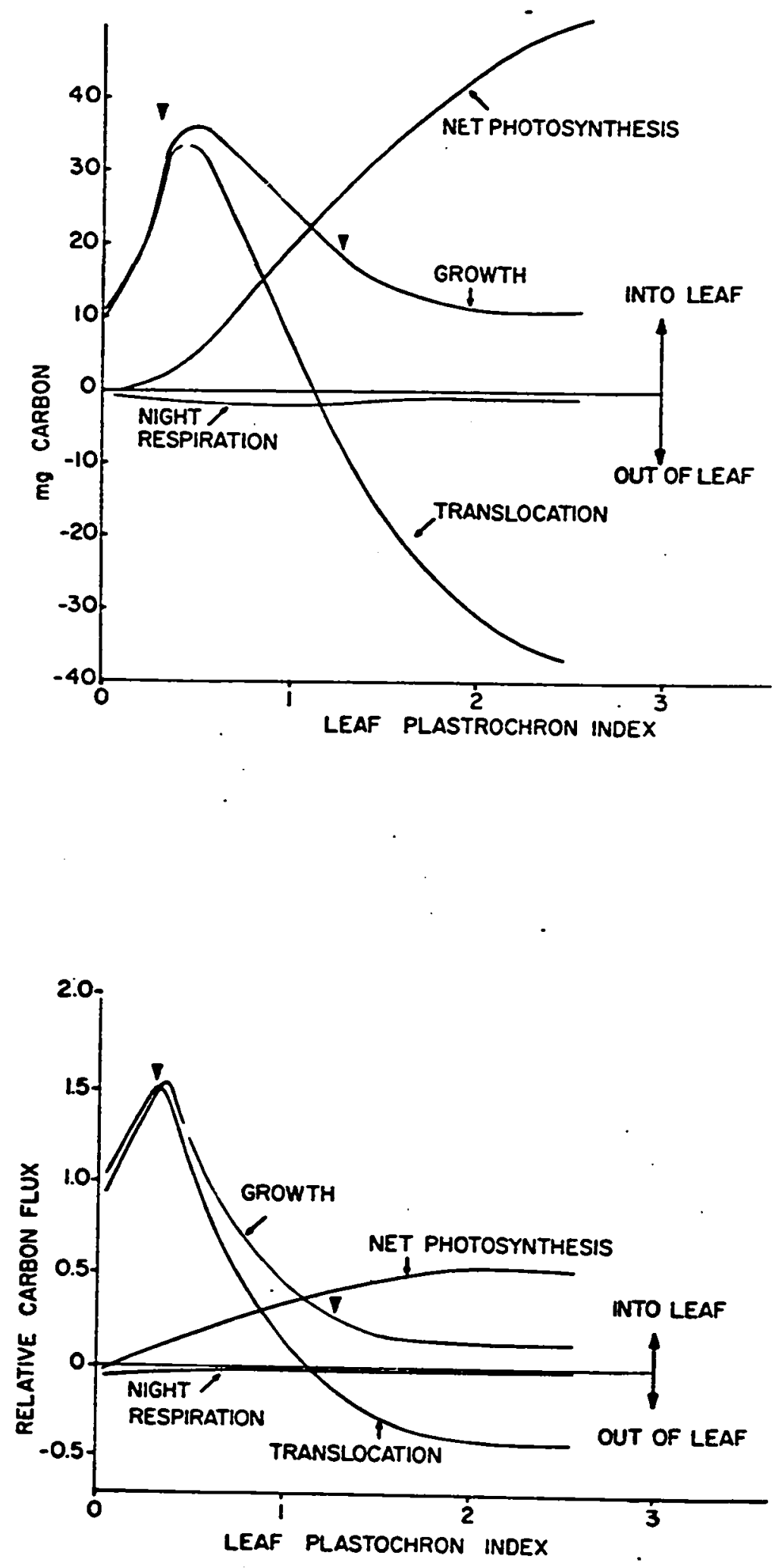


\section{Sugar Synthesis}

Carbon is imported and exported from leaves primarily as sugar. It was of interest therefore to examine the synthesis of certain sugars, especially the transport sugars sucrose, stachyose and raffinose, as the leaf matures. Webb and Gorham (1964) found that stachyose was labelled with ${ }^{14} \mathrm{C}$ following a ${ }^{14} \mathrm{CO}_{2}$ pulse when primary leaves began to export, but not before. By using the LPI to establish leaf age it was hoped that a more precise estimate could be made of the stage of leaf development when stachyose and raffinose are first synthesized. The incorporation of ${ }^{14} \mathrm{C}$ into certain other sugars was examined to determine their possible involvement in stachyose and raffinose synthesis. Lamina 5 of 20 plants of different ages were excised and fed ${ }^{14} \mathrm{CO}_{2}$ continuously for $5 \mathrm{~min}$. This time period was chosen because maximum incorporation of ${ }^{14} \mathrm{C}$ into stachyose and sucrose occurs approximately 5 min after ${ }^{14} \mathrm{CO}_{2}$ application (Webb and Gorham, 1964).

Each leaf blade was divided into distal and proximal halves prior to extraction and each half was analyzed separately. The procedure for the extraction and analysis of sugars is described in Materials and Methods. The leaves were extracted twice in hot $80 \%$ ethanol. The insoluble residues were combusted and the evolved ${ }^{14} \mathrm{CO}_{2}$ counted. The soluble extract was purified by ion-exchange chromatography and the neutral fraction chromatographed to determine the 
amount of ${ }^{14} \mathrm{C}$ in each of 7 sugars and related compounds. ${ }^{14} \mathrm{C}$ analyses were made at each step in the procedure to determine the percentage of label incorporated into each fraction.

In general the distal halves of leaves between the ages of LPI 0.0 and 1.0 were more advanced than the proximal halves, as would be expected. For example, the distal half of one leaf (LPI 0.8 ) synthesized ${ }^{14} \mathrm{C}$-stachyose, ${ }^{14} \mathrm{C}$ raffinose, and ${ }^{14} \mathrm{C}$-galactinol although these compounds could not be detected in the proximal half. However, due to the variability between samples these differences were not often statistically significant and the data from the two halves of each leaf were pooled.

The proportion of ${ }^{14} \mathrm{C}$ incorporated into ethanol soluble and ethanol insoluble fractions was determined by measuring the total activity in the ethanol extract and in the combusted insoluble residue. As leaf 5 matures an increasing proportion of ${ }^{14} \mathrm{C}$ is incorporated into the insoluble fraction (Fig. 23). This result was unexpected for two reasons. A similar analysis of leaves which had received a 5 min pulse but were allowed to continue photosynthesis in unlabelled $\mathrm{CO}_{2}$ for $2 \mathrm{hr}$ showed the opposite pattern--high incorporation into insoluble material in young leaves and relatively little in older leaves (Fig. 23). Secondly, the synthesis of cell wall material and other high molecular weight compounds is expected to be greatest in 
young leaves and least in older leaves.

This unexpected pattern might reflect an increasing capacity for rapid starch synthesis as the leaf matures. To test this possibility starch was solubilized and then precipitated from dried ethanol insoluble residues of leaves which had been exposed to ${ }^{14} \mathrm{CO}_{2}$ for $5 \mathrm{~min}$.

Two leaves were used and triplicate determinations of total ethanol insoluble ${ }^{14} \mathrm{C}$ and ${ }^{14} \mathrm{C}$-starch were made. The age of the first leaf was LPI $1.4 ; 28 \%$ of the ${ }^{1{ }^{4}} \mathrm{C}$ in this leaf following a 5 min exposure to ${ }^{14} \mathrm{CO}_{2}$ was ethanol insoluble. The age of the second leaf was LPI 3.4 ; it contained 49\% ethanol insoluble ${ }^{14} \mathrm{C}$.

Samples of the dried insoluble residues were carefully weighed and extracted with perchloric acid by the technique of McCready et al. (1950). The starch content was measured by counting the ${ }^{14} \mathrm{C}$ in the extracts before and after precipitating the starch with I-KI (Pucher et al., 1948).

Perchloric acid extracted over $92 \%$ of the ${ }^{14} \mathrm{C}$ from the insoluble residues of both leaves. I-KI precipitation removed $34 \%$ of the ${ }^{14} \mathrm{C}$ from the perchloric acid extract of the older leaf but none from the extract of the younger leaf. Apparently the younger leaf did not synthesize ${ }^{14} \mathrm{C}-\mathrm{starch}$ but in the older leaf approximately $34 \%$ of the ${ }^{14} \mathrm{C}$ not incorporated into ethanol soluble compounds was incorporated into starch. 
Samples of the ethanol extract were assayed for ${ }^{14} \mathrm{C}$ before and after purification by ion-exchange resins to determine the percentage of soluble ${ }^{14} \mathrm{C}$ which is incorporated into the neutral fraction. The results are plotted against leaf age in Figure 24. At LPI $0.66 .4 \%$ of the soluble ${ }^{14} \mathrm{C}$ was in the neutral fraction and this percentage rose linearly with time to $27 \%$ at LPI 4.0 .

The neutral fraction of each leaf extract was taken to dryness, redissolved in a small amount of water and chromatographed as described in Materials and Methods. Seven sugars and related compounds were identified: stachyose, raffinose, sucrose, galactinol, myo-inositol, glucose and fructose.

The amount of ${ }^{14} \mathrm{C}$ in individual sugars and related compounds was expressed as a percentage of the total:14 $\mathrm{C}$ in the neutral fraction. These results are plotted against leaf age in Figures 25 and 26. Sucrose becomes labelled with ${ }^{14} \mathrm{C}$ even in very young leaves as does myo-inositol and the two hexose sugars. At approximately LPI 0.6 stachyose, raffinose and galactinol are first detected and the percentage of these compounds in the neutral fraction rises rapidly by LPI 1.0. The amount of labelled stachyose rises until approximately LPI 3.0 when it falls off slightly. The percentage of labelled raffinose begins to fall off at LPI 1.5 . Incorporation of ${ }^{14} \mathrm{C}$ into sucrose at first drops as stachyose and raffinose become labelled and then rises 
FIG. 23

Percentages of total fixed ${ }^{14} \mathrm{C}$ recovered in the ethanol insoluble fraction of lamina 5 of $\mathrm{C}$. pepo plants which had been exposed to ${ }^{14} \mathrm{CO}_{2}$ for $5 \mathrm{~min}$ and frozen immediately (o) or $2 \mathrm{hr}$ later $(\bullet)$.

FIG. 24

${ }^{14} \mathrm{C}$ in the neutral fraction expressed as a percentage of the total ethanol soluble ${ }^{14} \mathrm{C}$. Lamina 5 of $\mathrm{C}$. pepo plants was exposed to ${ }^{14} \mathrm{CO}_{2}$ for $5 \mathrm{~min}$. 

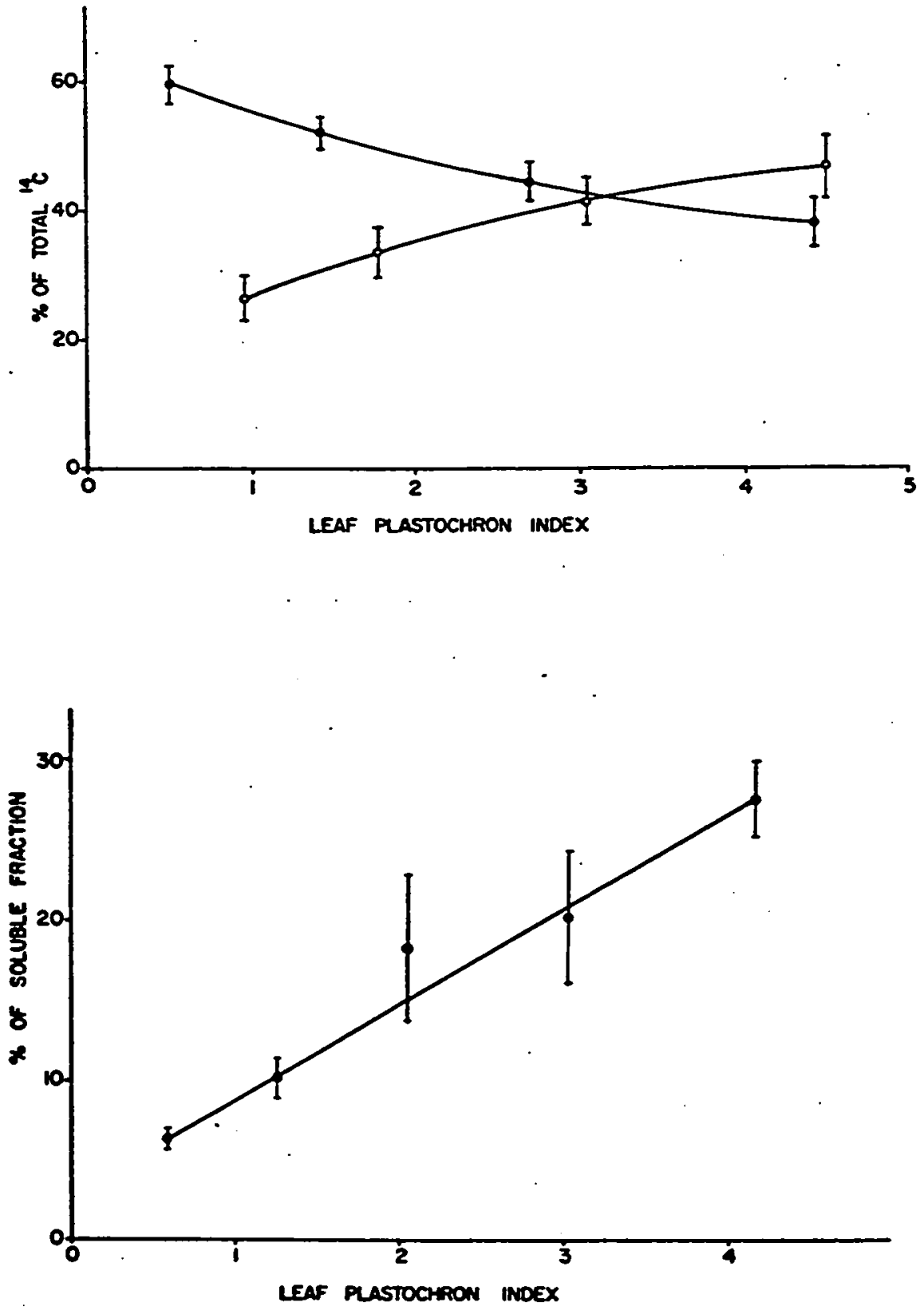
FIG. 25

Amount of ${ }^{14} \mathrm{C}$ in the translocation sugars, sucrose (0), stachyose (•) and raffinose ( 1 ), expressed as a percentage of the total ${ }^{14} \mathrm{C}$ in the neutral fraction. Lamina 5 of $\underline{\text {. }}$. pepo plants was exposed to ${ }^{14} \mathrm{CO}_{2}$ for $5 \mathrm{~min}$.

FIG. 26

Amount of ${ }^{14} \mathrm{C}$ in galactinol $(\bullet)$, myo-inositol (0), glucose ( 1 ) and fructose ( $(0)$, expressed as a percentage of the total ${ }^{14} \mathrm{C}$ in the neutral fraction. Lamina 5 of $\underline{\mathrm{c}}$. pepo plants was exposed to ${ }^{14} \mathrm{CO}_{2}$ for $5 \mathrm{~min}$. 

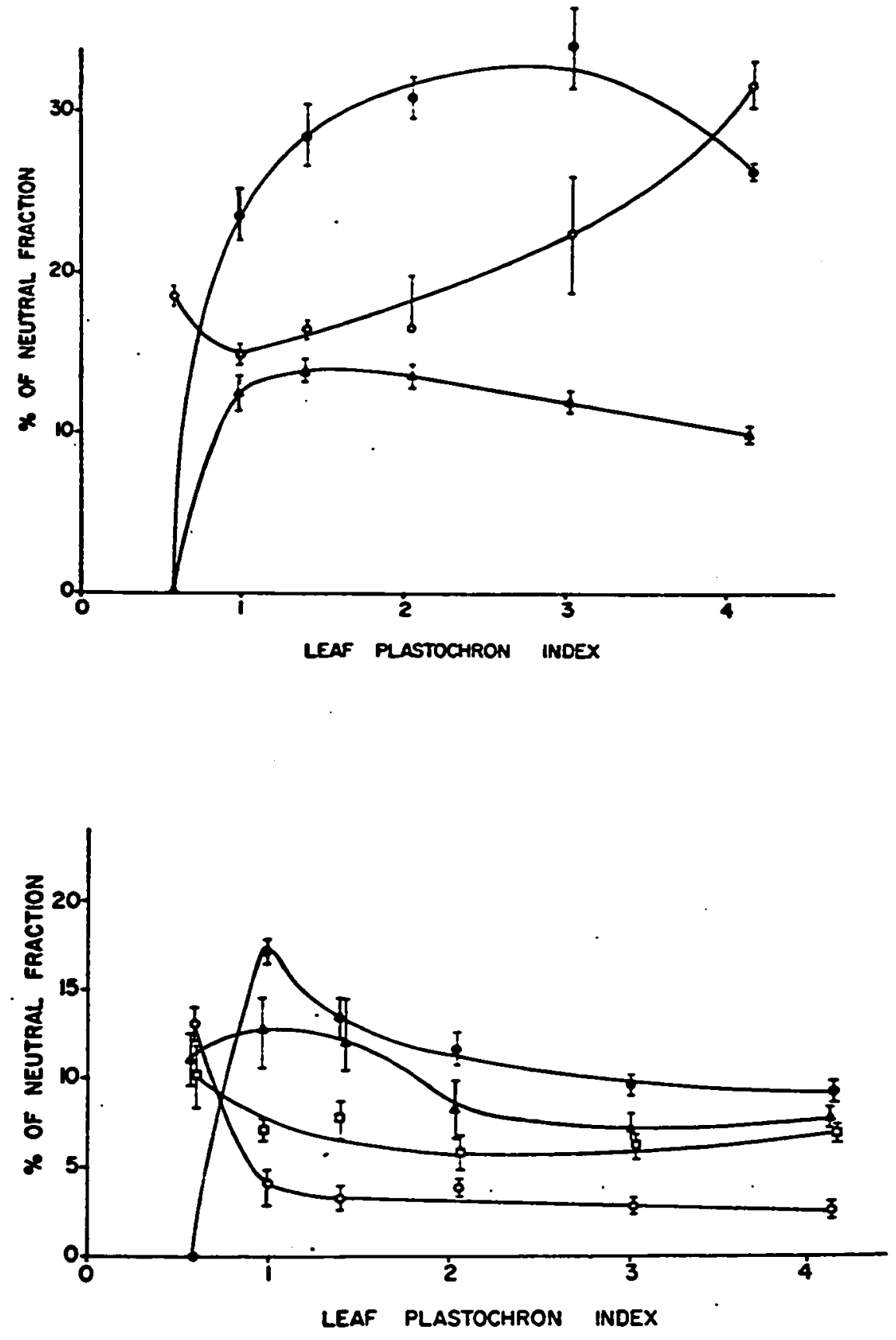
steadily with time. The percentage activity in myo-inositol drops rapidly in sharp contrast with the pattern for galactinol which is similar to that of stachyose and raffinose.

At LPI $0.656 \pm 6 \%$ of the ${ }^{14} \mathrm{C}$ in the neutral fraction is found in the 7 compounds analyzed (Figs 25 and 26). This percentage rises rapidly and in leaves older than LPI 1.0 over $90 \%$ of the ${ }^{14} \mathrm{C}$ in the neutral fraction is found in these compounds. No effort was made to identify unknowns from younger leaves although it was noticed that 15 to $30 \%$ of the ${ }^{14} \mathrm{C}$ activity remained at the origin suggesting perhaps that many of these compounds were low molecular weight polysaccharides.

Although the amount of labelled stachyose, raffinose and galactinol falls in older leaves when expressed as a percentage of the neutral fraction, this drop is made up by the increasing size of the neutral fraction. When plotted as a percentage of the total ${ }^{14} \mathrm{C}$ fixed by the leaf (Fig. 27) there is little or no decrease in the level of these compounds as the leaf grows.

\section{MICRO-AUTORADIOGRAPHY OF ${ }^{14} \mathrm{C}$ FOLLOWING ${ }^{14} \mathrm{CO}_{2}$ FIXATION}

Micro-autoradiography is an obvious approach to the study of vein loading. It might be possible by this technique to identify the path of movement of ${ }^{14} \mathrm{C}$-1abelled 
FIG. 27

Amount of ${ }^{14} \mathrm{C}$ in stachyose (•), raffinose

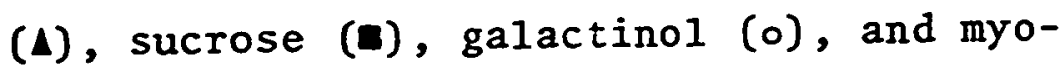
inositol $(\Delta)$, expressed as a percentage of the total ${ }^{14} \mathrm{C}$ fixed by the leaf during a 5 min exposure to ${ }^{14} \mathrm{CO}_{2}$. 


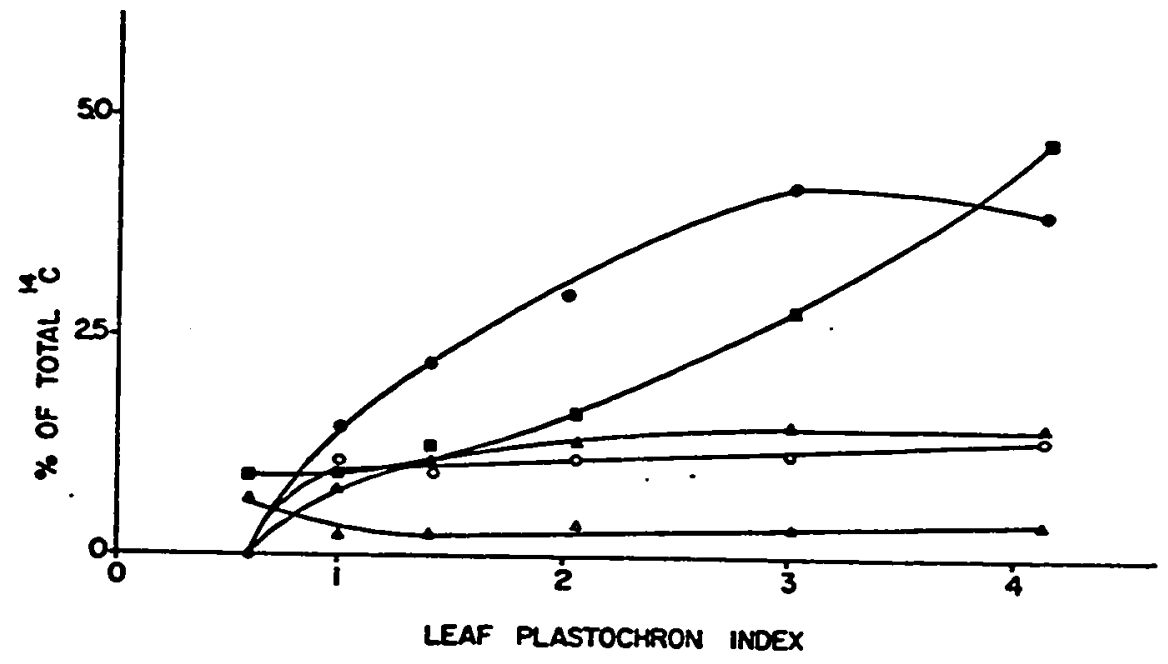


photosynthate from the mesophyl1 to the minor veins and also to identify centers of active accumulation if these centers exist.

An attempt was made to develop a technique for autoradiography of water soluble compounds in leaves fed with ${ }^{14} \mathrm{CO}_{2}$. Previous autoradiography experiments (e.g. Geiger and Cataldo, 1969; Trip, 1969) have been limited by the paraffin embedding technique. The high energy of $\beta$ particles emitted by ${ }^{14} \mathrm{C}$ causes lateral "spreading" of reduced silver in the photo-emulsion away from the centers of particle disintegration. The greater the thickness of the section or the photo-emulsion, the greater will be the effect of spreading. If the sections are too thick it is difficult to achieve the resolution necessary to localize activity within single cells. The use of methacrylate or epoxy resins as embedding materials might conceivably improve the resolution of autoradiographs by allowing thin sections $(\leq 1 \mu)$ to be used. In addition, the methacrylate and epoxy resins provide superior structural preservation.

To prevent the movement of water soluble compounds a flash freezing and freeze-drying technique similar to that described by Webb and Gorham (1964) was employed. Leaves were excised and immediately plunged into isopentane cooled to near the freezing point with liquid nitrogen. The tissue was immediately transferred, without warming, to a vacuum desiccator previously cooled to $-38^{\circ} \mathrm{C}$, evacuated over 
phosphorous pentoxide to a pressure of approximately 20-50 $\mu$ $\mathrm{Hg}$ and lyophilized for 7 days at $-38^{\circ} \mathrm{C}$. After this period the desiccator was brought to room temperature and air was allowed into the desiccator very slowly through a glass tube filled with Drierite.

Small pieces of the dry leaf tissue were immersed directly into one of a number of embedding media including methyl methacrylate, butyl methacrylate, glycol methacrylate, Epon-Araldite mixture (Mollenhauer, 1964) and Spurr resin (Spurr, 1969). The best results in terms of ease of embedment and structural preservation of tissue was obtained with Spurr resin (Fig. 29). The tissue appeared similar, in the light microscope, to samples prepared by conventional fixation and embedding techniques. The tissue showed some signs of damage, such as cracks in the cytoplasm of companion cel1s, which were probably caused by drying.

Since the components of the Spurr resin are not of equal viscosity, the tissue was embedded first in vinyl cyclohexene dioxide (VCD), the least viscous component of the resin, and then transferred to mixtures containing the more viscous components according to the following schedule:

(a) VCD - $12 \mathrm{hr}$

(b) VCD : diglycidyl ether of polypropyleneglycol (DER) : nonenyl succinic anhydride (NSA); 1.: $0.6: 0.5(w / w)--12 \mathrm{hr}$

(c) VCD : DER : NSA; $1: 0.6: 2.6(\mathrm{w} / \mathrm{w})--12 \mathrm{hr}$

(d) VCD : DER : NSA : dimethylaminoethano1; $1: 0.6: 0.5: 0.04(w / w)--48 \mathrm{hr}$. 
- 

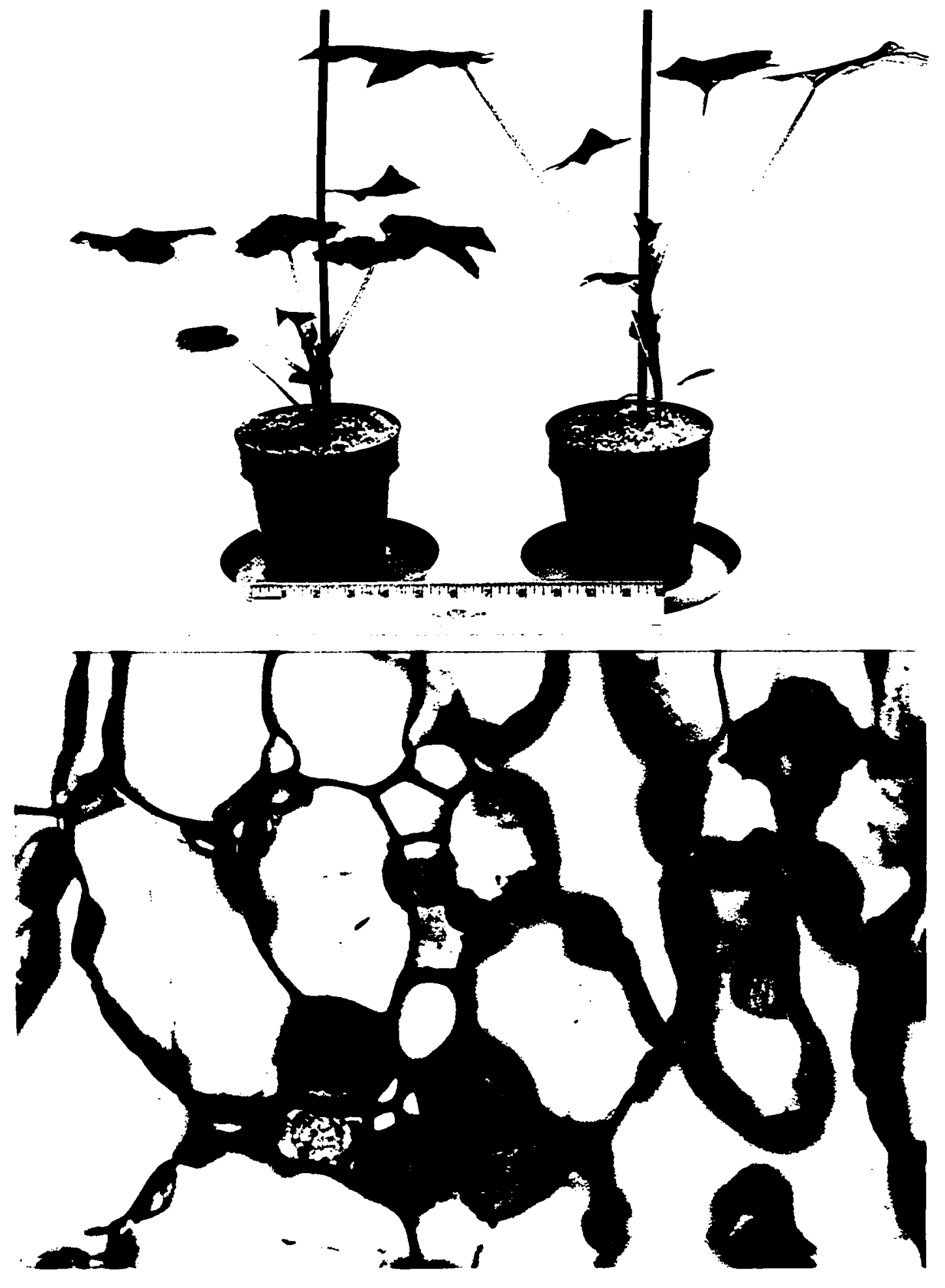

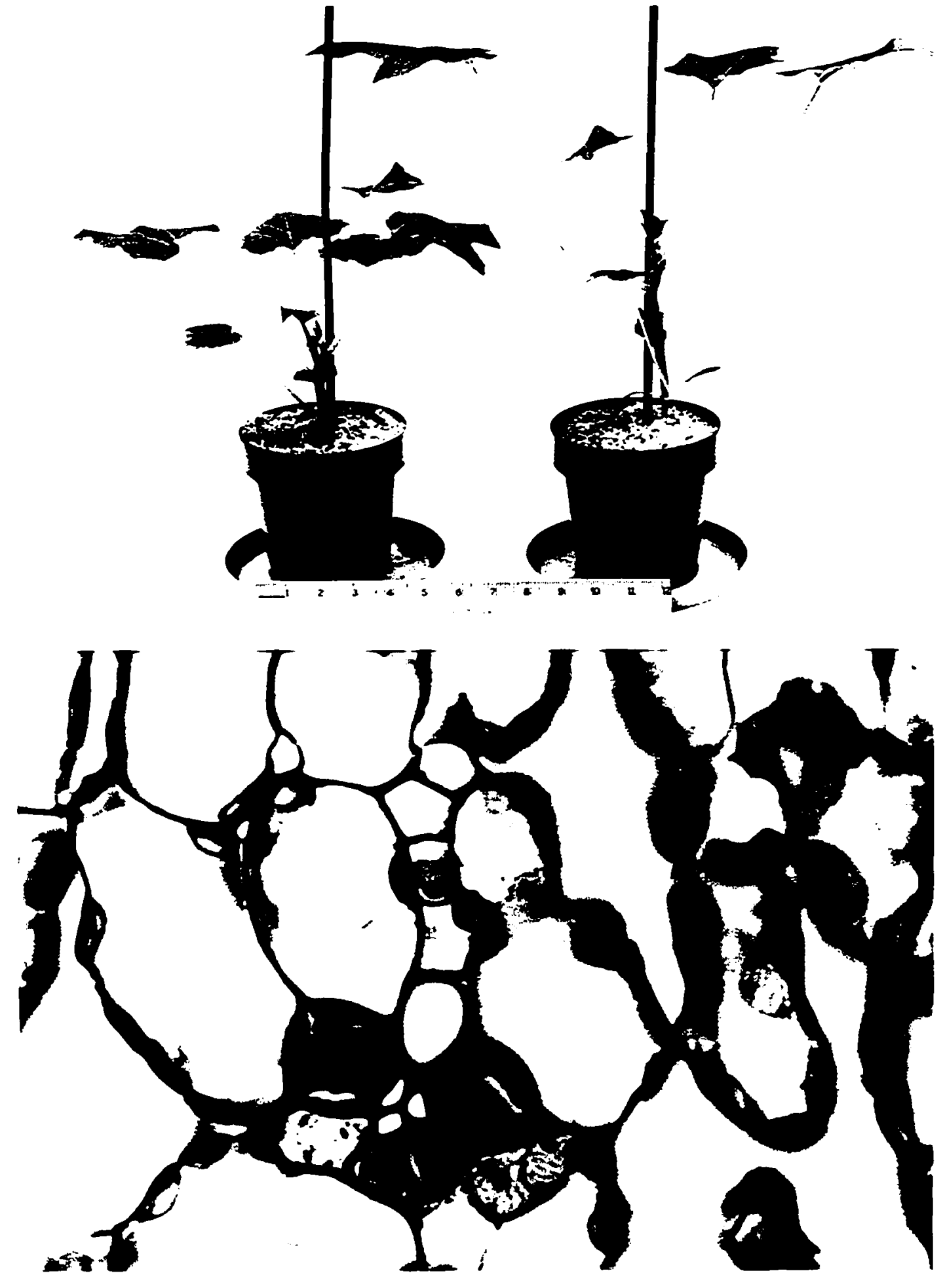
All embedding was carried out in a desiccator over Drierite at room temperature and at atmospheric pressure. The samples were hardened in an oven at $70^{\circ} \mathrm{C}$ for $8 \mathrm{hr}$.

Before attempting to cut the sections onto water a test was performed to measure the leaching of water soluble ${ }^{14} \mathrm{C}-1$-labelled compounds from the plastic embedded section when floated on water. Sections were cut $5 \mu$ thick on a dry glass knife from a block containing embedded freeze-dried leaf tissue which had been allowed to fix ${ }^{14} \mathrm{CO}_{2}$ for $5 \mathrm{~min}$. Half the sections were placed in scintillation vials in groups of ten and alternate sections were floated on water for $15 \mathrm{~min}$ at room temperature before being transferred to scintillation vials. The samples were counted in a toluene : PPO scintillation fluor.

In a number of such tests those sections floated on water contained only 30 to $50 \%$ of the ${ }^{14} \mathrm{C}$ found in sections not floated on water. It was concluded that water soluble substances would be leached from sections floated on water when cut. This observation placed some limitation on the technique since sections could not be floated on water and stretched with xylene in the usual fashion. A few sections were flattened with a small roller and fastened to glass slides with double-backed Scotch tape. These sections were coated with Ilford L4 emulsion using the wire-1oop technique of Caro and Tubergin (1962).

The resolution of these autoradiographs was inadequate. 
Silver grains were detected in intercellular spaces and $20 \mu$ to the side of leaf transections. This spreading was undoubtedly due to a certain amount of leaching during the embedment procedure since similar sections washed in water before autoradiography showed good resolution of silver grains in the mesophyll cytoplasm, especially in chloroplasts. No further attempts to improve the technique were made.

\section{STRUCTURE OF MINOR VEINS IN MATURE LEAVES}

The minor veins of Cucurbita pepo are arranged in a reticulate pattern typical of dicotyledon leaves (Fig. 30). Areoles are usually delimited by veins which contain a single file of tracheids. These are seventh order veins according to the classification of Fischer (1885). Occasionally a lower order (larger) vein borders an areole on one side. Areoles are frequently traversed by veinlets which end blindly and may branch (Fig. 30).

No mesophyll cell is more than $60 \mu$ from the closest vein. Therefore, products for translocation must be moved no more than the distance equivalent to approximately 6 palisade cell diameters or 3 spongy mesophyll cell diameters to reach the nearest conducting elements.

When viewed in cross-section the cells of the minor 
veins are arranged in a regular pattern (Figs 31, 37, 59, 60). The adaxial (upper) phloem consists of one sieve element and one companion cell in veins of the sixth and seventh order (Fischer, 1885). The companion cell lies above the sieve element. The adaxial phloem is usually separated from the $x y l e m$ by a single parenchyma cell. In veins of the seventh order the xylem is usually composed of a single cell in cross section. The abaxial (lower) phloem may or may not be separated from the xylem by a parenchyma cell. Generally in the smallest veins no parenchyma separates the phloem and xylem and the tracheid may occur next to abaxial sieve elements (Fig. 31). Abaxial phloem of seventh order veins generally consists of 2 to 3 large intermediary cells (übergangszellen--Fischer, 1885) and associated sieve elements (Figs 31,60 ). The spatial relationship between cells in the abaxial phloem suggests that intermediary cells are companion cells in the ontogenetic sense although this was not proven by developmental studies. The term abaxial companion cell will be used in further reference to this cell type. The smallest minor veins are apparently uniseriate in origin (Fig. 36).

The minor veins are surrounded laterally and abaxially by a single layer of bundle sheath cells (Figs 31 , $37,59,60,64)$. There are no intercellular spaces within the vein or between the cells of the vein and bundle sheath. Only the adaxial companion cell and occasionally the abaxial 
companion cells are exposed to the intercellular space of the leaf (Figs 31, 37, 60). Apart from their intimate relationship with the minor veins, bundle sheath cells can not be distinguished morphologically from the mesophyll. The walls of the bundle sheath cells which abut the minor vein are usually free of chloroplasts.

Mature abaxial sieve elements appear, in the light microscope, to contain little cytoplasm (Fig. 32). Pores are not visible in the end walls. Abaxial companion cells are filled with cytoplasm which stains deeply with methylene blue and contains numerous small vacuoles (Fig. 32). The coincident end walls of the sieve elements and companion cells reveal the close ontogenetic relationship between these cell types.

Elements of the xylem appear, in paradermal section, to be tracheids (Fig. 33), although wall perforations may have gone undetected. Secondary wall thickenings are deposited in a helical pattern. The terminal tracheid is usually filled with material which appears homogeneous in the light microscope and stains deeply with methylene blue (Fig. 33). Occasionally the secondary walls of the terminal tracheid of a blind ending stains only weakly with safranin. (Fig. 30).

Adaxial sieve elements are wider than abaxial sieve elements and the pores in the end walls are large enough to be seen with the light microscope (Fig. 34). The cytoplasm 
FIG. 30 (UPPER LEFT)

Paradermal view of cleared leaf stained with safranin. Light micrograph. Minor veins are arranged in a reticulate pattern. Secondary walls of terminal tracheid of blind endings often stain weakly (arrow). Elongated cells occasionally extend beyond the terminal tracheid (arrow head). $\times 160$

\section{FIG. 31 (UPPER RIGHT)}

Transection of mature minor vein. Light micrograph. Cells of the vein are arranged in a regular pattern. Cell types from the abaxial (lower) surface are: companion cells (CC) and sieve elements (SE), tracheids (T), parenchyma cell (PA), adaxial sieve element ( $\mathrm{SE}^{\prime}$ ) and adaxial companion cell (CC'). Vein is bounded by cells of the bundle sheath (BS). $\times 1,000$

FIG. 32 (LOWER LEFT)

Paradermal section of minor vein abaxial phloem. Light micrograph. Note the coincident end walls of companion cells (CC) and sieve elements (SE). $\times 610$

\section{FIG. 33 (LOWER RIGHT)}

Paradermal section of tracheids $(T)$ in a blind ending. Light micrograph. Terminal tracheid is filled with an amorphous material. $\times 480$ 


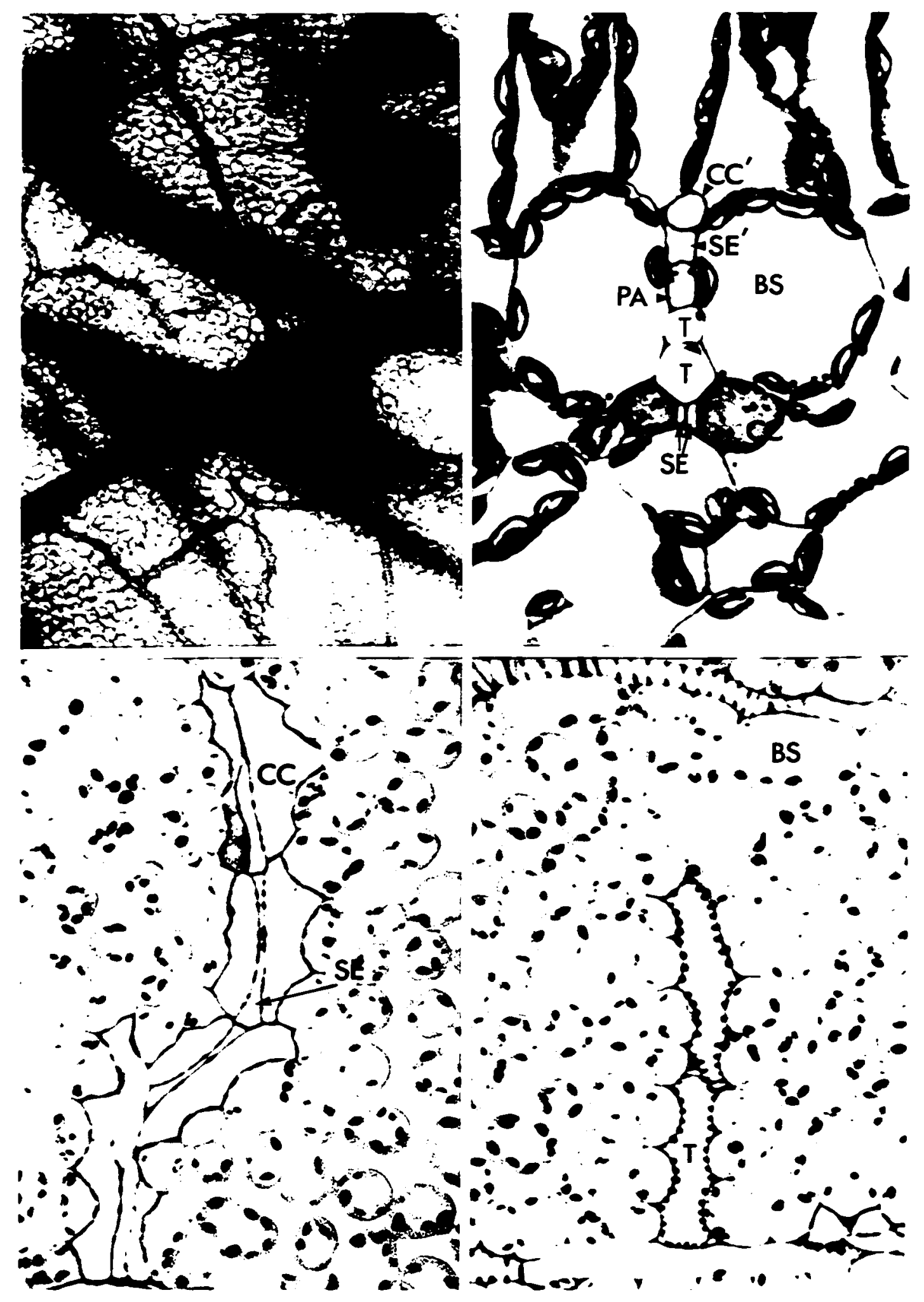




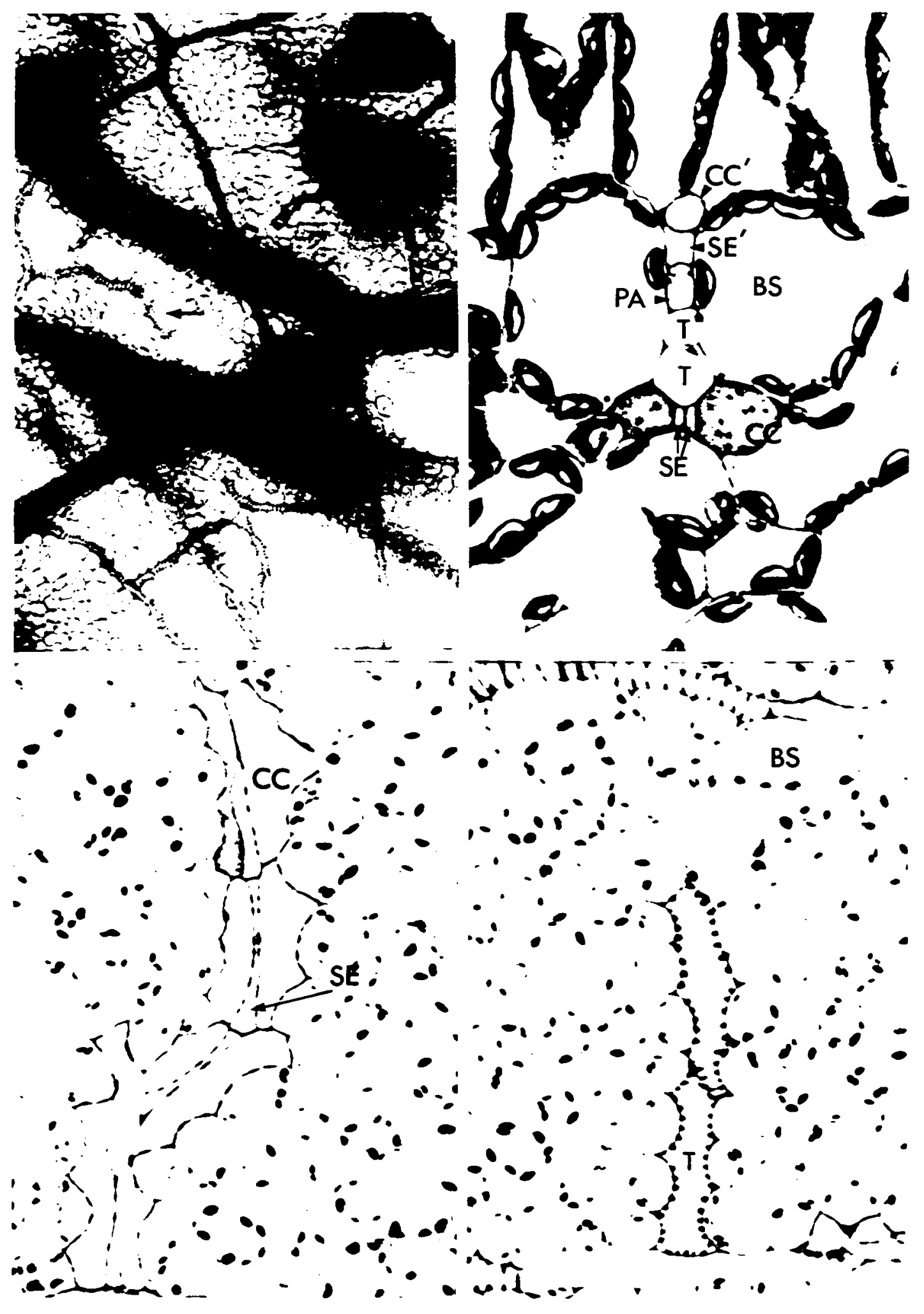


of the adaxial companion cells is extremely dense and most of the cell volume is occupied by vacuole (Fig. 35).

In the terminal veinlets the adaxial phloem, xylem, and abaxial phloem most frequently end together although this is not always the case. It can be seen in cleared leaves stained with safranin that elongated cells occasionally continue beyond the last differentiated tracheary element and may reach across the areole to the opposite bordering vein. When examined through serial paradermal sections these elongated cells are usually found to consist of both abaxial and adaxial phloem.

\section{E. ULTRASTRUCTURE OF MINOR \\ VEINS IN MATURE LEAVES}

\section{Abaxial Phloem}

\section{(1) Sieve Elements}

Except for their diminutive size the abaxial sieve elements of the minor vein closely resemble the sieve elements in the vascular bundles of the stem. Transversely oriented sieve plates interrupt the sieve tube conduit (Figs 38-40). Although it is not possible to resolve the pores of the sieve plate in the light microscope they are plainly visible when viewed in paradermal sections with the electron microscope. The sieve plate is so small that generally one 
FIG. 34 (UPPER LEFT)

Paradermal section of mature minor vein adaxial sieve elements (SE'). Light micrograph. Open pores are easily visible (arrow heads). Bundle sheath cells (BS) line the vein. $\times 950$

FIG. 35 (UPPER RIGHT)

Paradermal section of adaxial companion cell (CC') and sieve elements (SE'). Light micrograph. Companion cell contains large vacuoles $(V)$ and dense cytoplasm. $\quad \times 830$

\section{FIG. 36 (LOWER LEFT)}

Transection of young leaf. Light micrograph. Minor vein in centre of picture (between arrows) has apparently arisen from divisions in the third layer of cells from the upper leaf surface. $\times 940$

\section{FIG. 37 (LOWER RIGHT)}

Transection of developing minor vein. Light micrograph. Adaxial companion cell ( $\left.\mathrm{CC}^{\prime}\right)$ is vacuolate and the cytoplasm is dense. Adaxial sieve element (SE') contains little cytoplasm. Tracheid (T) is mature. Abaxial sieve element (SE) between two companion cells (CC) is immature. Parenchyma cell at PA. $\times 1,400$ 


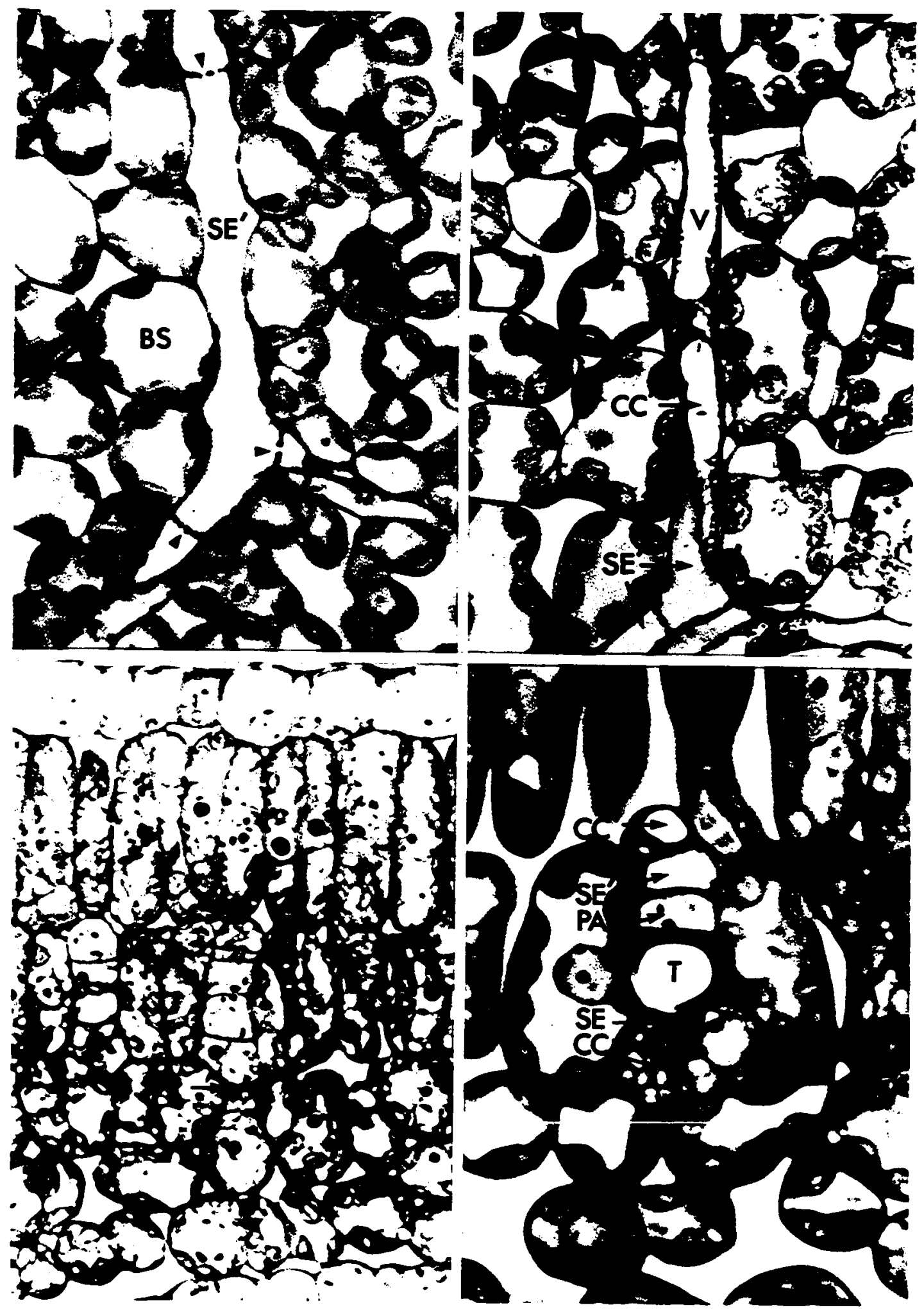




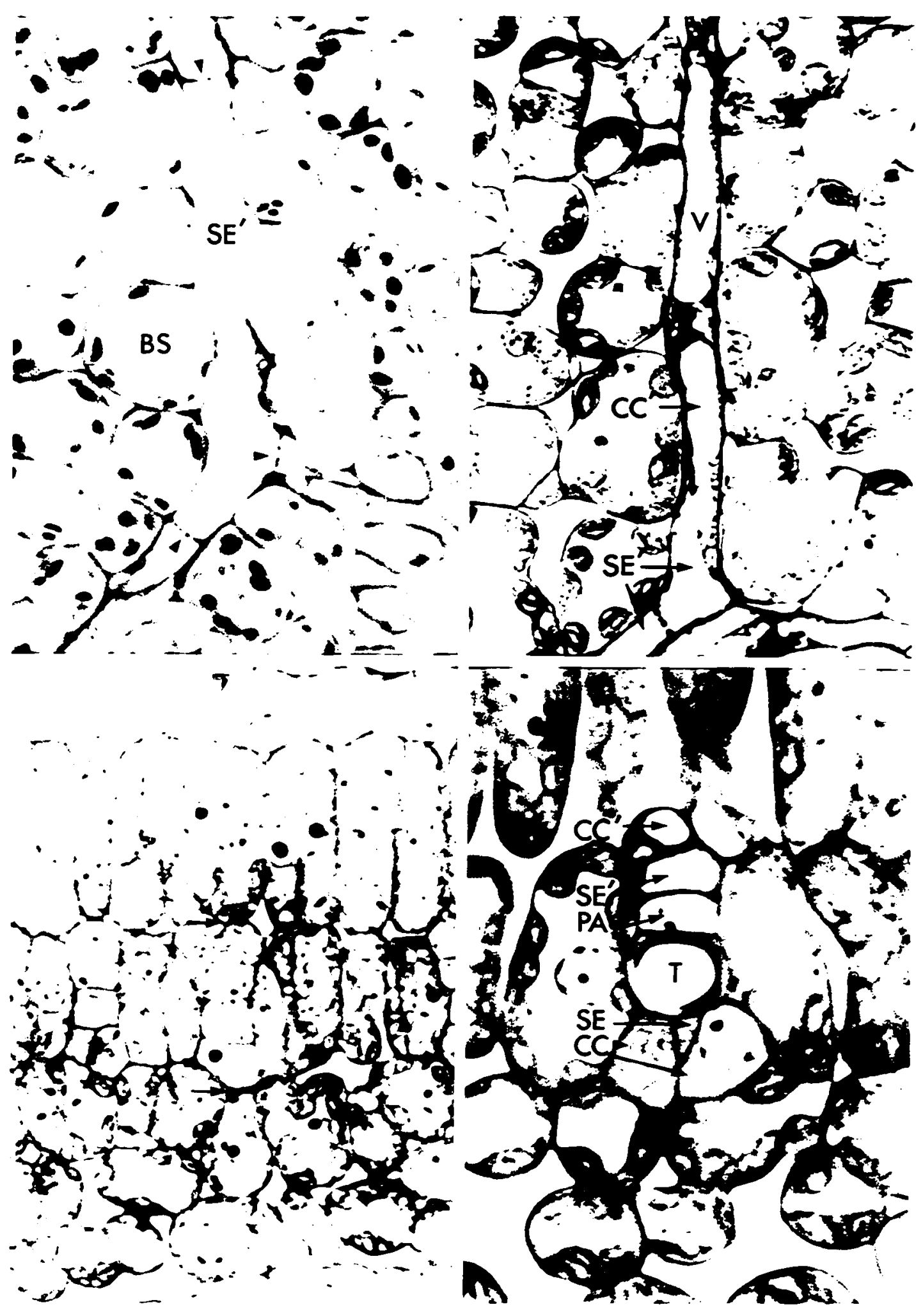




\section{FIG. 38}

Paradermal section of mature minor vein abaxial sieve elements (SE) and companion cells (CC). Electron micrograph. Pore (P) in the sieve plate is plugged with P3-protein (P3) which appears to form a longitudinally oriented strand. Companion cells are connected to bundle sheath cells by numerous plasmodesmata (PL). Mitochondrion at M, plastid at PD. $x$ 23,200 


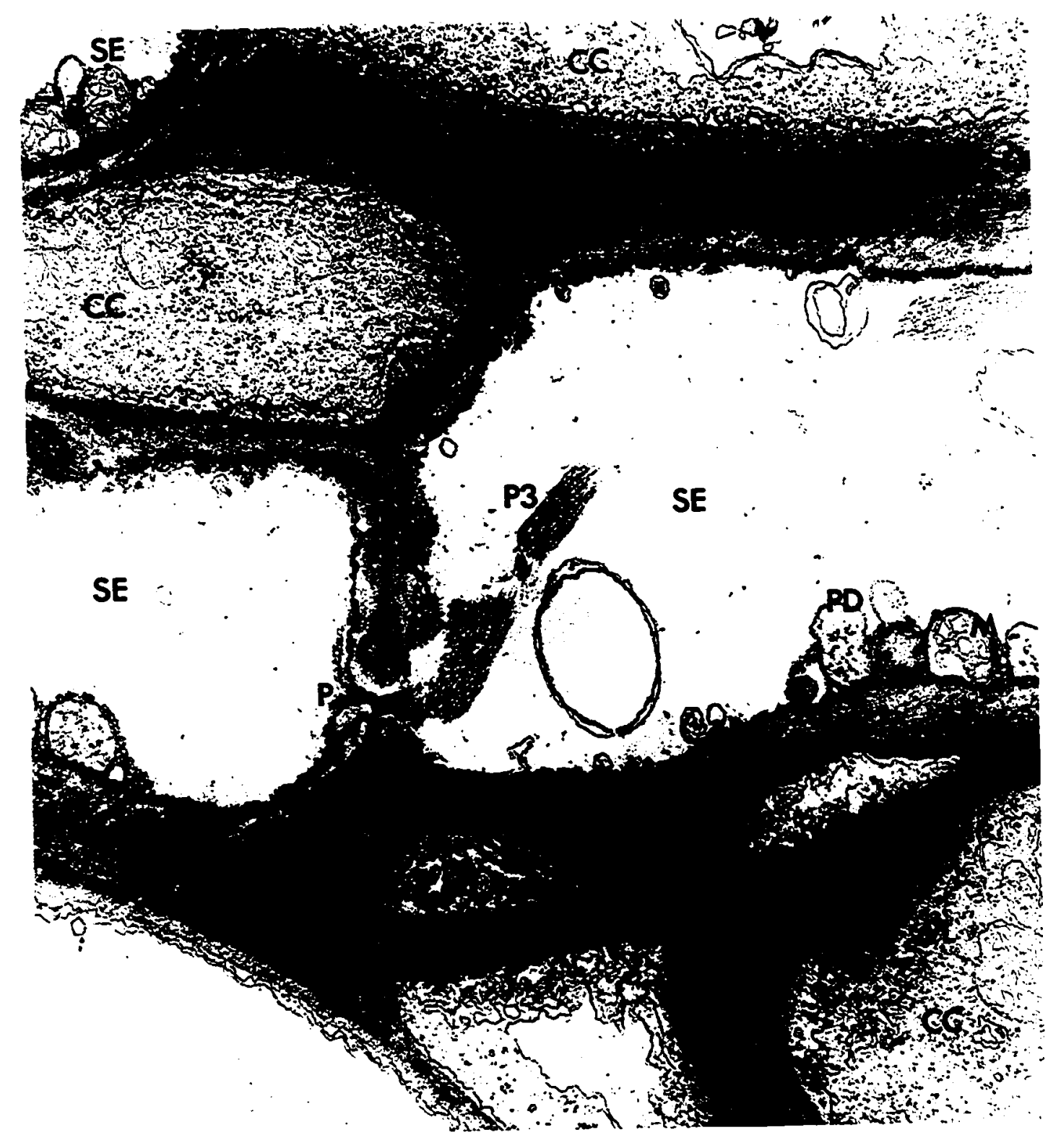




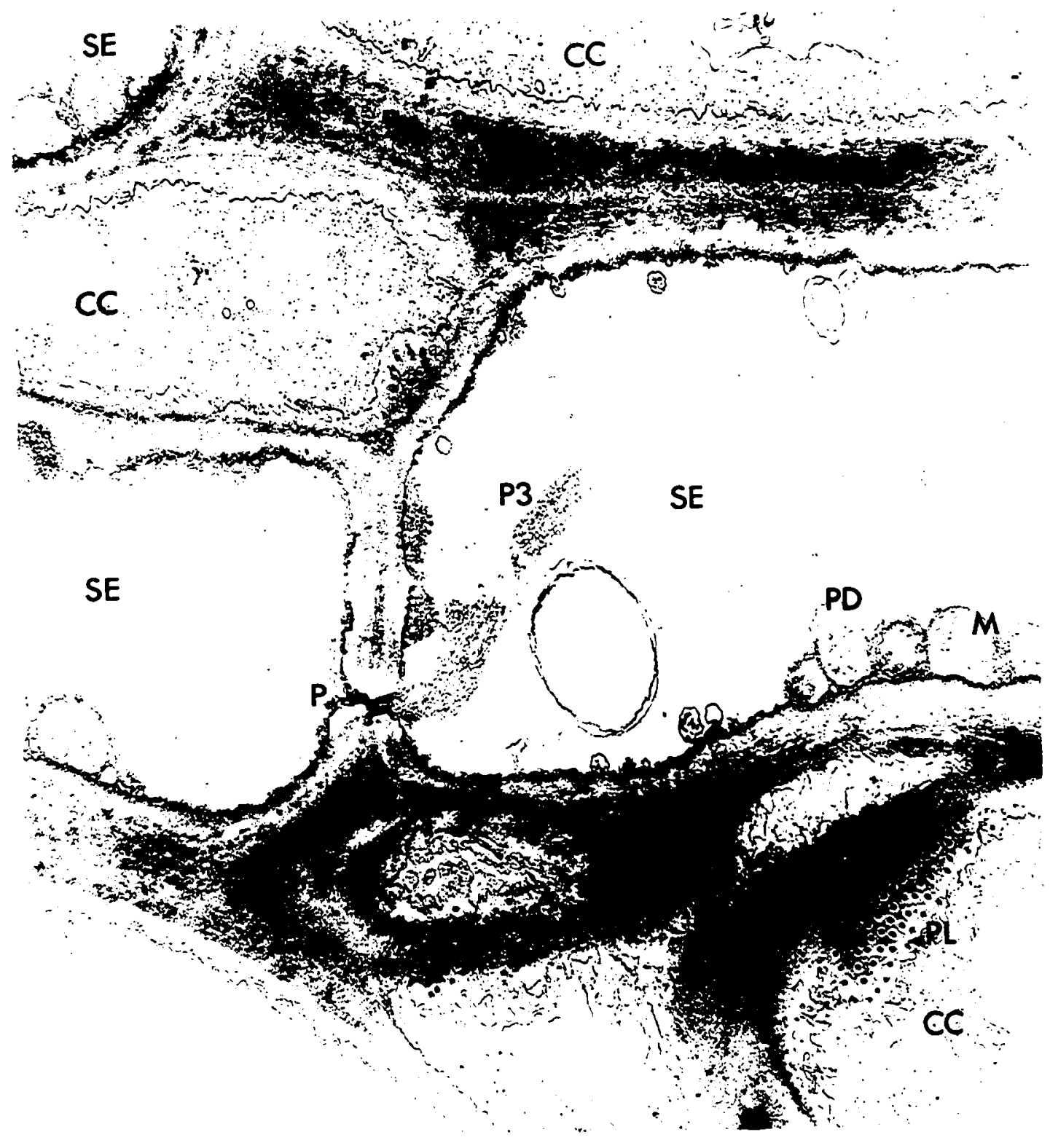


FIG. 39

Paradermal section of a sieve plate (SP) between two mature abaxial sieve elements. Electron micrograph. The pore in the sieve plate is narrow and lined with callose (C). $x 45,600$

FIG. 40

Paradermal section of a sieve plate (SP) between two mature abaxial sieve elements. Electron micrograph. The sieve pore is filled with fibrillar P-protein. Profiles of endoplasmic reticulum (ER) line the walls and sieve plate. Mitochondrion at M. $\times 39,900$ 


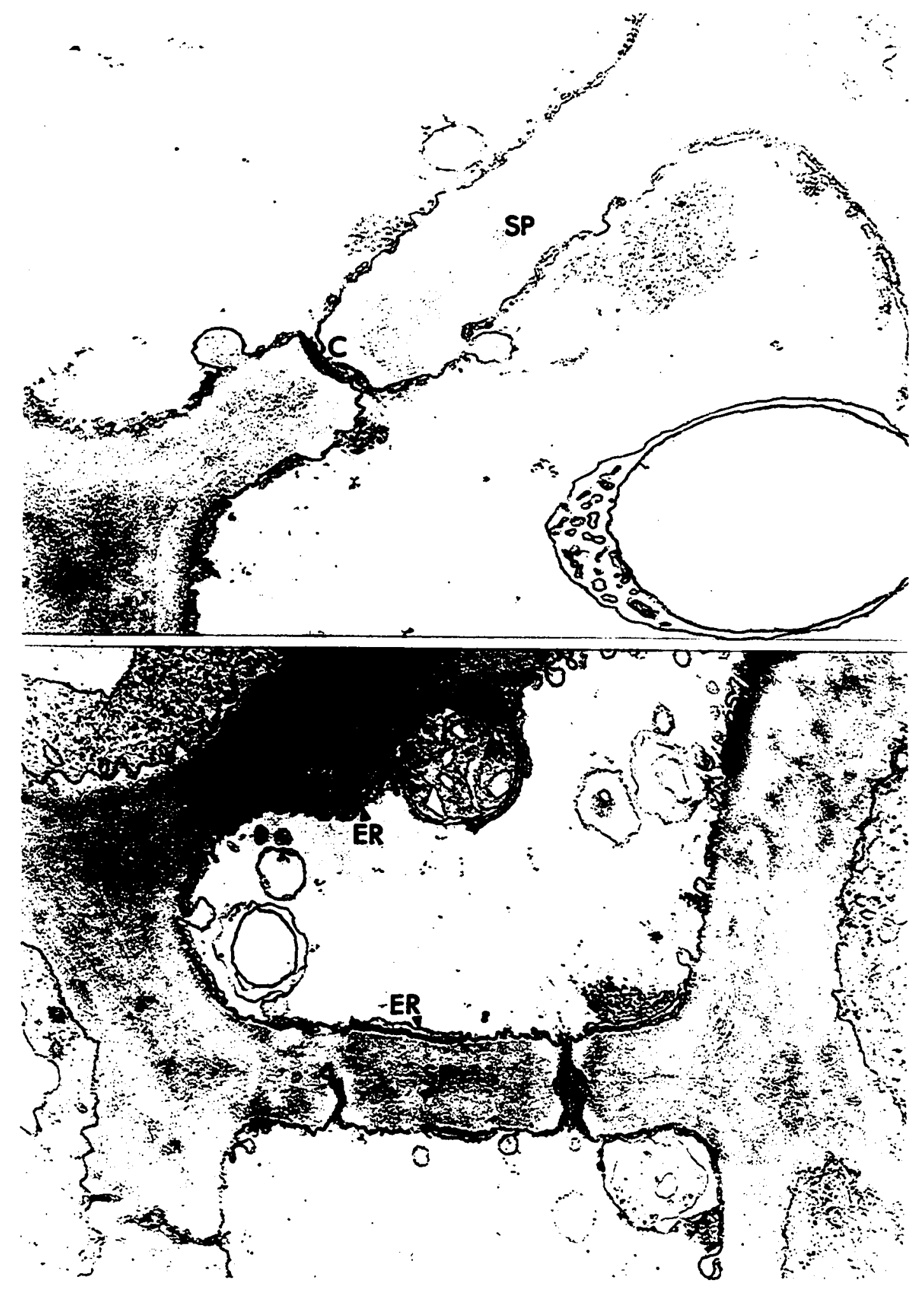




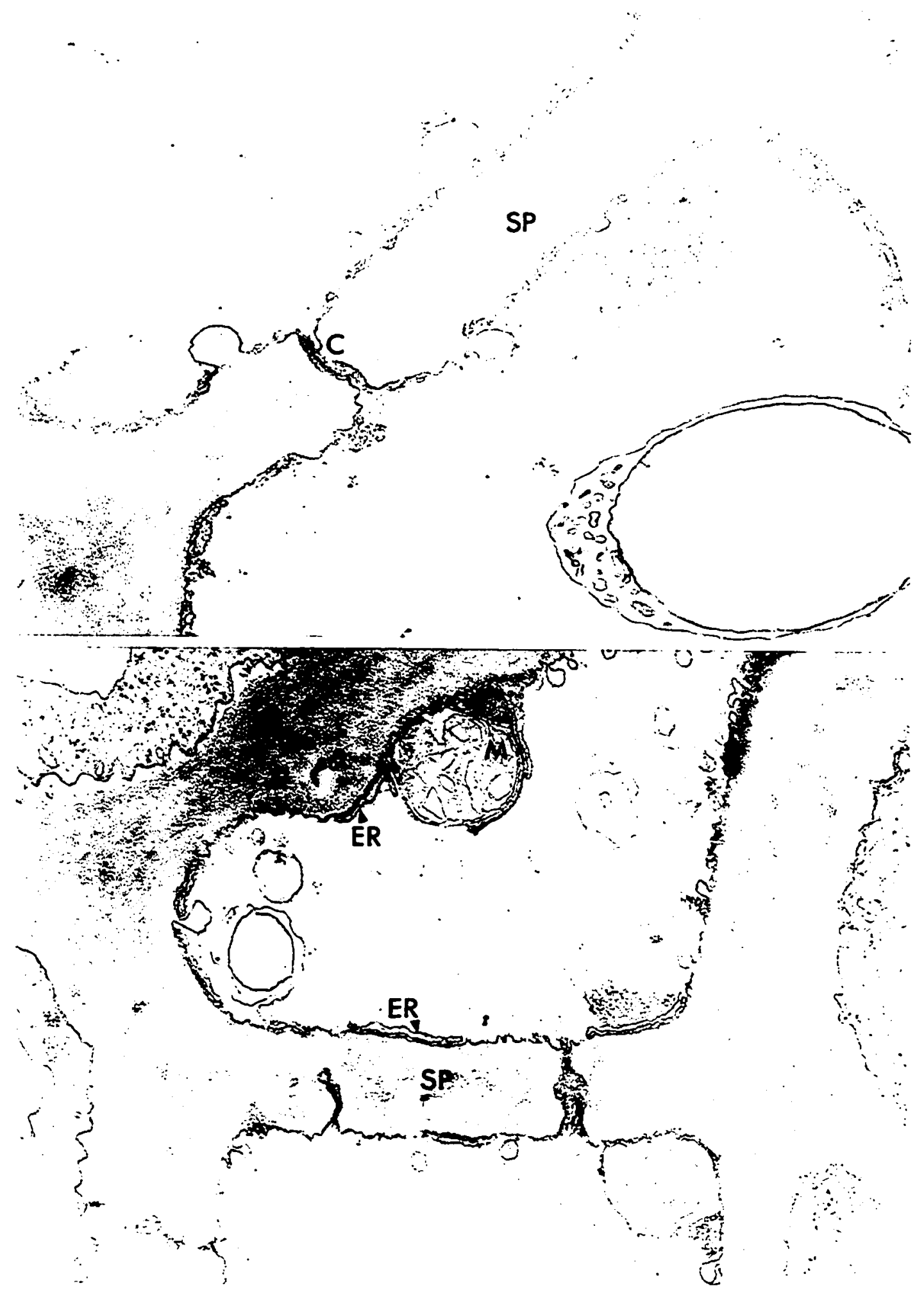


or at most 2 pores are visible in a single paradermal section. The pores are narrow and are usually plugged with P-protein (Figs 38-40). A thin layer of callose lines the pores. Cellular organelles line the walls of the sieve elements leaving the lumen of the sieve tube virtually empty. P-protein usually occupies a parietal position although it may be displaced toward the sieve plates.

The P-protein in mature sieve elements is either fibrillar or tubular. Fibrillar protein is less abundant than in sieve elements of the vascular bundles of the stem (compare Figs 38-44 with micrographs in the papers of Cronshaw and Esau, $1968 \mathrm{a}, \mathrm{b}$; and Evert et al., 1973). Two types of tubular P-protein are found. One type has a tubule diameter of approximately $240 \AA$ and is aggregated in a regular lattice arrangement into discrete bodies (Figs 43, 44). The second type of tubule is more narrow (approximately $170 \AA$ in diameter) and is also aggregated into bodies although these usually do not have the same highly ordered appearance (Figs 38, 41, 42).

Cronshaw and Esau (1968a) found similar forms of P-protein in the stem phloem of Cucurbita maxima. They classified the various types as follows: P1, large diameter tubules; P3, fibrillar protein; P4, smaller diameter tubules. P3-protein fibrils are apparently the precursors of P4protein tubules, although not all the P3-protein is necessarily converted to P4-protein. In the vascular bundles of 
FIG. 41

Paradermal section of two mature abaxial sieve elements (SE) and a companion cell (CC). Electron micrograph. P4-protein tubules are aggregated into a discrete body (P4). Branched plasmodesmata (PL) connect the companion cell and a sieve element. Sieve element plastid at PD. $\times 29,400$

\section{FIG. 42}

Paradermal section of two mature abaxial sieve elements. Electron micrograph. The sieve elements are joined by a lateral sieve plate which is plugged with P4protein (P4). Companion cell at CC. $\times 21,800$ 


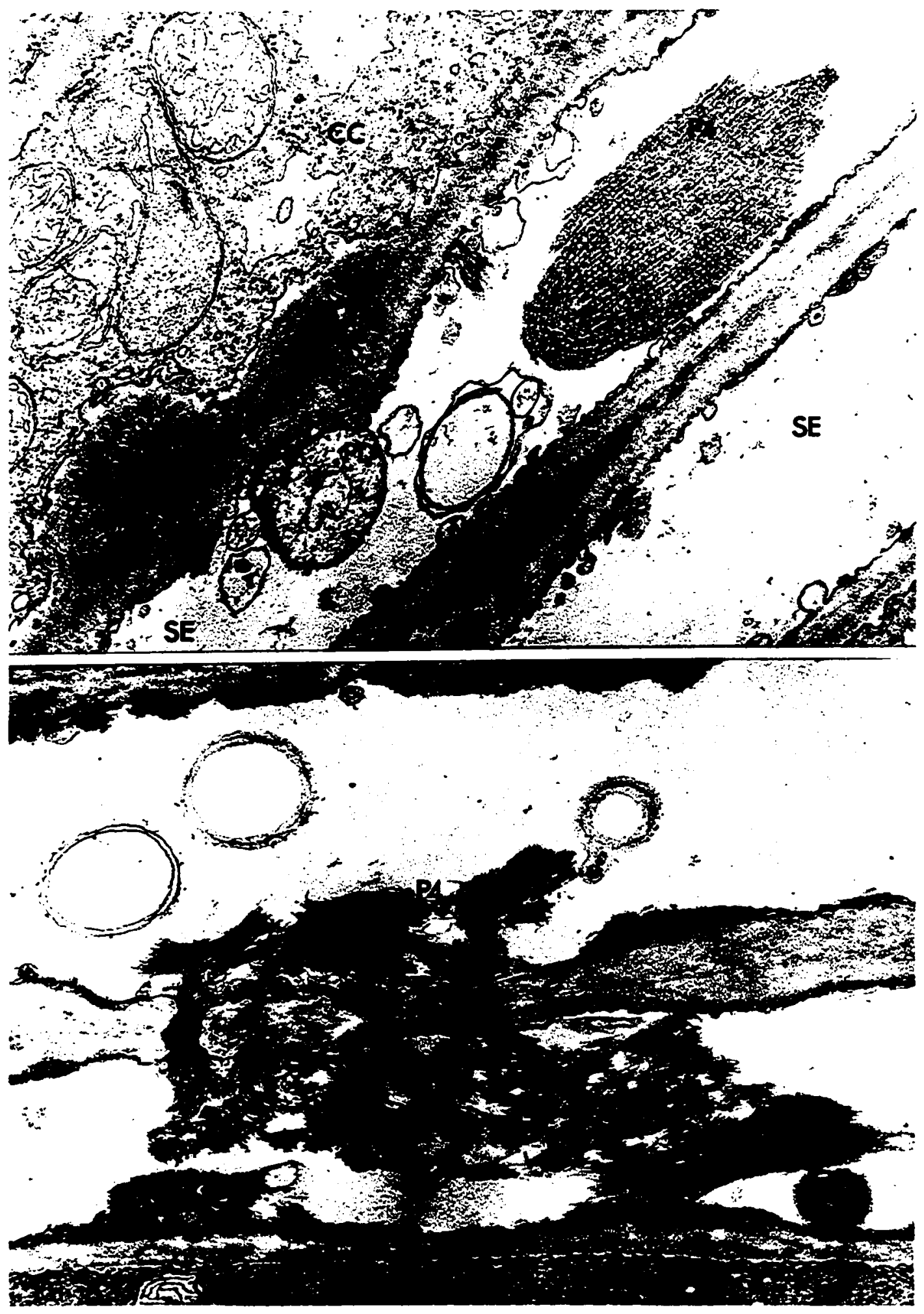




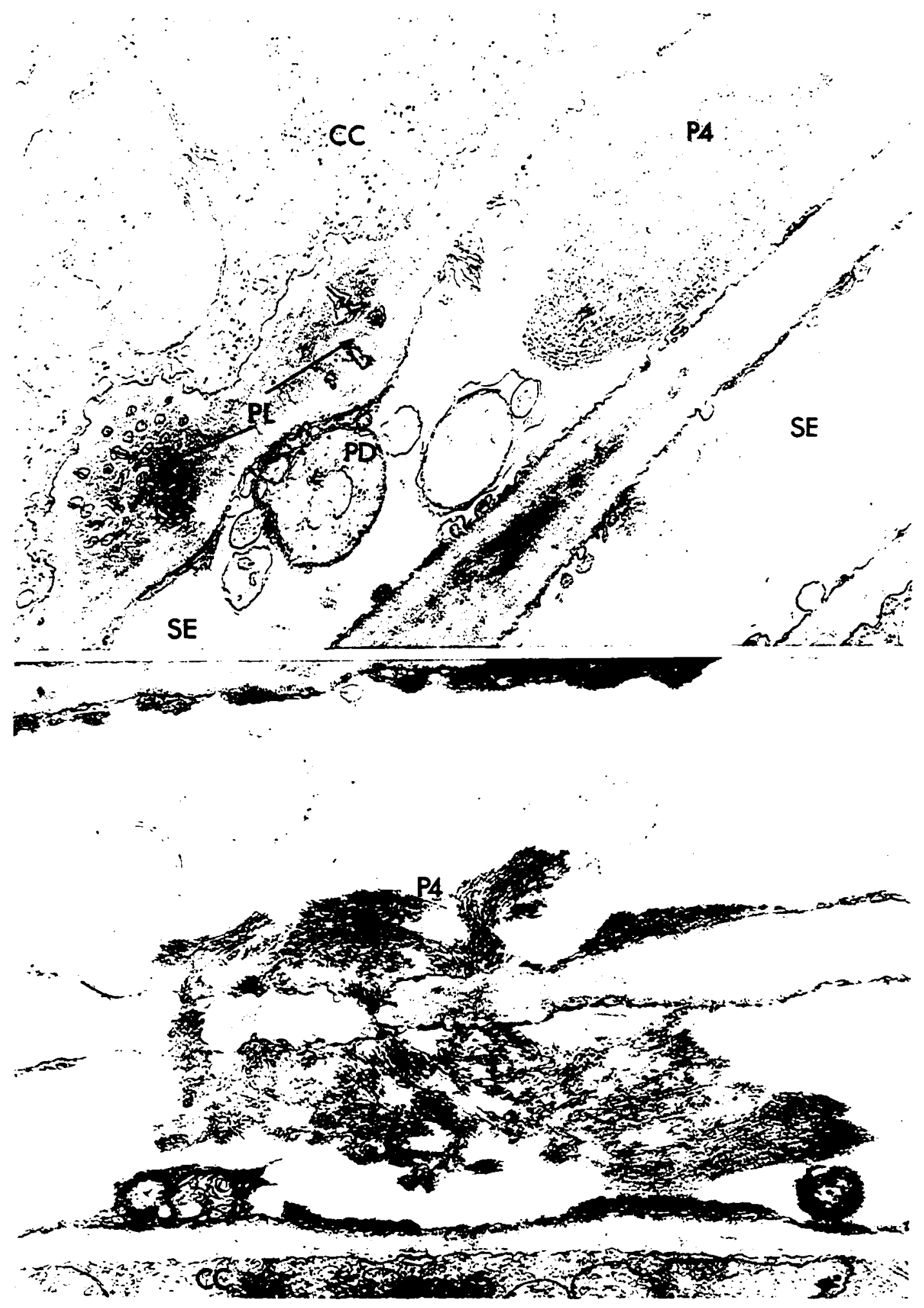


the stem P3 and P4 bodies disperse to become loose fibrillar protein when the sieve elements mature. PIprotein bodies apparently do not disperse (Cronshaw and Esau, 1968a,b). The absence of P3-protein bodies and the scarcity of fibrillar protein in minor vein abaxial sieve elements suggests that $\mathrm{P3}$-protein is largely converted to P4-protein. The P4-protein does not disperse as it does in sieve elements of the stem vascular bundles.

In Figure 38 it appears that the $\mathrm{P} 4$-protein which traverses the sieve plate forms a longitudinally oriented strand. This is the only micrograph obtained which suggests such a structure. No evidence for the existence of strands as postulated by either Thaine $(1962,1969)$ or Fensom (1972) was obtained.

The walls of the sieve elements are thin and an inner layer suggestive of a nacreous wall (Esau and Cronshaw, 1968b) is only occasionally encountered. The cell wall is lined by the intact plasmalemma which is continuous through the pores (Figs 38-40). The tonoplast is absent in mature sieve elements. Numerous membrane profiles occupy the lumen of the sieve tube (Figs 38-43). In section these profiles often appear in concentric pairs. The endoplasmic reticulum of mature sieve elements lies in a single layer closely appressed to the plasmalemma (Figs 39-40) or occasionally it is arranged in the form of stacked membranes (Fig. 45). Plasmodesmata connect the sieve elements to the 
FIG. 43 (ABOVE)

Transection of three mature abaxial sieve elements and surrounding companion cells. Electron micrograph. A P-protein body (P1), composed of P1protein, is shown in one sieve element. Two sieve elements are connected by a lateral sieve plate (SP). Mitochondrion at M. $\times 28,600$

FIG. 44 (LOWER LEFT)

Paradermal section of a mature abaxial sieve element showing a $\mathrm{Pl}$-protein body (P1) in longitudinal view. Electron micrograph. Companion cell at left. $x 42,700$

FIG. 45 (LOWER RIGHT)

Transection of a mature abaxial sieve element (SE) and companion cell (CC). Electron micrograph. Endoplasmic reticulum (ER) in the sieve element is arranged in the form of a stack, the so-called sieve element reticulum. x 8,400 


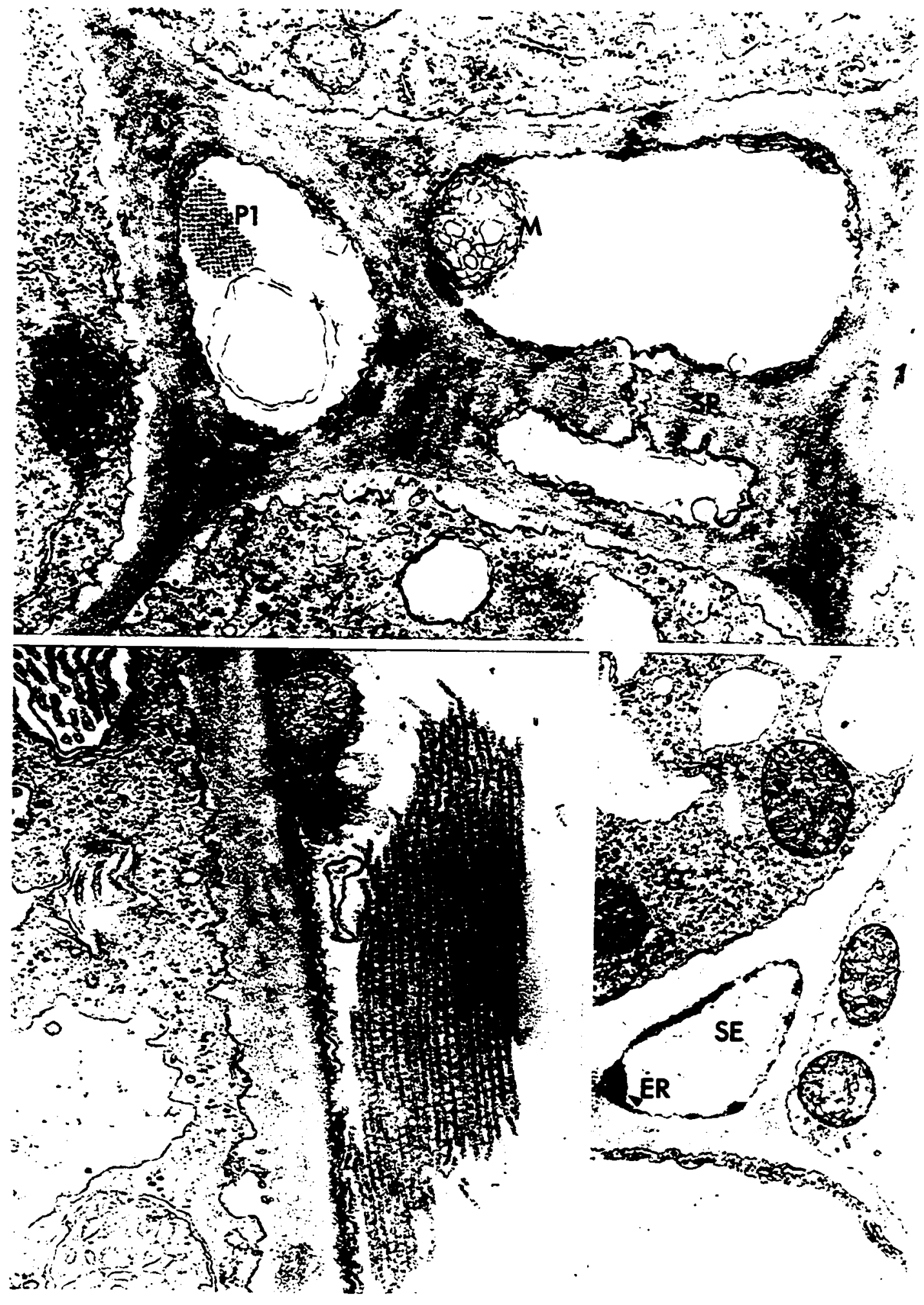




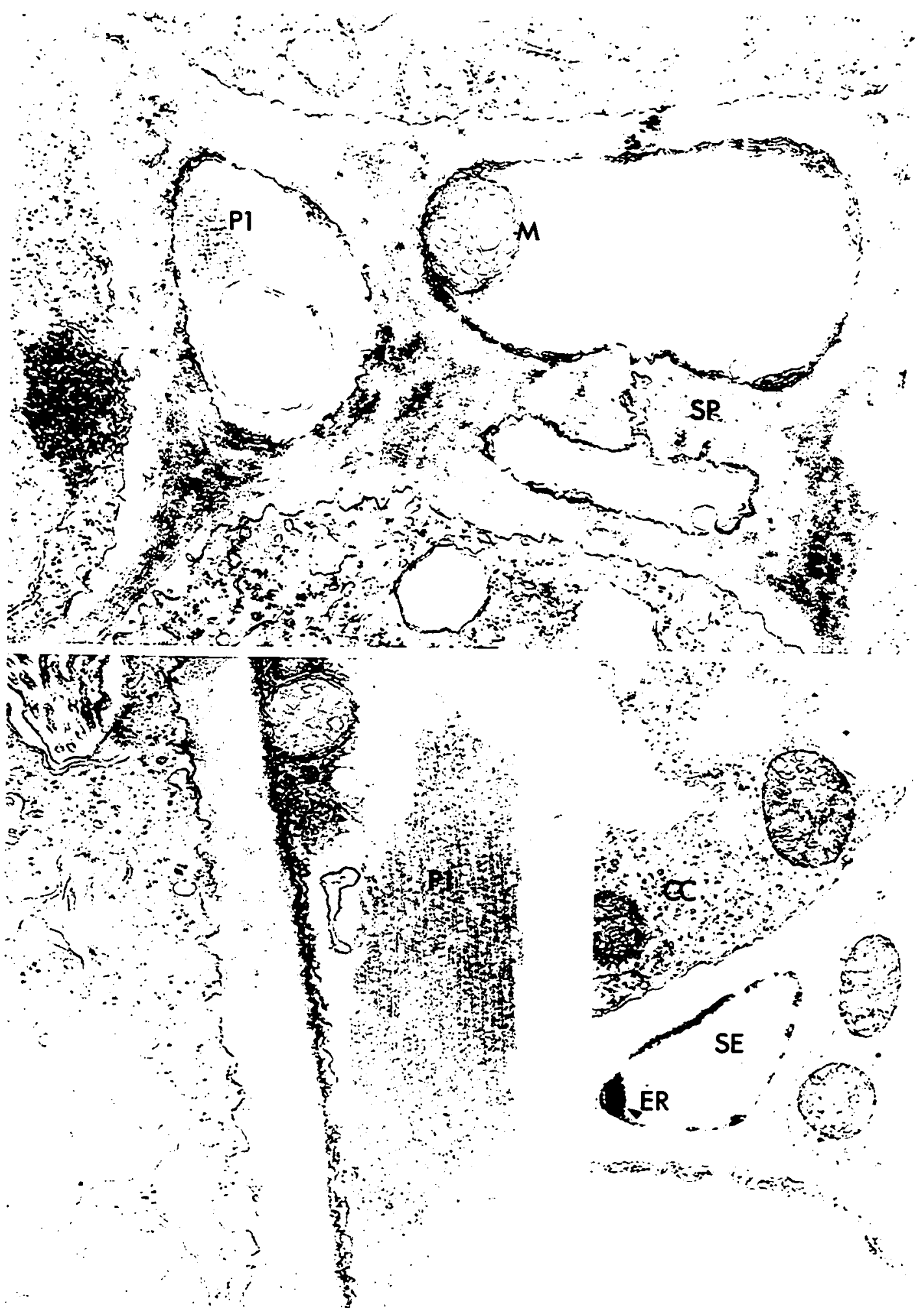


companion cells (Fig. 41). Where plasmodesmata occur the cell walls of both the sieve element and companion cell, especially the companion cell, are thickened (Fig. 41). These wall thickenings, which are visible in the light microscope (Fig. 32), reveal the large number of connections between these cells. Plasmodesmata are single on the sieve element side and branched on the companion cell side.

The mitochondria of mature sieve elements are slightly smaller (approximately $0.5 \mu$ in diameter) than those of associated nucleate cells and the matrix is more electron dense (Figs 38, 44). The mitochondria are rounded in appearance. There is an abundance of internal membranes and cristae appear swollen (Figs 38, 40, 43, 44). Sieve element plastids are not as numerous as mitochondria. The plastids are bounded by a double membrane, internal membranes are scarce or absent, and the matrix is extremely sparse (Fig. 41). Plastids are approximately the same size or slightly smaller than mitochondria in the same cell. No starch granules are present in plastids of mature sieve elements.

\section{(2) Companion Cells}

The cytoplasm of the companion cells appears dense when viewed in either the light (Fig. 31) or electron microscopes (Figs 43-46). The contour of the vacuoles is irregular although this may be an artifact of preparation. 
The degree of interconnection between vacuoles is unknown.

Plastids in the companion cell are bounded by double membranes but invaginations of the internal membrane are few and there are no grana (Fig. 48). Companion cell plastids are larger than mitochondria in the same cell but are not nearly as numerous. Starch is sometimes formed (Fig. 48).

In abaxial companion cells of leaves which are fully expanded the endoplasmic reticulum (ER) is not abundant. When present it is usually smooth. In Figures 43 and 48 , rough ER is present. The abaxial phloem of these veins was mature, that is, the pores of the sieve elements were open, but the leaf was not yet fully expanded.

Companion cells are connected to the cells of the bundle sheath by numerous plasmodesmata which are arranged in clusters where the walls are slightly thickened (Figs 38, $46,47)$. Over 300 plasmodesmata have been counted in a single cluster. In fourth and fifth order veins large companion cells are found as well as smaller ones which are of approximately the same diameter as the associated sieve elements (Fischer, 1885). In these veins the large companion cells are situated at the periphery of the phloem in contact with the bundle sheath cells. Figure 49 pictures the abaxial phloem of a vein of the fifth order. As in higher order (smaller) veins the large companion cells are connected to the bundle sheath cells by numerous plasmodesmata. 
FIG. 46

Paradermal section of an abaxial companion cell (CC) and bundle sheath cells (BS) joined by numerous plasmodesmata (PL) which occur in clusters. Electron micrograph. The mitochondria $(M)$ in the companion cell are located close to the plasmalemma. $\times 9,100$

\section{FIG. 47}

Longitudinal section through the common walls of a companion cell (CC) and a bundle sheath cell. Electron micrograph. The wall is traversed by numerous plasmodesmata (PL). $x 17,400$ 


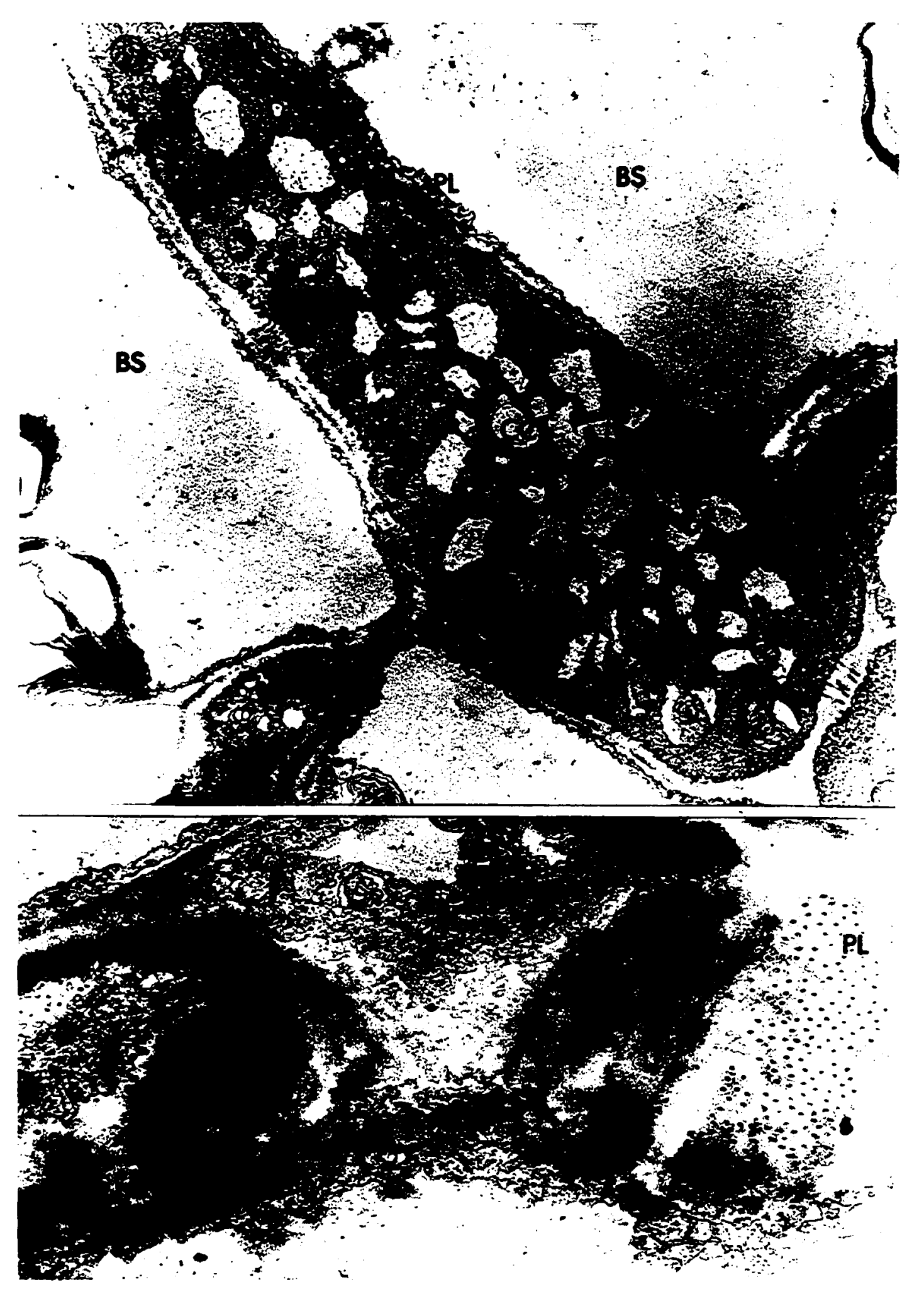




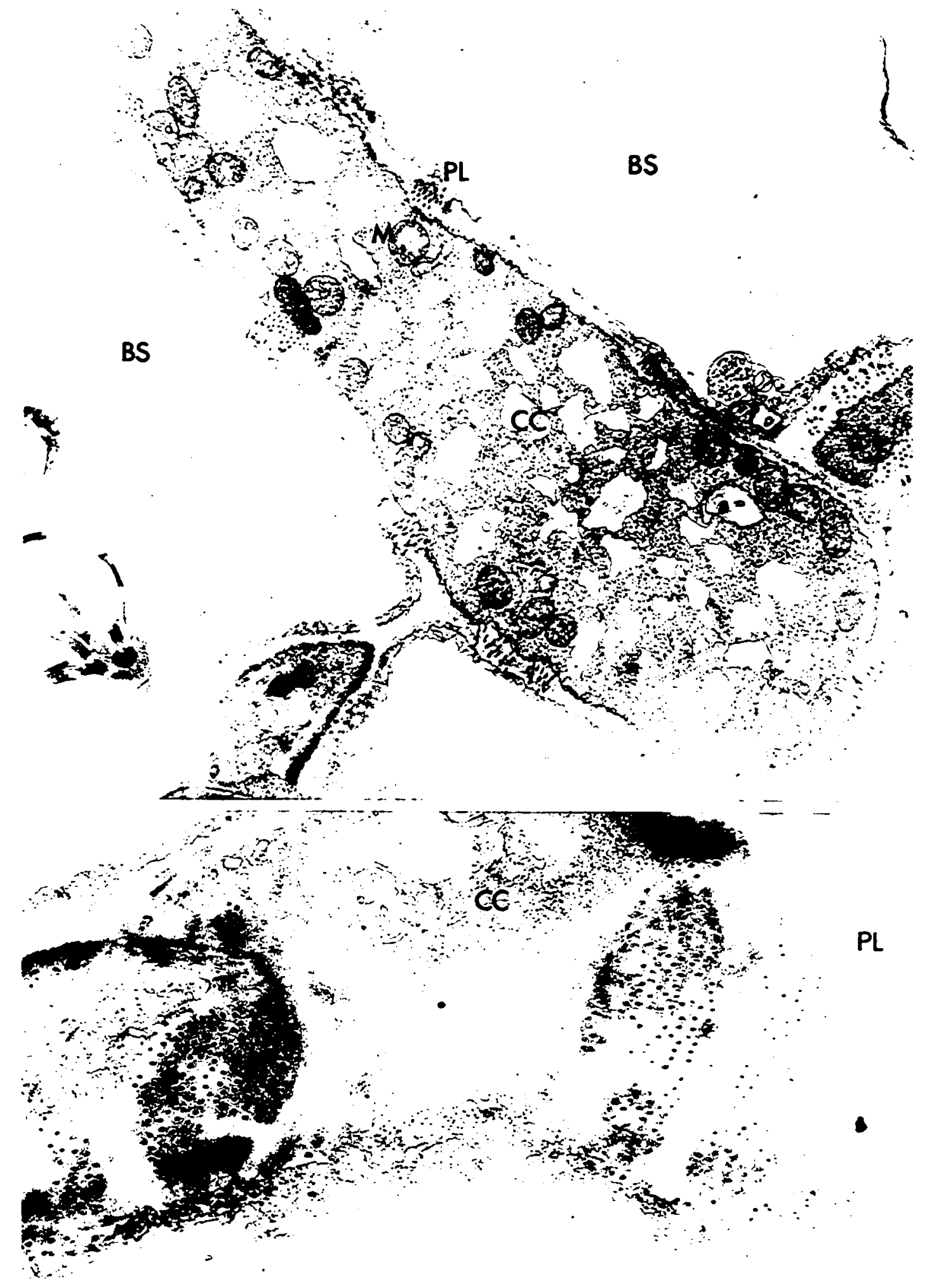




\section{FIG. 48}

Transection of an abaxial companion cell and sieve element (SE). Electron micrograph. The sieve element has probably been cut at the tip. Mitochondria (M), smooth endoplasmic reticulum (arrows) and rough endoplasmic reticulum (arrow heads) in the companion cell are plentiful. Plastid at PD contains starch grain (SG). Tracheid at T. $\times 9,900$ 


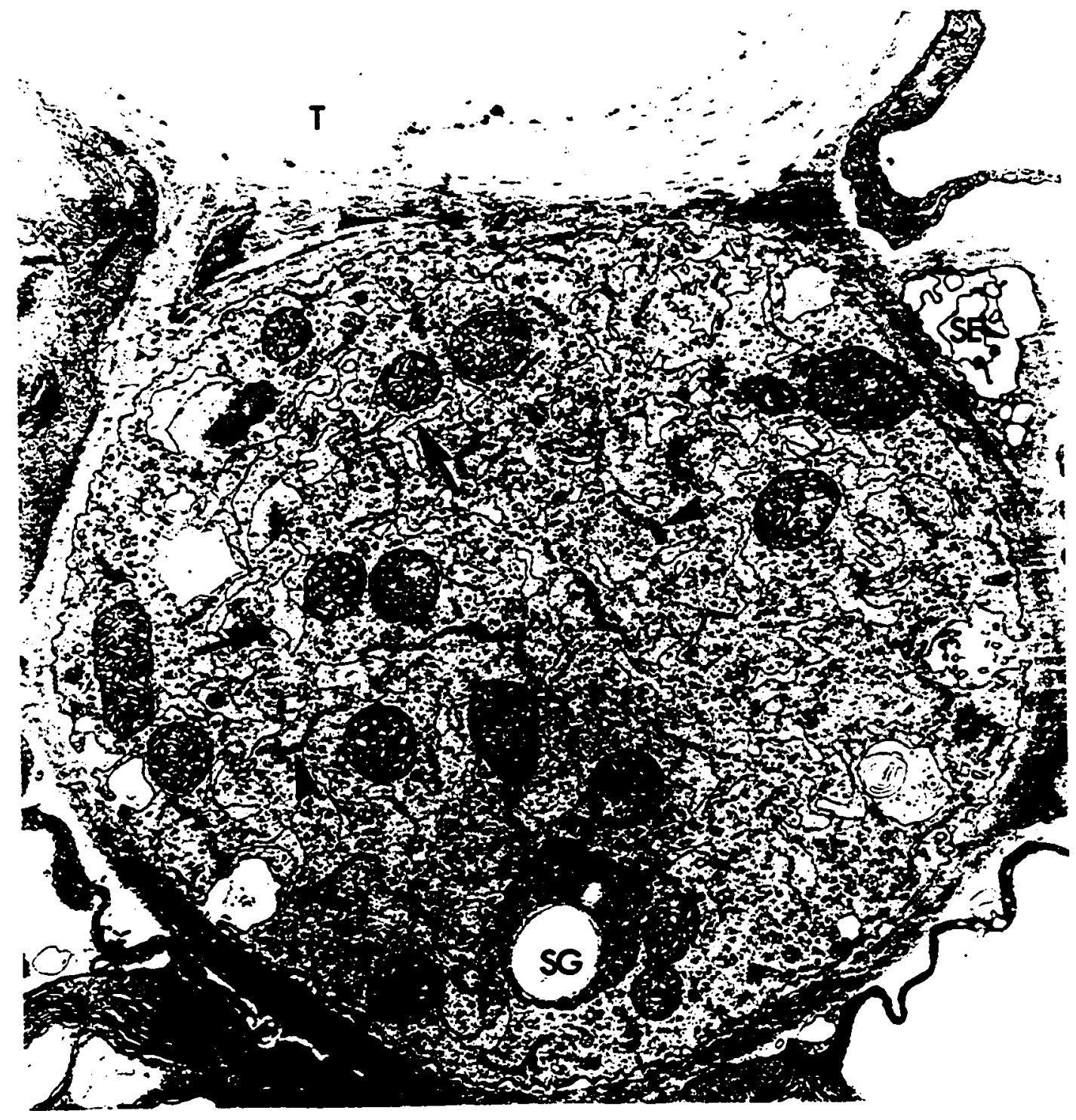




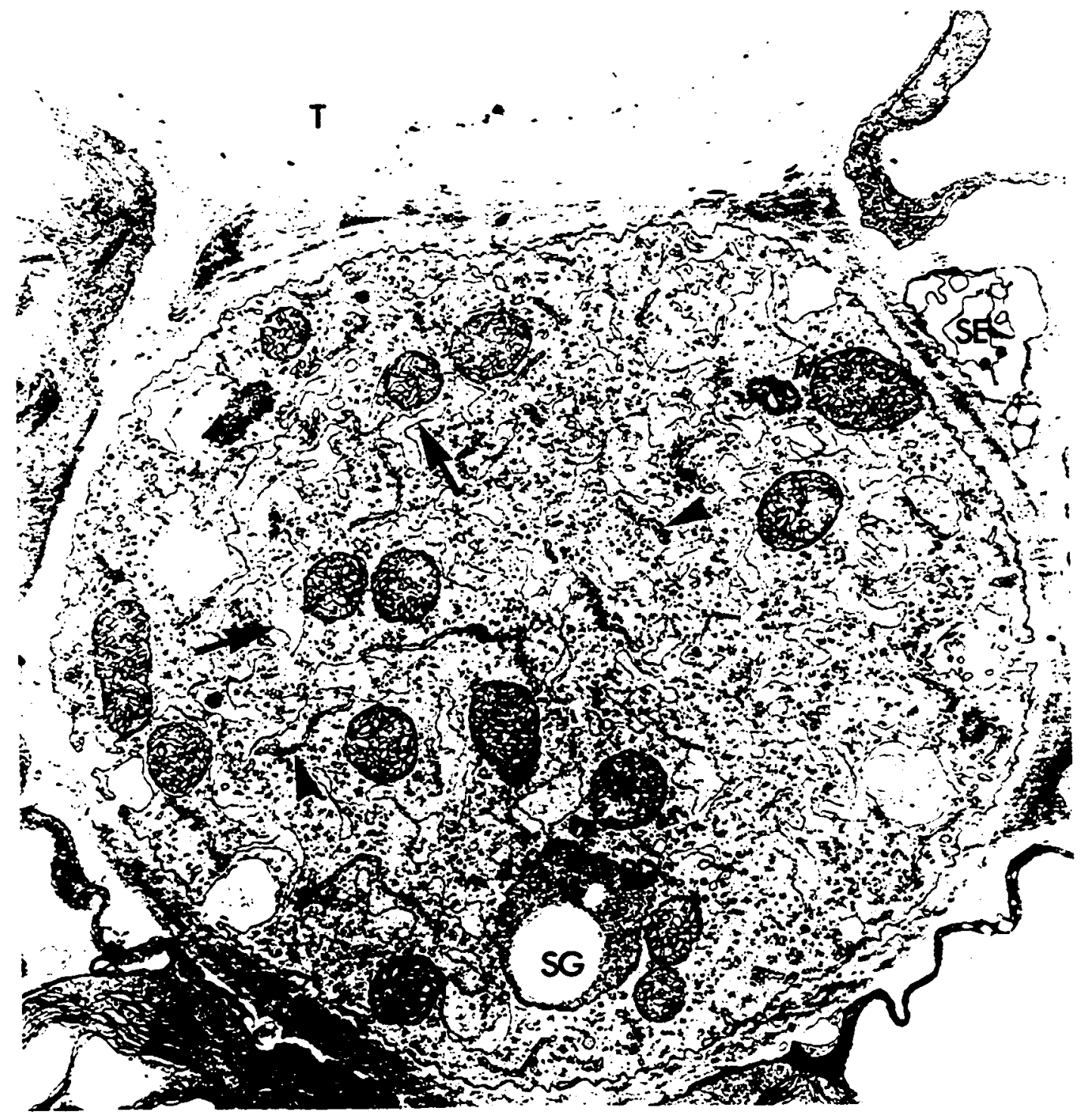




\section{II. $\underline{x y l e m}$}

Tracheids are devoid of cytoplasm at maturity, although terminal elements are often filled with a dense material which stains deeply with methylene blue (Fig. 33) and has an amorphous appearance in electron micrographs (Fig. 50). The primary wall of the mature tracheids is hydrolyzed except where protected by secondary wall (Fig. 50).

\section{Parenchyma}

A large central vacuole occupies most of the volume of minor vein parenchyma cells and organelles are restricted to the periphery of the cell (Figs $31,59,60$ ). Mitochondria and chloroplasts are present. The mitochondria are normal in appearance but not as numerous as they are in the companion cells. The chloroplasts are slightly smaller than those of the mesophyll and grana are present. Osmophilic globules and large starch grains are commonly found (Fig. 59). Occasional plasmodesmata connect the parenchyma cells of the minor veins to bundle sheath cells (Fig. 59).

\section{Adaxial Phloem}

\section{(1) Sieve Elements}

The adaxial phloem of sixth and seventh order veins consists, in cross-section, of a single sieve element and 
FIG. 49

Transection of the abaxial phloem of a fifth order vein. Electron micrograph. Companion cells (CC) are smaller in the interior of the phloem than at the periphery where they abut bundle sheath cells (BS). Plasmodesmata (PL) join the large companion cells and bundle sheath cells. Tracheid (vessel member?) at T. Sieve elements at SE. $\times 4,600$

\section{FIG. 50}

Transection of a mature minor vein tracheid filled with amorphous, electron-dense material (*). Electron micrograph. The primary wall $(W)$ of the tracheid has been hydrolyzed (HW) except where protected by secondary wall (SW). $\times 114,600$ 


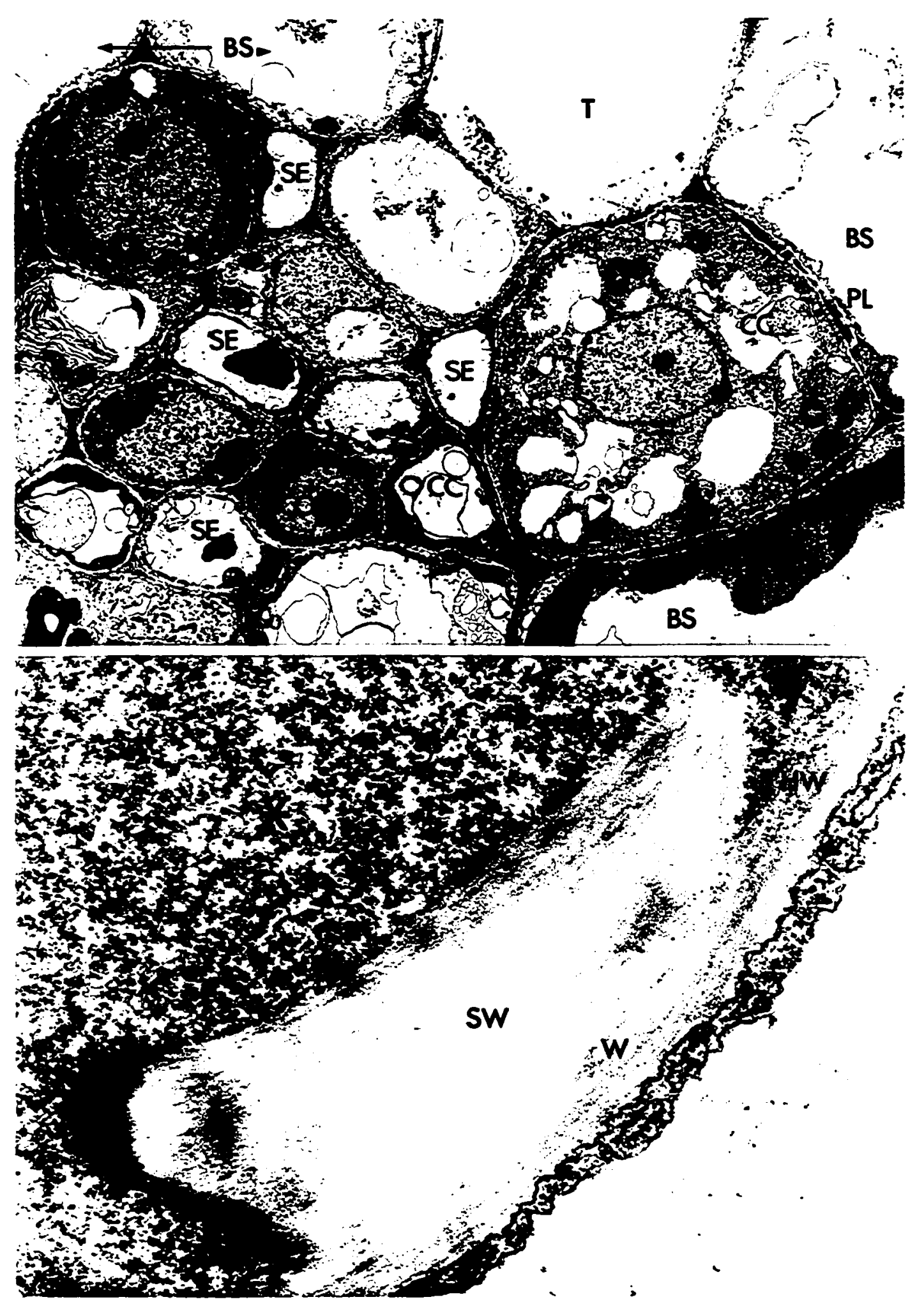




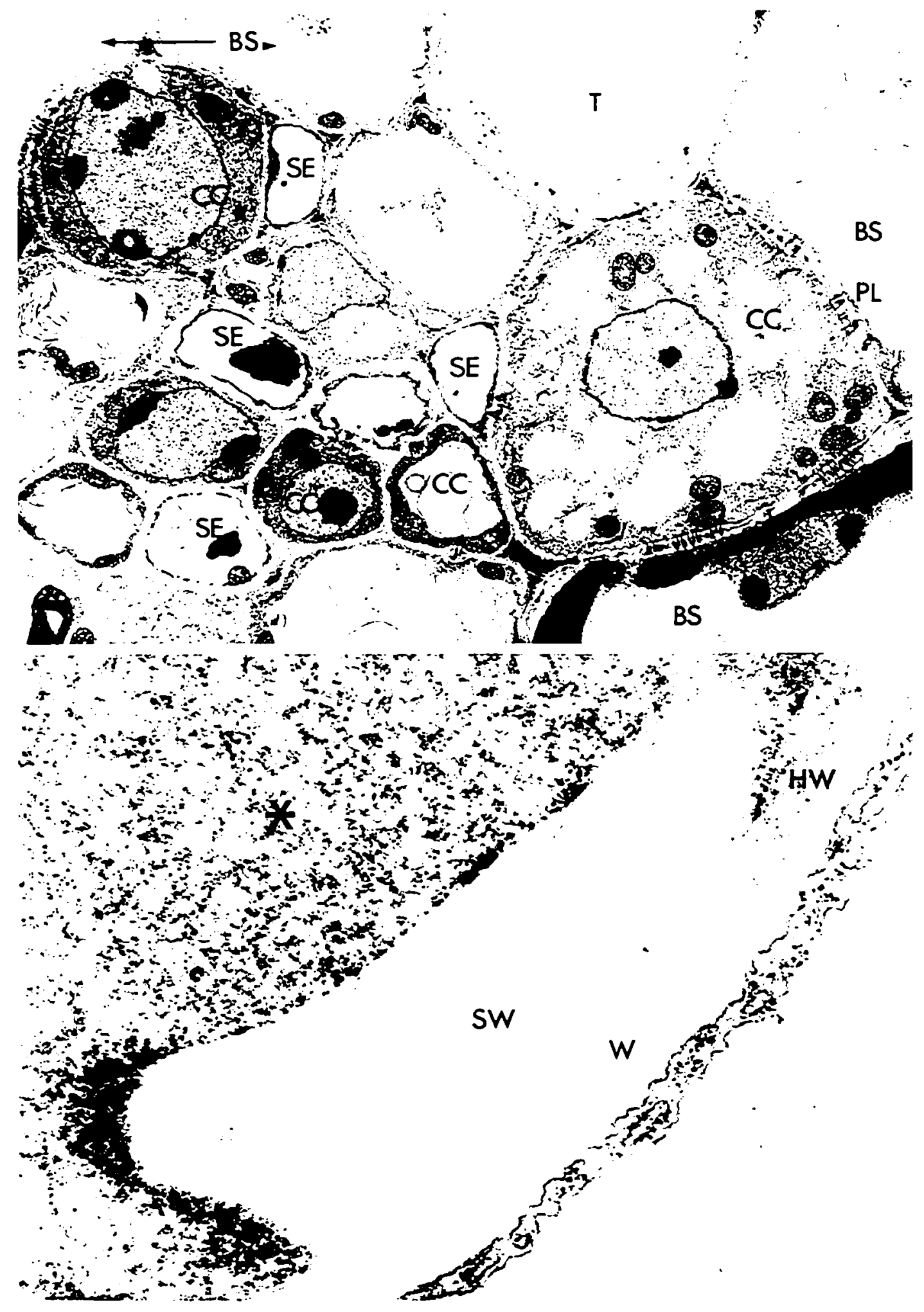


companion cell (Fischer, 1885; Figs 31, 59, 60). Sieve elements of the adaxial phloem differ markedly in structure from those of the abaxial sieve elements of the same veins. In many respects adaxial sieve elements resemble extrafascicular sieve elements of the stem rather than those found within the vascular bundles. The adaxial sieve elements are wider in diameter (approximately $6 \mu$ ) than the abaxial sieve elements (approximately $2 \mu$ ). The lumen of mature adaxial sieve elements is essentially free of cytoplasm (Figs 51, 52, 54, 55, 60). The tonoplast is absent and P-protein and cell organelles usually occupy a parietal position close to the plasmalemma. P1, P3 and P4-protein bodies are found in immature (Fig. 62) and mature (Figs 51-53) sieve elements. Much of the fibrillar P3-protein remains as such, i.e. it is not converted to tubular P4protein. As in the extrafascicular sieve elements of the stem the P-protein bodies do not disperse. Therefore, the sieve elements contain little fibrillar p-protein.

Aside from occasional pieces of P-protein the sieve plate pores of the adaxial sieve elements are free from obstruction (Fig. 51, 52). The pores are large and callose, if present at all, forms only a thin layer. A comparison of Figures 51 and 52 with Figures 6 and 7 of the paper by Cronshaw and Esau (1968b) reveals a marked similarity between pores of the minor vein adaxial sieve elements and those of the extrafascicular sieve elements of the stem phloem. The 
FIG. 51

Paradermal section of mature adaxial sieve elements. Electron micrograph. p4-protein (P4) extends through some of the pores (P); the rest are open. Cell walls of the sieve elements are less electron-dense than walls of bundle sheath cells (BS). Callose at $C$. $\times 16,100$

\section{FIG. 52}

Paradermal section of sieve plate between two mature adaxial sieve elements. Electron micrograph. P4-protein (P4) is associated with the pores. Callose at C. $\times 21,500$ 


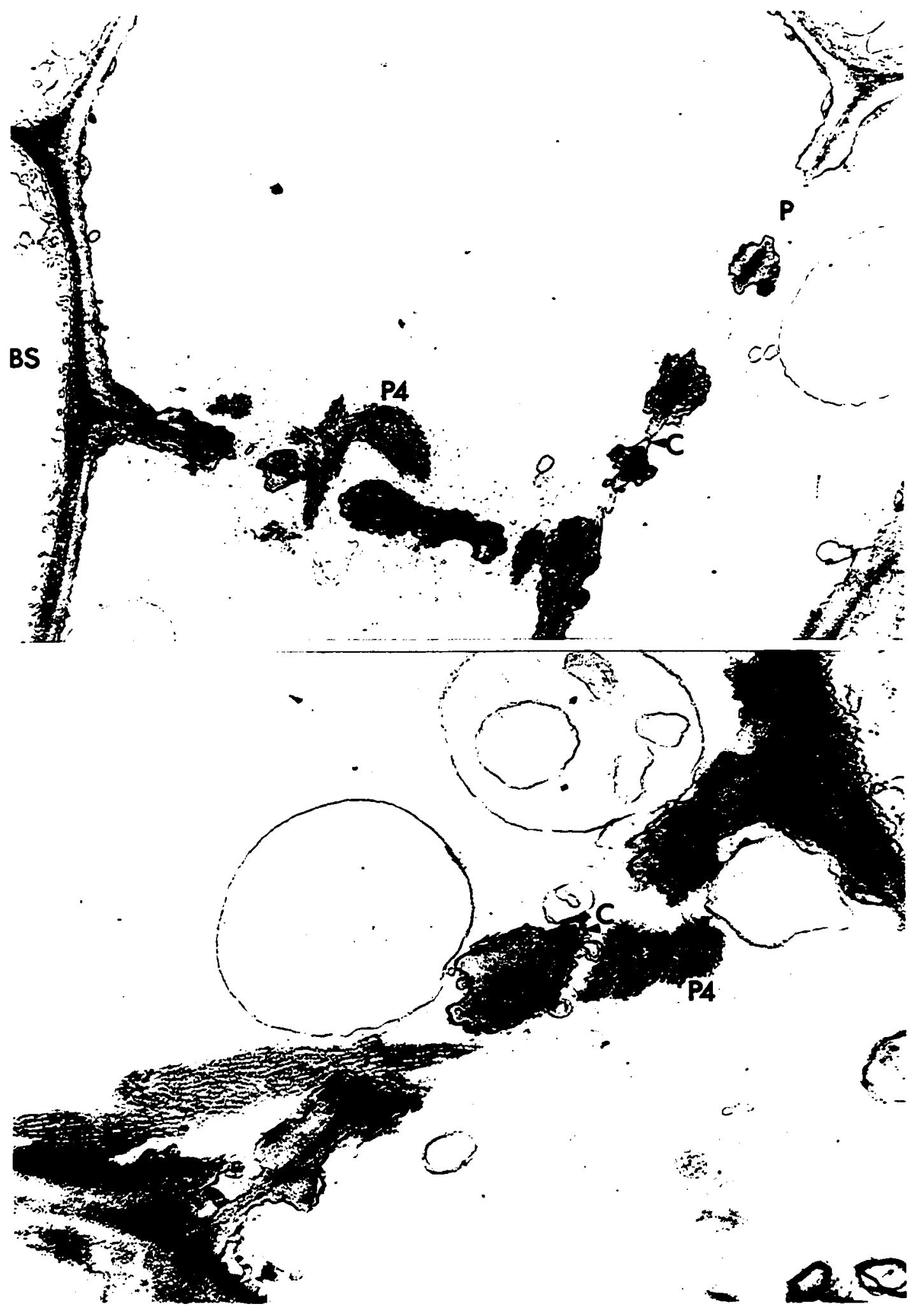




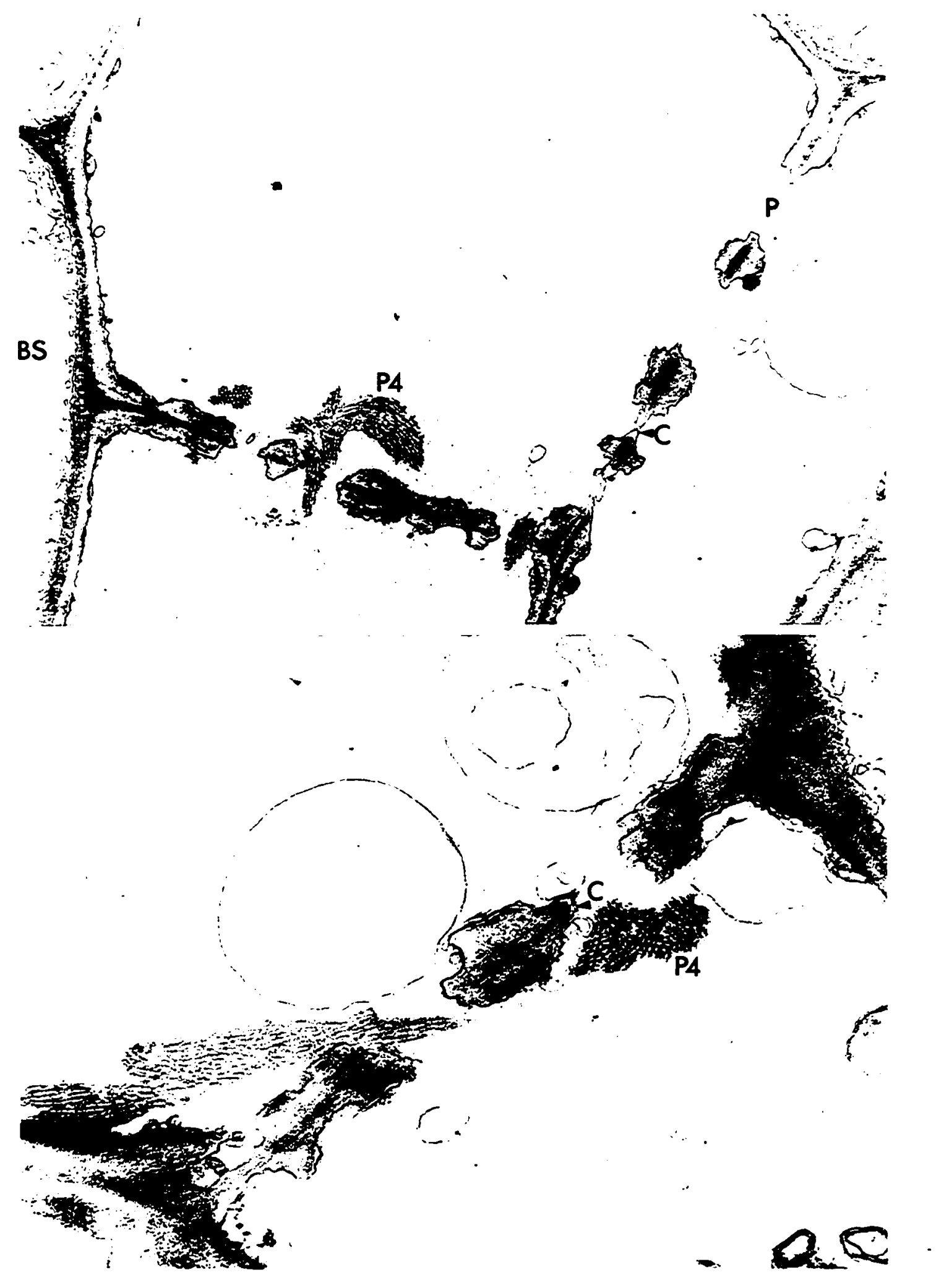


FIG. 53 (ABOVE)

Paradermal section of mature adaxial sieve element showing two P-protein bodies. Electron micrograph. The fibrillar protein is $\mathrm{P3}$-protein (P3), the tubules are P1-protein (PI). $\times 45,200$

FIG. 54 (LOWER LEFT)

Transection of mature adaxial phloem. Electron micrograph. P-protein fibrils and tubules occupy a parietal position in the sieve element ( $S E^{\prime}$ ). Companion cell (CC') cytoplasm is dense. Plasmodesmata (PL) join the companion cell and sieve element. Dictyosomes at D. Microtubules (arrow head) line the plasmalemma beneath the fibrillar P-protein body. $\times 17,800$

\section{FIG. 55 (LOWER RIGHT)}

Paradermal section of adaxial sieve element showing parietal distribution of P-protein and cell organelles. Electron micrograph. Mitochondrion at $M$, plastid at PD. The outer membrane of the plastid has been broken and is folded back (arrow heads). $\times 12,700$ 


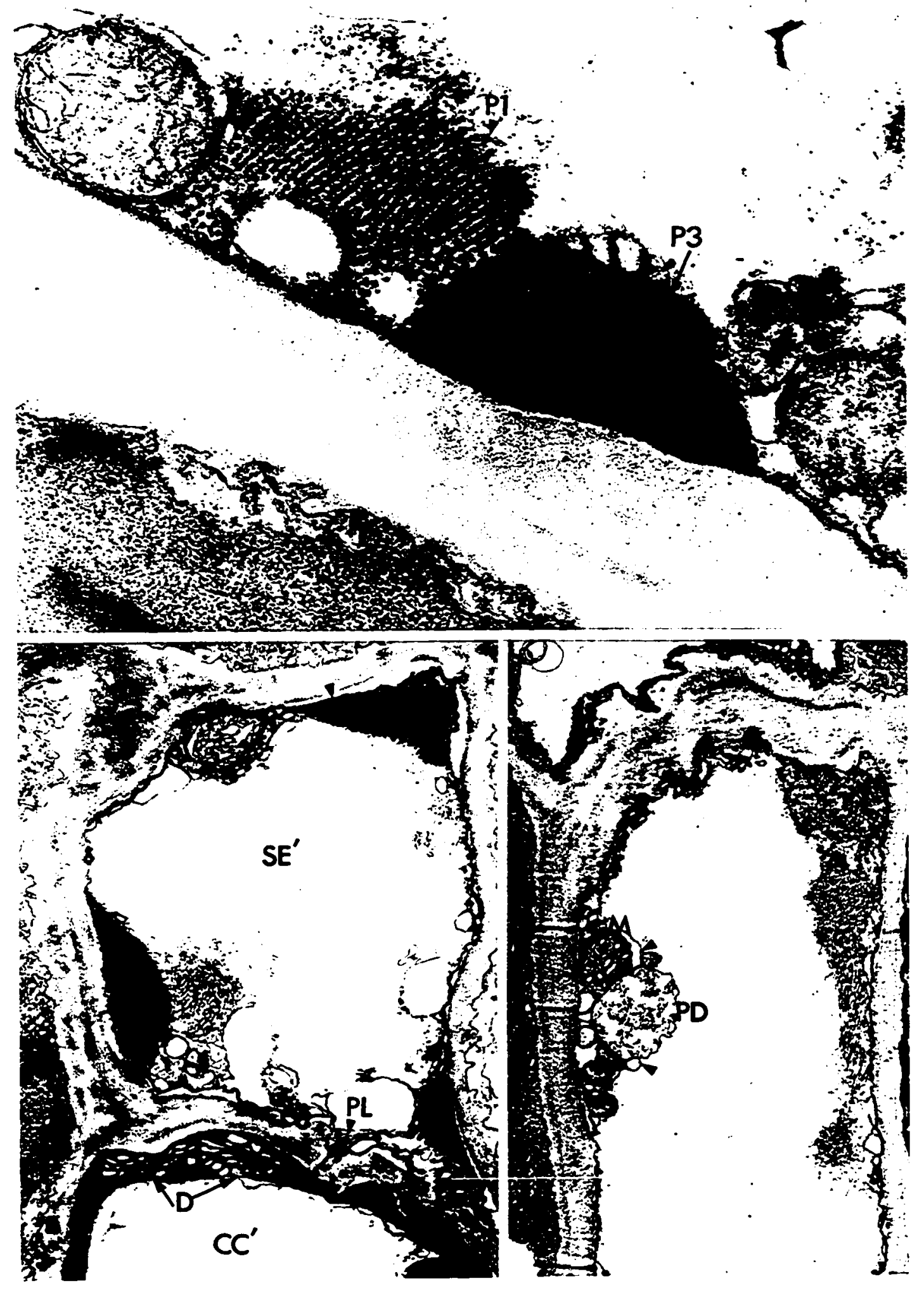




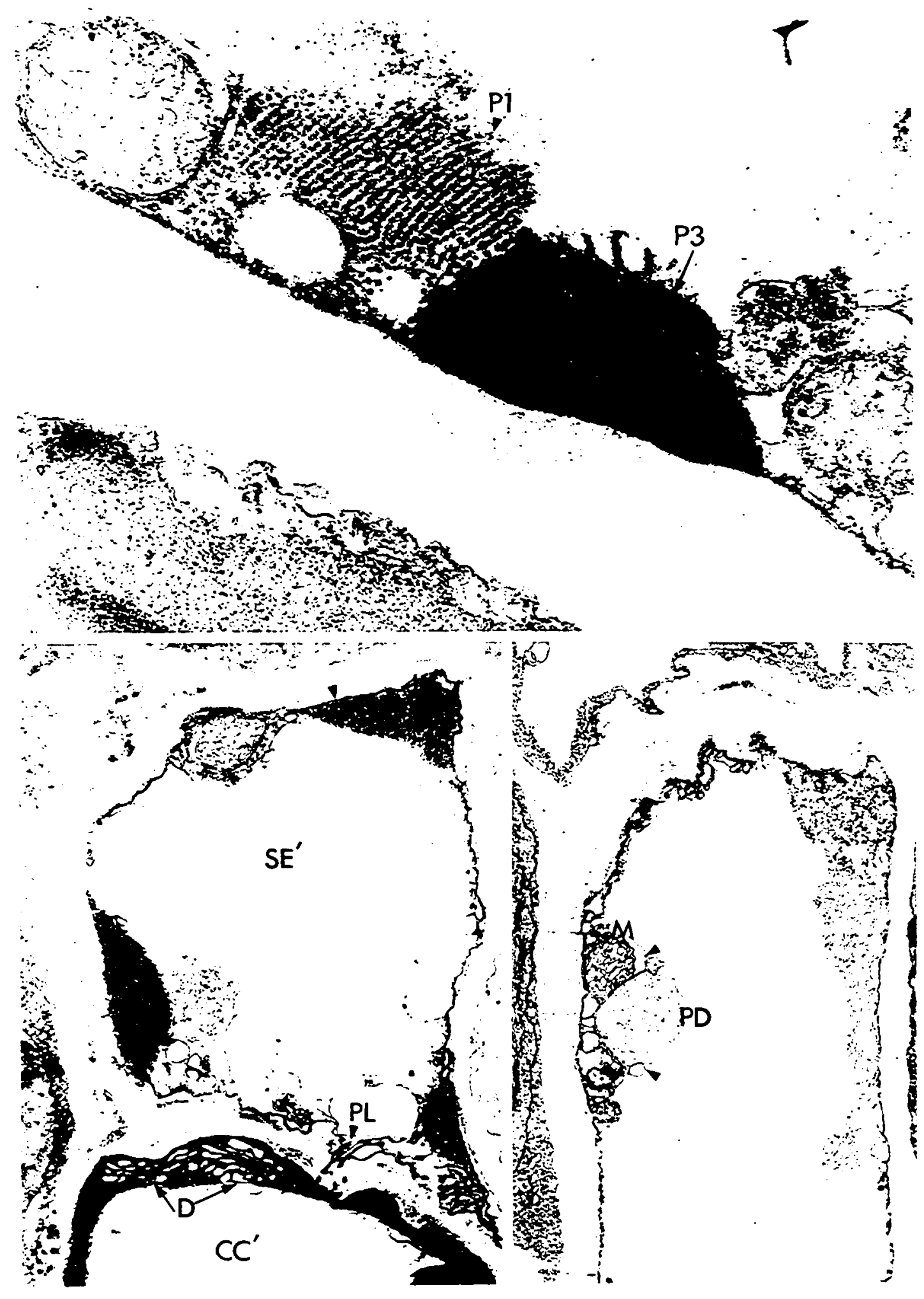


pores of both cell types have little associated callose and the edges of the pores have an irregularly-sculptured appearance. Cell walls of the adaxial sieve elements appear less electron-dense than those of associated cells (Fig. 51).

Mitochondria in adaxial sieve elements are relatively normal in appearance (Figs 53-55). They are bounded by a double membrane, the stroma is dense, and there are a large number of internal membranes. The cristae appear somewhat swollen but this feature is sometimes true of mitochondria in mesophyll cells. In contrast to mitochondria in other cell types those in mature sieve elements always appear round.

Occasionally, plastids are encountered in adaxial sieve elements (Fig. 55). These organelles are degenerate in appearance, the stroma is sparse and there are no internal membranes. No starch has been detected in these plastids. The plasmalemma is intact in mature sieve elements and extends through the pores (Figs 51, 52). Membrane fragments are common in the cell lumen. Microtubules are plentiful in immature sieve elements (Fig. 61) but in immature sieve elements they are restricted to a single location, between P-protein bodies and the plasmalemma (Fig. 54).

\section{(2) Companion Cells}

Companion cells of the adaxial phloem are markedly 
different in appearance from those of the abaxial phloem. The cell interior is highly vacuolate and the cytoplasm is restricted mainly to the cell periphery (Figs $31,35,60$ ). The cytoplasm is extremely dense due primarily to the large number of closely compacted ribosomes (Figs 56-58).

Mitochondria are numerous but are degenerate in appearance; the matrix is sparse and there are few internal membranes (Figs 56-58). Plastids are large and without grana but they often produce starch granules (Figs 56, 60). The cytoplasm also contains large osmiophilic bodies (Figs 56-59), dictyosomes and dictyosome derived vesicles (Figs $54,56,58)$. The companion cells and sieve element are connected by plasmodesmata which are branched on the companion cell side (Figs 54,60 ). Plasmodesmata also connect cells of the palisade mesophyll and bundle sheath with the adaxial companion cell (Fig. 54). These plasmodesmata are not as numerous as those between the abaxial companion cell and bundle sheath cells.

F. DEVELOPMENT OF THE MINOR VEINS

\section{U1trastructure}

Preliminary to the light microscope study of vein development described below, thin sections of developing sieve elements were cut and observed in the electron 
FIG. 56

Paradermal section of mature adaxial sieve element (SE') and companion cell (CC'). Electron micrograph. Companion cell is highly vacuolate. Mitochondrion at $M$, dictyosome at $D$, osmiophilic body at $O B$. The electron lucent region of the osmiophilic bodies is probably an artifact of tissue preparation. $x 5,200$

FIG. 57

Paradermal section of adaxial companion cell (CC'). Electron micrograph. Note the density of cytoplasm compared to other cells. Mitochondrion at M, osmiophilic body at OB. $x 34,400$

FIG. 58

Paradermal section of adaxial companion cell showing densely compacted ribosomes $(*)$. Electron micrograph. Mitochondrion at $M$, osmiophilic body at $O B$. $\times 49,600$ 


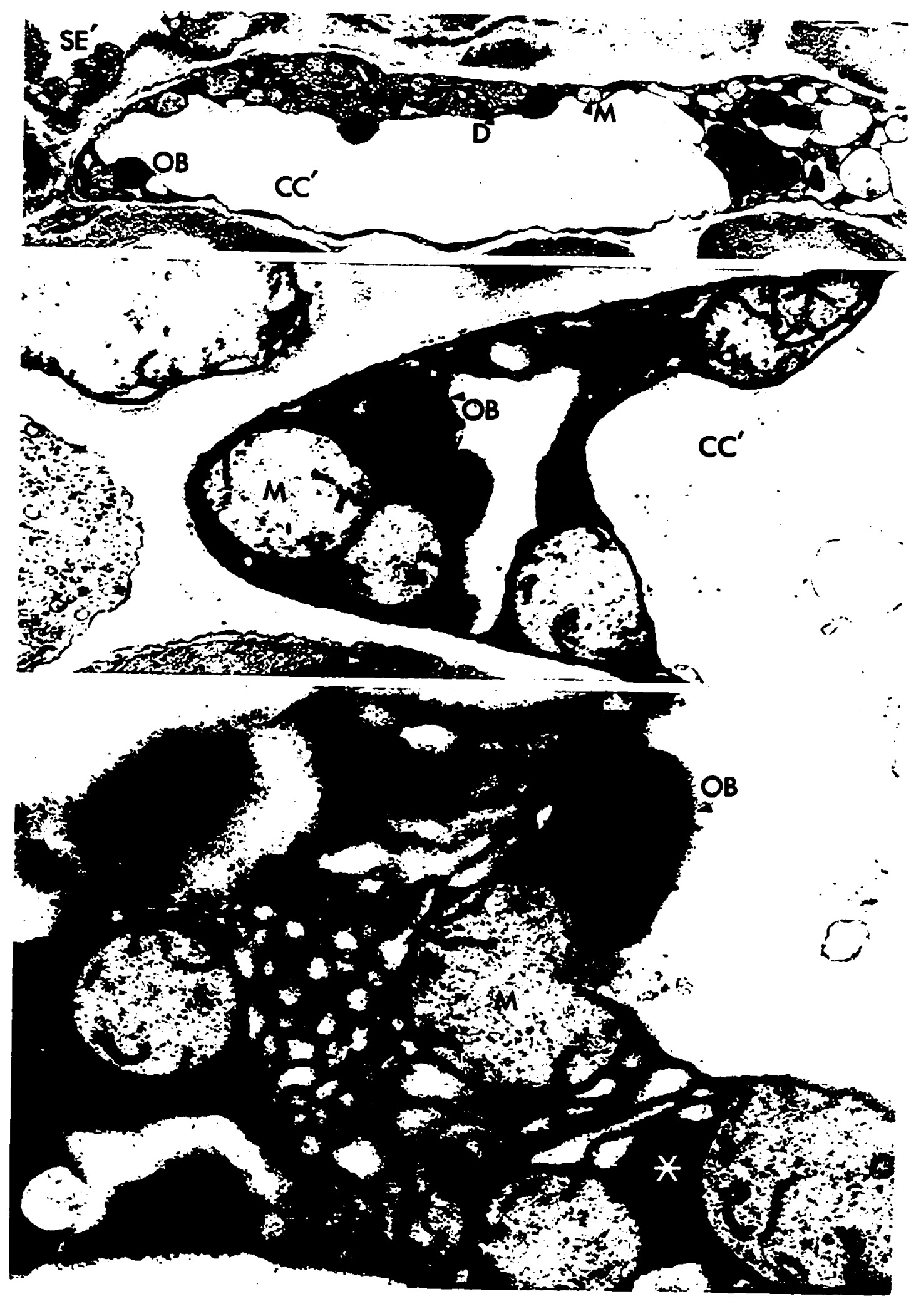




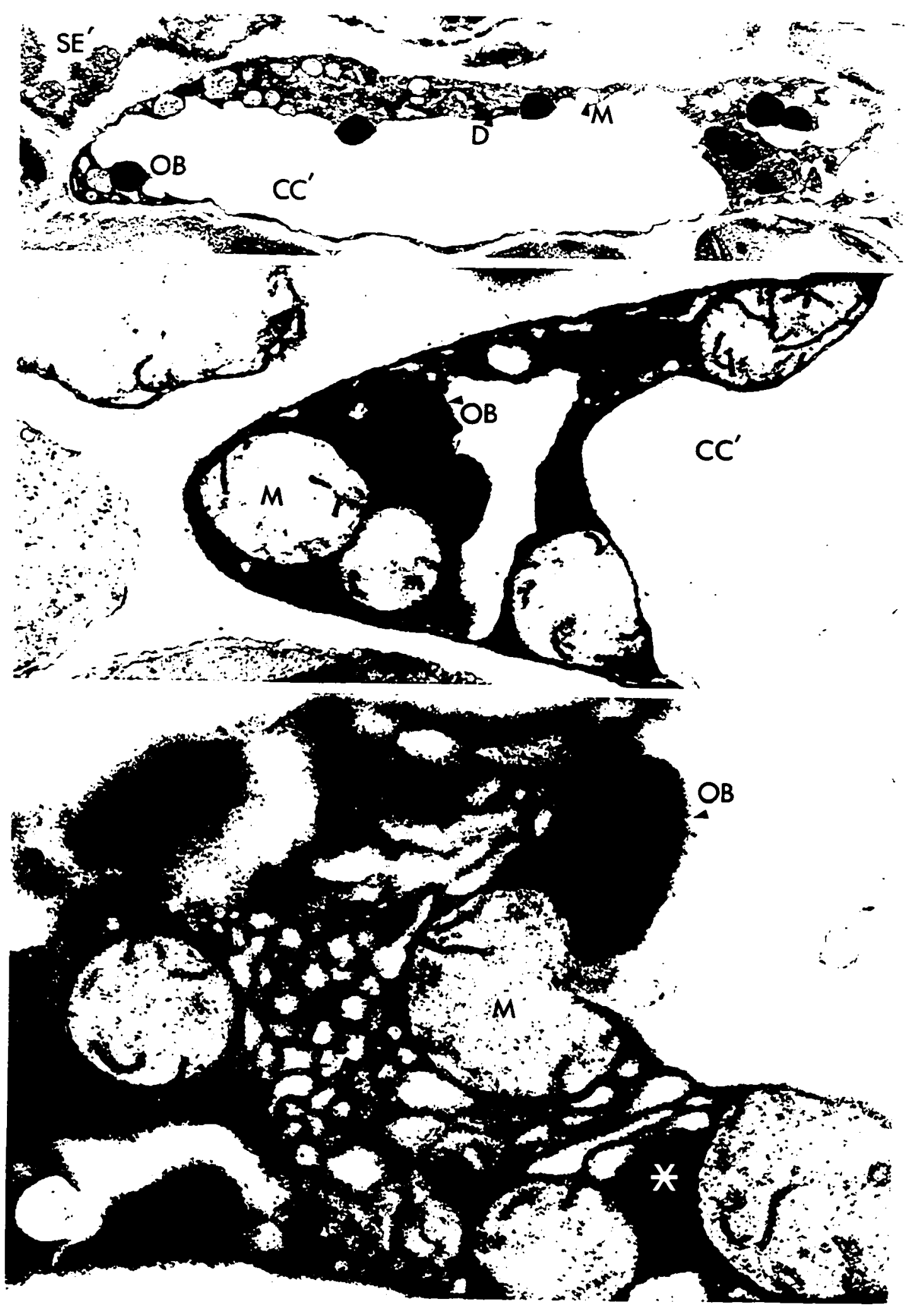


FIG. 59

Transection of immature minor vein. Electron micrograph. Adaxial sieve element (SE') contains P-protein (arrow heads). Probable tracheid precursor $(T)$ is without secondary walls. Plasmodesmata connect the abaxial companion cell (CC) to bundle sheath cells (BS). Parenchyma cell at PA contains a plastid with starch grains. Adaxial companion cell at CC', abaxial sieve element at SE. $\quad \times 4,800$

FIG. 60

Transection of minor vein nearing maturity. Electron micrograph. Cytoplasm of adaxial companion cell (CC') is dense. Lumen of adaxial sieve element (SE') is virtually empty. One tracheid ( $T$ ) contains no cytoplasm; another has deposited secondary wall (SW) material but is still filled with cytoplasm. Plasmodesmata between the abaxial companion cells (CC) and bundle sheath cells (BS) are numerous. Abaxial sieve elements at SE. $\quad \times 3,700$ 


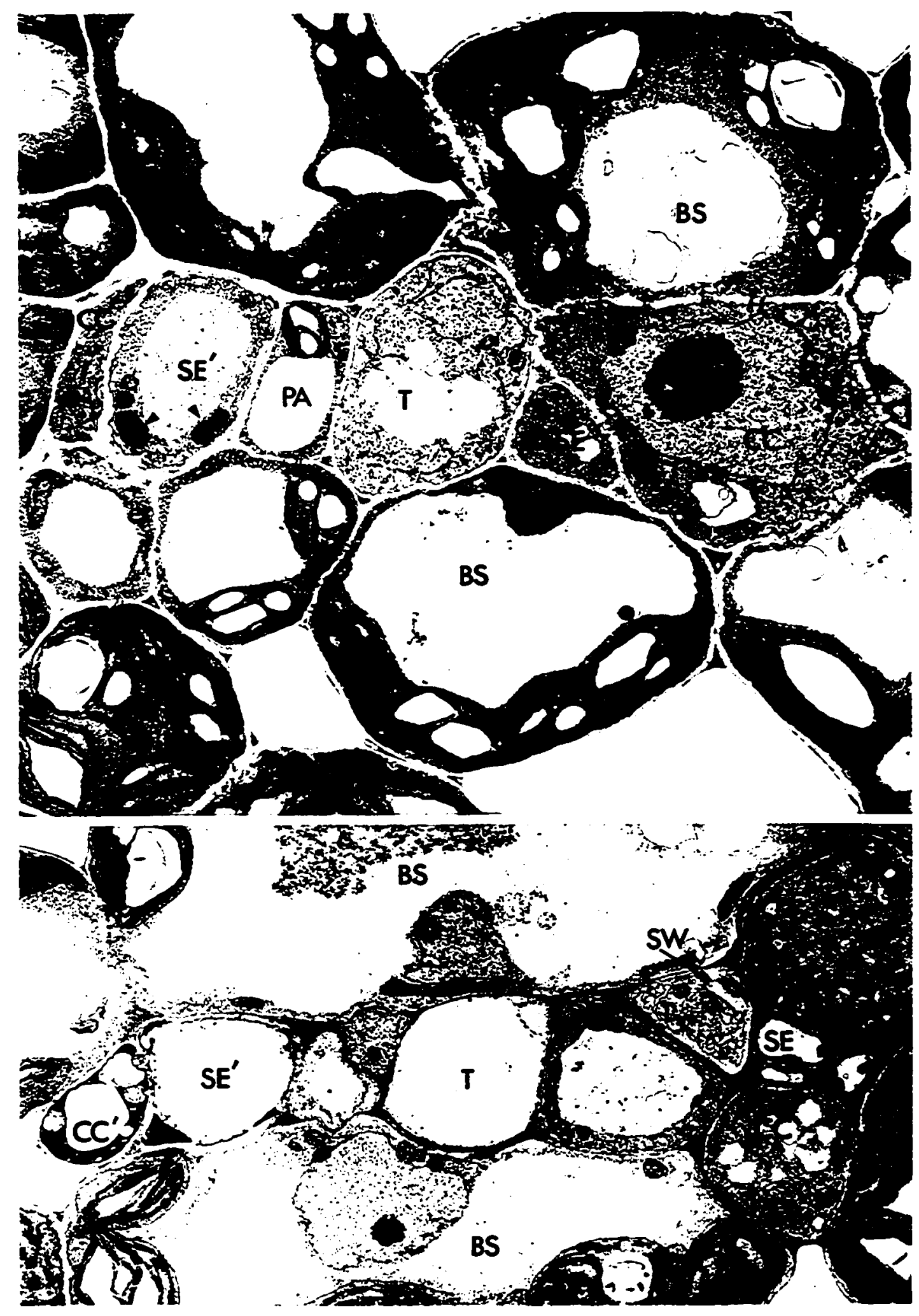




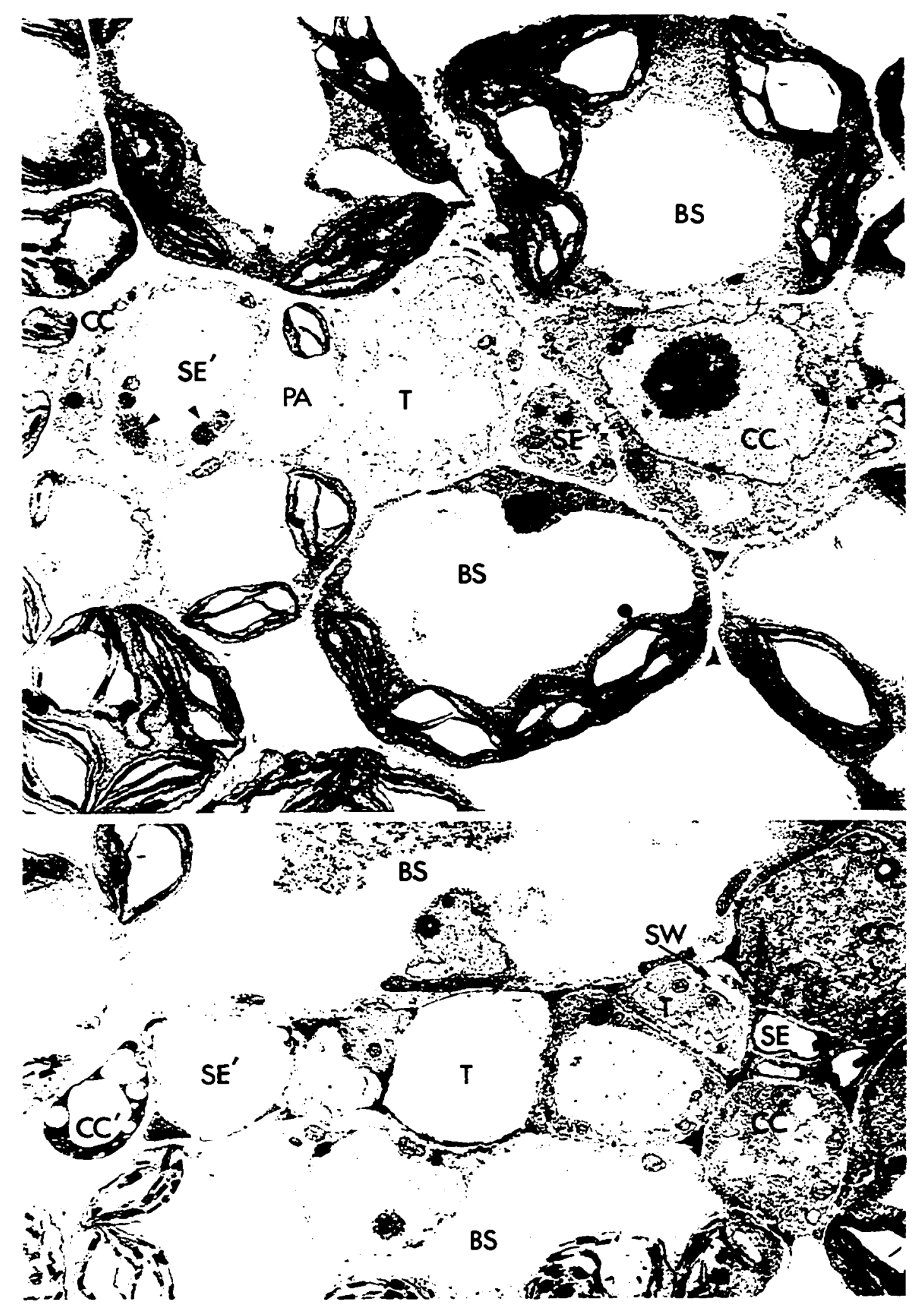


microscope. This study was not extensive and no attempt was made to document the development sequence in detail. Figures 59 and 60 are cross-sections of minor veins. The vein in Figure 59 is immature but the cell types are easily distinguished by their relative positions in the vein. The adaxial sieve element contains $\mathrm{P}$-protein bodies. The large cell in the middle of the vein is presumed to be a tracheid precursor, although no secondary wall formation is evident. The narrow abaxial sieve element is immature. The minor vein in Figure 60 is mature except that cytoplasm remains in one tracheid.

In Figures 61-63 examples of developing adaxial sieve elements are pictured. These micrographs suggest that the developmental process which the adaxial sieve elements undergo is similar to the well-documented sequence described for the phloem of many species (Esau, 1969). The cytoplasm of immature sieve elements contains the usual cytoplasmic components (Fig. 61). Microtubules are oriented parallel to the axis of electron dense fibrils of the cell wall. P-protein bodies are evident in the immature sieve element pictured in Figure 61. As the sieve element matures, callose is deposited on the sieve plate and primary cell wall material is removed from beneath the callose platelets (Fig. 62). By the time the sieve plate pores have opened, which presumably signals the functional maturity of the cell, the cytoplasm has degenerated to the state characteristic of 
FIG. 61

Paradermal section of an immature adaxial sieve element (SE') and other unidentified cells. Electron micrograph. Sieve element contains P-protein (arrows). Microtubules (arrow heads) are distributed close to the plasmalemma parallel to electron-dense fibrils in the cell wall (CW). $\times 23,600$

FIG. 62

Paradermal section of sieve plate between two immature adaxial sieve elements ( $\mathrm{SE}^{\prime}$ ). Electron micrograph. Callose (C) has been deposited on the plate and wall material beneath the callose has been removed. Endoplasmic reticulum (ER) is intimately associated with the developing callose platelets. $\times 9,400$

FIG. 63

Paradermal section of adaxial sieve elements. Electron micrograph. One pore $(P)$ in the sieve plate has opened. The plasmalemma (arrow head) lines the wall. A membrane, presumably the tonoplast, is also present and is broken at the ends (arrows). $\times 8,200$ 


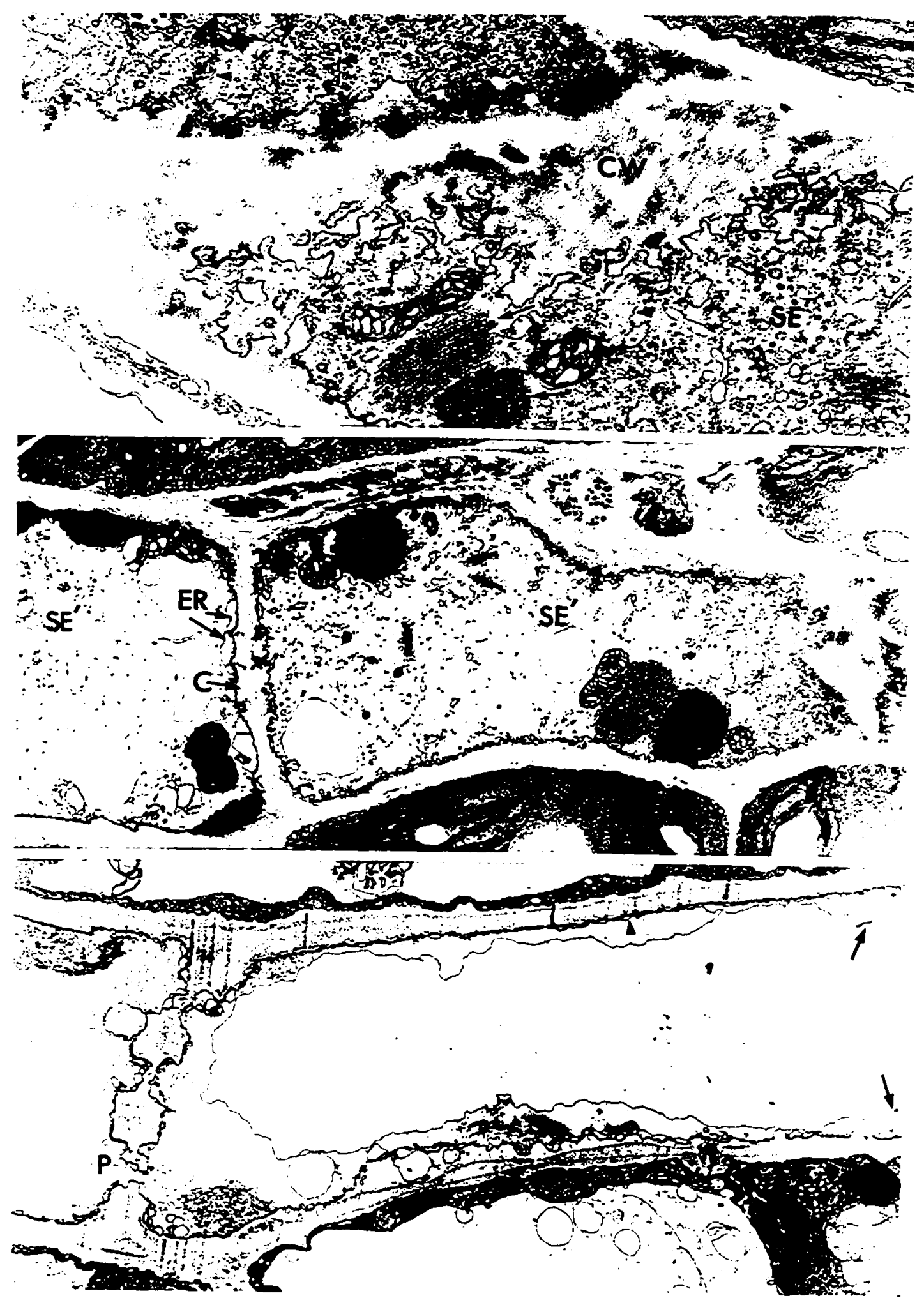




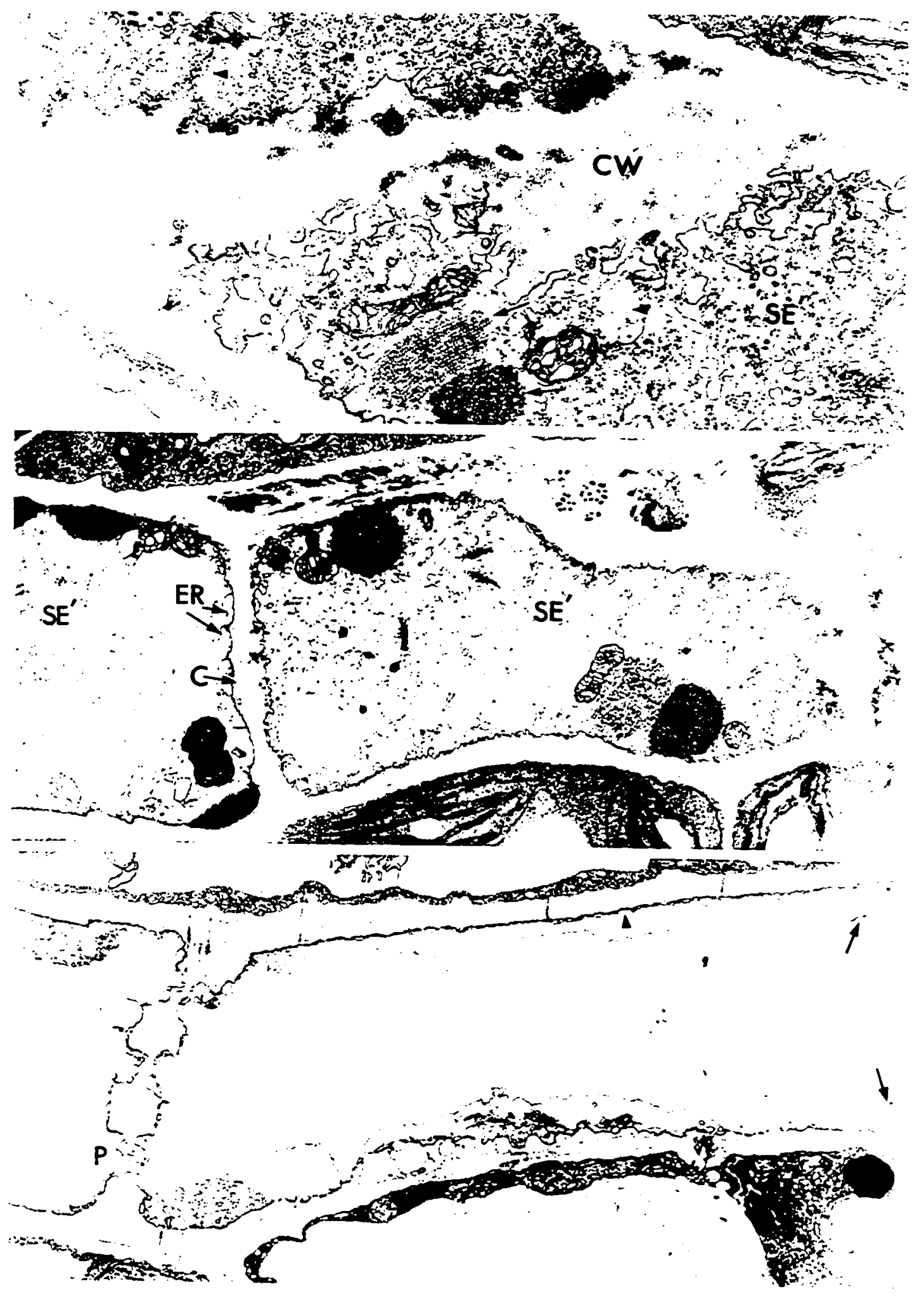


mature sieve elements (Fig. 63). In Figure 63 the tonoplast is apparently present although at least one sieve pore has opened. The tonoplast is generally thought to disintegrate before the pores open (Esau, 1969). Figure 64 pictures an immature adaxial sieve element in paradermal section. Although the pores are not open at either end of the cell, fibrillar material, presumably originating from P3-protein bodies, has formed a slime plug.

II. Development in Relation to Phloem Transport

An experiment was undertaken to study the structural development of the minor veins of developing leaves in relation to their phloem transport function. In order to facilitate the interpretation of the data ${ }^{14} \mathrm{C}$-transport experiments were conducted on each leaf used for microscopic examination.

Leaf 3 was first labelled with ${ }^{14} \mathrm{CO}_{2}$ for 5 min as previously described. Two hours later sections of leaf 5 were removed, fixed in glutaraldehyde, post-fixed in osmic acid, and processed as usual for electron microscopy. Two areas of each leaf were sampled, one in the distal and one in the proximal region of the lamina (Fig. 65). Care was taken to sample comparable regions in each leaf. Once the areas to be fixed had been removed the lamina was frozen and autoradiographed. Paradermal sections of samples embedded in 
FIG. 64

Paradermal section of an immature adaxial sieve element. Electron micrograph. Pores are not yet open at either sieve plate (SP). Dense material, presumably composed of $\mathrm{P}-$ protein fibrils, has accumulated at one end of the cell. Companion cell at CC. Bundle sheath cell at BS. $x 3,200$ 


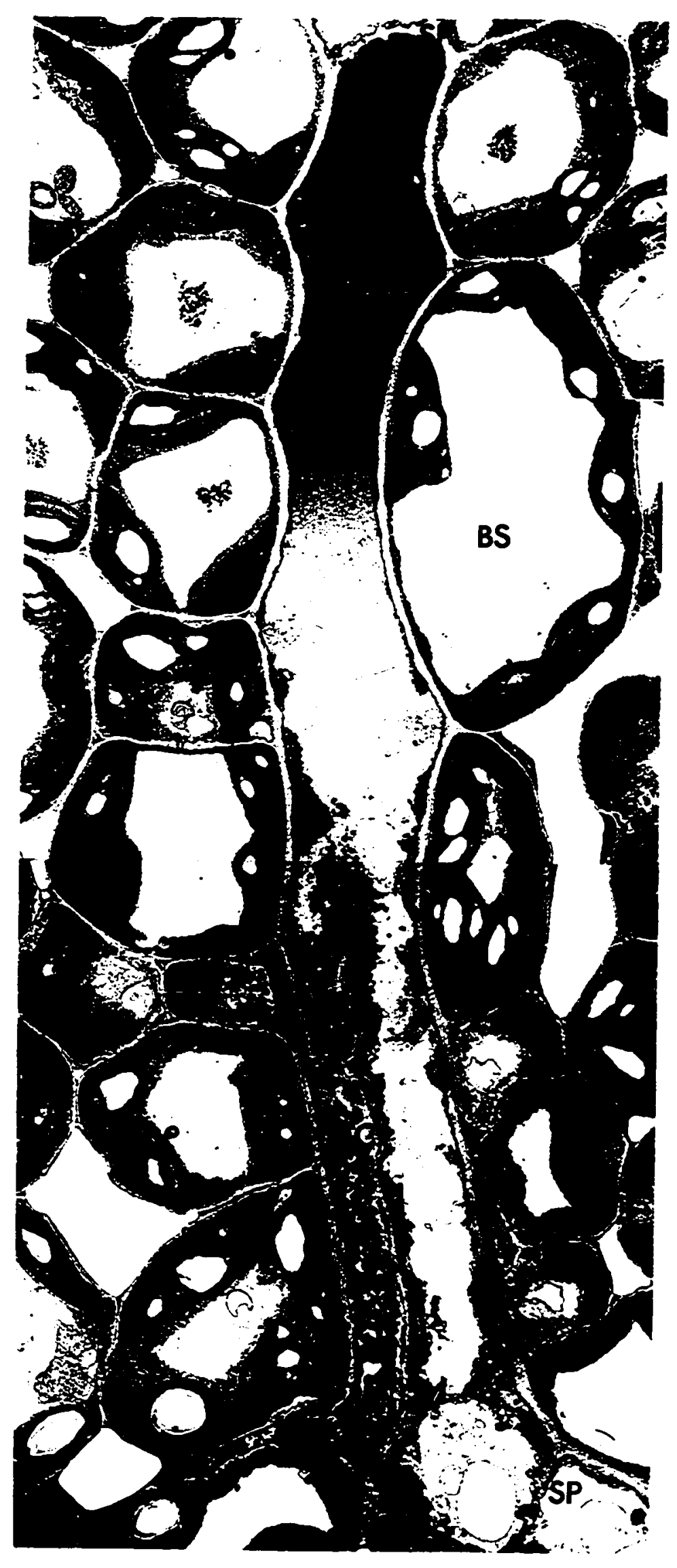




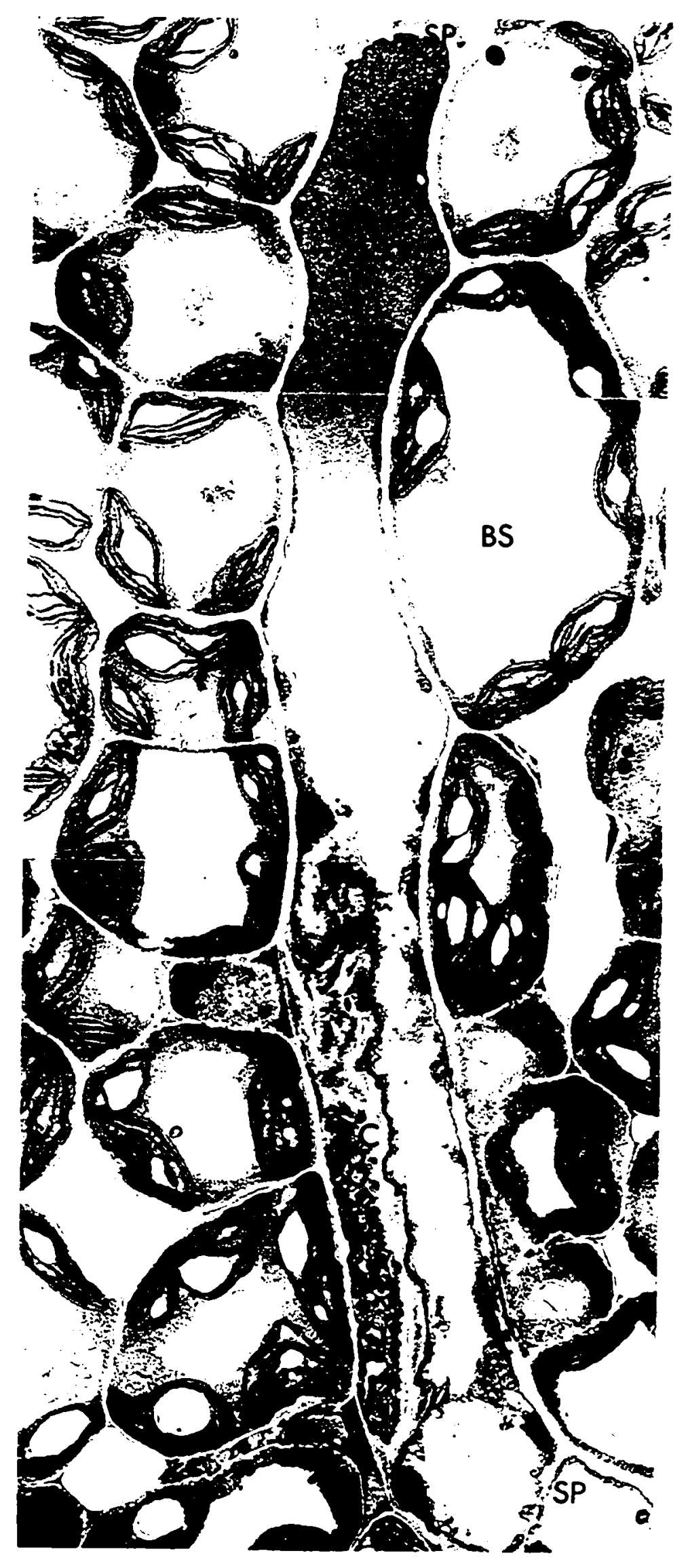


FIG. 65

Schematic outline drawings of developing areoles in paradermal view. Autoradiographs of leaves from which the samples were taken are drawn at the left. Arrows point from the position in the leaf where the sample originated to a series of drawings of a representative areole from that sample. The areoles are drawn at three levels: adaxial sieve elements, xylem, and abaxial sieve elements. Lines normal to the longitudinal axes of the cells indicate the positions of end walls. Scale beneath autoradiographs $=4 \mathrm{~cm}$, beneath areoles $=100 \mu$. A light micrograph of the areole from the proximal position of leaf III at the level of the adaxial sieve elements is shown in Figure 66. A light micrograph of an areole from the proximal position of leaf $I$ at the level of the xylem is shown in Figure 67.

\section{LEGEND:}

Adaxial sieve elements

with open sieve plate pores

with closed sieve plate pores

Xylem

tracheids with secondary walls deposited, no cytoplasm

tracheids with secondary walls deposited, containing cytoplasm

tracheids with no secondary walls deposited

Abaxial sieve elements

with no cytoplasm visible in

light microscope

filled with cytoplasm 


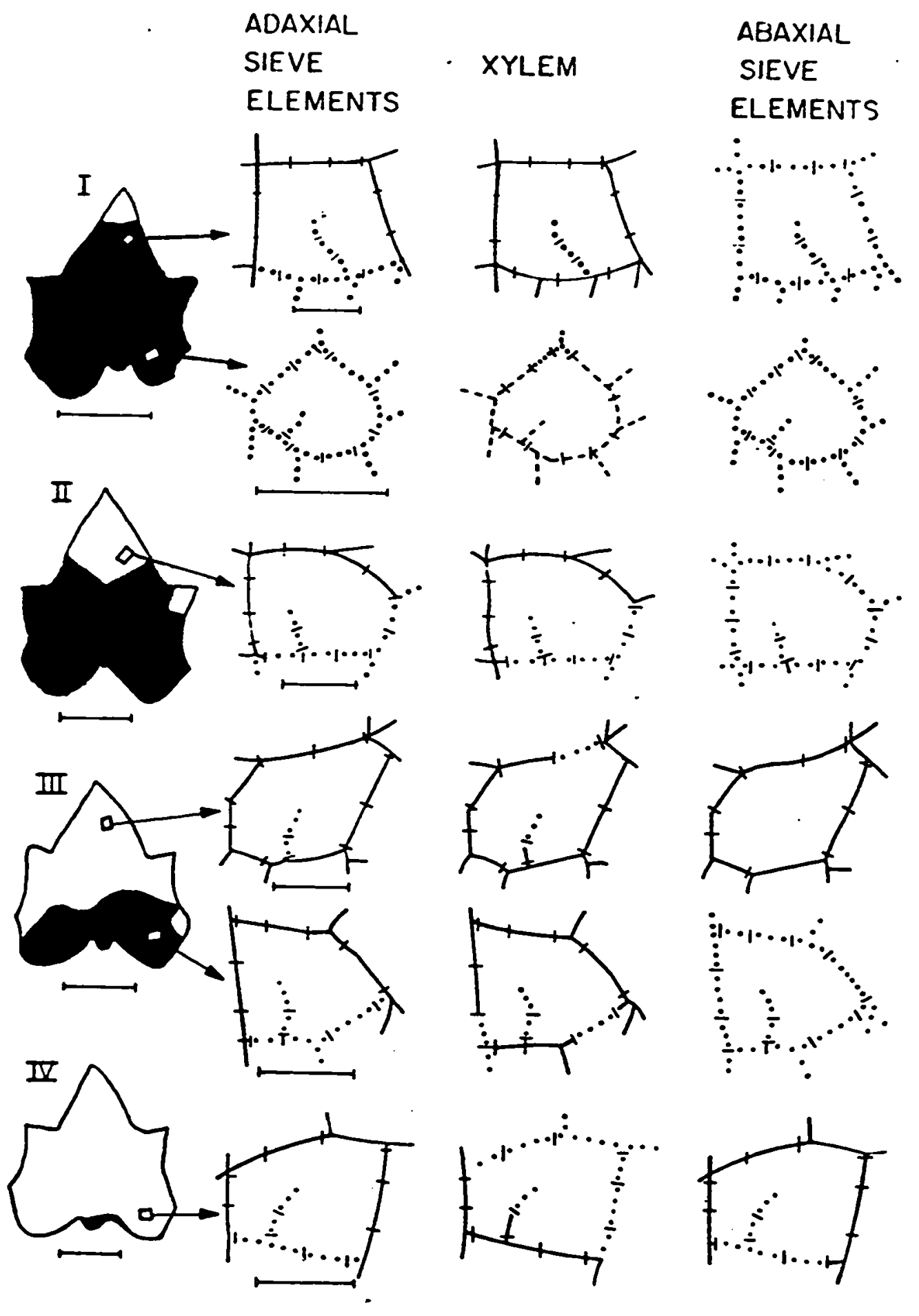


Epon-Araldite were cut serially, $1 \mu$ thick, placed in order on glass slides, stained with methylene blue, and examined in the light microscope.

The degree of structural development of the adaxial phloem, abaxial phloem and xylem was studied. Particular attention was paid to single areoles which were thoroughly examined through serial sections. The structural state of development of each cell in the areole was recorded. Cucurbita minor veins are ideally suited for this study, since the cells are arranged with great regularity. Most of the areoles studied, and all those outlined in Figure 65, were bounded by veins of the sixth or seventh order. Almost all mesophyll cells are surrounded by veins of these size classes, although some areoles are bounded by larger veins (Fig. 30). Usually one or 2 areoles from a single series of sections were examined thoroughly and a general assessment of the state of maturity of other veins was also made. Variability was low; the data obtained from one or two areoles gave a good indication of the state of maturity of the sample.

The data are recorded as outline drawings of individual areoles (Fig. 65). Important features of development which are easily distinguished in the light microscope are indicated. Pores in the end walls of adaxial sieve elements were easily visible and were used as the distinguishing characteristic of maturity. Since pores are not visible in 
the sieve plates of abaxial sieve elements, the presence or absence of cytoplasm in these cells are recorded instead.

It cannot be assumed that the pores have been perforated simply because the sieve element appears free of cytoplasm. Therefore, thin sections of some veins were obtained and examined in the electron microscope to determine if the pores in the abaxial sieve elements were open (open in the sense of being perforated, not necessarily free of P-protein or other material). Although it is difficult to ascertain the position of cells within areoles in the electron microscope, some assessment of the number of sieve elements with open pores could be made. Tracheids were examined in the light microscope for the presence or absence of cytoplasm and secondary wall thickenings.

In larger veins not all elements of the phloem or xylem develop together so that one or more mature sieve elements or tracheids may be found in otherwise immature vascular tissue. In the sixth and seventh order veins this is not the case. The adaxial phloem contains only one sieve element and one companion cell and there is only one tracheid. In the abaxial phloem there may be two or more sieve elements and companion cells but these sieve elements develop in unison.

Development of the adaxial and abaxial sieve elements is continuous and proceeds from the larger veins toward the blind endings (Fig. 65; adaxial sieve elements in 
the distal position of leaf I, abaxial sieve elements in the proximal position of leaf IV). Development of the xylem follows the same general pattern (Fig. 65; distal and proximal position of leaf I, distal position of leaf II; Fig. 67) but may be discontinuous, i.e. isolated immature tracheids are sometimes found within regions of mature xylem (Fig. 65, distal position of leaf III). Vascular development is more advanced in the distal than in the proximal region of maturing leaves (Fig. 65, leaves I and III). Since the leaf develops basipetally this pattern is to be expected.

Development of the vascular tissue with time at a single location in the leaf may be followed by examining sections taken from either the distal or proximal position of progressively older leaves. By referring to the diagrams of autoradiographs obtained from these leaves it is possible to relate the development of the minor veins to the transport function of that particular area of the lamina. Since the import-export transition in the distal region is somewhat complicated by intralaminar transport, it is best to follow the changing structural pattern in the proximal position where it is clear that export follows immediately the loss of import capacity.

\section{(1) Proximal Position}

Apparently functional adaxial sieve elements with 
open pores are visible within the areole while import continues (Fig. 65, leaf III; Fig. 66). When import stops and export begins (Fig. 65, leaf IV) some of the adaxial sieve elements closest to the blind ending still have closed pores. Tracheids mature at approximately the same rate as adaxial sieve elements. When export has just begun approximately half the tracheids in the areole are completely mature, i.e. secondary wall thickenings are visible and the cytoplasm has disappeared. Abaxial sieve elements mature rapidly. While import continues the abaxial sieve elements are filled with cytoplasm and obviously not mature (Fig. 65, leaf III). However, when export begins many of the abaxial sieve elements of the areole appear empty (Fig. 65, leaf IV). When thin sections of the abaxial sieve elements of leaf IV were examined in the electron microscope it was observed that the sieve plate pores of cells essentially empty of cytoplasm were still closed. Only in the larger (probably fourth and fifth order) veins did mature abaxial sieve elements have open pores. In leaves slightly older than leaf IV (LPI 1.6) open pores were seen in abaxial sieve elements of the sixth and seventh orders.

\section{(2) Distal Position}

The same general pattern of development emerges when the minor veins in the distal position of the lamina are examined. Adaxial sieve element and tracheid development 


\section{FIG. 66}

Paradermal section of developing areole in the plane of the adaxial sieve elements. Light micrograph. Towards blind ending, sieve plate pores have not yet opened (arrows). Pores are open in rest of areole (arrow heads). This areole is drawn schematically in Figure 65 (proximal position, leaf III). x 560

FIG. 67

Paradermal section of developing areole partially in the plane of the xylem. Light micrograph. Tracheids (T) have deposited secondary cell walls and are filled with cytoplasm. Examination of serial sections revealed no other cells in the areole with secondary wall thickenings. This areole is drawn schematically in Figure 65 (proximal position, leaf I). $\times 700$ 


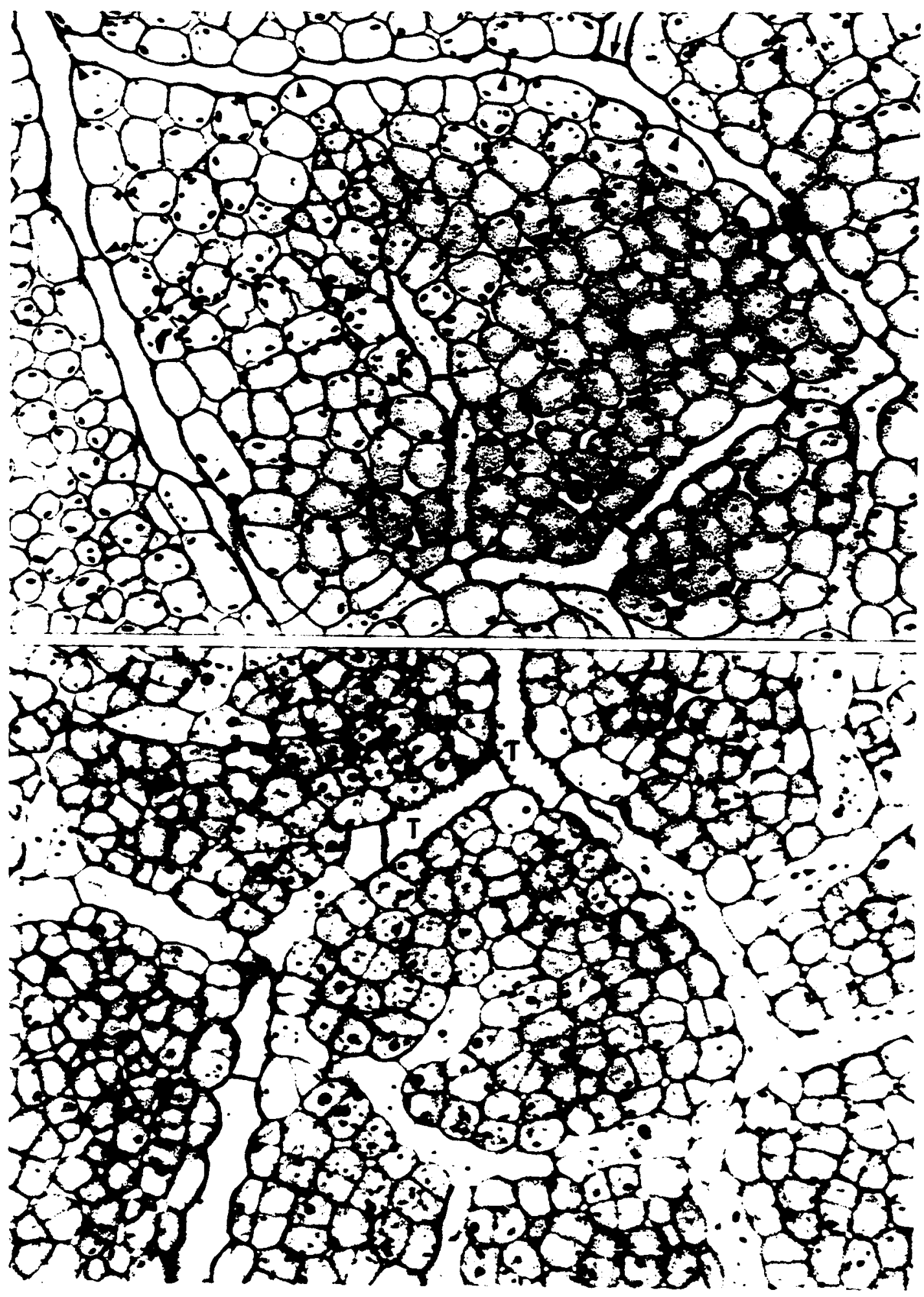




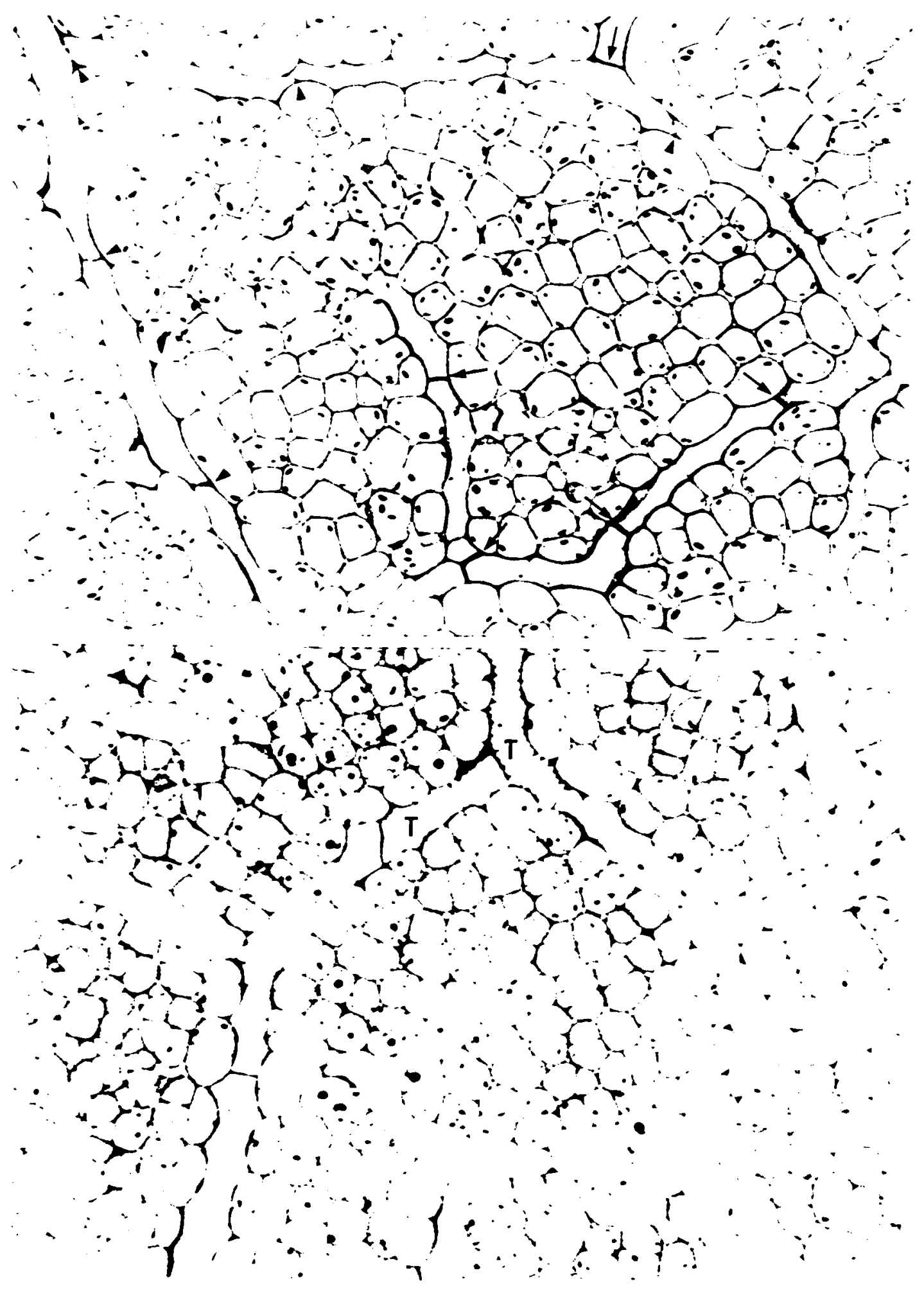


within the areole is not obviously correlated with the transition from import to export. Mature elements of both cell types are present before export begins (Fig. 65, leaf I). However, abaxial sieve elements in the sixth and seventh order veins appear to mature, at least to the stage at which cytoplasm is no longer visible, only after import has ceased (Fig. 65, leaf III). In leaf II the abaxial sieve elements were still immature although import had stopped. Abaxial sieve elements without cytoplasm do not appear within the areole until the leaf is slightly older (Fig. 65, leaf III). While import to the distal position of leaf II had definitely stopped it is not certain that export had yet begun. Certainly the lamina as a whole would not export and it is difficult if not impossible to detect intralaminar transport in leaves of this age. Abaxial sieve elements from the distal position of leaf III were examined in the electron microscope. The pores of sieve elements in sixth and seventh order veins were closed. Those in some abaxial sieve elements of larger veins were open. Sixth and seventh order veins from the distal position of leaf IV (not drawn in Fig. 65) contained abaxial sieve elements with open pores. 


\section{DISCUSSION}

\section{A. IMPORT AND EXPORT IN \\ THE DEVELOPING LEAF}

The maturation of dicotyledonous leaves progresses basipetally except for the acropetal development of the major venation (Esau, 1965). These investigations have shown that the functional development of a leaf from an importing to an exporting organ also progresses in a basipetal fashion. The suggestion of Jones and Eagles (1962) that bidirectional transport within a single leaf is a consequence of export from the tip and import by the base has been substantiated.

The tip of leaf 5 of Cucurbita pepo stops importing ${ }^{14} \mathrm{C}$-labelled photoassimilate from mature leaves when the lamina is approximately $10 \%$ expanded. Progressive basipetal loss of import capacity is linearly related to time and continues through the length of the lamina and petiole. Import capacity is also lost basipetally in leaves of Beta vulgaris and Nicotiana tabacum.

In addition to basipetal loss of import capacity the abaxial side of the petiole begins to lose the ability to import before the adaxial side. Similarly, vascular differentiation begins at the abaxial side of young petioles of Luffa cylindrica (Cucurbitaceae) and extends toward the 
adaxial side (Shah and Jacob, 1969).

Transport from mature leaves into importing leaves of materials labelled by ${ }^{14} \mathrm{CO}_{2}$ assimilation occurs primarily in the phloem although trace quantities of ${ }^{14} \mathrm{C}$ pass through physiological blocks to phloem transport and are distributed evenly throughout the leaf blade. These materials undoubtedly travel in the transpiration stream. Perhaps ${ }^{14} \mathrm{C}$ is transported in the phloem to the roots where it is picked up by the xylem and carried baci to the leaves. It is also possible that lateral transfer of ${ }^{14} \mathrm{C}$ from the phloem to the xylem occurs all along the path of phloem transport.

Just prior to loss of import capacity by the lamina base the leaf blade begins the export of ${ }^{14} \mathrm{C}$-labelled photosynthate. The delay of export caused by covering all but the extreme basal region of the lamina strongly suggests that export capacity develops basipetally.

Export from the lamina base begins at the same time that import ceases ( $45 \%$ leaf expansion). This suggests that in all regions of the lamina loss of import capacity is immediately followed by the beginning of export. The fact that cessation of import by the leaf tip is not immediately followed by export from the lamina is explained by the redistribution of translocate from the leaf tip to the stillimporting leaf base. This creates a situation wherein an increasingly larger source (the distal end of the lamina) exports to a steadily diminishing sink (the proximal end of 
the lamina). Eventually the supply to the lamina base exceeds the demand and the excess is translocated out of the leaf blade (35\% leaf expansion). Shortly thereafter the entire leaf blade exports (45\% leaf expansion).

By relocating carbon from the leaf tip to the leaf base carbon is conserved in the growing lamina. The pattern of basipetal leaf development is ideal in this regard; the physiologically younger, importing region is "downstream" from the more mature exporting tissue. Conservation of carbon within the growing leaf is also demonstrated by the pattern of ${ }^{14} \mathrm{C}$ distribution out of the exporting lamina. At LPI 1.1, when export from the lamina begins, almost all the ${ }^{14} \mathrm{C}$ exported goes to the growing petiole. As the petiole loses the capacity to import from other mature leaves the quantity of ${ }^{14} \mathrm{C}$ imported from its own leaf blade rapidly diminishes.

It should be noted that although import to the leaf tip ceases at $10 \%$ leaf expansion it was not possible to demonstrate export from the tip and subsequent redistribution within the lamina until $20 \%$ leaf expansion (LPI 0.7 ). Initial export from the leaf tip is either too low to be detected by the methods used or does not immediately follow the loss of import capacity.

The demonstration of intra-laminar phloem transport does not agree with the results of Larson et al. (1972) who could find no evidence of redistribution within the lamina 
of eastern cottonwood leaves. The difference in results may be due to the transient nature of intra-laminar transport. In these experiments with cucurbit leaves redistribution could only be detected in leaves at LPI 0.7. Redistribution probably ceases when import to the base of the lamina stops at LPI 1.3. This is a period of only 0.6 plastochrons. Larson et al. (1972) studied leaves over an 8-plastochron period in increments of 1 plastochron. If the developmental patterns of these two plants are comparable intra-laminar transport could easily have been overlooked.

It must be emphasized that these results are not in conflict with the commonly held view that exporting leaves will not under ordinary circumstances either import from other mature leaves (Canny, .1962) or redistribute photosynthate within the leaf blade (Nakata and Leopold, 1967). The redistribution which has been demonstrated is a consequence of basipetal development of the export function of the phloem; it is transient in nature and is not expected to continue in a fully exporting leaf.

It is interesting to note that the loss of import capacity in lamina 5 of $\underline{\mathrm{C}}$. pepo plants is accomplished within 1.0 plastochron unit. There may be some significance in this figure; it suggests a connection between the rates of leaf initiation and development. Let us consider the state of maturity of successively older leaves of a single plant during the plastochron interval between PI 5.3 and 6.3 . 
The assumption will be made that each leaf follows approximately the same general pattern of development as leaf 5 with regard to the Leaf Plastochron Index. The experiments of Larson and Gordon (1969) on Populus deltoides plants suggests that this assumption is a realistic one. During the interval PI 5.3 to 6.3 , leaf 6 will import fully (LPI 6 $(-) 0.7$ to $(+) 0.3)$; leaf 5 will lose the ability to import (LPIs 0.3 to 1.3 ); leaf 4 will import to the petiole and export from the lamina (LPI 1.3 to 2.3); and leaf 3 will export only ( $\mathrm{LPI}_{3} 2.3$ to 3.3 ). As the plant ages the same pattern will be continually repeated in newly maturing leaves. This orderly development undoubtedly benefits the plant since needed carbohydrate, and probably many other factors, are appropriated to leaves which need them most. As leaf 6 enters the phase of rapid growth leaf 5 begins to lose the capacity to import and growth slows down. In this way an adequate supply of materials is made available to each rapidly growing leaf without undue competition from other leaves.

How does one explain the fact that more than one leaf of Beta vulgaris and Nicotiana tabacum plants undergoes basipetal loss of import capacity at one time? It should be recalled (see Results) that these plants translocate primarily along the same orthostichy, that is mature leaves export to leaves directly above them. It is possible that a vertical file of leaves develops in much the same orderly 
way as do the leaves of $\underline{C}$. pepo plants and that each orthostichy functions somewhat independently. In other words, there may be a number of translocating systems, similar to the one in C. pepo, within a single plant. It should be possible to test these ideas empirically by careful analysis of translocation patterns and by the alteration of growth patterns by selective leaf excision.

\section{B. LEAF GROWTH}

Leaf area and dry weight increase with time in a typical sigmoid fashion. Exponential growth is followed by a brief linear growth phase and a slow levelling off until maximum area and dry weight are attained at approximately LPI 4 .

Growth in petiole length is more complex. At first, growth of the petiole parallels that of the lamina but as laminar growth declines the petiole begins to increase its rate of elongation again. Continued growth of the petiole provides the advantage of keeping the older leaf blades from being shaded by younger leaves above them, producing a typical conical shaped plant.

One can only surmise how continued growth of the petiole is controlled. Perhaps the petiole is at first limited in extension growth by the supply of one or more growth factors. It seems unlikely that carbohydrate is in 
short supply since the leaf blade transports sugar directly to the petiole. Perhaps growth is limited by the supply of a growth stimulating hormone. It might be suggested that this same hormone is produced and used by the growing leaf blade but as the growth potential of the blade is exhausted excess hormone is transported out of the lamina and into the petiole.

Petiole and stem growth is inhibited by handling. This inhibition may be a response to ethylene produced as a result of mechanical stress. Ethylene causes a reduction in longitudinal growth but an increase in radial expansion in pea epicotyls, and is involved in the growth inhibition of etiolated pea epicotyls caused by mechanical resistance (Goesch1 et al, 1966). Ethylene is also involved in the coiling of pea tendrils following contact stimulation (Jaffe, 1970). Mechanical irritation of Bryonia shoots decreases the auxin concentration (Boyer, 1967) which is a well-known ethylene response (Michener, 1938).

\section{PHOTOSYNTHESIS AND RESPIRATION}

The rate of net photosynthesis in leaf 5 of plants raised in the growth cabinet remains constant throughout the day. In similar experiments with Cucumis Hopkinson (1964) found that net photosynthesis rose to a maximum during the first 2 hours of the light period and then steadily declined 
to approximately half this value by the end of the day. Hopkinson noted that this effect was more pronounced in leaves initiated later in the life of the plant. Perhaps an analysis of other leaves of $\underline{\mathrm{C}}$. pepo would have demonstrated decreasing photosynthesis during the day as observed by Hopkinson .

Hopkinson (1964) also reported that respiration declined during the night period. This result is in agreement with the present study. Since dark respiration during the day is approximately equal to initial night respiration it seems likely that respiration during the night declines as a result of the depletion of food reserves.

The difference in night and dark day-time respiration is not nearly as pronounced in young leaves. At LPI 0 both night respiration and dark day-time respiration are approximately equal. This may be due to continued transport of food into young leaves during the night. At approximately LPI 1 the difference between night and dark day-time respiration becomes pronounced. This is the point where import to the leaf finally ceases and export begins.

Photosynthetic capacity rapidly increases as the leaf grows, reaches a maximum at approximately $70 \%$ leaf expansion and then steadily declines. This is in agreement with many published results (see Literature Review). Photosynthesis in Cucumis leaves declined rapidly within 8 days after maximum photosynthetic capacity was attained 
Hopkinson, 1964). Although a significant decline in photosynthesis was noted in leaf 5 of $\underline{C}$. pepo in this study it was not as severe as recorded for Cucumis. It has been noticed that the age at which $\underline{\mathrm{C}}$. pepo leaves senesce depends to a large extent on growth conditions. Perhaps the decline in photosynthetic activity is an early manifestation of aging and is also affected by conditions of growth.

Increased photosynthetic capacity is paralleled by the development of intercellular spaces in the leaf mesophy11. Intercellular spaces develop in the distal region of the leaf in advance of the proximal region. This manifestation of basipetal maturation has also been recorded by Isebrands and Larson (1973) in Populus deltoides leaves. These authors found it difficult to measure the irregularly shaped mesophyll cells and devised instead an index of intercellular space development. By the use of this index they were able to demonstrate basipetal development of inter-. cellular spaces but were not able to provide a quantitative measure of the percentage volume of air spaces. By weighing photographs of air spaces and mesophyll tissue of developing leaves it was possible in these experiments to determine quantitatively the degree of air space formation.

Intercellular space development in both the distal and proximal portion of the lamina is linear with time, plateaus in the distal mesophyll at LPI 1.2, in the proximal mesophyll at LPI 1.6 and continues slowly to a maximum of ca 
$23 \%$ of the total volume of the leaf. Although air space development plateaus by LPI 1.6 photosynthetic capacity continues to increase sharply until approximately LPI 2.0 . This suggests that although air spaces are needed for the efficient circulation of $\mathrm{CO}_{2}$ in the mesophyll their development does not limit photosynthesis in the growing leaf as suggested by Isebrands and Larson (1973).

\section{CARBON BALANCE}

During early growth (prior to LPI 0.5) the leaf is supplied with carbohydrate by older leaves. The immature leaf is not well equipped for gas exchange; the cells are compacted with few intercellular spaces and the rate of photosynthetic $\mathrm{CO}_{2}$ fixation is low. However, the close proximity of cells allows rapid dispersal of nutrients imported in the phloem. The intimate relationship between growth and carbon import during this period is revealed by measurements of carbon balance and especially by calculations of relative carbon flux.

The dependency of early rapid growth on phloem imported nutrients may be particularly advantageous to the expanding leaf. If the major carbon source for immature leaves was $\mathrm{CO}_{2}$ fixation growth would be unduly affected by periods of depressed photosynthesis. Dependency on phloem imported nutrients allows the supply of food to be buffered 
by the reserves of the entire plant, not only the growing leaf.

It is interesting to speculate that the rate at which starch is hydrolyzed in mature parts of the plant during the night depends on the length of the night period so that reserves are depleted just as the day begins again. In this way maximum usage would be made of available food. It should be possible to test this hypothesis by alteration of day and night lengths and the quantitative analysis of starch reserves.

As growth (measured by absolute or relative carbon flux) peaks and photosynthetic capacity increases the relationship between the import of assimilates and growth becomes less apparent. From this point on intercellular spaces rapidly develop and the lamina becomes increasingly efficient at gas exchange. Eventually net photosynthesis during the day supplies enough carbon for growth and night respiration. At this point import to the lamina stops and export begins.

It is during the decline in growth that import capacity is lost. This is especially clear when growth is expressed in terms of relative carbon flux (compare Fig. 21 with Fig. 22). Import capacity is lost at the leaf tip when relative growth peaks and at the lamina base when the rapid decline in relative growth slows down. At first appearance this would suggest that loss of import capacity is triggered 
by the decline in relative growth. This is unlikely, however, since loss of import capacity begins at the leaf tip which is relatively more mature than the rest of the lamina. It is necessary instead to consider the carbon balance of localized regions of the leaf. Import stops and export begins only when the supply of carbon from photosynthesis is adequate to meet the demands of growth and night respiration. Measurements of carbon flux on the whole lamina show that this point is reached when the rapid decline in relative growth is almost complete. This is undoubtedly the condition of the leaf tip when it loses the capacity to import. At this point the relative growth of the whole lamina peaks. This is a clear demonstration that developmental events are coordinated in such a way that the flow of carbon into the leaf from other leaves continues at a maximal rate until the lamina as a whole reaches its peak of relative growth. This elegant pattern underlines the principle that carbon is conserved within the actively growing leaf, a principle which is also demonstrated by intralaminar transport.

Export from the lamina begins when net photosynthesis supplies more than enough carbon for the demands of growth and night respiration. Measurements of carbon flux indicate that loss of carbon from the leaf begins at LPI 1.1 when translocation is first detected by ${ }^{14} \mathrm{C}$ displacement studies. (There is probably a slight error here. Export of ${ }^{14} \mathrm{C}$ should be detected before net carbon loss begins since 
some carbon continues to be imported at this stage. Since ${ }^{14} \mathrm{C}$ displacement studies are more direct the error is probably in the estimates of carbon flux.) Between LPI 1.1 and 1.3 the base of the lamina continues to import from other mature leaves and from the leaf tip. However, at this time there is a sufficient influx of carbon from photosynthesis to allow export from the distal end of the lamina, past the importing base, to the petiole. The petiole is the primary recipient of the export carbohydrate until LPI 2 when it ceases to import from other mature leaves. Simultaneous import and export in the developing lamina occurs only during the period LPI 1.1-1.3. Carbon is transported from the Iamina to the petiole and from other leaves to the petiole between LPI 1.1-2.0.

At LPI 2 photosynthesis reaches a maximum. The net carbon fixed during the day is exported except for the small amount needed to sustain continuing growth and night respiration. It is curious that photosynthetic capacity begins to decline soon after it reaches a maximum. Since growth continues slowly for an extended period the leaf probably realizes full export potential for only a short period, if at all.

E. ${ }^{14} \mathrm{CO}_{2}$ METABOLISM

There is no doubt that the transition of the leaf 
from a growing importing organ to a mature exporting one involves major changes in metabolism. Certain of these changes can be demonstrated by feeding ${ }^{14} \mathrm{CO}_{2}$ to developing leaves and analyzing the pattern of ${ }^{14} \mathrm{CO}_{2}$ incorporation. This technique allows conclusions to be drawn about the development of the photosynthetic function. Some caution must be used in the interpretation of results, however. Unless ${ }^{14} \mathrm{C}$ is supplied long enough to reach isotopic saturation the quantity of ${ }^{14} \mathrm{C}$ recovered from specific fractions of the leaf is only a measure of the rate of incorporation per unit time. If certain pools are not as readily accessible as others within the experimental time period the amount of material in these pools will be underestimated. A 5-min time period was chosen in these experiments because maximum incorporation of ${ }^{14} \mathrm{C}$ into sucrose, raffinose and stachyose occurs within 5 min of ${ }^{14} \mathrm{CO}_{2}$ application (Webb and Gorham, 1964). Not all of the pools of the leaf reach isotopic saturation in this time.

The general trend in carbon metabolism as the leaf ages is toward carbohydrate synthesis. This is in keeping with the development of the phloem export function. As the leaf matures an increasing percentage of ${ }^{14} \mathrm{C}$ supplied as a 5 -min ${ }^{14} \mathrm{CO}_{2}$ pulse is incorporated into the ethanol insoluble fraction. Preliminary experiments indicate that this reflects an increasing capacity for starch synthesis. When the 5 -min pulse is followed by $2 \mathrm{hr}$ in unlabelled $\mathrm{CO}_{2}$ this 
trend is reversed. In younger leaves more ${ }^{14} \mathrm{C}$ is found in the ethanol insoluble fraction after $2 \mathrm{hr}$, undoubtedly because of continued synthesis of insoluble compounds from soluble precursors. In older, exporting leaves the amount of ${ }^{14} \mathrm{C}$ found in the ethanol insoluble fraction after $2 \mathrm{hr}$ is less than when leaves are supplied ${ }^{14} \mathrm{CO}_{2}$ for only $5 \mathrm{~min}$. This suggests a certain amount of turnover from the insoluble to the soluble pool within $2 \mathrm{hr}$ and supports the idea that incorporation into starch is responsible for the high levels of ethanol insoluble ${ }^{14} \mathrm{C}$ in older leaves given a 5 -min pulse of ${ }^{14} \mathrm{CO}_{2}$.

Within the ethanol soluble fraction a greater percentage of incorporated ${ }^{14} \mathrm{C}$ is recovered from the neutral fraction as the leaf matures. By the time export begins approximately $90 \%$ of the ${ }^{14} \mathrm{C}$ in the neutral fraction is recovered in the 7 sugars and related compounds analyzed in these experiments.

Raffinose and stachyose first become labelled with ${ }^{14} \mathrm{C}$ supplied as ${ }^{14} \mathrm{CO}_{2}$ at LPI 0.6 . At this time the distal 30 of the leaf no longer imports but the leaf does not export. The first indications of intralaminar transport are detected at LPI 0.7 . Perhaps the inability to detect intralaminar transport between LPI 0.3 , when import at the leaf tip ceases, and LPI 0.7 is in some way connected to the lack of available raffinose and stachyose. To suggest that no transport sugars are available from LPI 0.3-0.6 is not 
correct since sucrose synthesis can be demonstrated in leaves of this age. There is no assurance of course that the sucrose which is synthesized is available for transport. Perhaps the synthesis of raffinose and stachyose is required to achieve a high enough solute concentration to allow sugar to move from the mesophyll to the conducting cells. There is also the possibility that another, unknown step limits the vein loading process at this stage and it would not be possible for sugar in any quantity to be loaded. In any case it is naive to suggest a causal relationship simply on the basis of a positive correlation. If these sugars are in some way particularly adapted to the translocation process it is not unlikely that their synthesis will coincide with their initial use. No causal relationship need be inferred. At this point it is of interest to speculate on the role of raffinose and stachyose as translocation sugars. There is evidence, from this work and from other results (Webb, unpublished) that suggests raffinose and stachyose may be specific transport sugars; specific in the sense that their primary function is in translocation.

First, the correlation between the initial synthesis of these sugars and the beginning of carbohydrate transport has been demonstrated. Sucrose is synthesized by much younger leaves which do not export. Second, it has been observed that ${ }^{14} \mathrm{C}$-labelled raffinose and stachyose are readily metabolized by immature importing organs although 
their turnover in mature, exporting leaves is slow (Webb, 1971). In other words when the leaf is importing it is an aggressive medium for these sugars. When export begins the leaf provides a stable environment for the sugars until they are loaded into the phloem and exported to immature tissues.

The capacity of the maturing leaf to metabolize raffinose and stachyose may be a matter of enzyme regulation. This recalls Arnold's (1969) suggestion that sucrose and sucrose derivatives are preferred translocation sugars because they require hydrolysis before being metabolized and are therefore protected derivatives of glucose. The use of raffinose and stachyose as well as sucrose adds a further metabolic constraint in the necessity of an alphagalactopyranosidase for complete hydrolysis. Perhaps the added constaint which Arnold visualized is required not along the translocation path but in the source leaf. By the regulation of this specific enzyme the conversion of a developing leaf from an organ which rapidly metabolizes imported sugars to one which is responsible for the synthesis and export of these same sugars could be readily accomplished.

One might wonder then at the use of stachyose as a translocation sugar when raffinose (which contains one less galactose moiety) should be just as stable. Arnold (1969) considered and discounted the possibility that oligosaccharides are useful in translocation because they do not develop the osmotic pressure per glucose equivalent that 
glucose does. The reason Arnold gave for rejecting this proposal is not convincing. He stated that not enough evidence is available to predict the osmotic behaviours of different sugars in the sieve tube. It seems to this author that in the absence of evidence to the contrary it may be assumed that the use of higher sugars as translocates allows a greater concentration of carbohydrate to be moved without generating a corresponding increase in osmotic pressure.

It is also possible that raffinose and stachyose are not readily metabolized by mature leaves because they are rapidly compartmentalized for transport. This stable compartment could conceivably be the apoplast.

The labelling patterns of compounds in the neutral fraction give some insight into the pathways of raffinose and stachyose synthesis. Kandler (1967) has reviewed the available evidence for a proposed synthetic sequence as follows:

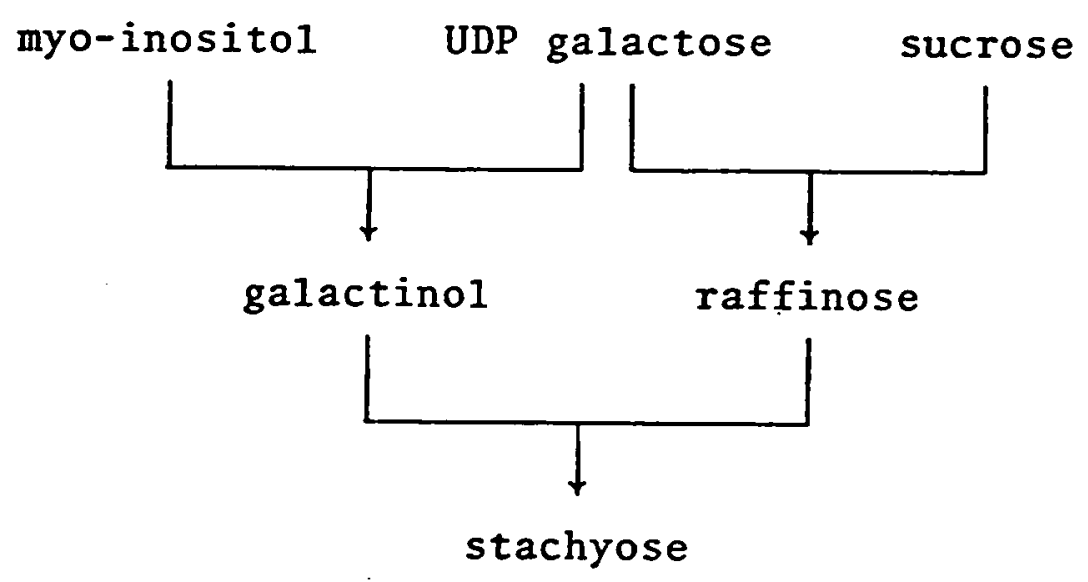

According to this scheme raffinose is formed by the 
addition of the galactose moiety of UDP galactose to sucrose. The addition of another galactose unit from galactinol forms stachyose. This scheme is supported by the kinetics of ${ }^{14} \mathrm{C}$ labelling following application of ${ }^{14} \mathrm{CO}_{2}$ to leaves of various species. Enzymes for galactinol and stachyose synthesis have been isolated but there has been difficulty in establishing an in vitro system for raffinose synthesis.

The evidence from the present study on the ${ }^{14} \mathrm{CO}_{2}$ labelling patterns in developing $\underline{C}$. pepo leaves supports the scheme outlined above. The appearance of ${ }^{14} \mathrm{C}$-galactinol in developing leaves coincides with the appearance of ${ }^{14} \mathrm{C}$ raffinose and ${ }^{14} \mathrm{C}$-labelled stachyose. At the same time the quantity of ${ }^{14} \mathrm{C}$-myo-inositol within the neutral fraction rapidly drops, a pattern which could easily be explained by the incorporation of myo-inositol into galactinol. Similarly the transitory drop in the level of ${ }^{14} \mathrm{C}$-sucrose in the neutral fraction is consistent with its use in the synthesis of raffinose. Although raffinose is supposedly synthesized before stachyose, it is not as strongly labelled as stachyose in these experiments, perhaps as a result of its further use in the synthesis of stachyose. It should be emphasized again that although observations on the initial synthesis of compounds in developing leaves is significant there is some danger in overinterpreting quantitative labelling data on older leaves when only one brief ${ }^{14} \mathrm{CO}_{2}$ presentation time is used. 


\section{F. STRUCTURE OF MATURE MINOR VEINS}

Almost every mesophyll cell of $\underline{C}$. pepo leaves is surrounded by veins of the sixth or seventh order; veins which are separated from the mesophyll by only a single layer of bundle sheath cells. Transport of water and nutrients between the mesophyll and the conducting tissue is thus readily accomplished.

The minor veins of $\underline{\mathrm{C}}$. pepo and other members of the Cucurbitaceae contain both adaxial and abaxial phloem. In other families with bicollateral bundles adaxial (internal) phloem does not extend into the minor veins. Apparently the abaxial phloem collects photosynthate from the mesophyll. The large companion cells (übergangszellen) seem ideally suited to such a task since they are connected to the bundle sheath cells by an unusually large number of plasmodesmata. The adaxial phloem does not seem as highly specialized. The companion cells and sieve elements are of approximately the same diameter. Companion cells are smaller than those in the abaxial phloem and few plasmodesmata traverse the common wall with bundle sheath cells. Perhaps the primary site of collection is the abaxial phloem and the adaxial phloem fulfills a supplementary role.

There is also the possibility that the adaxial phloem serves to import nutrients and ceases to function when export begins. The lack of definitive callose on the 
sieve plates suggests, however, that this is not the case. In addition, the sieve elements of the adaxial phloem seem as susceptible to the fixation damage usually encountered in other sieve elements (ex. displaced P-protein) and generally attributed to pressure release upon cutting. This suggests that the osmotic potential of the cells is high, i.e. they are carrying solute.

In the abaxial phloem of the smallest veins xylem and phloem often lie in juxtaposition. Esau (1967) suggested that this arrangement facilitates entry of water from the xylem into the phloem. This idea merits some consideration although it is unclear whether additional water is needed beyond that which is carried along with the translocate. If one considers that sugars may be transported across membranes by carrier enzymes and not by mass flow they may well be highly concentrated when they enter the sieve tube conduit. However, one would suspect that a requirement for water flow directly from the xylem to the sieve elements would make the translocation system more readily sensitive to the effects of water stress that is usually the case (Crafts and Crisp, 1971). Perhaps the tracheids contribute only a percentage of the required water.

Adaxial sieve elements do not come in direct contact with the xylem. A parenchyma cell invariably lies between the two cell types. The fact that in the smallest veins this is the only cell which is structurally unspecialized 
leads one to suspect that it serves a particular purpose: that of maintaining a barrier between tracheid and sieve element. Perhaps the adaxial phioem is not particularly specialized for the uptake of photosynthate from the mesophyll and therefore the usual barrier between xylem and phloem is maintained.

\section{G. ULTRASTRUCTURE OF MATURE}

MINOR VEINS

\section{Sieve Elements}

The ultrastructure of sieve elements in the minor veins is similar to those in other parts of the plant body. The mature cell is enucleate and the tonoplast and ribosomes are absent. Mitochondria, plastids and endoplasmic reticulum (ER) lie in a parietal position close to the plasmalemma. Sieve elements of the adaxial and abaxial phloem are joined by well-differentiated sieve plates with pores lined by callose. The pores of the abaxial sieve elements are narrow and typically plugged with P-protein while those of the adaxial sieve elements are wide and are usually unobstructed. These contradictory observations on the pores of sieve elements in the same vein demonstrate the difficulty in determining unequivocally the degree of obstruction sieve pores normally experience. However, it is difficult to agree with the suggestion of Spanner and co-workers (e.g. Siddiqui 
and Spanner, 1970) that pores are normally plugged and this condition assists an electroosmotic mechanism of phloem transport. Although their hypothesis draws support from the appearance of abaxial sieve elements it is completely inconsistent with the structure of those in the adaxial phloem. It seems more likely that plugging of pores is an artefact of fixation caused by sudden pressure release. The pores become plugged if there is sufficient P-protein to fill them and if they are narrow enough that the $P$-protein is not easily swept through.

In the phloem of the minor veins, unlike those of the stem, tubular $\mathrm{P} 4$-protein is present in mature sieve elements. P4-protein tubules are apparently formed from fibrillar P3-protein and return to the fibrillar state when the sieve elements of the stem reach maturity. It is unclear at present why the transition back to the fibrillar state does not take place in sieve elements of the minor veins. The transition between the fibrillar and tubular form is undoubtedly affected by the surrounding chemical environment (e.g. salt concentration) and this may well account for the difference.

The presence of tubular P4-protein in mature sieve elements does not support the concept. that highly organized sieve element strands motivate phloem transport. If this were true one would expect the structure of P-protein from various parts of the plant body to be similar. This is not 
the case.

In other respects the P-protein components of abaxial and adaxial minor vein sieve elements are similar to those in the vascular bundles of the stem and the extrafascicular sieve elements respectively. As in the extrafascicular phloem the P3-protein in adaxial sieve elements does not disperse but remains as discrete bodies when the cells mature. Perhaps the P3-protein in extrafascicular and adaxial sieve elements does not disperse because the flow of assimilates in these cells is slow. The P-protein bodies are not membrane bound and they are undoubtedly subject to pressure from the translocation stream. This pressure may be wholly or partially responsible for the dispersal of the bodies.

The distribution of $\mathrm{P}$-protein in sieve elements is essentially parietal and the lumen of the cells appears empty except for occasional membranes. It is somewhat difficult to reconcile the presence of membranes with a mass flow of solute unless the membranes are attached to a solid structure. Otherwise, they would be expected to flow with the solution and obstruct the pores. Considering the close association between the ER and the plasmalemma and the varied forms which the ER assumes in mature sieve elements it is entirely possible that these membranes are extensions of the ER. In fact, this would explain the numerous instances where membranes appear in concentric pairs. 
The presence of microtubules between P-protein bodies and the plasmilemma in mature sieve elements is of interest. Cronshaw and Esau (1968b) also reported the occurrence of microtubules, similarly situated, in the stem phloem of Cucurbita. This raises the possibility that microtubules may in some way be concerned with cold inhibition of translocation. Microtubules are depolymerized by low temperature. If the P-protein bodies are held in parietal position by the microtubules they might easily be released by cold. This would explain why sieve element pores of cold treated phloem appear plugged (Giaquinta and Geiger, 1973).

However, there are drawbacks to this suggestion. It is not clear how the P-protein could be returned to a parietal position when the cold block is removed or the phloem acclimated to cold conditions. Of course, this is a consideration which must be given to any explanation of the results of Giaquinta and Geiger (1973). Further, the presence of microtubules in mature sieve elements appears to be restricted to a few species (Esau, 1969). A third drawback to this proposal is the demonstrated inability of vinblastine sulphate to inhibit phloem transport. Perhaps the presence of microtubules beneath the P-protein bodies only signifies that they are protected from hydrolysis during cell maturation much as the primary wall of tracheary elements is protected from hydrolysis by the secondary wall. 


\section{Companion Ce11s}

The companion cells of the abaxial and adaxial

phloem of the minor veins differ greatly in appearance. The companion cells of the abaxial phloem are large and densely filled with cytoplasm and the vacuoles are small. The companion cells of the adaxial phloem are smaller, the cytoplasm is even more dense and the cells are highly vacuolate.

The most characteristic feature of the large abaxial companion cells is the number of plasmodesmata which connect these cells to those of the bundle sheath: The plasmodesmata are so numerous that it is difficult to believe that they do not perform some special function. The most obvious suggestion is that they serve to collect photoassimilate from the symplast of the bundle sheath cells.

The occurrence of numerous plasmodesmata at this location does not appear to be widespread among different plants. Plasmodesmata between transfer cells and bundle sheath cells are rare. This suggests that two alternative pathways exist for the migration of photosynthate to the phloem. If plasmodesmata are present the solute remains in the symplast. If no plasmodesmata are present the photosynthate is recovered from the apoplast across the plasma membrane. Transfer cells are particularly adapted for the recovery of photosynthate from the apoplast. This subject warrants further attention. Reports on the ultrastructure of minor veins have not adequately described the connections 
between companion cells and bundle sheath cells (Esau, 1967; Esau and Hoefert, 1971; Geiger and Cataldo, 1969).

The suggestion that abaxial companion cells of $\underline{C}$. pepo function in the active uptake of photosynthate is supported by the arrangement of numerous mitochondria in a parietal position close to the common wall with the bundle sheath cells. The mitochondria probably supply the energy required for active uptake across the concentration gradient. The companion cells of the adaxial phloem do not seem as well suited to active uptake since in appearance they are much like companion cells in the stem and have few protoplasmic connections with the bundle sheath. Perhaps, as discussed above, adaxial companion cells collect assimilate from the surrounding apoplast. The mitochondria in these cells appear degenerate and quite unlike those in the abaxial companion cells or in other parenchyma cells. O'Brien and Thimann (1967) reported that mitochondria of Avena coleoptile companion cells are disorganized. They suggested this was caused by an enrichment of the cells with acidophilic material. Perhaps this is also true of $\underline{C}$. pepo adaxial companion cells. The disorganization of the mitochondria may take place during fixation as a result of the release of hydrolytic agents from 1ysosomes or the vacuole. 


\section{H. MINOR VEIN DEVELOPMENT}

Minor vein development in the distal and proximal regions of the leaf apparently follows the same pattern in relation to the transition from import to export. However, it is more difficult to interpret the data obtained from the distal region since the translocation pattern is somewhat confused by intralaminar transport. Therefore the following discussion pertains especially to the proximal region. Descriptions of import and export apply to a restricted region of tissue, not to the translocation pattern of the whole lamina.

The phloem of the minor veins develops continuously from the larger toward the smaller veins. The last elements to mature are those in the terminal veinlets which end within the areole. This pattern of structural development is important to the understanding of the functional development of the veins. Because the veins mature continuously it is not necessary for their development to be complete before export can begin. Sieve elements which are mature and are capable of accumulating photosynthate from the mesophyll will have access to a continuous file of mature sieve elements which lead out of the leaf.

Sieve elements of the abaxial phloem of the fourth and fifth order veins mature structurally (the pores open) just as export begins. Since these are the lowest order veins which contain characteristically large companion cells 
(Übergangszellen) with numerous protoplasmic connections to the bundle sheath (Fischer, 1885), they are probably the largest ones capable of vein loading. If this is true tha correlation between the development of the abaxial phloem and initial export is very clear. Since most of the mesophyll is surrounded by sixth and seventh order veins it is quite likely that only a small percentage of the mesophyll cells donate photosynthate during the initial period of export. As the abaxial veins continue to mature more of the mesophyll cells will have access to functionally mature conducting cells. It should be recalled that the smallest veins do not extend from epidermis to epidermis and therefore there is no reason to suppose that photosynthate originating in mesophyl1 surrounded by immature sieve elements can not pass laterally out of the areole to larger, functional phloem. The only restriction to lateral movement would appear to be one of distance.

The evidence suggests, therefore, that assimilate is exported as soon as abaxial phloem develops, which is capable of retrieval from the mesophyll cells. Larger veins may be capable of export but incapable of vein loading. Perhaps this explains why Kocher and Leonard (1971) were able to detect export from immature leaves when radioactive substances were painted onto the leaf surface. The labelled material may have entered large, mature sieve elements which normally would not accumulate photosynthate. 
These data suggest that export is limited by the development of the veins. This may or may not be the case. Again, as discussed above, there is danger in assuming a causal relationship on the basis of a positive correlation. For example, there is no assurance that photosynthate is available for loading and export until the veins are mature. The lack of available translocate might explain why export does not begin before it does via the adaxial phloem. Certainly the sieve elements in the adaxial phloem develop before those in the abaxial phloem and the adaxial sieve elements of the sixth and seventh order veins are structurally mature before export begins. Export must be limited either by the availability of translocate or the ability of the adaxial phloem to export if loaded. The first suggestion seems more likely since considerations of carbon balance have shown that export occurs only when carbon is available in excess. It is unlikely that while import continues photosynthate would be made available to the exporting system.

The inability of the adaxial phloem to export early might also be explained by the fact that the sieve elements are engaged at the time in import. This recalls the suggestion that the internal (adaxial) and external (abaxial) phloem transport in different directions during periods of simultaneous import and export (sec Literature Review). In the experiments of Peterson and Currier (1969) fluorescent dye travelled toward the leaf blade in the internal phloem 
and toward the stem in the external phloem when it was applied laterally to petioles of Ecballium (Cucurbitaceae) which were translocating bidirectionally. As noted in the Literature Review, these leaves were only $5 \%$ expanded and no evidence was provided to prove that bidirectional transport was, in fact, taking place. Further, it should be noted that there is an anastomosis of the phloem of the vascular bundles of $\underline{C}$. pepo at the nodes of the stem and at the junction of the petiole and leaf blade. It is rather difficult to reconcile this fact with the proposition that the internal and external phloem translocate in different directions. It was also noted by Koch (see Esau, 1969) that the adaxial and abaxial phloem of the bicollateral minor veins of Ecballium also anastomose. However, the possibility should not be ruled out that adaxial (internal) phloem is primarily responsible for importing assimilates and then assumes the role of a supplementary exporter. This proposition fits with the data of Peterson and Currier (1969) and with the present study of vein development. Perhaps a similar study of minor vein development in a species without bicollateral veins. would shed more light on the subject. 


\section{SUMMARY}

The present study has described some of the biochemical, physiological and structural changes which accompany the transition of a leaf from an importing to an exporting organ. Development is progressive and proceeds in a basipetal direction. This basipetal pattern is manifest by many parameters of development including loss of import capacity, the initiation of assimilate export, enlargement of intercellular spaces, maturation of the minor venation, and the development of the photosynthetic function.

As relative growth $\left(\frac{d W}{d t} \frac{1}{W}\right)$ of the lamina increases to a maximum the leaf depends almost entirely on imported food. There is little if any net photosynthetic fixation of $\mathrm{CO}_{2}$ and night respiration is high. As relative growth of the lamina peaks the leaf tip ceases to import. At this point the tip of the leaf is more mature than the rest of the lamina so that the relative growth of the tip has slowed considerably and photosynthetic capacity has markedly increased before import to the tip ceases. This pattern is repeated progressively and basipetally. As the growth requirements of the lamina tissue decreases and the ability to fix $\mathrm{CO}_{2}$ increases an excess of elaborated carbon com. pounds is produced and export begins.

The minor venation develops continuously from the 
larger to the smaller veins. Before import to a particular region ceases many of the sieve elements of the adaxial phloem of the minor veins are mature (the sieve plate pores are open). As import capacity is lost export begins although the material initially exported from the distal region of the leaf is retrieved by the still-expanding importing base, thereby delaying the onset of export from the lamina. Export from the lamina begins as the rapid decline in relative growth slows and just before the extreme base of the lamina ceases to import. Initial export is directed mainly to the petiole which continues, for a short period, to import from the rest of the plant.

During the period when import capacity is lost, photosynthetic capacity rapidly increases and night respiration decreases. The initial synthesis of stachyose and raffinose, sugars which are transported out of the leaf, occurs after the leaf tip loses the capacity to import but before export from the lamina begins. Initial export from each area of the lamina coincides with the maturation of sieve elements in the abaxial phloem of the fourth and fifth order veins which are probably the largest veins capable of loading photoassimilates from the mesophyll.

As the leaf matures and growth stops, the amount of carbon exported from the leaf over a 24 -hour period is equal to the net amount fixed during the day minus the almost negligible amount lost by respiration during the night. The 
ultrastructure of mature sieve elements in the minor veins appears similar to those in the rest of the plant. U1trastructural observations on mature minor veins suggest that phytosynthate is actively loaded into the sieve elements of the abaxial phloem. The assimilate apparently follows a symplastic route from the bundle sheath through the companion cells to the sieve elements. The adaxial phloem appears to be functional in mature leaves although not as well adapted to vein loading. 


\section{LITERATURE CITED}

Anderson, R., and J. Cronshaw. 1969. The effects of pressure release on the sieve plate pores of Nicotiana. J. Ultrastruct. Res. 29:50-59.

, and J. Cronshaw. 1970. Sieve-plate pores in tobacco and bean. Planta 91:173-180.

Arnold, W.N. 1969. The selection of sucrose as the translocate of higher plants. J. Theoret. Biol. 21: 13-20.

Atkinson, M.R., G. Eckermann, M. Grant, and R.N. Robertson. 1966. Salt accumulation and adenosine triphosphate in carrot xylem tissue. Proc. Nat. Acad. Sci. 55: 560-564.

Avery, G.S., Jr. 1933. Structure and development of the tobacco leaf. Amer. J. Bot. 20:565-592.

Bailey, L.H. 1929. The domesticated cucurbitas. Gentes. Herb., Itaca. 2: 63-115.

Barrier, G.E., and W.E. Loomis. 1957. Absorption and transiocation of 2-4 dichlorophenoxyacetic acid and $\mathrm{P}^{32}$ by leaves. Plant Physiol. 32:225-231.

Behnke, H.-D. 1971a. The contents of the sieve-plate pores in Aristolochia. J. Ultrastruct. Res. 36:493-498. 1971b. Phytoferritin in sieve-tube plastids. Naturwiss. 58:151-152.

- 1972. Sieve-tube plastids in relation to angiosperm systematics--an attempt towards a classification by ultrastructural analysis. Bot. Rev. 38: 155-197.

Biddulph, 0., and R. Cory. 1960. Demonstration of two translocation mechanisms in studies of bidirectional movement. Plant Physiol. 35:689-695.

, and R. Cory. 1965. Translocation of ${ }^{14} \mathrm{C}$ metabolites in the phloem of the bean plant. Plant Physiol. 40:119-129. 
Bieleski, R.L. 1966a. Accumulation of phosphate, sulfate and sucrose by excised phloem tissues. Plant Physiol. 41:447-454. 1966b. Sites of accumulation in excised phloem and vascular tissues. P1ant Physiol. 41:455-466.

Blackman, V.H. 1919. The compound interest 1 aw and plant growth. Ann. Bot. 33:353.

Bledsoe, C., C.V. Cole, and C. Ross. 1969. 01igomycin inhibition of phosphate uptake and ATP labelling in excised Maize roots. Plant Physiol. 44:1040-1044.

Bonnemain, M.J. 1965. Sur le transport diurne des produits d'assimilation lors de la floraison chez la Tomate. Compt. Rend. 260:2054-2057.

Bowling, D.J.F. 1968. Translocation at $0^{\circ} \mathrm{C}$ in Helianthus annuus. J. Exp. Bot. 19:381-388.

Boyer, N. 1967. Modifications de la croissance de la tige de Bryone (Bryonia dioica) à la suite d'irritations tactiles. C.R. Acad. Sci. (Paris) Ser. D 264: 2114-2117.

Brovchenko, M.I. 1965. On the movement of sugars from the mesophyll to the conducting bundles in sugar-beet leaves. Fiziol. Rastenii. 12:270-279.

Canny, M.J. 1960. The breakdown of sucrose during translocation. Ann. Bot. 24:330-344.

1962. The mechanism of translocation. Ann. Bot. 26: 603-617.

- 1971. Translocation: mechanisms and kinetics. Ann. Rev. Plant Physio1. 22:237-260.

, and M.J. Askham. 1967. Physiological inferences from the evidence of translocated tracers: a caution. Ann. Bot. 31:409-416.

, and K. Markus. 1960. The metabolism of phloem isolated from grapevine. Aust. J. Biol. Sci. 13: 292-299.

and O.M. Phillips. 1963. Quantitative aspects of a theory of transiocation. Ann. Bot. 27:379-402. 
Caro, L.G., and R.P. van Tubergin. 1962. High-resolution autoradiography. I. Methods. J. Cell Biol. 15: 173-188.

Clarke, A.E., and B.A. Stone. 1962. $\beta-1,-3$ glucan hydrolases from the grape vine (Vitus vinifera) and other plants. Phytochem. $1: 175-188$.

Cohen, G.N., and J. Monod. 1957. Bacterial permeases. Bact. Rev. 21:169-194.

Cormack, R.G.H., and P. Lemay. 1963. Sugar in the intercellular spaces of white mustard roots. J. Exp. Bot. 14:232-236.

Coulson, C.L., A.L. Christy, D.A. Cataldo, and C.A. Swanson. 1972. Carbohydrate translocation in sugar beet petioles in relation to petiolar respiration and adenosine 5'-triphosphate. Plant Physio1. 49:

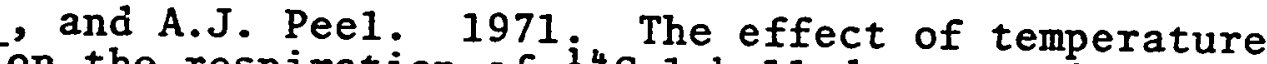
on the respiration of ${ }^{14} \mathrm{C}-1$ abelled sugars in stems of willow. Ann. Bot. 35:9-15.

Crafts, A.S., and C.E. Crisp. 1971. Phloem transport in plants. W.H. Freeman and Co., San Francisco.

Cronshaw, J., and R. Anderson. 1969. Sieve plate pores of Nicotiana. J. Ultrastruct. Res. 27:134-148. , and R. Anderson. 1971. Phloem differentiation in tobacco pith cultures. J. Ultrastruct. Res. 34:

, and $K$. Esau. 1967. Tubular and fibrillar components of mature and differentiating sieve elements. J. Cell Biol. 34:801-815.

, and K. Esau. 1968a. P-protein in the phloem of Cucurbita. I. The Development of the P-protein bodies. J. Cel1 Biol. 38:25-39.

and K. Esau. 1968b. P-protein in the phloem of Cucurbita. II. The P-protein of mature sieve elements. J. Cell Biol. 38:292-303.

Currier, H.B., K. Esau, and V.I. Cheadle. 1955. Plasmolytic studies of phloem. Amer. J. Bot. $\underline{42: 68-81 .}$ 
Curtis, O.F. 1929. Studies on solute translocation in piants. Experiments indicating that translocation is dependent on the activity of living cells. Amer. J. Bot. 26:154-168.

- 1935. The translocation of solutes in plants. McGraw-Hil1, New York.

Czaninski, Y., and A.-M. Catesson. 1969. Localization uitrastructuale d'activités peroxidasiques dans les tissus conducteurs végétaux au cours du cycle annue1. J. Microscopie $\underline{8}: 875-888$.

Delisle, A.L. 1938. Morphogenetical studies in the development of successive leaves in Aster, with respect to relative growth, cellular differentiation, and auxin relationships. Amer. J. Bot. 25:420-430.

Denne, P.M. 1966. Leaf development in Trifolium repens. Bot. Gaz. 127:202-210.

Deshpande, B.P., and R.F. Evert. 1970. A reevaluation of extruded nucleoli in sieve elements. J. Ultrastruct. Res. 33:483-494.

Dickmann, D.I. 1971. Photosynthesis and respiration by developing leaves of cottonwood (Populus deltoides Bartr.). Bot. Gaz. 132:253-259.

Duloy, M.D., and F.V. Mercer. 1961. Studies in translocation. 1. The respiration of the phloem. Aust. J. Biol. Sci. 14:391-401.

Engleman, E.M. 1963. Sieve element of Impatiens sultanii. 1. Wound reaction. Ann. Bot. 29:83-101.

Erickson, R.O., and F.J. Michelini. 1957. The plastochron index. Amer. J. Bot. 44:297-305.

Esau, K. 1939. Development and structure of the phloem tissue. Bot. Rev. $5: 373-432$.

- 1961. Plants, viruses and insects. Harvard University Press, Cambridge, Mass.

. 1965. Plant anatomy. 2nd Ed. John Wiley and Sons, New York.

- 1967. Minor veins in Beta leaves: structure related to function. Proc. Amer. Philos. Soc. 111: 219-233. 


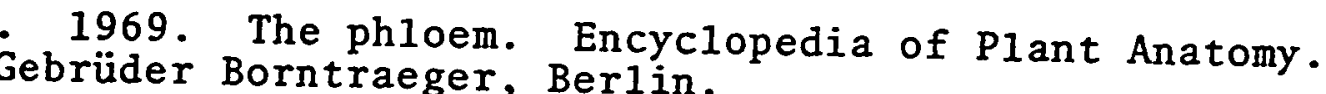
1971. Development of P-protein in sieve elements of Mimosa pudica. Protoplasma 73:225-238.

- 1972. Cytology of sieve elements in minor veins of sugar beet leaves. New Phytol. 71:161-168.

and V.I. Cheadle. 1965. Cytologic studies on phloem. Univ. Calif. Publs. Bot. $\underline{36}: 253-344$.

, and J. Cronshaw. 1967. Tubular components in cells of healthy and Tobacco mosaic virus-infected Nicotiana. Virology 33:26-35.

, and J. Cronshaw. 1968a. Plastids and mitochondria in the phloem of Cucurbita. Can. J. Bot. 46:877-880. and J. Cronshaw. 1968b. Endoplasmic reticulum in the sieve elements of Cucurbita. J. U1trastruct. Res. 23:1-14.

, J. Cronshaw, and L.L. Hoefert. 1967. Relation of beet yellows virus to the phloem and to translocation in the sieve tube. J. Cell Biol. 32:71-87. , E.M. Engleman, and T. Bisalputra. 1963. What are transcellular strands? Planta 59:617-623.

and R.H. Gill. 1970a. Observations on spiny vesicles and $\mathrm{P}$-protein in Nicotiana tabacum. Protoplasma 69:373-388.

, and R.H. Gill. 1970b. A spiny cell component in the sugar beet. J. U1trastruct. Res. 31:444-455. , and R.H. Gill. 1972. Nucleus and endoplasmic reticulum in differentiating root photophloem of Nicotiana tabacum. J. U1trastruct. Res. 41:160-175. , and L.L. Hoefert. 1971. Composition and fine structure of minor veins in Tetragonia leaf. Proto-

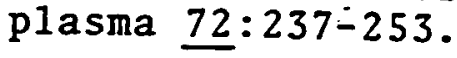

Eschrich, W. 1965. Physiologie der Siebröhrencallose. Planta 65:280-300. 1967. Bidirektionelle Translokation in Siebröhren. Planta 73:37-49. 
1970. Biochemistry and fine structure of phloem in relation to transport. Ann. Rev. Plant Physiol. 21: 193-214.

H.B. Currier, S. Yamaguchi, and R.B. McNairn. 1965. Der Einfluss verstärkter Callosebildung auf den Stofftransport in Siebröhren. P1anta 65:49-64.

, R.F. Evert, and W. Heyser. 1971. Proteins of the sieve-tube exudate of Cucurbita maxima. Planta 100: 208-221.

, R.F. Evert, and J.H. Young. 1972. Solution flow in tubular semipermeable membranes. Planta 107:279-300.

Evert, R.F., and F.J. Alfieri. 1965. Ontogeny and structure of coniferous sieve cells. Amer. J. Bot. 52:1058-1066.

J.D. Davis, C.M. Tucker, and F.J. Alfieri. 1970. On the occurrence of nuclei in mature sieve elements. Planta 95:281-296.

, and W.F. Derr. 1964. Slime substance and strands in sieve elements. Amer. J. Bot. 51:875-880.

and B.P. Deshpande. 1969. Electron microscope investigations of sieve-element ontogeny and structure in U1mus americana. Protoplasma 68:403-432.

, and B.P. Deshpande. 1970. Nuclear P-protein in sieve elements of Tilia americana. J. Cell. Biol. 44: 462-466.

,W. Eschrich, and S.E. Eichhorn. 1971. Sieve-plate pores in leaf veins of Hordeum vulgare. Planta 100: 262-267.

, W. Eschrich, and S.E. Eichhorn. 1973. P-protein distribution in mature sieve elements of Cucurbita maxima. Planta 109:193-210.

and L. Murmanis. 1965. Ultrastructure of the secondary phloem of Tilia americana. Amer. J. Bot. 52: 95-106.

L. Murmanis, and I.B. Sachs. 1966. Another view of the ultrastructure of Cucurbita phloem. Ann. Bot. 30: 563-585.

, C.M. Tucker, and J.D. Davis. 1968. Aspects of sievetube member ontogeny and structure in U1mus americana.

Amer. J. Bot. 55:716. 
, C.M. Tucker, J.D. Davis, and B.P. Deshpande. 1969. Light microscope investigation of sieve-element ontogeny and structure in Ulmus americana. Amer. J. Bot. 56:999-1017.

Fensom, D.S. 1957. The bio-electric potentials of plants and their functional significance. 1. An electrokinetic theory of transport. Can. J. Bot. 35 :
573-582.

1972. A theory of translocation in phloem of Heracleum by contractile protein microfibrillar material. Can. J. Bot. 50:479-497.

Fischer, A. 1885. Studien über die Siebröhren der Dicoty1enblätter. Ber. Verh. Kön. Sächs. Ges. Wiss Liepzig, Math-Phys. C1. 37:245-290.

Fisher, D.B. 1967. An unusual layer of cells in the mesophyll of soybean leaf. Bot. Gaz. 128:215-218.

1970a. Kinetics of C-14 translocation in soybean. I. Kinetics in the stem. Plant Physiol. 45:107-113. 1970b. Kinetics of C-14 translocation in soybean. 118. Kinetics in the leaf. Plant Physiol. 45:114iI i970c. Kinetics of C-14 translocation in soybean. $119-125$.

Foster, A.S. 1936. Leaf differentiation in angiosperms. 1952. Foliar venation in Angiosperms from an ontogenetic standpoint. Amer. J. Bot. 39:752-766.

Fraser, D.E., and R.G.S. Bidwell. 1973. Photosynthesis and photorespiration in a developing plant. Can. Soc. of Plant Physiologists, eastern meetings, abstract.

Gardner, D.C.J., and A.J. Peel. 1969. ATP in sieve tube sap from willow. Nature 222:774.

, and A.J.Peel. 1972. Some observations on the 107:217-226.

Geiger, D.R. 1966. Effect of sink region cooling on trans1672. 
and J.W. Batey. 1967. Translocation of ${ }^{14} \mathrm{C}-$ sucrose in sugar beet during darkness. Plant Physio1. 42:1743-1749.

and D.A. Cataldo. 1969. Leaf structure and translocation in sugar beet. Plant Physiol. 44:45-54.

, and A.L. Christy. 1971. Effect of sink region anoxia on translocation rate. Plant Physiol. 47: 172-174.

J. Malone, and D.A. Cataldo. 1971. Structural evidence for a theory of vein loading of translocate. Amer. J. Bot. 58:672-675.

, and S.A. Sovonick. 1970. Temporary inhibition of translocation velocity and mass transfer rate by petiole cooling. Plant Physiol. 46:847-849.

, and C.H. Swanson. 1965. Sucrose translocation in the sugar beet. Plant Physiol. 40:685-690.

Giaquinta, R.T., and D.R. Geiger. 1973. Mechanism of inhibition of translocation by localized chilling. Plant Physiol. 51:372-377.

Goeschl, J.D., L. Rappaport and H.K. Pratt. 1966. Ethylene as a factor regulating the growth of pea epicotyls subjected to physical stress. Plant Physiol. 41 : 877-884.

Gunning, B.E.S., and J.S. Pate. 1969. "Transfer cells." Plant cells with wall ingrowths, specialized in relation to short distance transport of solutes-their occurrence, structure and development. Protoplasma 68:107-133.

J.S. Pate, and L.G. Briarty. 1968. Specialized "transfer cells" in minor veins of leaves and their possible significance in phloem translocation. J. Cel1. Biol. 37: C7-C12.

Gustafson, F.G. 1956. Absorption of $\mathrm{Co}^{60}$ by leaves of young plants and its translocation through the plant. Amer. J. Bot. 51:437-444.

Haberlandt, G.F.J. 1914. Physiological plant anatomy. Macmillan and Company, London.

Hamme1, H.T. 1968. Measurement of turgor pressure and its gradient in the phloem of oak. Plant Physiol. 43: 1042-1048. 
Harel, S., and L. Reinhold. 1966. The effect of 2,4-dinitrophenol on translocation in the phloem. Physiol.

P1antarum 19:634-643.

Hartt, C.E. 1965. Light and translocation of ${ }^{14} \mathrm{C}$ in detached blades of sugar cane. Plant Physiol. 40:718-724.

Hawker, J.S. 1965. The sugar content of cell walls and intercellular spaces in sugar cane stems and its relation to sugar transport. Aust. J. Biol. Sci. 18:959-969.

Heslop-Harrison, J. 1962. Effect of 2-thiouracil on cell differentiation and leaf morphogenesis in Cannabis sativa. Ann. B̈ot. 26:375-387.

Hill, A.W. 1908. The histology of the sieve-tubes of angiosperms. Ann. Bot. 22:245-290.

Ho, L.C., and D.C. Mortimer. 1971. The site of cyanide inhibition of sugar translocation in sugar beet leaf. Can. J. Bot. 49:1769-1775.

, and A.J. Peel. 1969. Investigation of bidirectional movement of tracers in sieve tubes of Salix viminalis L. Ann. Bot. 33:833-844.

Hopkinson, J.M. 1964. Studies on the expansion of the leaf surface. IV. The carbon and phosphorus economy of a leaf. J. Exp. Bot. 15:125-137.

Humphreys, T.E., and L.A. Garrard. 1971. Sucrose leakage from the maize scutellum: evidence for the participation of the phloem. Phytochem. 10:981-995.

Husain, A., and D.C. Spanner. 1966. The influence of varying concentrations of applied sugar in the transport of tracers in cereal leaves. Ann. Bot. 30:549-561.

Isebrands, J.G., and P.R. Larson. 1973. Anatomical changes during leaf ontogeny in Populus deltoides. Amer. J. Bot. 60:199-208.

Jaffe, M.J. 1970. Physiological studies on pea tendrils. VII. Evaluation of a technique for the asymmetrical application of ethylene. P1ant Physiol. 46:631-633. , and A.W. Galston. 1967. Physiological studies on pea tendrils. III. ATPase activity and contractability associated with coiling. Plant Physiol. 42:845-847.

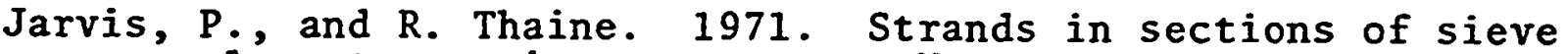
elements cut in a cryostat. Nature N.B. 232:236-237. 
Johnson, R.P.C. 1968. Microfilaments in pores between frozen-etched sieve elements. Planta 81:314-332.

Jones, H., and J.E. Eagles. 1962. Translocation of ${ }^{14}$ Carbon within and between leaves. Ann. Bot. 26:505-510.

, R.V. Martin, and H.K. Porter. 1959. Translocation of ${ }^{14}$ Carbon in tobacco following assimilation of ${ }^{14}$ Carbon dioxide by a single leaf. Ann. Bot. 23 : 493-508.

Joy, K.W. 1964. Translocation in sugar beet. I. Assimilation of ${ }^{14} \mathrm{CO}_{2}$ and distribution of materials from leaves. J. Exp. Bot. 15:485-494.

- 1967. Carbon and nitrogen sources for protein synthesis and growth of sugar beet leaves. J. Exp. Bot. 18:140-150.

Kandler, 0. 1967. Biosynthesis of poly- and oligosaccharides during photosynthesis in green plants. In Harvesting the Sun. (Edit. A. San Pietro, F.A. Greer and T.J. Army). Academic Press, New York.

Kenda11, W.A. 1955. Effect of certain metabolic inhibitors on translocation of ${ }^{32} \mathrm{P}$ in bean plants. Plant Physiol. 30:347-350.

Kennecke, M., H. Ziegler, M.A. Rongine de Fekete. 1971. Enzymaktivitaten im Siebröhrensaft von Robinia pseudoacacia $L$. und anderer Baumarten. Planta 98: $330-356$.

Kleinig, H., I. Dörr, and R. Kollmann. 1971a. Vinblastineinduced precipitation of phloem proteins in vitro. Protoplasma 73:293-302.

, I. Dörr, C. Weber, and R. Kollmann. 1971b. Filamentous proteins from plant sieve tubes. Nature N.B. $229: 152-153$.

Kluge, M., D. Becker, and H. Ziegler. 1970. Untersuchungen über ATP und andere organische Phosphorverbindungen im Siebröhrensaft von Yucca flaccida und Salix triandra. Planta 91:68-79.

and H. Ziegler. 1964. Der ATP-Gehalt der Siebröhrensaft von Laubbäumen. Planta 61:167-177.

Kocher, H., and O.A. Leonard 1971. Translocation and metabolic conversion of ${ }^{14} \mathrm{C}-1$ abelled assimilates in detached and attached leaves of Phaseolus vulgaris $L$. in different phases of leaf expansion. Plant

Physiol. 47:212-216. 
Kollmann, R., I. Dörr, and H. Kleinig. 1970. Protein filaments--structural components of the phloem exudate. 1. Observations with Cucurbita and Nicotiana. Planta 95:86-94.

Kriedmann, P.E. 1968. Photosynthesis in vine leaves as a function of light intensity, temperature and leaf age. Vitis $\underline{7}: 213-220$.

Kuo, C.F., and C.H. Lou. 1966. Histochemical observations on the distribution of adenosine triphosphatase in phloem and motor organs in higher plants. Acta Bot. Sin. 14:41-49.

Kuo, J., T.P. O'Brien, and S.-Y. Zee. 1971. The transverse veins of the wheat leaf. Aust. J. Biol. Sci. 25: 721-737.

Kursanov, A.L. 1961. The transport of organic substances in plants. Endeavor 20:19-25.

- 1963. Metabolism and the transport of organic substances in the phloem. Advan. Bot. Res. 1: 209-278.

, and M.I. Brovchenko. 1970. Sugars in the free space of leaf plates: their origin and possible involvement in transport. Can. J. Bot. 48:1243-1250.

Larson, P.R., and J.C. Gordon 1969. Leaf development, photosynthesis, and ${ }^{14} \mathrm{C}$ distribution in Populus deltoides seediings. Amer. J. Bot. 56:1058-1066.

and J.G. Isebrands. 1971. The plastochron index as applied to developmental studies of Cottonwood. Canad. J. Forest Research 1: $1-11$.

J.G. Isebrands, and R.E. Dickson. 1972. Fixation patterns of ${ }^{14} \mathrm{C}$ within developing leaves of eastern cottonwood. Planta 107:301-314.

Leonard, O.A., and R.K. Glenn. 1968. Translocation of assimilates and phosphate in detached bean leaves. Plant Physiol. 43:1380-1388.

Lester, H.H., and R.F. Evert. 1965. Acid-phosphatase activity in sieve-tube members of Tilia americana. Planta 65:180-185.

MacRobbie, E.A.C. 1971. Phloem translocation. Facts and mechanisms: a comparative survey. Biol. Rev. 46: 429-481. 
Maksymowych, R. 1961. Cell division in leaf development of Xanthium pennsylvanicum. Amer. J. Bot. 48:529.

and R.0. Erickson. 1960. Development of the lamina in Xanthium italicum represented by the plastochron index. Amer. J. Bot. 47:451-459.

, and M.A. Kettrick. 1970. DNA synthesis, ce11 division, and cell differentiation during leaf development of Xanthium pennsylvanicum. Amer. J . Bot. 57: 844-849.

and Z.S. Wochok. 1969. Activity of marginal and plate meristems during leaf development of Xanthium pennsylvanicum. Amer. J. Bot. 56:26-30.

Mason, T.G., and E.J. Maske11. 1928. Studies on the transport of carbohydrates in the cotton plant. II. The factors determining the rate and the direction of movement of sugars. Ann. Bot. 42:571-636.

, and E. Phillis. 1936. Concerning the independence of solute movement in the phloem. Ann. Bot. 50: 23-58.

McCready, R.M., J. Guggolz, V. Silviera, and H.S. Owens. 1950. Determination of starch and amylose in vegetables. Analyt. Chem. 22:1156-1158.

McGivern, Sister M.J. 1957. Mitochondria and plastids in sieve-tube cells. Amer. J. Bot. 44:37-48.

McNairn, R.B., and H.B. Currier. 1968. Translocation blockage by sieve plate callose. Planta 82:369-380.

Michelini, F.J. 1958. The plastochron index in developmental studies of Xanthium italicum Moretti. Amer. J. Bot. $45: 525-533$.

Michener, H.D. 1938. The action of ethylene on plant growth. Amer. J. Bot. 25:711-720.

Milthorpe, F.L., and J. Moorby. 1969. Vascular transport and its significance in plant growth. Ann. Rev. Plant Physiol. 20:117-138.

Mishra, U., and D.C. Spanner. 1970. The fine structure of the sieve tubes of Salix coprea (L.) and its relation to the electroosmotic theory. Planta 90: 43-56. 
Mollenhauer, H.H. 1964. Plastic embedding mixtures for use in electron microscopy. Stain Techn. 39:111-114.

Moorby, J. 1964. The foliar uptake and translocation of caesium. J. Exp. Bot. 15:457-469.

Morretes, B.L. de. 1962. Terminal phloem in vascular bundles of leaves of Capsicum annuum and Phaseolus vulgaris. Amer. J. Bot. 49:560-567.

Nakata, S., and A.C. Leopold. 1967. Radioautographic study of translocation in bean leaves. Amer. J. Bot. 54:769-772.

Nelson, C.D. 1962. The translocation of organic compounds in plants. Can. J. Bot. 40:757-770.

Newcomb, E.H. 1967. A spiny vesicle in slime producing cells of the bean root. J. Ce11. Biol. 35:C17-C22.

Northcote, D.H., and F.B.P. Wooding. 1966. Development of sieve tubes in Acer pseudoplatanus. Proc. Roy. Soc. B. 163: $524-537$.

O'Brien, T.P. 1970. Further observations on hydrolysis of the cell wall in the xylem. Protoplasma 69:1-14.

, and K.V. Thimann. 1967. Observations on the fine structure of the oat coleoptile. III. Correlated light and electron microscopy of the vascular tissues. Protoplasma 63:443-478.

Palevitz, B.A., and E.H. Newcomb. 1971. The ultrastructure and development of tubular and crystalline P-protein in the sieve elements of certain Papilionaceous legumes.

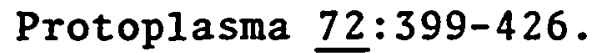

Parthasarathy, M.V., and K. Mühlethaler. 1969. Ultrastructure of protein tubules in differentiating sieve elements. Cytobiologie 1:17-36.

, and P.B. Tomlinson. 1967. Anatomical features of metaphloem in stems of Sabal, Cocus and two other palms. Amer. J. Bot. 54:1143-1151.

Partridge, S.M. 1948. Filter-paper partition chromatography of sugar. I. General description and application to the qualitative analysis of sugars in apple juice, egg white and foetal blood of sheep. Biochem. J. 42:938-953.

Pate, J.S., and B.E.S. Gunning. 1969. Vascular transfer cells in angiosperm leaves. A taxonomic and morphological survey. Protoplasma 68:135-156. 
B.E.S. Gunning and F.F. Milliken. 1970. Function of transfer cells in the nodel regions of stems, particularly in relation to the nutrition of young seedlings. Protoplasma 71:313-334.

, and T.P. O'Brien. 1968. Microautoradiographic study of the incorporation of labelled amino acids into insoluble compounds of the shoot of a higher plant. Planta 78:60-71.

Pee1, A.J., and P.E. Weatherly. 1959. Composition of sieve tube sap. Nature 184:1955-1956.

, and P.E. Weatherly. 1962. Studies in sieve-tube exudation through aphid mouthparts. I. The effects of light and girdling. Ann. Bot. 26:633-646.

Peterson, C.A., and H.B. Currier. 1969. An investigation of bidirectional translocation in the phloem. Physiologia Plantarum 22:1238-1250.

Phillis, E., and T.G. Mason. 1933. Studies on the transport of carbohydrates in the cotton plant. III. The polar distribution of sugar in the foliage leaf. Ann. Bot. 47: 585-634.

Plaut, Z., and L. Reinhold. 1969. Concomitant photosynthesis implicated in the light effect on translocation in bean plants. Aust. J. Biol. Sci. 22: 1105-1111.

Plymale, E.L., and R.B. Wylie. 1944. The major veins of mesomorphic leaves. Amer. J. Bot. 31:99-106.

Pray, T.R. 1954. Foliar venation of angiosperms. I. Mature venation of Liriodendron. Amer. J. Bot 41: 663-670.

1955a. Foliar venation of angiosperms. II. Histogenesis of the venation in Liriodendron. Amer. J. Bot. 42:18-27.

- 1955b. Foliar venation of angiosperms. IV. Histogenesis of the venation of Hosta. Amer. J. Bot. 42: 698-706.

- 1963. Origin of vein endings in angiosperm leaves. Phytomorph. $13: 60-81$.

Pucher, G.W., C.H. Leavenworth, and H.B. Vickery. 1948. Determination of starch in plant tissues. Analyt. Chem. 20: 850-853. 
Richardson, M. 1968. Translocation in plants. Edward Arnold Ltd., London.

Richardson, S.D. 1957. The effect of leaf age on the rate of photosynthesis in detached leaves of tree seedlings. Acta Botanica Neerlandica $\underline{6}: 445-457$.

Ryle, G.J.A. 1972. A quantitative analysis of the uptake of carbon and of the supply of ${ }^{14} \mathrm{C}-1$ abelled assimilates to areas of meristematic growth in Lolium temulentum. Ann. Bot. 36:497-512.

Salin, M.L., and P.H. Homann. 1971. Changes of photorespiratory activity with leaf age. Plant Physiol. 48:193-196.

Saurer, W., and J.V. Passingham. 1970. Studies on the growth of spinach leaves (Spinacea oleracea). J. Exp. Bot. $21: 151-158$.

Seth, A.K., and P.F. Wareing. 1967. Hormone directed transport of metabolites and its possible role in plant senescence. J. Exp. Bot. 18:65-77.

Shah, J.J., and R. Jacob. 1969. Development and structure of phioem in the petiole of Luffa cylindrica. Amer. I. Bot. 56:821-831.

Shih, C.Y., and H.B. Currier. 1969. Fine structure of phloem ceils in relation to translocation in the cotton seedling. Amer. J. Bot. 56:464-472.

Shiroya, M., G.R. Lister, C.D. Nelson, and G. Krotkov. 1961. Translocation of ${ }^{14} \mathrm{C}$ in tobacco at different stages of development following assimilation of ${ }^{4} \mathrm{CO}_{2}$ by a single leaf. Can. J. Bot. 39:855-864.

Siddiqui, A.W., and D.C. Spanner. 1970. The state of the pores in functioning sieve plates. Planta 91:181-189.

Sij, J.W., and C.A. Swanson. 1973. Effect of petiole anoxia on phloem transport in squash. Plant Physiol. 51: 368-371.

Singh, A.P., and L.M. Srivastava. 1972. The fine structure of corn phloem. Can. J. Bot. 50:839-846.

Spanner, D.C. 1958. The translocation of sugar in sieve tubes. J. Exp. Bot. $9: 332-342$.

- 1962. A note on the velocity and energy requirement of translocation. Ann. Bot. 26:511-516.

- 1970. The electroosmotic theory of phloem transport in the light of recent measurements of Heracleum phloem. J. Exp. Bot. 21:325-334. 
Spurr, A.R. 1969. A low-viscosity epoxy resin embedding medium for electron microscopy. J. U1trastruct. Res. $\underline{26}: 31-43$.

Srivastava, L.M., and T.P. O'Brien. 1966. On the ultrastructure of cambium and its vascular derivatives. II. Secondary phloem of Pinus strobus L. Protoplasma 61:257-276.

Stout, P.R. 1961. Proc. 9th Ann. Calif. Fertilizer Conf., pp. 21-23.

Sunderland, N. 1960. Cell division and expansion in the growth of the leaf. J. Exp. Bot. 11:68-80.

Surikow, T. 1971. The uptake of sugars by Chara corallina. J. Exp. Bot. 22: 526-533.

Swanson, C.A. 1959. Translocation of organic solutes. In Plant Physiology: Ed. F.C. Steward. Vol. 2, pp. 481-551. Academic Press, New York.

, and D.R. Geiger. 1967. Time course of low temperature inhibition of sucrose translocation in sugar beets. Plant Physiol. 42:751-756.

Tamulevich, S.R., and R.F. Evert. 1966. Aspects of sieve element ultrastructure in Primula obconica. Planta 69:319-337.

Thaine, R. 1961. Transcellular strands and particle movement in mature sieve tubes. Nature 192:772-773.

- 1962. A translocation hypothesis based on the structure of plant cytoplasm. J. Exp. Bot. 13: 152-160.

1965. Surface associations between particles and the endoplasmic reticulum in protoplasmic streaming. New Phytol. 64:118-130.

1969. Movement of sugars through plants by cytoplasmic pumping. Nature 222:873-875.

, S.L. Ovenden, and J.S. Turner. 1959. Translocation of labelled assimilates in the soybean. Aust.

J. Biol. Sci. 12:349-372.

, M.C. Probine, and P.Y. Dyer. 1967. The existence of transcellular strands in mature sieve elements.

J. Exp. Bot. 18:110-127. 
Thompson, R.G., and D.S. Fensom. 1972. The effect of Cytochalasin B on translocation in Heracleum phloem. Proc. Can. Soc. Plant Physiologists, Halifax, N.S. Abstract.

Thrower, S.L. 1962. Translocation of labelled assimilates in the soybean. II. The pattern of translocation in intact and defoliated plants. Aust. J. Biol. Sci. 15:629-649.

Trip, P. 1969. Sugar transport in conducting elements of sugar beet leaves. Plant Physiol. 44:717-725.

, and J.R. Colvin. 1970. Sieve elements of minor veins in the leaves of Beta vulgaris L. Ann. Bot. 34: 1101-1106.

and P.R. Gorham. 1968a. Bidirectional translocation of sugars in sieve tubes of squash plants. Plant Physiol. 43:877-882.

, and P.R. Gorham. 1968b. Translocation of sugar and tritiated water in squash plants. Plant Physiol. 43:1845-1849.

Turkina, M.V. 1961. Sucrose absorption by plant conducting tissues. Fiziol. Rastenii. $\underline{8}: 649-657$.

Tyree, M.T. 1970. The symplast concept. A general theory of symplastic transport according to the thermodynamics of irreversible processes. J. Theor. Biol. 26: $181-214$.

, and D.S. Fensom. 1970. Some experimental and theoretical observations concerning mass flow in the vascular bundles of Heracleum. J. Exp. Bot. 21: 304-324.

Ullrich, W. 1961. Zur Sauerstoffabhangigkeit des Transportes in den Siebröhren. Planta 57:402-429.

Walding, H.F., and P.E. Weatherly. 1972. The effect of cooling on translocation in Salix viminalis. J. Exp. Bot. 23: 338-345.

Walker, T.S., and R. Thaine. 1971. Proteins and fine structural components in exudate from sieve tubes in Cucurbita pepo stems. Ann. Bot. 35:773-790.

Wardlaw, I.F. 1968. The control and pattern of movement of carbohydrates in plants. Bot. Rev. 34:79-105. 
- 1972. Temperature and the translocation of photosynthate through the leaf in Lolium temulentum.

Planta 104:18-34.

Watson, G.R., and J.P. Williams. 1970. Rapid method for wet combustion and scintillation counting of ${ }^{14} \mathrm{C}-$ labelled organic materials. Ann. Biochem. 33:356-365.

Weatherly, P.E. 1962. The mechanism of sieve tube translocation: observation, experiment and theory. Adv. Sci. 18:571-577.

, and R.P.C. Johnson. 1968. The form and function of the sieve tube: a problem in reconciliation. Int. Rev. Cytol. 24:149-192.

Webb, J.A. 1967. Translocation of sugars in Cucurbita melopepo. IV. Effects of temperature change. Plant Physiol. 42:881-885.

- 1970. The translocation of sugars in Cucurbita melopepo: $V$. The effect of leaf blade temperature on assimilation and transport. Can. J. Bot. 48: 935-942.

- 1971. Translocation of sugars in Cucurbita melopepo. VI. The reversible low temperature inhibition of ${ }^{14} \mathrm{C}$ movement and cold acclimation of phloem tissue. Can. J. Bot. 49:717-733.

and P.R. Gorham. 1964. Translocation of photosynthetica11y assimilated ${ }^{14} \mathrm{C}$ in straight-necked squash. Plant Physiol. 39:663-672.

, and P.R. Gorham. 1965. The effect of node temperature on assimilation and translocation of ${ }^{14} \mathrm{C}$ in the squash. Can. J. Bot. 43:1009-1020.

Weber, C., and H. Kleinig. 1971. Molecular weights of Cucurbita sieve tube proteins. Planta 99:179-182.

Wergin, W.P., and E.H. Newcomb. 1970. Formation and dispersal of crystalline P-protein in sieve elements of soybean (Glycine max L.). Protoplasma 71:365-388.

Whittle, C.M. 1964. Translocation and temperature. Ann. Bot. 28:339-344.

Willenbrink, J. 1966. Zur lokalen Hemmung des Assimilat transports durch Blausäure. 2. Pflanzenphysio1. 55: 119-130. 
Williamson, R.E. 1972. An investigation of the contractile protein hypothesis of phloem translocation. Planta 106:149-157.

Wooding, F.B.P. 1967. Fine structure and development of phloem sieve tube content. Protoplasma 64:315-324. - 1969. P-protein and microtubular systems in Nicotiana callus phloem. Planta 85:284-298. , and D.H. Northcote. 1965. An anomalous wall thickening and its possible role in the uptake of stem-fed tritiated glucose by pinus pinea. J. Ultrastruct. Res. 12: 463-472.

Wylie, R.B. 1939. Relations between tissue organization and vein distribution in dicotyledon leaves. Amer. J. Bot. 26:219-225.

- 1943. The role of the epidermis in foliar organization and its relations to the minor venation. Amer. J. Bot. 30:273-280.

- 1952. The bundle sheath extensions in leaves of dicotyledons. Amer. J. Bot. 39:645-651.

Yen, L.F., and T.C. Shih. 1965. The presence of a contractile protein in higher plants. Sci. Sinica 14: 601-608.

Zee, S.-Y. 1969a. The localization cf acid phosphatase in the sieve element of Pisum. Aust. J. Biol. Sci. 22: 1051-1054.

- 1969b. Fine structure of the differentiating sieve elements of Vicia faba. Aust. J. Bot. 17: 441-456.

Ziegler, H., and G.H. Vieweg. 1961. Der experimentelle Nachweis einer Massenströmung im Phloem von Heracleum mantegazzianum Somm. et Lev. P1anta 56:402-408.

Zimmermann, M.H. 1957. Translocation of organic substances in trees. II. On the translocation mechanism in the phloem of white ash. Plant Physiol. 32:399-404. 